\title{
Cheese Making
}

Cheddar

Swiss

Brick

Edam

Limburger

Cottage, etc.

DECKER 





\title{
CHEESE MAKING
}

CHEDDAR, SWISS, BRICK, LIMBURGER, EDAM, COTTAGE, ETC.

\author{
B Y \\ J OH N. DECKER, B.Agr. \\ LATE PROFESSOR OF DAIRYING, OHIO STATE UNIVERSITY
}

FIFTH REVISED EDITION BY

F. W. WOLL, Ph.D.

PROFESSOR OF AGRICULTURAL CHEMISTRY, UNIVERSITY OF WISCONSIN

I L L US TR A T E D

MADISON, WIS.

MENDOTA BOOK COMPANY

1909

ALL RIGHTS RESERVED 

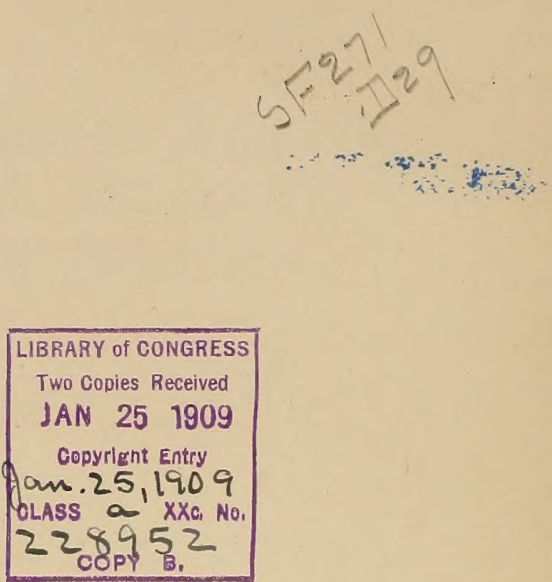

COPYRIGHTED

JOHN W. DECKER

1900

MENDOTA BOOK COMPANY

1909

Cantwell Printing Company MADISON, WISCONSIN 



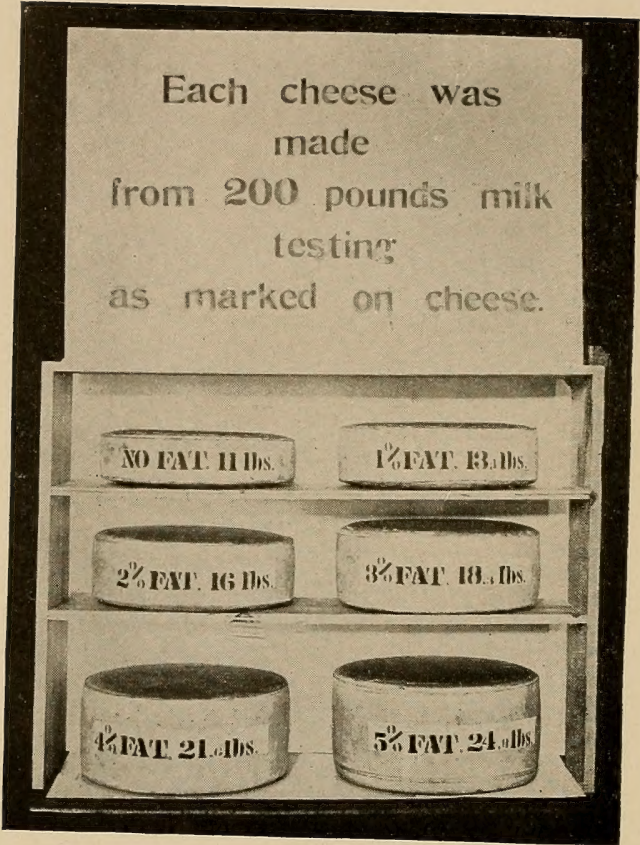

Value of Fat in Milk for Cheese Production.

The yield of cheese increases, and its quality improves, with increasing fat contents of the milk. 


\section{TABLE OF CONTENTS.}

Chapter.

Page.

I-The Constitution of Milk . . . . . . . 1

II-Secretion and Contamination of Milk . . . . 12

III-Milk Testing . . . . . . . . . . . 24

IV-Enzymes . . . . . . . . . . . . . 34

V-The Deportment of Rennet . . . . . . . 43

VI-Cheddar Cheese . . . . . . . . . . 48

VII-Cutting and Heating the Curd . . . . . . 57

VIII-Drawing the Whey-Dipping and Milling the Curd . . . . . . . . . 63

IX-Salting and Pressing the Curd . . . . . . 78

$\mathrm{X}$-Curing and Shipping the Cheese . . . . . 94

XI-Judging Cheese . . . . . . . . . . 110

XII-Hints on the Construction and Operation of Cheese Factories . . . . . . . . . 117

XIII-Organization of Cheese Factory Associations . . 131

XIV-Swiss Cheese-its Characteristics . . . . . 137

$X V$-Swiss Cheese-from Milk to Curing Cellar . . 144

XVI-Swiss Cheese-Work in the Cellar . . . . . 158

XVII-Brick Cheese . . . . . . . . . . . 162

XVIII-Limburger Cheese . . . . . . . . . . . . . . . 169

XIX-Edam Cheese . . . . . . . . . . . . . . . 174

XX-Cottage, Neufchatel and Soft Cream Cheese . . 184

XXI-Foreign and Domestic Cheese of Minor Importance 189

Appendix. 1-Composition of Milk and Its Products . . . 196

2-Analyses of Different Kinds of Cheese . . . 197

3-The Cheese Market of the United States . . . 197

4 -Yield of Cheese from 100 Pounds of Milk . . 198

5 - Government Standards of Purity for Cheese . . 198

6-Definition of a good American Cheddar Cheese . 199

7-Defects in American Cheddar Cheese . . . . 199

8-Standards for Grading Canadian Cheddar Cheese 206 
T 0

STEPHEN MOULTON BABCOCK, Рн.D.

CHIEF CHEMIST OF THE WISCONSIN EXPERIMENT STATION

WHO, AS A TEACHER, AND LATER AS A CO-WORKER, BY PATIENT LABOR AND WISE COUNSEL, INSPIRED THE AUTHOR WITH A

GREATER LOVE FOR THE PROFESSION

OF DAIRYING

THIS BOOK IS INSCRIBED 


\section{PREFACE TO FOURTH EDITION.}

The American dairy school is of recent origin, the first one having beèn started in Wisconsin in 1891 .

With the dairy school came the need of pedagogic statements of the subjects taught therein.

It fell to the lot of the author of this book to make such a statement of cheese making. His first attempt was printed in 1893 under the title of "Cheddar Cheese Making." This first attempt met with an encouraging reception and was translated into the French language by Emile Castel for the use of the Canadians in the Province of Quebec. A second and revised edition under the same name was printed in 1895. In 1900 the book was again revised and the scope enlarged to include Swiss, Brick, Limburger, Edam and Cottage cheese, and the title changed to that of "Cheese Making." The edition printed at that time is now exhausted and our nowledge of the subject has increased, requiring a number of important changes to bring the book up to date.

Because of their relation to the subject, milk testing and dairy bacteriology have been touched upon briefly. An exhaustive treatment has not been necessary as there are textbooks treating these subjects.

This is primarily a text-book and not a reference volume. To make the latter out of it would make it unwieldly for the former purpose. An analytical index, a complete table of contents, and references to original matter will, however, assist the busy man, student or instructor to look up references quickly or to find original data.

Columbus, O., Jan. 1, 1905.

JoHN W. DeCKER. 


\section{PREFACE TO FIF'TH EDITION.}

The untimely death of the author of this book last year removed a pioneer student and investigator of cheese making in this country. By education and training Professor Decker was equipped as few for educational work in his chosen profession, and he gave to this work his undivided energies and enthusiasm. As instructor in dairying in the University of Wisconsin and later as professor of dairying in the Ohio State University he labored untiringly and with great success for the upbuilding of the dairy industry of these states, and for the general advancement of American dairying.

The work done in writing this book has been of as great importance as Professor Decker's labors as a teacher and lecturer. For fifteen years it has been the standard book in the English language on the subject of Cheese Making and has been used as a text-bcok in all American agricultural colleges in which special courses in cheese making are offered. In preparing a new edition of my lamented co-worker's book, it has been my effort to retain, as far as possible, its stamp of individuality, and changes have only been introduced where it was deemed very desirable to do so. Discussions of a number of new topics have, however, been added in order that the book may continue to be a thoroughly reliable and up-to-date guide to the manufacture of American cheddar and other kinds of cheese made in this country. Among new subjects that have been discussed in this edition may be mentioned: Cold-curing and paraffining of cheddar cheese, use of acidimeter, Hart's test for casein in milk, a synopsis of defects in American cheddar cheese, manufacture of Camembert, Gouda, Italian, Potted, Sage and other kinds of fancy cheese, etc.

Acknowledgement is due my colleagues, Professor E. H. Farrington and Messrs. M. Michels and Roy. T. Harris, for valuable aid rendered in the preparation of this edition; also to Wisconsin Experiment Station and Creamery Package MIfg. Co. of Chicago, for the loan of euts.

Madison, Wis., Dec. 28, 1908.

F. W. WOLL. 
CHAPTER I.

THE CONSTITUTION OF MILK.

\section{Uses of Milk.}

Cows' milk is given for the primary purpose of nourishing the young calf until it can seek its own food. Man has diverted milk from its original purpose and has made it one of the most important human foods. The cow originally gave only enough milk to nourish its calf until this could take care of itself and, therefore, produced milk for only a brief period of time; but the modern dairy cow has been gradually developed by intelligent selection, feeding, and breeding so that she produces milk in large quantities and for nearly an entire year after each calving. Aside from its use for direct consumption, milk is used for the manufacture of a number of human food products, like cream, butter, cheese, condensed milk, etc.

\section{Composition of Milk.}

Since milk was by nature intended for the nourishment of the calf, one might expect to find that it contains all the food elements necessary for the building up of the young animal's body. An analysis reveals the presence of water, which is absolutely necessary for the maintenance of life; ash is needed for the bones; nitrogenous material in the form of casein and albumen, etc., nourishes the muscles, hair, hoofs and horns; and carbonaceous matter in the form of sugar and fat maintains the heat of the body. We shall now consider triefly the main characteristics of the various components of milk.

\section{Albuminoids or Froteins.}

The albuminoids or proteins contain the nitrogen of the milk and consist mainly of two substances, casein and albumen.

Casein. The casein is the part of the milk that is curdled by rennet or weak acids. It is commonly supposed to be dissolved 
in the water of the milk, but this is not strictly true. If milk be filtered through a porcelain filter it will leave a gelatinous mass on the filter, which is the easein; or, if skim milk be revolved for a long time in a separator bowl, a layer of casein will be deposited on the walls of the kowl. Casein is dissolved in solutions of borax, sodium phosphate, and alkalies. It is used commercially as a sizing for paper.

Albumon. The easein does not constitute all of the protein of milk. When milk has been coagulated by rennet the casein is precipitated. If the whey be heated to $180^{\circ} \mathrm{F}$. another precipitate will be thrown down. This is the albumen. It is much like the white of an egg which is coagulated by heat. It is in solution until the heat precipitates it. Albumen is not incorporated in Cheddar cheese in the ordinary method of manufacture, and cannot apparently be so incorporated without resulting in the making of sour cheese.

In addition to the casein and albumen of the milk, small amounts of other nitrogenous components are always present, but our knowledge of these substances is as yet incomplete.

\section{Ash.}

The ash is the bone-forming part of the milk and consists largely of phosphates of calcium and potash, with some chlorides. Although the ash is present only in small quantities in the milk it is of great importance in cheese making. Part of the calcium salts is supposed to be suspended as fine particles in the milk or held in combination with the casein, but a part is certainly held in solution and on this solubility of calcium salts depends the property of coagulation by rennet. If ammonium oxalate be added to milk in sufficient quantity, the soluble calcium salts will be changed to insoluble calcium oxalate, and the milk will not eurdle with rennet. Similar results can be obtained by heating the milk to $180^{\circ} \mathrm{F}$. When a soluble calcium salt is added to such milk, the rennet will again act, in fact it will work faster than before because of the increase in the soluble calcium salts in the milk.

\section{Milk Sugar.}

The sugar of milk crystallizes in hard erystals; it is not as sweet as common cane sugar. It caramelizes at a high tempera- 
ture, giving the peculiar scalded taste to the milk. It is separated from milk by evaporating whey in a vacuum pan. Commercial milk sugar is used in infant foods and in medicines.

\section{Fat.}

The fat of the milk is a mixture of several fats, mainly of stearic, palmitic and oleic acids, in combination with glycerine. With these are a number of fats that are both volatile and soluble. In this latter respect butter fat differs from the fats used in oleomargarine. Filled cheese is maäe by introducing oleo oils into milk in the place of the butter fat.

The fat of milk is in emulsion-that is, it is distributed through the milk serum in the form of minute globules, which can only be seen by the aid of a microscope. They vary nor-

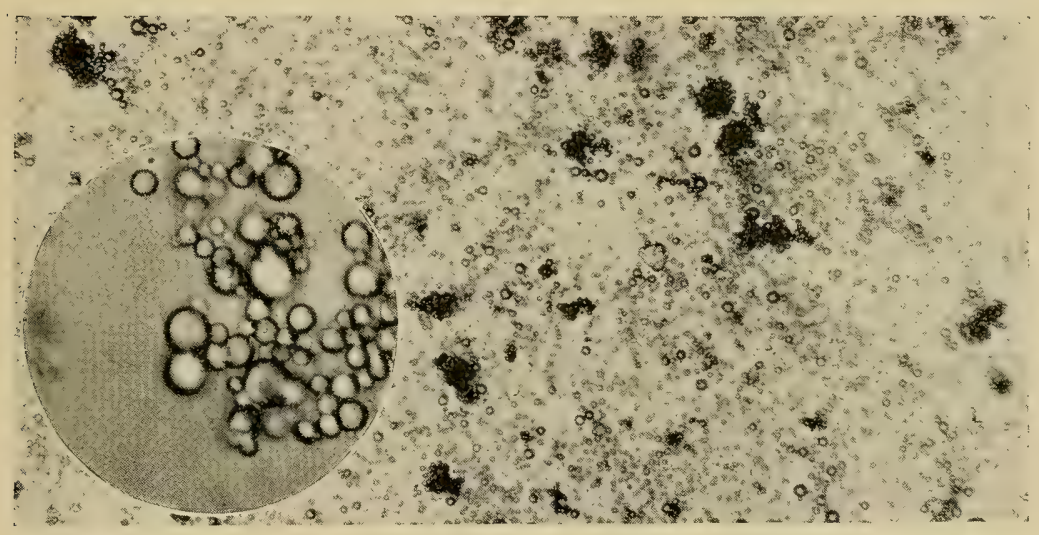

Fig. 2.-The fat globules as seen through a microscope. The portion included in the circle is highly magnified. The clotting is due to an albuminous substance that collects around they globules soon after the milk is drawn.

mally in size from 1-40,000 of an inch to $1-2000$ of an inch in diameter. On account of their minute size they are necessarily very numerous.

It is estimated that there are $150,000,000$ fat globules in a single drop of average milk. The average production of fat globules by a good dairy cow has been estimated to be $38,210,000$ per second.

The fat globules being lighter than the surrounding serum naturally rise when the milk is left standing, and crowding 
close together form a layer known as the cream. In the manufacture of cheese it is necessary to get an eren distribution of the fat globules at the time of coagulation by the rennet, which is secured by constant stirring of the milk.

\section{Average Composition of Milk.}

The average composition of cows' milk, with the normal variations for each constituent, is given in the following table. Thousands of milk analyses are on record, but these vary greatly, so that it would be difficult to give an absolutely correct average, but the figures here given are within the range of usual variations.

Average. Minimum. Maximum.

Water .......... 87.4 per ct. 82.0 per ct. 90.0 per ct.

Fat ........... " " $3.7 \quad 2.3 \quad 7.8$ " "

Casein and albumen..... $3.2 \quad$ " ، $\quad 25 \quad$ " ،

Milk sugar.......... $5.0 \quad$ "6 $\quad 3.5 \quad$ " $\quad 6.0$ "

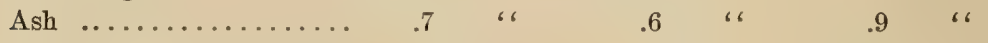

Specific gravity $\left(60^{\circ}\right.$ F. $) \quad 1.032$ " $\quad 1029$ ، 1.036 "6

\section{Use in Animal Economy.}

The chart given below shows how the different constituents of milk are ustally grouped, with an approximate statement of their use as food in animal economy.

Use in

Animal Economy

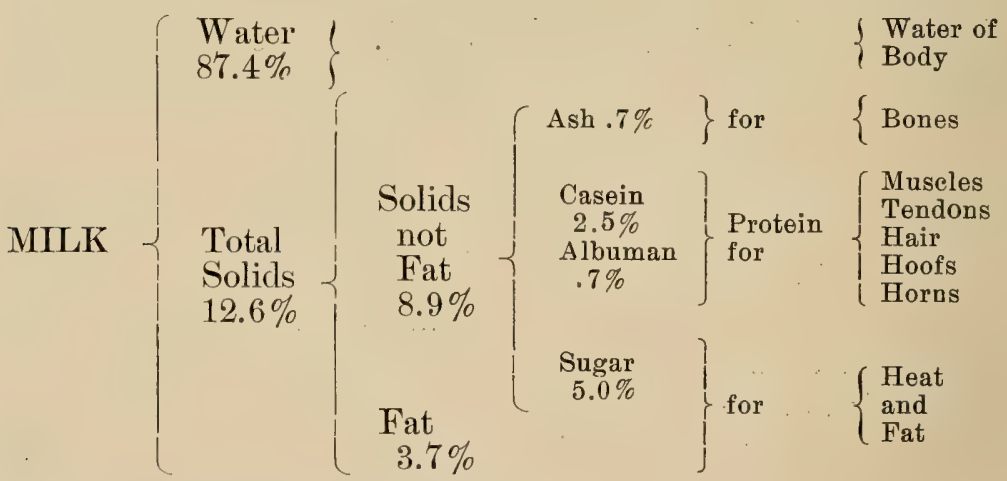

\section{Variations in Factory Milk.}

The following table will give a fair idea of the average composition of milk as delivered to an American cheese factory :*

*Bulletin 82, Geneva (N. Y.) Experiment Station. 
TABLE SHOWING AVERAGE MONTHLY COMPOSITION OF AMERICAN FACTORY MILK, IN PER CENT.

\begin{tabular}{|c|c|c|c|c|c|c|c|c|}
\hline Month. & $\begin{array}{l}\dot{\Phi} \\
\stackrel{\Phi}{\varpi} \\
\vec{z}\end{array}$ & 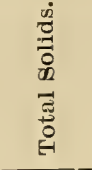 & 寄 & 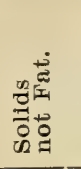 & 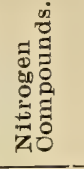 & 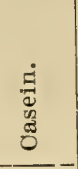 & $\begin{array}{l}\frac{\Xi}{0} \\
\stackrel{\Xi}{\Xi} \\
\vdots \\
\end{array}$ & 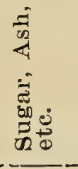 \\
\hline May.. & 87.40 & 12.60 & 3.63 & 8.97 & 3.14 & 2.44 & 0.70 & 5.83 \\
\hline June & 87.53 & 12.47 & 3.55 & 8.92 & 3.07 & 2.35 & 0.72 & 5.85 \\
\hline July. & 87.63 & 12.37 & 3.59 & 8.78 & 3.00 & 2.27 & 0.73 & 5.78 \\
\hline August & 87.51 & 12.49 & 3.78 & 8.71 & 3.05 & 2.32 & 0.73 & 5.66 \\
\hline September.. & 87.33 & 12.67 & 3.75 & 8.92 & 3.10 & 2.41 & 0.69 & 5.82 \\
\hline October.... & 86.87 & 13.13 & 4.00 & 9.13 & 3.36 & 2.60 & 0.76 & 5.77 \\
\hline
\end{tabular}

This table shows that the total solids in factory milk vary between 12 and 13 per cent, and the fat varies between 3.5 and 4.0 per cent. These are averages for the milk in the vat at the factory. Individual cows or herds may produce milk varying considerably from these averages. In the table the sugar, ash, etc., are combined. Milk contains approximately 5 per cent of milk sugar and .7 per cent ash.

\section{Io. Effect of Fat on Quality of Cheese.}

Cheese made from separator skim, milk is hard and honry, and though undoubtedly possessing some food value, it is too tough to be eaten.

Cheese made from part skim milk, though rather dry, is better than full-skim cheese, and the cheese from full-cream milk is more mellow and agreeable to the taste than either of these. Cheese made from exceptionally rich milk or from milk fortified by addition of eream is still softer and more palatable. This difference in quality is recognized on the market, as can be seen by the quotations, full skims ranging from 1 to 4 cents in value, and full creams from 7 to 13 cents per pound. Cheese containing less than 50 per cent of fat in the total solids has been made from at least partly skimmed milk. 


\section{Effect of Fat on Quantity of Cheese.}

About five and a half to six pounds of cheese can be obtained from one hundred pounds of separator skim milk, the amount depending on the amounts of water and easein in the cheese. Butter fat will carry about a tenth of its weight of water with it into the cheese. A rough way of estimating the probable yield of cheese from milk of a certain test would be to multiply the per cent of fat by 1.1 , and add 5.7 (the average amount of cured cheese obtained from $100 \mathrm{lks}$. of separator skim milk). For instance, from 3 per cent milk there would be obtained $3 \times 1.1=3.3$ plus 5.7 equal to $9 \mathrm{lbs}$; and from 4 per cent milk, $4 \times 1.1=4.4$ plus 5.7 equal to $10.1 \mathrm{lbs}$.

A somewhat more accurate method is as follows: Cheese contains on the average 37 per cent of water and 63 per cent solids. By dividing 100 , the total per cent of solids and water, by 63 , the per cent of solids in the cheese, we obtain the factor 1.58. Of the solids not fat, the casein and ash going into the cheese forms about one-third. Some fat is lost in the whey, so that, on the average, about 91 per cent of the fat goes into the cheese. Then the following formula will give the pounds of cheese obtainable from a hundred pounds of milk:

$$
1.58 \text { (Solids not Fat }+.91 \text { Fat })
$$

Example: Solids not fat 8.92 , Fat 4 per cent.

$8.92 \div 3=2.74$ or $1 / 3$ solids not fat. .91 of $4=3.64$.

$3.64+2.74=6.38$ or the total solids $\times 1.58=10.08$ pounds of cheese.

No rule for calculating the yield of cheese from a given amount of milk can give absolutely correct results cn account of varying factors, as will be explained later.

\section{Yield of Cheese from Milk of Different Composition.}

Dairy school students who work for dairy certificates are often required to report their work each month on blanks furnished them. From 347 such reports covering 40,900,890 pounds of milk made into $3,800,000$ pounds of cheese, the following table has been prepared:*

\footnotetext{
*Eleventh report Wisconsin Experiment Station, p. 142.
} 
PER CENT OF FAT IN CHEESE FROM MILKS OF DIFFERENT COMPOSITION.

\begin{tabular}{r|c|c|c}
\hline \multicolumn{1}{r|}{$\begin{array}{c}\text { Per cent Fat in } \\
\text { Millk. }\end{array}$} & $\begin{array}{c}\text { Yield of Oheese } \\
\text { per 100 lbs. } \\
\text { Milk. }\end{array}$ & $\begin{array}{c}\text { Per cent Fat in } \\
\text { Oheese. }\end{array}$ & $\begin{array}{c}\text { Pounds of Oheese } \\
\text { for one Pound } \\
\text { of Fat. }\end{array}$ \\
3.13 & 9.19 & 29.7 & 2.94 \\
3.38 & 9.24 & 32.3 & 2.73 \\
3.60 & 9.41 & 34.0 & 2.61 \\
3.84 & 9.81 & 35.1 & 2.56 \\
4.09 & 10.30 & 35.8 & 2.51 \\
4.45 & 10.71 & 37.8 & 2.41 \\
\hline Average....3.75 & & $\overline{34.1}$ & 2.63 \\
\hline
\end{tabular}

It will be observed that the results with the rule given above correspond very closely to the results in actual practice. The results given in the preceding table illustrate the difference in the quality of the cheese due to differences in the fat content of the milk used; as the fat in the milk increases, it also increases in the cheese, making a mellower cheese which is more pleasing to the consumer.

The yield of cheese per pound of fat, however, decreases with the increase of fat in the milk. In the case of 3-per ct. milk, nearly 3 pounds of cheese is obtained per pound of fat while 4-per ct. milk produces about $2 \frac{1}{2}$ pounds of cheese per pound of fat in the milk.

It will be seen that, on the average, 2.63 pounds of cheese was obtained per pound of fat in these trials. Experiments made under a variety of conditions have shown that a pound of fat in normal factory milk will produce 2.7 lbs. of green Cheddar cheese. This makes a convenient method of calculating the approximate yield of cheese from the test of the milk; e. g. 100 lbs. of milk testing 3.7 per ct. will make $3.7 \times 2.7=10.0$ lbs: of green cheese. The factor 2.6 will give the average yield of cured cheese.*

It has been shown from market quotations that the true value of milk for cheese is in proportion to its fat content. $\uparrow$

*"Testing Milk and Its Products," 18th ed., p. 199 (see p. 24, footnote, in this book).

†leventh Report, Wisconsin Experiment Station, p. 143. 


\section{Colostrum Milk.}

The first milk given by a cow directly after parturition is called colostrum milk, and is much more viscous than normal milk, being sometimes as thick as syrup, and usually of a deep yellow color. The composition of colostrum milk is different from that of normal milk, the albuminoids sometimes amounting to 15 per cent, and the fat content being generally below that of normal milk; the specific gravity of colostrum milk may run as high as 1.085 . Under the microseope, cells which have scaled off from the inside of the udder can be seen floating in the milk ("colostrum bodies"), and while these are present the milk is unfit for cheese. After four or five milkings the milk secretion will generally ke normal, but the milk should not be used for cheese making until a week after freshening.

\section{Curd.}

The curd is the coagulated casein which holds in its meshes most of the fat, some water, and small portions of albumen, milk sugar and ash, plus salt that is added in the process of manufacture. Green cheese is about one-third water, as will be seen from the following table.* Green cheese and curd are synonymous, for the cheese is simply the curd pressed together.

COMPOSITION OF GREEN CHEESE, IN PER CENT.

\begin{tabular}{|c|c|c|c|c|c|}
\hline Water. & Solids. & $\begin{array}{c}\text { Solids } \\
\text { not Fat. }\end{array}$ & Fat. & $\begin{array}{l}\text { Casein, } \\
\text { etc. }\end{array}$ & $\begin{array}{l}\text { Sugar, } \\
\text { Ash, etc. }\end{array}$ \\
\hline 36.69 & 63.51 & 29.16 & 34.14 & 23.44 & 5.17 \\
\hline
\end{tabular}

In the above table the sugar, ash, etc., are grouped together. Our own analyses showed the ash of cheese to vary from 2.38 to 3.85 per cent, of which ash, about 2.5 per cent, was the natural ash of the milk, the remainder being salt that was added to the curd. Over 40 per cent water makes a poor cheese. Cheese for the home market contains 36 to 37 per cent and export cheese 33 to 36 per cent of water. 


\section{I5. Whey.}

In the manufacture of cheese, the milk is curdled by rennet, and the curd cut into small pieces from which the liquid portion, or whey, is expelled. It consists of the major part of the water of the milk, which carries with it nearly all the soluble components, viz., the albumen, milk sugar, ash, and also a small portion of fat, as the globules break away from the surface of the curd when it is eut.

\section{Composition of Whey.}

The average ecmposition of whey for an entire season in an American cheese factory is as follows: Water 93.12 per cent, total solids 6.88 per cent, fat .27 per cent, nitrogenous substances .81 per cent, sugar, ash, etc., 5.80 per cent.

\section{I7. Losses of Fat in Whey.}

At the Minnesota Experiment Station in 1892 cheese was made from normal milk of different fat contents. The following table shows the losses of fat from these different milks:

LOSSES OF FAT IN MILK OF DIFFERENT FAT CONTENTS.

\begin{tabular}{l|c|c|c|c}
\hline \hline Per cent fat in milk. . $\ldots \ldots \ldots \ldots \ldots$ & 3.5 to 4 & 4 to 4.4 & 4.5 to 5 & 5 to 5.5 \\
Per cent fat in whey $\ldots \ldots \ldots \ldots \ldots$ & .38 & .36 & .39 & .32 \\
Number of trials ............. & 28 & 31 & 14 & 4 \\
\hline
\end{tabular}

In another series of experiments where cream was added to milk to make it test 6 per cent, the loss of fat in the whey was no greater than in the whey from normal milk similar to that to which the cream was added.

In all cases the richer milk made more cheese, which would of course leave less whey from each 100 pounds of milk. It is easily seen from this that the fat in rich milk can be worked into cheese mcre economically than the fat in poor milk. What effect could this have in applying the second rule given in paragraph 11 ?

\section{I8. Whey from Swiss Cheese.}

As explained above (15), the fat that goes into the whey is the fat g'obules that are knocked off from the surface of the curd particles. By using the kind of a knife used in Cheddar 
cheese making, the loss of fat can be reduced to .3 or .4 per cent, instead of 7 per cent when the old Swiss harp is used.

By careful operation many makers are reducing the fat test of the whey to .2 per cent.

\section{Constituents Recovered in Cheese.}

The different components of the milk have been discussed, together with their relation to recovery or loss in cheese making. The following table gives a good idea of where the different parts of the milk go to in the manufacture of Cheddar cheese:*

GENERAL SUMMARY OF SEASON'S RESULTS RELATING TO LOSS OF . MILK-CONSTITUENTS IN CHEESE MAKING.

\begin{tabular}{|c|c|c|c|c|c|}
\hline & $\begin{array}{l}\text { Pounds } \\
\text { in } 100 \\
\text { Ibs. of } \\
\text { milk. }\end{array}$ & $\begin{array}{l}\text { Pounds } \\
\text { lost in } \\
\text { whey } \\
\text { for } 100 \\
\text { lbs. of } \\
\text { milk. }\end{array}$ & $\begin{array}{c}\text { Pounds } \\
\text { recover- } \\
\text { ed in } \\
\text { cheese } \\
\text { for 100 } \\
\text { lbs. of } \\
\text { milk. }\end{array}$ & $\begin{array}{c}\text { Per } \\
\text { cent } \\
\text { lost in } \\
\text { Whey. }\end{array}$ & $\begin{array}{c}\text { Per } \\
\text { cent Re- } \\
\text { covered } \\
\text { in the } \\
\text { Oheese. }\end{array}$ \\
\hline Solids in Milk & 12.52 & 6.20 & 6.32 & 49.52 & 50.48 \\
\hline F'at in Milk. . & 3.66 & 0.25 & 3.41 & 6.83 & 93.17 \\
\hline Nitrogen Compounds in Milk. & 3.07 & 0.73 & 2.34 & 23.78 & 76.22 \\
\hline
\end{tabular}

In this table it will be seen that 93.17 per cent of the fat of the milk went into the cheese and our rule places the figure at 91 per cent. (11.)

\section{QUESTIONS ON CHAPTER I.}

1. What are the food elements which enter into the composition of milk? 2. What is the average composition of milk? 3. What is meant by total solids? 4. Of what do the solids not fat consist? 5. What is the difference between casein and albumen? 6. Of what importance are the soluble calcium salts in cheese making? 7. How much milk sugar in 100 pounds of milk? 8. How does milk sugar differ from cane sugar? 9. What is the nature of butter fat? 10. In what form is the fat found in milk? 11. What is the size of the fat globules? 12. How many fat globules in a drop of average milk? 13. What can be said about the distribution of the globules in the milk at the time of adding the rennet? 14. What is the effect of fat in

\footnotetext{
*Bulletin 82, Geneva Experiment Station.
} 
the milk on the quality and the quantity of the cheese? 15 . How much cheese can be made from one hundred pounds of separator skim milk? 16. How much will one per ct. of fat increase the weight of cheese made from the milk? 17. Give first rule for calculating approximately the yield of cheese from milk of a given fat content. 18. Give second rule for calculating yield of cheese when both fat and solids not fat in the milk are known. 19. What is colostrum milk, and how does it differ from normal milk? 20. What is the chemical composition of green cheese? 21. What is the whey and what elements of the milk does it contain? 22. How do the losses of fat compare in whey in ease of rich and poor milk? 23. How may excessive losses of fat in cheese making be avoided? 24. What proportion of the various constituents of the milk go into the curd and into the rwhey? 
CHAPTER II.

\section{SECRETION AND CONTAMINATION OF MILK.}

\section{Structure of the Udder.}

The udder of the eow where the milk is secreted, consists of two glands connected with each other along the median line, and with the posterior part of the abdomen, by fibrous tissue. Each quarter has one opening or teat. The teat is hollow, having an opening at the lower end closed by a sphincter muscle. The chamber of the teat opens into another chamber in the lower part of the udder just above the teat. From this chamber ducts diverge, dividing and growing smaller and smaller. The two halves separated by the fibrous band along the median line are entirely separate. The ducts end in little chambers about a thirtieth of an inch in diameter. These chambers or ultimate follicles are lined with cells. Arteries, blood vessels and nerves surround them and the blood brought by the arteries is changed by the cells into milk.

\section{I. Secretion of the Milk.}

While some parts of the blood may be taken into the milk without change, and white blood corpuscles are actually found in milk, the blood is for the most part changed by the cells. The fat globules are produced in the cells and discharged into the ducts.

If samples of the fore milk and strippings be analyzed, the solids not fat will be found to be the same. The strippings will, however, be much the richer in fat. This is explained on the ground that on account of the fat globules being lighter there is a natural creaming in the udder, or, that the fat globules being in an emulsion are retarded more by fricticn in their passage through the ducts than the soluble components of the milk. 


\section{Time of Secretion.}

Some authorities believe that milk is secreted to a large extent at the time of milking, since the udder has room for only

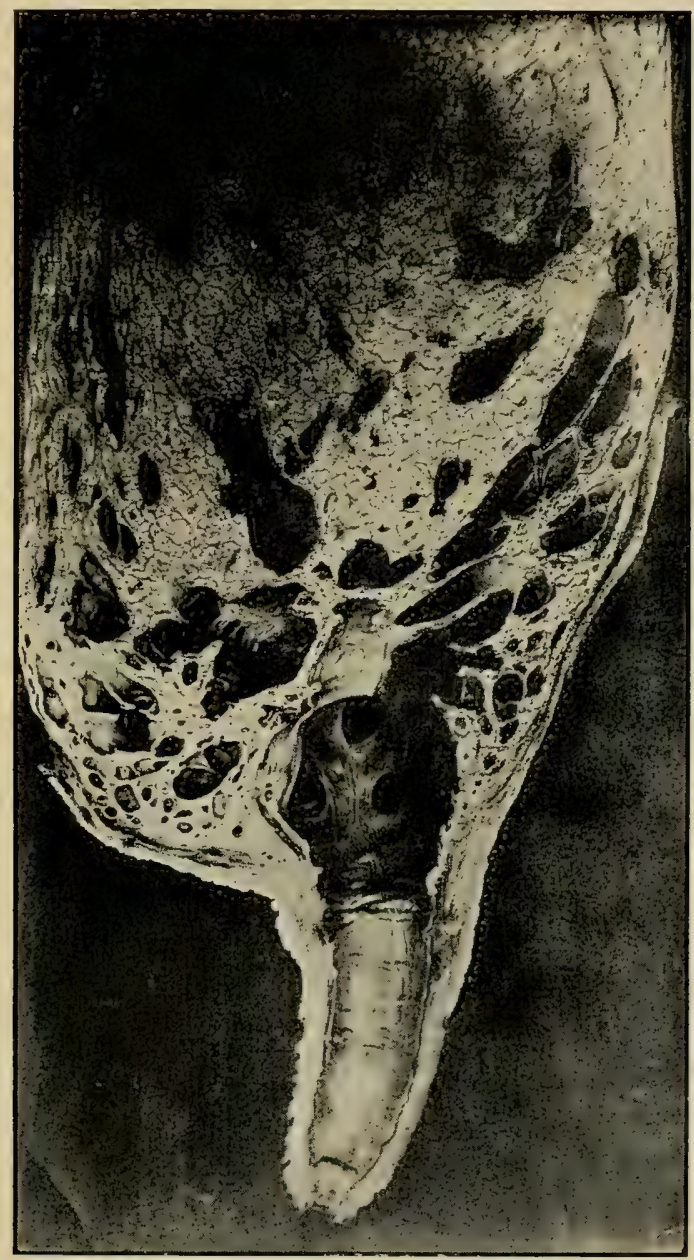

Fig. 3.-A section through a quarter of a cow's udder. From a photograph (Cornell Univ. Experiment Station).

a small portion of the milk yielded by the cow at a milking; when a cow is excited or disturbed at that time, she may fail to produce as much milk of the same quality as usual. 
On the other hand, the longer the period between milkings the larger will be the quantity of milk given, and if the udder is not emptied it will become very much distended; from these facts it is argued that milk production is a continuous process, though the rate of secretion may vary at different times.

\section{Cause of Bad Flavors.}

There are three causes for bad flavors in milk, namely: from strong-flavored feeds through the klood, by absorption from the air, and by kacterial infection.

\section{From Feed Eaten.}

Some strong-flavored feeds, like onions; turnips, cabbages, silage, rag weed, etc., put a like flavor into the milk given by the cow. The reader may have observed that when very hungry and faint, a little lunch will renew strength in a very few minutes. This shows how quickly the food is taken into the blood. In a like manner, when a cow eats strong-flavored feeds, the volatile substances constituting the flavor are taken into the blood and from the blood they go into the milk. Aerating milk (31) will in a measure set these volatile substances free. If strong-flavored feed is given the cow just before milking, the flavor will be sure to be found in the milk. If fed just after milking, the flavors will probably pass out of the cow's system before the next milking.

\section{Flavors by Absorption.}

Milk, especially when warm, will absorb odors through the medium of the surrounding air. It should therefore be kept away from the bad odors of hog pens, barnyards, swill barrels, and like odoriferous sources. It is very likely that the flavors of feed may get into the milk in this way.

\section{Bacterial Infection.}

Milk becomes sour upon standing. The souring is eaused by the growth of minute organisms, commonly ealled microbes or bacteria. These are plants consisting of but a single cell and so small that they can be seen only by a powerful microscope. They increase very rapidly and by their growth produce the changes observed in the milk. Some forms change the milk sugar into lactic acid and the milk kecomes sour, other kinds 
produce a ropiness of the milk without souring it, and other forms produce gas in the milk, and when made into cheese the curd becomes filled wth gas holes.

\section{Varieties of Bacteria in Milk.}

The following are some of the more common conditions produced in milk by bacterial growth:

Sour milk; gassy milk; bitter milk; slimy milk; soapy milk, which comes from a germ found on straw in the stable, producing a soapy taste and frothing of the milk; alcoholic fermentation; red milk; blue milk (not skimmed); green milk, ete. A bacillus known as coli communis which is present in immense numbers in the colon or larger intestine, finds its way from the manure into the milk and causes a large proportion of the gassy curds that our cheese makers have to deal with. This germ has been found to exist in the udder for a long time. It finds its way through the opening in the teat, gets a lodgement and remains there, to grow and contaminate the milk, until accidentally dislodged and carried out with the milk. Rusty spots in cheese are caused by bacillus rudensis (222).

\section{How Milk is Infected.}

When the milk is drawn from the udder, bacteria floating separately or clinging to particles of dust in the air fall into it. It will readily be seen that if the statle is closed tight and hay has been fed just before milking, a great deal of bacteria-laden dust will be stirred up and fall into the milk pail. If the cow lies down in the manure, or other filth, at milking time, the dust from this is stirred up and falls into the milk. Warm milk is a good medium for the germs to grow in, and they multiply very rapidly therein. If the milk is cooled the growth of the bacteria is checked for the time, but on warming up the milk again they will grow and multiply rapidly.

\section{The Wisconsin Curd Test.}

While associated in dairy work with Drs. Babcock and Russell at the Wisconsin Experiment Station, the author brought out what is known as the Wisconsin Curd Test for the detection of injurious fermentations. The apparatus consists of pint, or smaller glass jars, with perforated tops, which set in a frame 
in a water tank. Samples of the milk to be examined are taken in the various jars, which are then set in warm water in the water tank and raised to a temperature of $95^{\circ}$ to $100^{\circ} \mathrm{F}$. Ten drops of rennet extract are added to each sample and when the milk has curdled, the eurd is broken up with a ease knife. Care should be taken not to transfer the germs from one sample to another by the case knife or thermometer. As soon as the whey

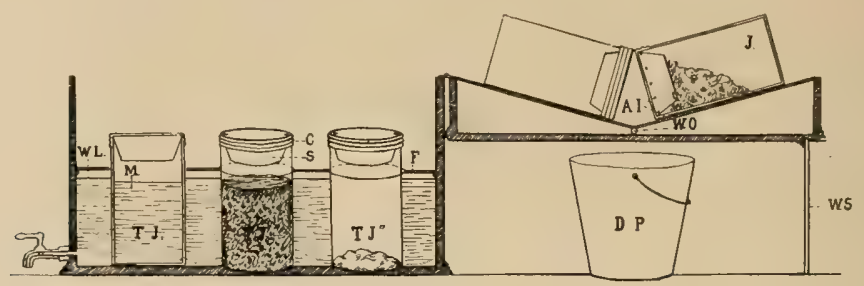

Fig. 4.-The Wisconsin Curd Test.

separates, it is strained off through the strainer top, leaving the curd behind in the jar. The eurd is then under the same conditions as a curd in the cheese vat, and the various kinds of bacteria will develop, giving their characteristis results. If the result te gas, it will show in the curd, or if it be a taint it will likewise be found there. Common Mason fruit jars and a

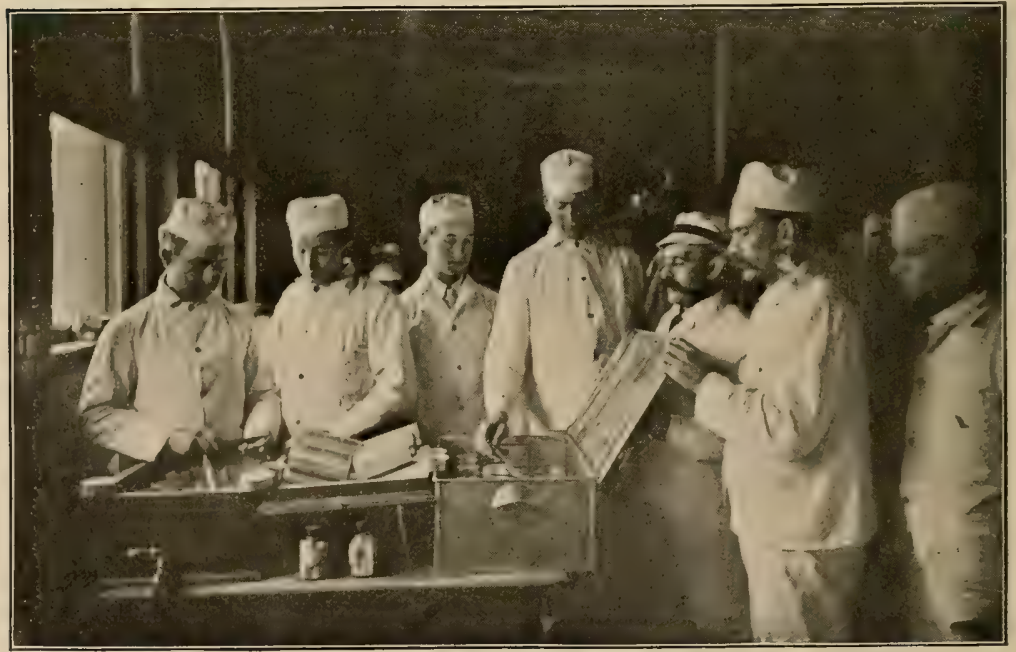

Fig. 5.-Students operating the Wisconsin Curd Test. 

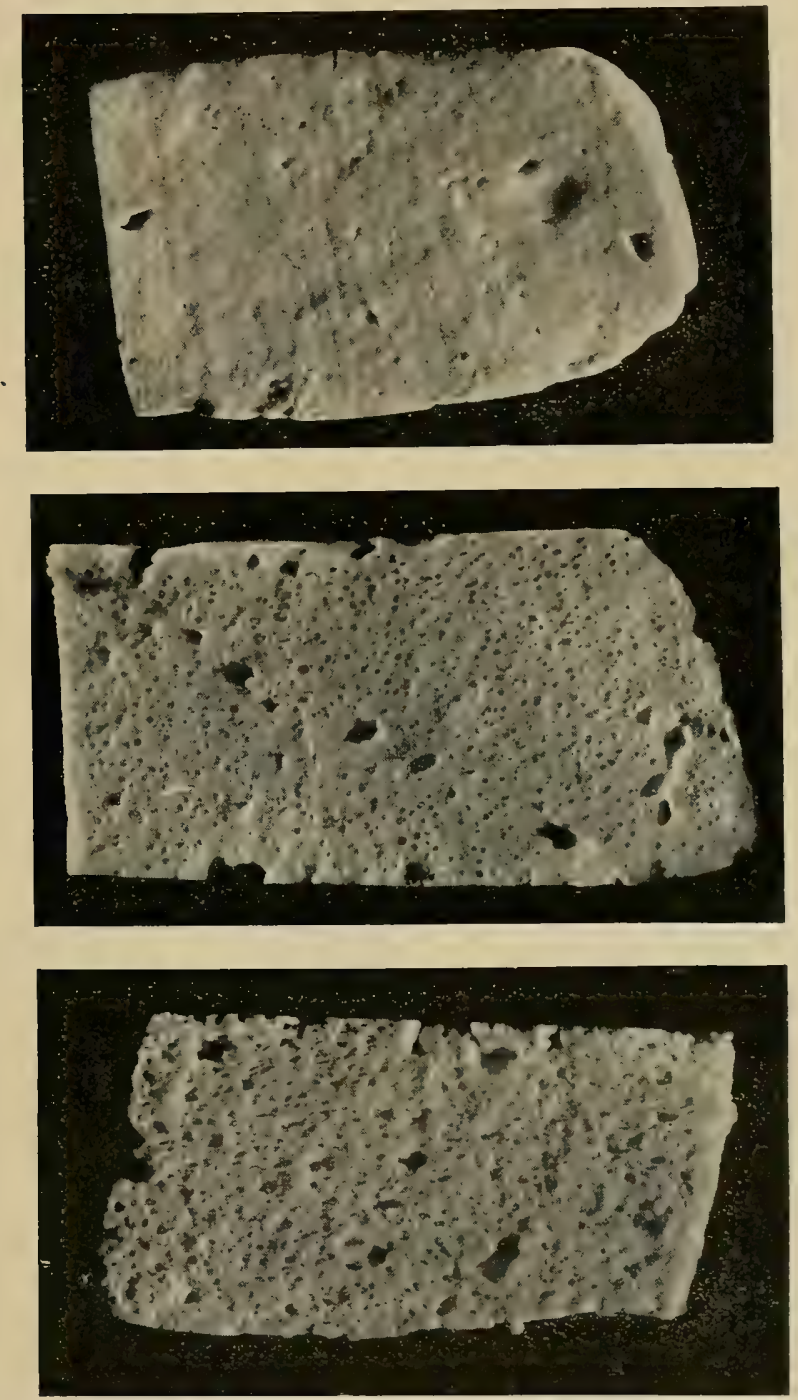

Fig. 6.-Curds from milk of different quality as produced in the Wisconsin Curd Test.

Upper figure, curd from a good milk. Large irregular holes mechanical. Middle figure, curd from tainted milk. Numerous small "pin holes" due to gas formed by rapid development of sugar-fermenting kacteria.

Lower figure, curd from a foul milk. When received this milk showed no abnormal symptom, but the foul odor and spongy texture appeared in six to eight hours.

By means of this test, the factory operator can detect with certainty the presence of taints in milk that are caused by the development of bacteria and molds. 
washtub can be used for this work, but the regular apparatus for the purpose sold by supply houses is much better. (See Fig. 4.)

\section{Care of Milk.}

Having explained the sources of bad flavors in milk, a few suggestions about the care of milk may be in order. It has been seen that one cause of such flavors is the feed that the cows may get. If it is necessary to feed turnips or similar feeds, they should not be fed to excess, and after milking, in order that the flavor may disappear from the cow's blood before the next milking.

\section{3r. Aeration.}

Milk should be aerated-that is, it should be exposed in thin films or streams to pure air, so that these volatile substances may escape. As milk will absorb odors from the air, especially when it is warm, great care should be taken to.aerate the milk in a place where the air is fresh and untainted. The barn is obviously a poor place in which to do this.

\section{Varieties of Aerators.}

The common aerater is a large tin vessel with fine holes in the bottom. It is held above the milk can by an iron frame. The milk is strained into this aerator and falls through the air in fine streams into the ean below. The Star cooler and aerator is arranged so that the milk flows in a thin film over a corrugated surface, and water flowing through the apparatus coo's the milk rapidly as it is being exposed to the air.

\section{The Barn Air.}

The air in the barn should be kept as free from dust as possible, for as previously explained, the particles of dust are loaded with bacteria. Good dairy farmers make a habit of airing out the stables before milking, and hay or dry fodder is not fed until after milking.

The stables should also be kept clean to prevent the milk from being injured by foul odors.

\section{Keep Cows Clean.}

The cows, if dirty, should be carded the same as a horse. There is no excuse for having a cow's flanks plastered over with filth. As previously explained, such filth is an incubator for 
the kinds of kacteria that spoil the milk. Just before milking, the cow's udder and flank should be dampened with a wet cloth or sponge to dislodge the dust and thus prevent its falling. The habit of wetting the teats, however, is a bad one, for dirt may be washed into the milk with the moisture.

While a limited number of lactic acid-producing germs in milk may not be detrimental, the germs that come from barn filth are very injurious.

\section{Cooling the Milk.}

As soon as the milk has been aerated, it should be cooled to $60^{\circ} \mathrm{F}$. or less. At $40^{\circ} \cdot \mathrm{F}$. there will be little, if any, change in the milk, and if it has to be kept a considerable length of time, this temperature should be approximated as near as possible.

\section{Covering the Cans.}

After the milk has been properly aerated and cooled, it should be covered to prevent evaporation from the eream that forms on the top. This cream can be readily worked back into the milk if it does not become leathery from evaporation.

\section{Kind of Utensils.}

Wooden pails should not be used for milk, for the reason that they cannot be easily and thoroughly cleaned; milk will soak into the wood and ferment, ready to contaminate the next lot of milk.

The seams of tin pails, eans and dippers should be filled flush with solder so that milk cannot collect and sour in erevices.

\section{Care of Utensils.}

All strainers, pails and other utensils in which the milk is handled should be rinsed first with lukewarm water, and then with toiling water, and if possible, exposed to a jet of steam to thoroughly sterilize them. Many germs are killed by direct sunlight, and the utensils should be set out in such a position that the sun can shine into them. After sealding they should not be wiped out with a towel or rag, as this would be likely to again introduce undesirable germs in them.

\section{Factory Cleanliness.}

No less important than the matter of cleanliness in the barn and the manner of milking, is the matter of cleanliness in the 
factory. Milk may be spoiled in an untidy factory after its delivery there. A few suggestions at this time regarding the care of the factory will be pertinent.

Almost every cheese-maker will keep the inside of the weigh-can and cheese vats clean, but the outside is often sorely neglected. Milk may be spilled on the floor, and not properly cleaned up. Water is slopped on the floor, and the maker wades through it without drying it up; when the whey is drawn from the vat, it often goes on the floor, and in order to keep his feet dry, he wears rubber boots.

\section{Rubber Boots.}

The rubber boots are an injury to his health and the slop unnecessary, to say nothing about the wear on the floor and its untidy appearance. One would think a housewife who kept her kitchen floor in such condition, a very slovenly woman, and there is no reason why a factory floor should be slopped over any more than a kitchen floor. If any water accidentally gets onto the floor, it should be mopped up at once. Rotten floors which have to be renewed often, and rheumatism and ill health for the operator, are the price paid for the doubtful privilege of

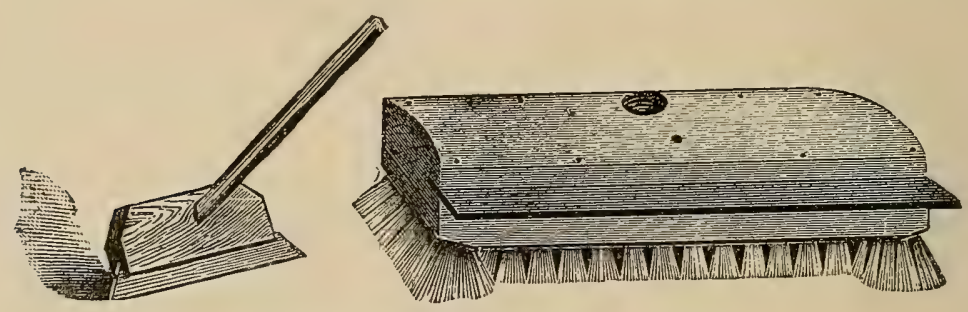

Fig. 7.-Rubier Mop and Floor Scrub.

making a mill pond of the factory floor. The old saying that "a penny earned is a penny saved" applies in a modified form to work in a factory, viz.: Care in preventing dirt will save the labor of cleaning it up.

\section{I. Scrubbing the Floor.}

At the close of the day's work, the floor should be scrubbed, first with lukewarm, and then with hot water, and then dried off with a rubber mop. Hot water will make the floor dry quickly, 
but it should never be used where milk has been spilled, or where milk or whey is on tinware, for heat will scald the milk on.

\section{Soaps.}

Powdered soap, such as "Gold Dust," is very effective in taking out dirt, but it is too expensive a form in which to use soap, as it dissolves readily and runs away. Salsoda is much cheaper and just as effective for a great many things, such as cleaning the floor. A mixture of cheap soap and salsoda can te dissolved in hot water and used for scrubbing, and then afterward rinsed off with hot water.

Sapolio is a soap mixed with infusorial earth, which may be used for scouring tinware.

\section{Scrubbing Brushes.}

Several good stiff serubbing brushes are needed for getting into corners. Brushes are now made in a number of different forms so as to apply to all conditions. There are round brushes on long handles for getting into pipes and tubes, strong brushes with sharp corners and round ends, and extra heavy floor scrubs. All these things make the work easier.

\section{Towels.}

The need of clean towels and clean cloths in factories for wiping hands and utensils, it would seem, is so evident that it may be thought unnecessary to mention the fact, but they are nevertheless absent in a large number of factories; hence mention of the matter is made here.

\section{Watch the Corners.}

In scrubbing the floor, the mop board should not be forgotten, nor the doors and other wood work. If the maker is careful in scrubbing the floor every day, a general scrubbing once a week will keep things looking bright.

\section{Shelves for Trinkets.}

The windows should be kept as clean as those in a dwelling house, nor should tools and little trinkets be laid on the windowsills. There should be shelves or drawers for all such things.

The curing room should likewise be kept in order. It should not be a dumping place for all sorts of material, which properly goes into the store room above. 


\section{How to Kill Molds.}

At the beginning of the season, the walls may be sprinkled with water, and the room closed tight, while two or three pounds of sulphur is burned in it; this method will kill molds.

\section{Antiseptics.}

A still better way is to wash the walls with limewater. Limewater is a disinfectant, and should ke used wherever it can be applied. Commercial sulphate of iron (copperas or green vitriol, as it is commonly called), is also a disinfectant, and should be put into drains and places that are likely to smell badly.

\section{To Prevent Dust.}

The boiler room must not be neglected. If coal is used, coal dust can be prevented by sprinkling the coal with water. The floor should be kept cleanly swept, and should be mopped twice a week, or as often as needed. Tools should have their regular places and be kept there.

The reader may consider it a waste of space to talk about all these little matters, but experience has taught the writer that they are the foundation of the business of cheese-making; makers often fail, because they do not recognize this fact.

It is much easier to keep a clean factory than a dirty one; the old saying that "an ounce of prevention is worth a pound of cure"' is true here, as well as in other cases.

\section{Factory Surroundings.}

Having gotten the inside of the factory clean, why not make the outside of it to match? Plant some trees, and in painting the factory, choose white or some light color, that will not absort, but will reflect the heat. A little extra effort may be put into graveling the roadways, to prevent their being cut up in wet weather. Level off the ground for a little space, seed it. down, and cut the grass with a lawn-mower. If a dry spell comes, there is plenty of water in the well, and the lawn can be sprinkled by using the steam pump. These things would take but little extra effort, and all will agree that the result would fully repay the effort.

Why should it not be the rule that a cheese factory is to be: kept not only clean, but attractive as well? 


\section{QUESTIONS ON CHAPTER II.}

1. Describe the structure of the udder of a cow. 2. What can be said about the secretion of the milk in the udder? 3. How do samples of the fore milk and strippings compare as to fat content? 4. How is the greater fat content of the strippings explained? 5. At what time is the milk secreted? 6. What are the three sources of bad flavors in milk? 7. How does the flavor of feed get into the milk? 8. Will warm milk absorb odors? 9. What are microbes or tacteria? 10. What can be said about the effect of different germs on milk? 11. What can be said about the bacillus known as coli communis? 12. How is milk infected? 13. What is the Wisconsin Curd Test and how is it used? 14. What is the value of the aeration of milk? 15. Describe some of the common aerators. 16. What can be said of the barn air at milking time? 17. Why should the cows be kept clean? 18. Why should a cow's udder and side be dampened just before milking? 19. Why should milk be cooled after aerating? 20. Why should the milk cans be covered over night? 21. Why are wooden milk pails not to be uised? 22. How should utensils be washed? 23. What is the effect of wet floors and rubter boots on a maker's health? 24. How would you make the surroundings of the factory attractive? 


\section{CHAPTER III.}

\section{MILK TESTING.}

\section{I. Development of Milk Testing.}

When one stops to think that only eighteen years ago, or even less, the only means that a cheese-maker had of determining the quality of milk was a cream tube, in which the milk was set for the eream to rise, and a lactometer that would read good milk when both skimmed and watered, he begins to realize what great progress has been made in milk testing in this brief time. This great change has been brought about by the work of the agricultural experiment stations, and this one line of progress is paying large dividends on all the money that has been invested in them.

As indicated in Chapter I (12) the value of milk for cheese making is dependent on its fat content. "New coins are handled with suspicion," and when the new method of paying for milk according to the test was first recommended, farmers and dairymen were slow to adopt it. At the present time, probably a majority of American Cheddar cheese factories are paying for milk in this way.

\section{The Babcock Test.}

The Babcock test for determining the fat content of milk was invented by Dr. S. M. Babcock of the Wisconsin Agricultural Experiment Station, and described in Bulletin No. 24, July, 1890; it is now not only in general use in this country, but in different countries of Europe, in India, New Zealand and Australia. It has literally "gone around the world." "*

The following apparatus is used in the Babcock test: Test bottles, pipette, acid measure, and centrifuge.

*The Babcock Test is described in detail in "Testing Milk and Its Products," by Professors Farrington and Woll (18th edition, 1908; Mendota Book Co., Madison, Wis., publishers). Full directions for making tests of milk and other dairy products, and discussions of all phases of the subject will be found in the book. 


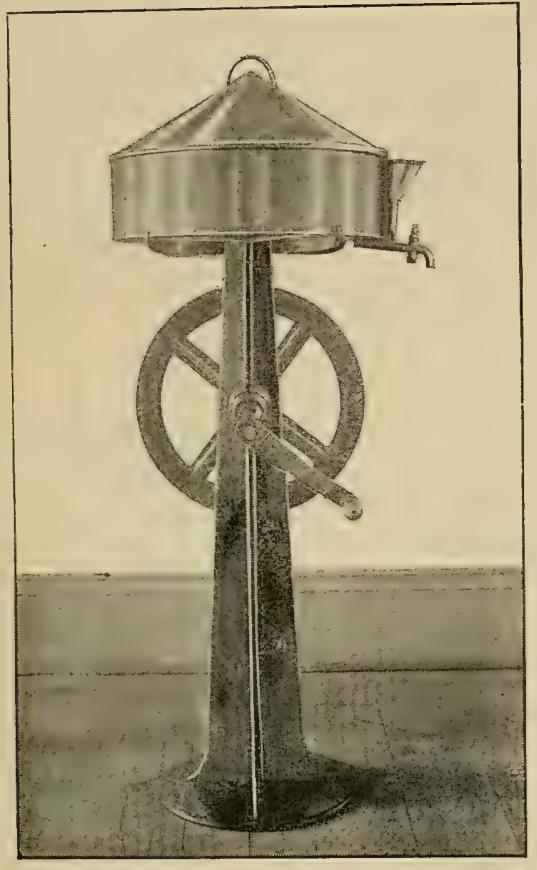

Fig. 8.-The first Babcock tester made.

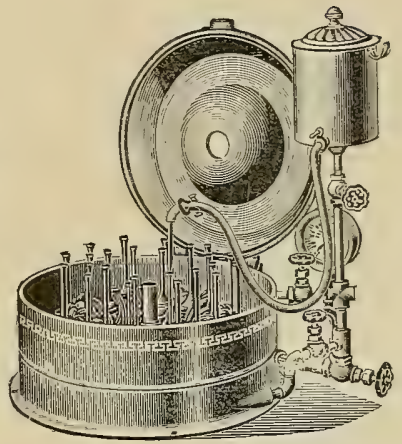

Fig. 10.-A modern steam turbine tester.

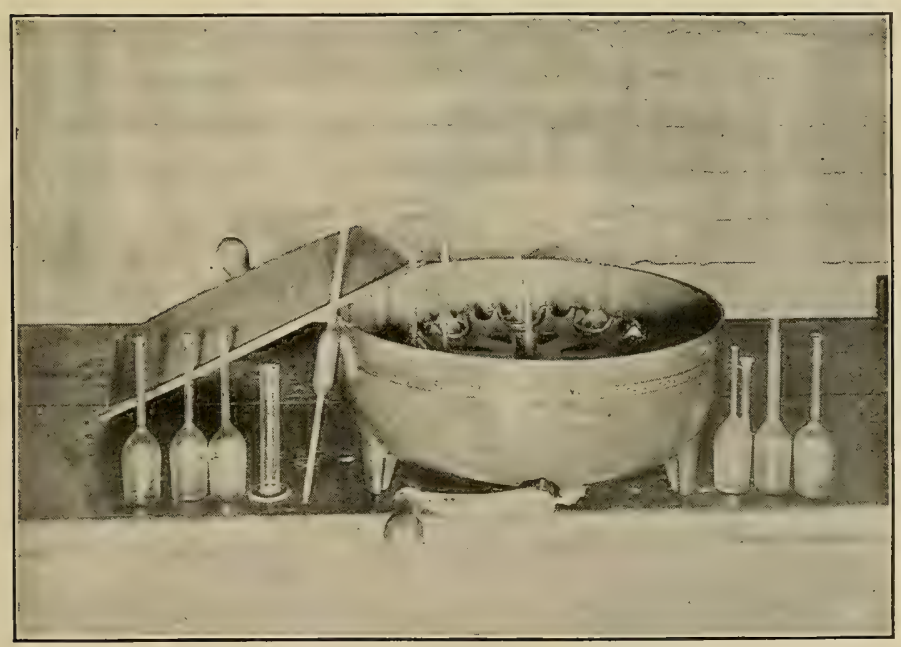

Fig. 9.-A modern Babcock hand-tester. 


\section{The Test Bottle.}

The Babcock test bottle holds atout two ounces and has a long, narrow neck, about the size of a lead pencil. The neck has graduations from 0 to 10 , which represent a volume of two cubic centimeters. The scale is marked off into fifty divisions; every
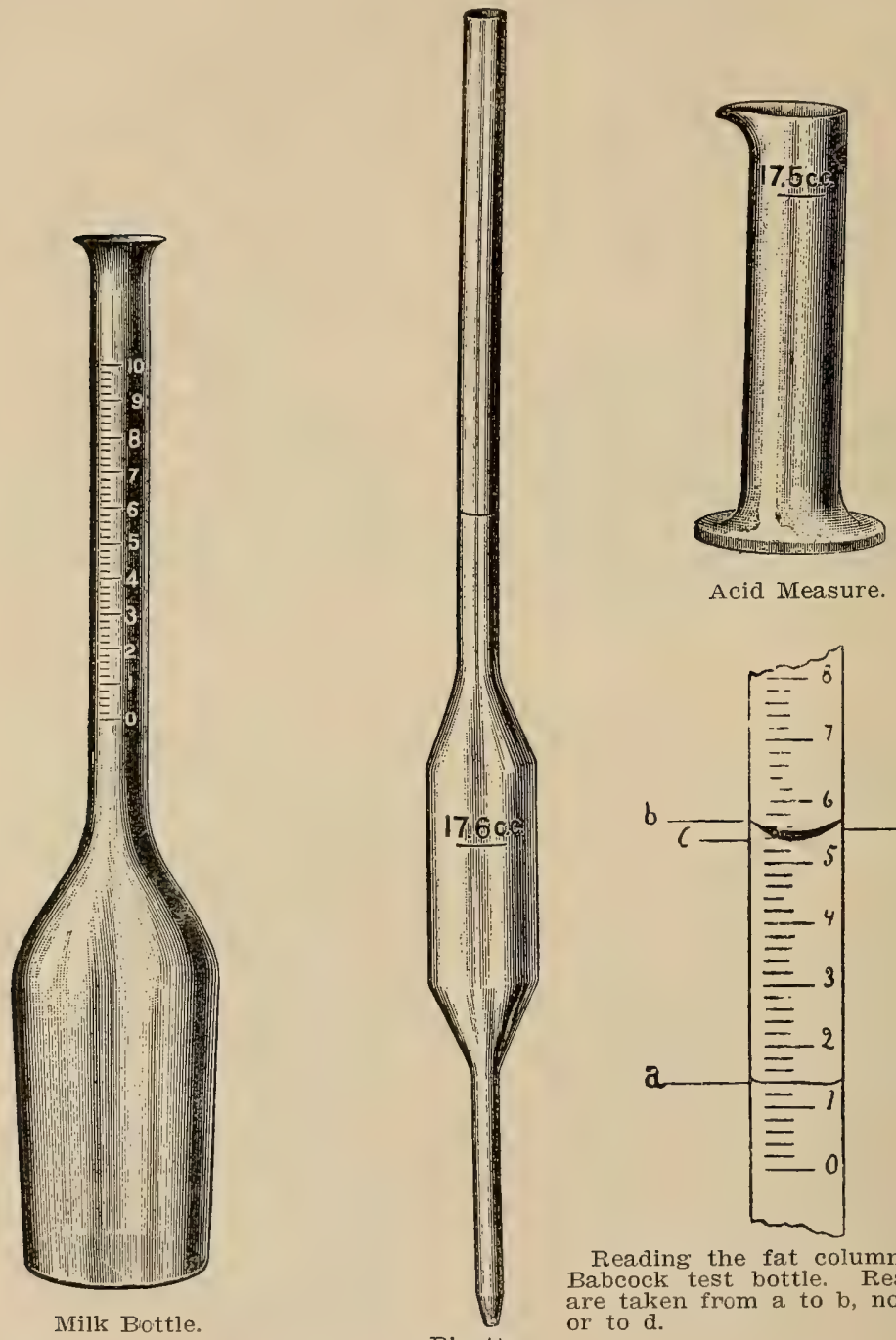

Acid Measure.

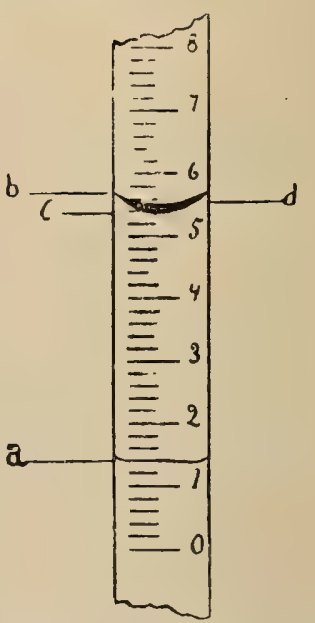

Reading the fat column in a Babcock test bottle. Readings are taken from a to $b$, not to $c$ Pipette. or to $d$.

Figs. 11-14.-Babcock Test Ware. 
five divisions marks one per cent and each division is therefore two-tenths of one per cent.

\section{The Pipette.}

The pipette is a glass tube with a bulb in the middle for measuring the milk. There is a mark on the upper narrow stem indicating 17.6 c. c.; this volume of average milk weighs eighteen grams.

\section{The Acid Measure.}

This is a glass cylinder with a 17.5 c. c. mark on it for measuring the sulphuric acid used in making the test.

\section{The Centrifuge.}

This is a machine for whirling the bottles. It consists of a drum 15 to 24 inches in diameter, with swinging sockets in the center for holding the bottles. The centrifuge is driven either by a crank or pulley and gear, by a steam turbine or by electricity.

\section{To Make the Test.}

The milk to be tested must be thoroughly mixed to get the fat gloubles evenly distributed. This can be done by pouring from one vessel to another several times. If the cream is somewhat hardened on a sample of milk it can be dissolved by warming the milk a little, but this must be done with eare as the milk will then churn easily. After the milk is thoroughly mixed, draw it up into the pipette by suction and then quickly place the finger over the upper end of it. By letting air in slowly under the finger the milk will run out till it drops to the 17.6 c. c. mark. Then deliver the contents into the bottle. Next measure 17.5 c. c. sulphuric acid into the bottle, and by a circular motion mix the acid and the milk thoroughly till the milk is all dissolved, that is, till no clots of curd are left.

Then put the bottle in the centrifuge and whirl four minutes. At the end of this time all the fat will be on the top of the liquid. Hot water is filled in to bring the fat up into the neck where the amount can be read on the scale. It is whirled another minute to bring the fat all into the neek in a solid mass. It must be read before it gets cold, while still in a perfectly liquid condition. The fat should be read off at a temperature of about 
$140^{\circ} \mathrm{F}$. Better results may be obtained by first filling water up to the neck and whirling, and then bringing the fat into the neck by a second filling prior to the final whirling.

Several precautions should be observed to get uniformly clear readings and reliable tests.

\section{Strength of Acid.}

First, the acid should be commercial sulphuric acid of a specific gravity of 1.82 to 1.83 . If too strong the fat will be charred and black specks will be found in the fat column. If too weak, there will be white matter with the fat. Dairy supply houses furnish a hydrometer for testing the specific gravity of the acid. If it is 1.81 it is too weak, and if over 1.83 too strong. If the acid is only a little too strong or too weak, the difficulty can be obviated by using a little more or a little less, as the case may require. One should observe the color of the fat. It ought to be a deep straw or yellow color. If white or light colored the acid is weak, if black it is too strong. As a general rule, there is little difficulty in getting good acid. Both milk and acid should have a temperature of about $70^{\circ}$ when tests are made.

Automatic acid measures can be obtained from supply houses which may be used for filling the bottles with the right amount of acid. The test bottles should be shaken one at a time and not in a tray, as in that case the milk in some bottles may not be thoroughly dissolved.

The acid should go to the bottom of the bottle without mixing much with the milk before the final shaking. If it mixes partially and then is allowed to stand, a portion of the milk will be acted upon too strongly by the acid, with the result that the fat will be charred and black specks will be found in the fat column.

\section{Speed of the Centrifuge.}

The speed of the ordinary tester, which is about eighteen inches in diameter, should be about one thousand revolutions per minute. The fat is forced to the top of the liquid by the centrifugal force, and unless this is sufficient all the fat will not be separated. If the speed is too great the bottles may be broken during the whirling. Steam turbine testerrs should always be provided with a steam gauge or a speed indicator which will 
show whether the speed required for the particular tester is maintained.

\section{Reading the Fat.}

The column of fat should be read from the bottom line, where it meets the water, to the highest point where it joins the glass. The upper surface is curved, and quite often the test is read low by reading only to the lower part of the curve. It should be read as high as the fat goes in testing milk. The same thing applies when reading tests of whey. It is quite often read two-tenths when four-tenths is the amount present. A pair of dividers will aid in measuring the fat. Open them to the full length of the fat column, then place the lower point on the zero line, and the upper point will show the per cent present at a glance. When reading without dividers, errors in subtracticn may occur. (See Fig. 14.)

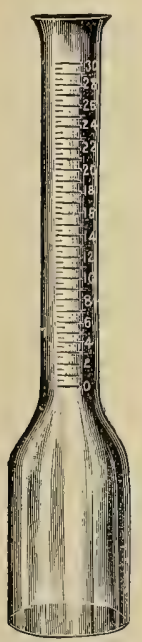

Fig. 15.-Test bottle for cheese and cream.

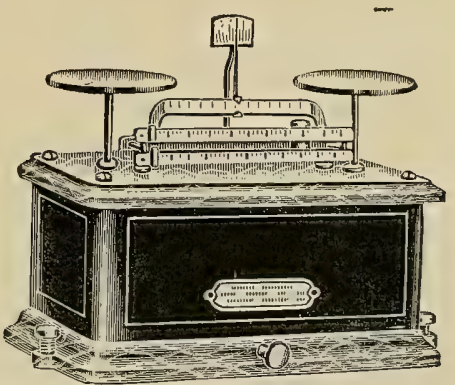

Fig. 16.-Torsion balance with percentage beams.

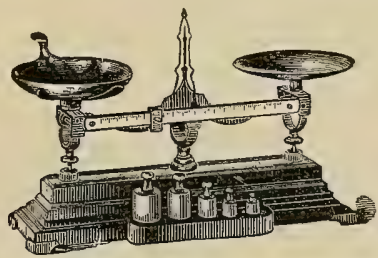

Fig. 17.-Troemner balance, for testing cheese.

Skim milk test bottles with specially narrow necks may be used in testing whey as well as skim milk.

\section{6r. Testing Cheese.}

Cheese may be tested by the Babcock test for its fat content, as well as milk. In making a test of milk, 17.6 c. c., or 18 grams is used. Cheese contains about one-third fat, so that we 
eannot take 18 grams; but if we balance the bottle on a small scale, such as druggists use for preseriptions, and weigh in four or five grams of cheese, this will make a convenient amount for the test. The cheese can be cut into small strips which will drop down the neek of the bottle. Then add fifteen cubic centimeters of boiling water and a few drops of ammonia, and shake till the cheese is dissolved into a creamy consistency. When the bottle is cold, add acid, and test as in the ease of milk. The reading of the fat is then multiplied by $\frac{18}{2}, a$ being the weight of the cheese taken. The quotient will be the per cent of fat in the cheese. If five grams of cheese is weighed out and the reading of the fat is 7.1 , we have $(7.1 \times 18) \div 5$, or $25.5 \%$ fat in the cheese.

A little balance with weights and a bar, reading to onetenth of a gram, is sold at a low price by dairy supply houses; balances with percentage beams are also on the market and will be found convenient in practical work. (Figs. 16 and 17.)

\section{Quevenne Lactometer.}

The Quevenne Lactometer is an instrument for ascertaining the specific gravity of milk. On the scale are a set of figures reading from 15 down to 40 . These figures mean thousandths, that is, 30 means 1.030 specific gravity. If we have a barrel that will hold $1,000 \mathrm{lbs}$. of water at $60^{\circ} \mathrm{F}$., and fill it with milk that reads 30 on our lactometer, we would have $1,030 \mathrm{lbs}$. of milk in the barrel. If the milk is heated above $60^{\circ}$, one-tenth of a pound will flow over the top for each degree above $60^{\circ} \mathrm{F}$., and likewise for every degree the milk is lowered, a tenth of a pound more can be put into the barrel. Sixty has been taken as an arbitrary standard of temperature for specific gravity of milk, and we must temper the milk near to that point. If it varies a few degrees, the reading can be corrected by adding or subtracting one-tenth to the reading of the lactometer for every degree of variation in temperature. Thus: if the lactometer reading is 32 , and the temperature $65^{\circ}$, add .5 to 32 , which would make the corrected reading for $60^{\circ} 32.5$. The best lactometers are made with an inside thermometer and these will be found very convenient in factory work. 


\section{Board of Health Lactometer.}

The Board of Health Lactometer has an arbitrary scale reading from 0 to $120 ; 100$ shows a specific gravity of 1.029 , which corresponds to 29 on the Quevenne scale. This is supposed to be the lowest specific gravity of pure milk, the average being about $1.032 \mathrm{sp}$. gr. This seale can be converted into the Quevenne seale by multiplying the reading by .29. By so doing one can use the Board of Health instrument if a Quevenne is not available.

\section{Detecting Watered Milk.}

The solic's other than fat make the milk denser and raise the lactometer reading, while the fat makes it lighter and lowers the reading. Each per cent of fat lowers it seven-tenths of a degree. If we multiply the per cent of fat found by the Babcock test by .7 and add the product to the lactometer reading it will give the reading of the milk if the fat were not present. If the specific gravity of the other solids is divided by 3.8 , the result will be per cent of solids not fat.

For instance, the lactometer reading is 31.5, the temperature $65^{\circ}$, and the fat 4 per cent, what is the per cent of solids not fat?

$$
31.5+.5=32+(4 \times .7=2.8)=34.8 \div 3.8=9.10 \%
$$
solids not fat.

If the solids not fat run below 8.5 per cent it is a poor sample of milk and has very likely been watered, especially in the case of mixed herd millk.

If 9 per cent solids not fat be taken as a basis for pure milk, and we find but 7.0 per cent, the way to get the amount of water added is readily found by proportion:

$$
\begin{aligned}
7.0: 9.0:: x & : 100 \\
9.0 x & =700 \\
x & =.66+
\end{aligned}
$$

$66+\%$ is the milk found to be present in the sample or about 34 per cent water has been added.

When patrons are paid by the fat test it does not pay to go to the trouble of hauling water to the factory.*

\footnotetext{
*For other methods of determining adulteration of milk, by watering or skimming, see "Testing Milk and Its Products," 18th ed., p. 113.
} 
In paying for milk by the test, composite samples are tested as follows:

\section{Composite Samples.}

The samples should be saved from each patron's milk every morning by stirring the milk in the weigh can with a dipper. An ounce measure is then filled with the milk, and emptied into a sample jar, labeled with the patron's name or number.

A still better way is to take the sample with a milk thief, which is a long tube three-fourths of an inch in diameter, with

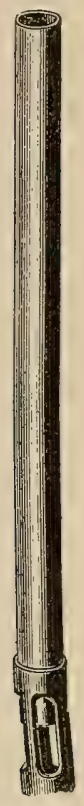

Fig. 18. The Scovell Sampling

Tube. a valve in the bottom. By lowering this into the weigh can an accurate sample of the milk runs in at the bottom and the valve is closed by striking the bottom of the can. The tube is then drawn out and emptied through the upper end into the sample jar. The Scovell sampling tube (Fig. 18) is another convenient apparatus for sampling milk in the factory weigh-can.

\section{Milk Samples, How Preserved.}

A small quantity of potassium bichromate, enough to color a jar of milk a bright yellow, is put into the clean jar; this chemical will preserve the milk for about two weeks.

Corrosive sublimate tablets sold by dealers in dairy supplies are now quite generally used and may give more satisfactory results; they are very poisonous and must be handled with care.

At the end of a week the composite sample of each patron's milk is tested, and the reading of the Babcock test shows the percentage of fat in the milk supplied by the patron during the week.

For method of making dividends according to

the test, see Chapter XIII.

\section{Test for Casein in Milk.}

If it is desired to determine the amounts of casein in different samples of milk, the following test invented by Prof. Hart of the Wisconsin Station in 1907\% may be used to advantage in factory work as well as in ehemical laboratories: Two c. c. of 
chloroform, 20 c. c. of a .25 per cent acetic-acid solution, and 5 c. c. of milk (both these latter of a temperature of about $70^{\circ} \mathrm{F}$.) is measured into small tubes of special construction holding about 35 c. c., the lower end of which is narrow and graduated to 1 e. c. The mixture is shaken for 15 to 20 seconds and the tubes then whirled $71 / 2$ to 8 minutes in a centrifuge of 15 inches diameter, making 2000 revolutions per minute. The use of a metronome is recommended to facilitate the control of the speed. After whirling, the tubes are taken out of the centrifuge and allowed to stand in an upright position for 10 minutes. The percentage of casein may then be read off directly from the scale on the lower end of the tubes, each division of which represents .2 per cent of casein when 5 e. c. of milk are measured out.

\section{QUESTIONS ON CHAPTER III.}

1. When and by whom was the Babcock milk test invented? 2. Describe the test bottle. 3. What is the volume included in the scale of the milk bottle and how is it divided? 4. What is the volume of the pipette and what weight of milk will it hold? 5. What is the volume of the acid measure? 6. What is the diameter of the centrifuge? 7. How is a test made? 8. What kind and how strong is the acid used? 9. At what speed should the centrifuge be run? 10. Describe how the fat should be read. 11. How can cheese be tested with the Babcock test? 12. Describe the Quevenne lactometer. 13. Describe the Board of Health lactometer and state its relation to the Quevenne. 14. How much does each per cent of fat lower the lactometer reading? 15. Give method and rule for detecting watered milk? 16. What is a composite sample? 17. Describe the Scovell sampling tube. 18. How are composite samples preserved? 19. Describe Hart's test for casein in milk. 


\section{CHAPTER IV.}

\section{ENZYMES.}

\section{Two Kinds of Ferments.}

As has been previously described, bacteria are the cause of the breaking-up of organic compounds into other compounds; as for example, milk sugar into lactic acid, or into alcohol and gas. Such changes or fermentations are termed organized ferments because they are the result of the growth of certain organisms or germs.

There is another class of changes which take place as a result, not of bacterial growth, but of the action of a chemical substance known in contradistinction to the organized ferments, as unorganized ferments or enzymes. Such, for instance, is a substance found in the saliva known as ptyalin, which has the property of changing starch to sugar. In the stomach is found pepsin which has the property of changing solid proteids to soluble peptones, and in the pancreatic juices is found trypsin, another enzyme with properties similar to pepsin. These enzymes are secreted by the protoplasm of cells which make up the particular glands where they are usually found. Bacteria have this property of secreting enzymes, and as our knowledge of fermentations increases it may be found that the changes we now suppose to be due to the direct action of the living protoplasm in the cells of plants and animals, are really due to enzymes secreted by the protoplasm. Enzymes have some characteristics in common in the manner in which they behave under changes of temperature. They are most active at temperatures near blood heat $\left(100^{\circ} \mathrm{F}\right.$.) and cease to act at low temperatures, while at high temperatures $\left(150^{\circ}\right.$ to $\left.200^{\circ}\right)$ they are destroyed. The enzymes do not seem to be used up in their action, but will work over and over again. 


\section{Galactase.}

Babcock and Russell in 1897 described an enzyme in milk to which they gave the name galactase. When milk is rendered sterile by chloroform, it will curdle upon standing as if it contained rennet, and the casein will be digested, that is, it is changed to soluble peptones. Galactase is killed at a temperature of $180^{\circ} \mathrm{F}$. Its optimum temperature is about $100^{\circ} \mathrm{F}$. It is believed that this enzyme is at least the major cause of the breaking-down of the casein in cheese and its change into soluble peptones and is therefore a most important factor in the ripening of Cheddar cheese.

\section{Rennet Extract.}

Since early times an extract from the calf's stomach has been used to curdle milk in the manufacture of cheese. Such an extract is supposed to contain two enzymes, one, rennin, having the property of coagulating the milk, and the other, pepsin, which afterwards digests the curd.

\section{7x. Rennets, Where Obtained.}

Commercial rennet is the stomach of new-born calves which are slaughtered before teing fed; the stomachs are cleaned and dried, before they are marketed.

The best rennets come from Bavaria; it is stated that the City of Copenhagen alone consumes annually 5,000,000 rennets in the manufacture of rennet extract. Cheese makers used to buy the rennets and make their own extracts as needed, and the majority of Swiss cheese makers do so now, but extracts, powders and tablets are now manufactured on an extensive scale, and are much more uniform and reliable than the old homemade extracts, which are likely to vary greatly.

The preparation of rennet powder is too complicated a process for a cheese maker to follow, but one can make his own extract for the season, if he wishes, as follows:

\section{How Rennet Extract Is Made.}

Prepare a sufficient number of rennets, say five hundred, by splitting them open so that the water can get into them. Then place the rennets in an oak barrel and fill it with water until the rennets are well covered. No more water than is necessary to dissolve the ferment should be used. 
A little salt should be added to the water, say three pounds of salt to one hundred pounds of water. The rennets should be stirred vigorously every day, to facilitate the solution of the ferment, and at the end of a week the liquid should be drawn off and the rennets wrung out with a clothes-wringer. They should be put into water again and soaked for another week, and the same operation repeated. As a usual thing, the ferment has not all been extracted from the stomachs till they have been soaked for four weeks. The liquid that has been obtained by soaking the rennets should be filtered through clean straw, charcoal and sand, and then an excess of salt added to preserve it.

The extract should be clear though of a dark color. The first sign of the decomposition of rennet extract is a muddy appearance.

If extract is prepared by the cheese-maker, enough to last the whole season should be made in the spring when the weather is cool; the extract should be kept in a cool place.

\section{Reliable Brands to be Preferred.}

The surest way of getting extract that can be depended on is to buy some reliable brand.

The practice of preparing extract every few days is not to be recommended as the strength of the different lots will vary and it will therefore not be possible to make cheese that will cure evenly. The use of whey as a solvent for the rennet is not advisable, because other ferments are introduced in the whey.

The comparison of extracts and their relative value wil? be taken up after the rennet test has been explained.

\section{Effect of Heat on Rennet.}

Rennet will not curdle milk at a very low temperature, tut as the temperature is raised it will begin to work and act with increasing rapidity until at a point above $100^{\circ} \mathrm{F}$. it is injured. By putting cold rennet into warm milk it may work faster up to $120^{\circ}$ or $130^{\circ} \mathrm{F}$., but when the rennet in weak solutions is heated to $105^{\circ} \mathrm{F}$. it begins to be weakened. A strong solution may be held at $150^{\circ}$ for fifteen minutes without being entirely destroyed, but it will be rendered much weaker. These high temperatures do not destroy the power of the rennet instantly but gradually. 


\section{Rennet Does Not Exhaust Itself.}

As has been said concerning enzymes, rennet does not seem to spend its energy, but will act over and over again. If a quantity of milk is coagulated and the whey applied to a like quantity of milk, the milk will be coagulated; this might be done indefinitely, if it were not for getting a larger volume of whey than we have of milk.

\section{Effect of Acid on the Action of Rennet.}

It has been said that the rapidity in the action of rennet is greatly affected by the temperature of the milk, but we find, if the temperature of the milk is held constant, the more lactic acid there is in the mill the faster the rennet will act, or if any acid be artificially added to the milk in quantities not sufficient to coagulate it, the action of the rennet will ke hastened; on the other hand, if alkali be added to the milk, the action of the rennet will be retarded.

\section{Rennet Extracts Not Alike.}

Another cause for varying rapidity of rennet action is the difference in the strength of the rennet extracts used. Rennets vary as to the amount of ferment contained in them, and it is very unlikely that two lots of extracts will be exactly alike.

\section{Rennet Action Dependent on Three Factors.}

It has been shown that the rapidity with which rennet coagulates milk is dependent on:

1. The strength of the rennet extract.

2. The temperature of the milk.

3. The acidity of the milk.

If the same rennet is used at the same temperature of the milk each time, the variation in the rapidity with which it caagulates the milk, must be due solely to the acidity or ripeness of the milk.

\section{J. B. Harris Discovers the Rennet Test.}

In the middle of the eighties J. B. Harris coneeived this idea, and used a teacupful of milk from the vat, to which he added a teaspoonful of rennet and noted the number of seconds required to coagulate the milk. When the milk was ripened 
down to a certain number of seconds, he found that he could foretell approximately the time that it would take for acid to develop.

\section{Rennet a Powerful Agent.}

Rennet is a very powerful agent. If four ounces of extract is used to one thousand pounds of milk, it is one part of rennet to four thousand of milk, and sometimes the proportion will be

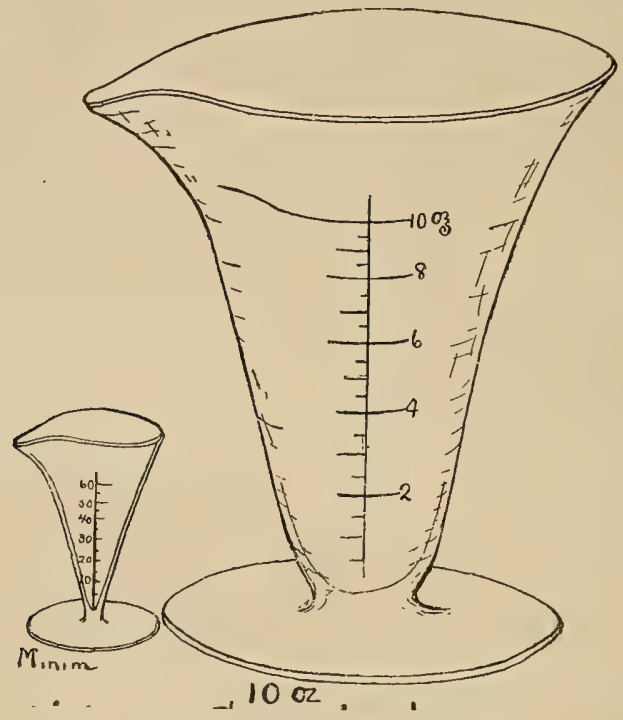

Fig. 19.-Glass Graduates.

as wide as one to sixteen thousand. It will be easily seen that since the rennet is such a powerful agent, it is not likely to be an entirely accurate test where a teaspoon is used for measuring the rennet, for then it would be difficult to measure exactly twice alike. Therefore, in place of the teaspoon, a minim or dram graduate was substituted, and for the teacup an eightounce glass graduate such as druggists use. This was much better than the first crude apparatus for making the test.

\section{I. Glass Graduates for Measuring.}

But the minim graduate is funnel shaped, and the top being broad in proportion to its volume, the chances for error are still too great in measuring. In actual practice, through haste in 
making the test, two or three drops of extract were likely to be left in the narrow bottom of the minim graduate, and the maker would be confused in not getting the results he expected by depending on it.

J. H. Monrad therefore proposed a new set of apparatus, which, though not so simple, leaves less chance for error.

\section{The Monrad Rennet Test.}

The apparatus for the Monrad test consists of a 160 c. c. tin cylinder for measuring the milk, a 5 c. c. pipette, a 50 c. c. glass flask, and a half-pint tin basin. By filling the tin cylinder till it overflows it always gives the right measure of milk quickly.

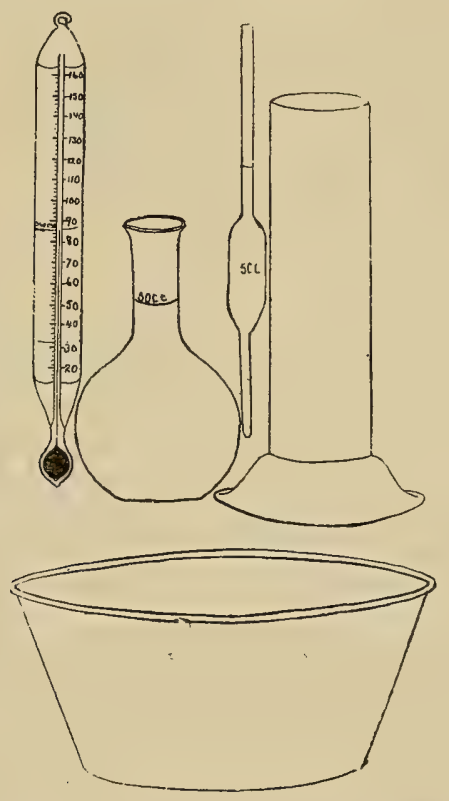

Fig. 20.-The Monrad Rennet Test.

Measuring the milk in a glass graduate is difficult, as it is hard to get the milk just to the mark, and if the glass is covered with white milk it is difficult to see the mark.

The rennet is first measured with the 5 c. c. pipette (Fig. 20). The rennet can very easily be measured by this instrument, and the tube being narrow makes the measurement accurate. The rennet in the pipette is delivered into the 50 c. c. flask, and 
what little rennet adheres to the inside of the pipette is rinsed into the flask with some water. The flask is then filled with water to the 50 c. c. mark on the neck, and the solution mixed by shaking. The temperature of the milk should be $86^{\circ} \mathrm{F}$. It is measured in the tin eylinder, emptied into the half-pint basin, and 5 c. c. of the dilute extract is measured into the 160 c. c. of milk. The number of seconds required to curdle the milk is then noted. If a few specks of charcoal are scattered on the milk and the milk started into rotary motion in the dish with a thermometer, the instant of curdling can be noted by the stopping of the specks. They will stop so suddenly as to seem to start back in the opposite direction.

\section{Use Thermometer to Stir Milk.}

By using a thermometer, the temperature can be constantly watched; and if the temperature should fall, it can quickly be brought back to $86^{\circ} \mathrm{F}$. by setting the basin in a pail of warm water for a few seconds.

\section{The Marschall Rennet Test.}

Another ingenious form of rennet test which is used in many factories is the Marschall test, as it keeps its own time. It consists of an ounce bottle with a mark on it to indicate 20 c. c.; and a spatula for stirring the milk; a 1 c. c. pipette is used for measuring rennet into the bottle in which it is diluted up to the mark on the bottle; a test tasin, which is a vessel of a little over a pint capacity, on the inner surface of which is a scale beginning with 0 at the top and numbering by half divisions to 7 near the bottom of the vessel. A hole in the bottom of the vessel is fitted with a cork in which is inserted a glass tube of a very fine bore. (See fig. 21.)

\section{How to Use the Test.}

To make a test the vessel is filled with milk at the desired temperature, and when the milk has drained through the little glass tube until the top is at the 0 mark, the diluted rennet is stirred in with the spatula. When the rennet thickens the milk sufficiently no more milk will run out and the operator notes the point on the scale to which the milk has run. The riper the milk the quicker it will thicken, with a corresponding lower reading on the scale. 


\section{Marschall Tests Not All Alike.}

Unfortunately the caliber of the glass tubes in the bottom of this test may vary so that different amounts of milk may run out from different Marschall tests. One may compare results with the same test from one day to another, but a great deal of confusion may result from comparing the results obtained with different Marschall tests.

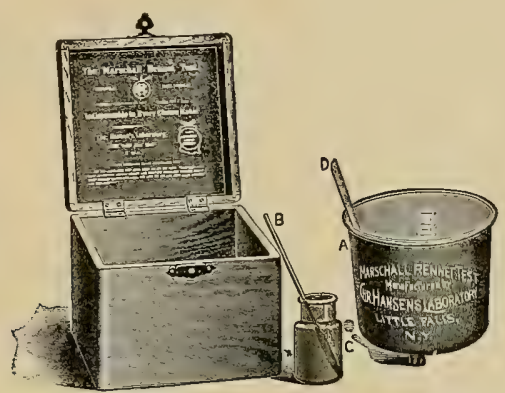

Fig. 21. The Marschall Rennet Test. A, graduated cup; B, 1 c. c. pipette; $\mathrm{C}$, glass in which to dilute the rennet; $\mathrm{D}$, spatula for stirring the milk.

\section{Errors to Be Avoided with Marschall Apparatus.}

1. As there is no thermometer included in the Marschall apparatus the operator is likely to forget that temperature affects the rennet action. One should always temper the vessel in cold weather before using, and should carefully observe the temperature of the milk, both when starting the test and at the time of coagulation. A few degrees in temperature will modify the results very materially.

2. One should exercise great care in running the milk into the milk in the vat. Where a large number of tests are made the rennet added may coagulate the milk.

3. The results with two pieces of apparatus can not be compared until they have been used first in testing the same milk.

\section{Pepsin as a Substitute for Rennet Extract.}

Scale pepsin has been used as a substitute for rennet in cheese making. It is made from stomachs of hogs. It both curdles and digests milk and so raises the question whether the curdling and digesting are not really after all two properties of one ferment. Scale pepsin solutions do not curdle very sweet milk as readily as the rennet extracts do. In milk containing .2 
per cent acid no difference can be observed. In such milk five grams or 75 grains of the scale pepsin is equal to four ounces of Hansen's rennet extract. Pepsin makes cheese of excellent flavor and texture. Enough cheese has been made to establish the value of pepsin in the making of Cheddar cheese.*

\section{QUESTIONS ON CHAPTER IV.}

1. What are the two general classes of ferments? 2. What are enzymes and where do they originate? 3 . What is the effect of temperature on enzymes? 4. Who discovered galactase and where is it found? 5. Describe galactase. 6. What is a rennet? 7. How are rennets preserved? 8. What is rennet extract? 9. Where do the best rennets come from? 10. How is rennet extract made? 11. Why are reliable brands of commercial extracts to be preferred to homemade extracts? 12. What is the effect of heat and acidity on rennet action? 13. On what three factors is the rapidity of rennet action dependent? 14. Who invented the rennet test? 15 . Why are glass graduates used in a rennet test inaccurate? 16. Describe the Monrad rennet test. 17. Describe the Marschall rennet test. 18. In what respect may Marschall tests differ? 19. What errors are to be avoided in using a Marschall test? 20. What is seale pepsin? 21. What is the effect of acidity of milk upon the curdling power of pepsin? 22. How does scale pepsin compare in strength with Hansen's rennet extract?

*Experiments with pepsin in cheese making have been conducted at Ont. Agric. College (Reports 30, p. 74 and 32, p. 108). 


\section{CHAPTER V. \\ THE DEPORTMENT OF RENNET.}

\section{Experiments in Rennet Action.}

In order that the student may better comprehend the deportment of rennet under different conditions, we shall briefly state the effect of the various conditions to which it may be subjected, and give some experiments with the apparatus used in the Monrad test, that will enatle the student to become familiar with the action of rennet under varying conditions.

\section{Effect of Acid and Alkali.}

Acid in the milk accelerates and alkali retards coagulation.

Experiment (a). Make a test of a sample of milk with the Monrad rennet test, observing carefully all conditions as to temperature, strength of rennet, etc. Record the result in your notebook. Now add a small quantity of dilute hydrochloric acid to the milk, being careful to stir this constantly while slowly adding the acid. If in a laboratory where decinormal solutions of acid and alkali are available, use about 25 c. c. of hydrochloric acid to a quart of milk, and note the number of seconds required to coagulate the milk, carefully observing all of the conditions for making a test properly.

Experiment (b). Repeat the experiment with an increased quantity of acid added to the milk.

Experiment (c). Add slowly a small quantity of dilute soda lye, being careful to stir the milk while adding it, and then make a test as before. Keep careful notes in your notebook.

Experiment (d). Make a rennet test of a sample of milk and set it where it will remain warm. Make tests half an hour or an hour later and note the time required for coagulation. The shortening in the time required is due to the ripening of the milk; the bacteria present have been changing the milk sugar into lactic acid. 


\section{Effect of Water in Milk.}

Diluting milk with water retards coagulation.

Experiment (a). Make a careful rennet test of a sample of milk. Next take one part of water and three parts of the milk in question. Mix them and then make a rennet test of the mixture.

Experiment (b). Repeat the experiment with one part of water and two parts of milk.

Experiment (c). Repeat the experiment with one part of water and one part of milk. Can you determine any law governing the rate of coagulation in relation to the amount of water present? Try these experiments with milks of different acidity.

\section{Effect of Salt $(\mathrm{NaCl})$.}

Salt in the milk checks the action of rennet, five per cent stopping it altogeher.

Experiment (a). Make a rennet test of a sample of milk, and record the result. Now add one per cent of salt by weight and make a careful rennet test. How does the salt affect the test? Try the same experiment with two, three, four and five per cent of salt in the milk.

\section{Effect of 'Temperature.}

Raising the temperature up to a certain point hastens, and lowering it retards, rennet action.

Experiment (a). Make a rennet test at the standard temperature of $86^{\circ} \mathrm{F}$, and record the result in your notebook. Now make tests at $95^{\circ}, 100^{\circ}, 110^{\circ}, 120^{\circ}, 130^{\circ}$ and $140^{\circ}$.

Experiment (b). Make a test at $86^{\circ}$ and then try tests at $80^{\circ}, 70^{\circ}, 60^{\circ}, 50^{\circ}$ and $40^{\circ}$. If much time is consumed in making the tests, the student should make occasional tests at $86^{\circ} \mathrm{F}$. to detect the rate of ripening of the milk.

\section{Effect of Anaesthetics.}

Anæsthetics, like chloroform and ether, suspend protoplasmic action but do not affect enzymes. In this way it is possible to distinguish between organized and unorganized ferments.

Experiment (a). Make a rennet test of a sample of milk and note the number of seconds required. Now add about 3 per cent of chloroform to the sample and shake it in a bottle or 
cylinder. Next make a rennet test of the milk. It curdles the milk, showing that rennet is an enzyme.

\section{Thermal Destruction Point.}

At about $104^{\circ}$ or $105^{\circ} \mathrm{F}$. rennet in weak solutions is destroyed.

Experiment (a). Make a rennet test of a sample of milk and note the number of seconds required. Next heat the rennet solution to $100^{\circ}$ for ten minutes and try a test with it on the same milk. Try heating it to $105^{\circ}, 110^{\circ}, 115^{\circ}$ and $120^{\circ}$ for five minutes and make tests after each heating. Do not forget to record the results in your notebook.

Experiment (b). Note the length of time required to coagulate 160 c. c. of milk at $86^{\circ} \mathrm{F}$. with 5 c. c. of strong commercial rennet extract. Next heat a portion of this strong rennet to $150^{\circ} \mathrm{F}$. for five minutes and note the length of time required for coagulating 160 c. c. of milk at $86^{\circ} \mathrm{F}$. with 5 c. c. of the extract.

\section{Effect of Strength of Rennet Solution.}

For a long time it was supposed that as the strength of the rennet solution was increased, the length of time required for coagulation was inversely shortened. This, however, is not true.

Experiment (a). Make a rennet test of a sample of milk.

1. Make up a new solution of rennet, measuring twc 5 c. c. pipettefuls of rennet in the $50 \mathrm{c}$. c. flask. This makes the rennet solution twice as strong as the solution commonly used. Note the time required for coagulation with this solution.

2. Make up a solution with three pipettefuls, or 15 c. c. of rennet in the 50 c. c. and make a test.

3. Make up a solution with four pipettefuls, or 20 c. c. in the 50 c. c. What are the results?

4. Make up a solution with 25 c. c. of strong rennet diluted to 50 e. c. It is suggested that the student secure a piece of cross-section paper and chart out the results obtained. If the rate of coagulation was diminished inversely in proportion to the increase in strength the results of these tests would, when recorded, make a straight line across the chart, whereas they really make a curved line. 


\section{Soluble Calcium Salts Required for Rennet Action.}

It has been previously stated that the soluble salts of calcium must be present in the milk or the rennet will not act (4).

Fill a Babcock pipette with rennet extract, add three or four drops of phenolphtalein solution and titrate with $\frac{N}{10}$ alkali.

Experiment (a). Make a rennet test of a sample of milk. Add a small quantity of a dilute solution of calcium chloride $\left(\mathrm{CaCl}_{2}\right)$ to the milk and make another test. The coagulation will be accelerated. How much?

Experiment (b). Heat a portion of the sample of milk to $190^{\circ} \mathrm{F}$. for ten minutes, cool it down and make a test. It will not coagulate, for the calcium salts have been rendered insoluble by the heat.

Experiment (a). Make a rennet test of a sample of milk. add 25 c. c. of a strong solution of ammonium oxalate, anc niake a rennet test. It will not coagulate because the soluble calcium salts have been changed to insoluble calcium oxalate.

\section{Effect of Milk Preservatives.}

There is a very pernicious practice among some dairymen of using antisepties to keep milk from souring. Among them are preservaline (boracic acid) and formaldehyde solution sold under the name of freezene, etc. These substances not only check the necessary bacterial fermentations in the manufacture of the cheese, but affect the rennet action.

Experiment (a). Make a rennet test of a sample of milk. Then add 1 per cent of boracic acid to the sample and make a rennet test. Try varying quantities of the boracic acid.

Experiment (b). Make a rennet test of a sample of milk and then add 1 per cent of formaldehyde solution to the milk and make a test. Try it with one-tenth of 1 per cent of formaldehyde in the milk.

Question: Should milk adulterated with preservatives be accepted at a cheese factory in view of the preceding results?

\section{Scale Pepsin Compared with Rennet.}

Dissolve four grams of seale pepsin in 100 c. c. of cold water. Now make rennet tests with this on milks of varying 
acidity, at the same time making tests with rennet extract on the same milks, for comparison.

\section{QUESTIONS ON CHAPTER V.}

1. What is the effect of acid in the milk on rennet action? 2. What is the effect of alkali on rennet action? 3. What is the effect of water in the milk on rennet action? 4. What is the effect of salt in the milk on rennet action? 5. What is the effect of temperature on rennet action? 6. At what temperature is rennet action destroyed? 7. What is the effect of anæsthetics on rennet? 8 . Is the time of curdling milk inversely proportional to the strength of the rennet solution? 9. What part of the ash of the milk is required for rennet action? 10. What is the effect of boracic acid on rennet action? 11. What is the effect of formaldehyde on rennet action? 12. What is the effect of acidity of milk on the curdling power of the pepsin solution? 13. What is the chemical reaction of pepsin solution and rennei extract? 


\section{CHAPTER VI. \\ CHEDDAR CHEESE.}

\section{Ioo. History of Cheddar Cheese.}

For some centuries cheese has been made in the farm dairies of England and Scotland. The people that eame to America continued the manufacture at home of their stirplus mill into cheese. The process varied in different dairies aod our British cousins have been particularly jealous of their way of making, being careful not to give away any of their secrets as they believed them to be. The term Cheddar came from a town of that name near Bristol.

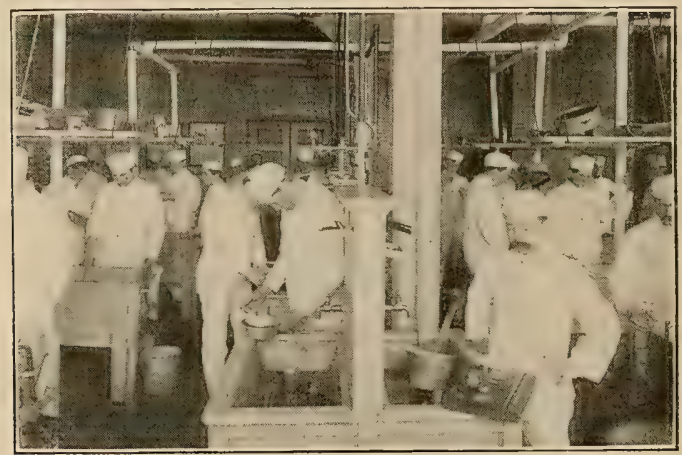

Fig. 22.- Students making Cheddar cheese.

\section{ror. Rise of Cheese Factory System in New York.}

The factory system of making cheese started in America. Jesse Williams, of Oneida County, New York, was the first factory operator. In 1851 he and his sons, located on different farms, brought their milk together and it was made into cheese under his supervision. From this beginning the factory system developed in New York and was carried into other states and Canada. 


\section{I02. In Ohio.}

In Ohio the first factory was built by Mr. Budlong, at Chardon, Geauga County, in 1860. The second one was built by Mr. Bartlett at Munson, Geauga County, in 1861. In 1862 John I. Eldridge built the third one in Aurora Township, Portage County. The building is yet standing, but is not in use at this time as a new building close by has taken its place. In 1863 Hurd Bros. built a factory at Aurora Station, which has been in continual operation to the present time. After 1863 the factories multiplied very rapidly in Ohio.

\section{ro3. In Wisconsin.}

In Wisconsin the factory system dates from about 1864, when Chestér Hazen started a factory at Ladoga, Fond du Lac County, and Stephen Faville started one near Watertown. At the present time there are about sixteen hundred cheese factories in the state, of which number probably about eleven hundred make Cheddar cheese, the others being Swiss, Brick and Limburger.

\section{Two Processes of Manufacture.}

There are two processes of manufacturing Cheddar cheese, one, the granular system, in which the curd is kept in the granular form from the time the whey is drawn until put to press; and the other, the matting system, in which the curd is allowed to mat into a solid mass as soon as the whey is removed, and is afterward milled to get it into the right condition for salting before pressing:

\section{ro5. Cheddar System Proper.}

The system in which the curd is matted is termed the Cheddar System. It produces a more meaty texture and uniform grade of cheese and has largely superseded the granular system at the present time.

The Cheddar system as improved in the United States and Canada has been introduced into Scotland and England through Mr. Drummond, an American, in charge of the Kilmarnock dairy school.

The following pages will treat of the best methods as we know them today for making Cheddar cheese. 
FIRST STEPS IN CHEESE MAKING.

\section{I06. Test for Over-Ripe Milk.}

Milk that has more than two-tenths of 1 per cent of lactic acid should not be received for cheese making. But as milk will not taste sour until it reaches nearly three-tenths of 1 per cent of acid, it is difficult to determine by the taste when to reject such milk.

The Farrington acid test can here be brought into use and the discrimination quickly made. The apparatus consists of a
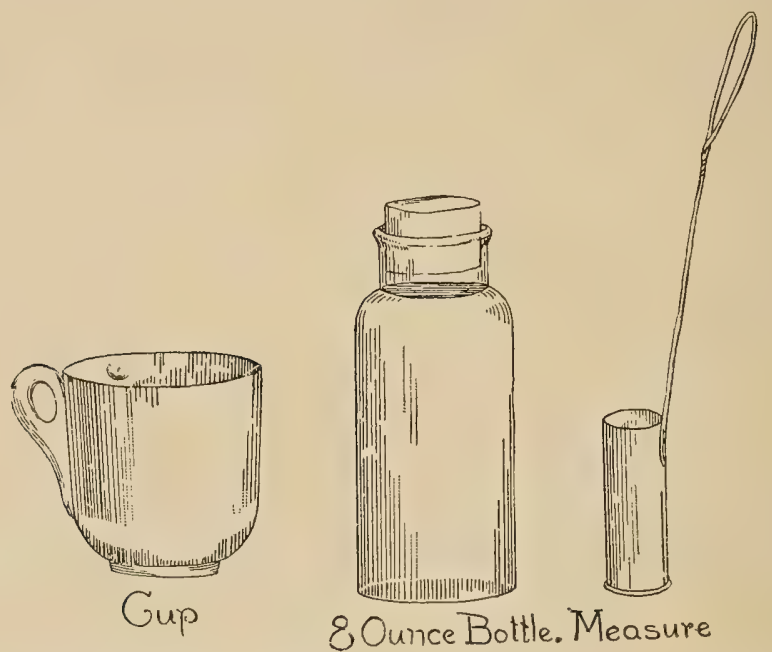

Fig. 23.-Farington's apparatus for rapid estimation of the acidity of apparently sweet milk or cream.

white teacup, an eight-ounce wide-mouth bottle, and a measure made by soldering a wire handle onto a No. 10 brass cartridge shell. Eight Farrington alkaline tablets are dissolved in the eight-ounce bottle of water, which makes a red liquid. A measure of the suspected milk is put into the teacup and then two measures of the red liquid added. If on stirring it, the pink shade remains, there is not two-tenths of a per cent of acid present and the milk can be accepted. If, on the other hand, the pink color disappears, there is too much acid present and the milk should be rejected."

*See "Testing Milk and Its Products," 18th ed., p. 130. 


\section{Stir Milk to Keep Cream Down.}

While the milk is being received it should be stirred in the vat to prevent cream from rising. As soon as all the milk has been received and the quantity figured up, the steam should be turned on and the milk heated to $86^{\circ} \mathrm{F}$., and a rennet test made. If the cheese maker is suspicious that the milk may be over-ripe, he should make a rennet test before the milk in the vat is heated up to $86^{\circ} \mathrm{F}$., by taking his sample for the rennet test in the basin in which the test is made and warming it in a pail of warm water.

If the milk is found to be over-ripe, he will have to hurry the process to keep ahead of the fermentation. On the other hand, if he finds the milk very sweet, and that he will have to wait an hour or more for it to ripen, he should use a starter.

\section{I08. Ripening the Milk.}

If the milk is ripened so as to coagulate in the same number of seconds each day; one can tell very closely the time when the whey can be drawn off from the curd. It should be ripened to a point where in two hours from the time the rennet is added to the milk there will be "one-eighth of an inch of acid" on the curd, as we shall see later on. (135.)

With a first-class quality of rennet extract the milk. when ripened to thirty seconds works off in about the right time, but such extract is very strong, one ounce being sufficient to coagulate one thousand pounds of milk in twenty minutes. If, however, the rennet extract was so weak that it would require four ounces of it to coagulate one thousand pounds of the same milk in twenty minutes, it would ke only one-fourth as strong as the former rennet, and the milk would then have to be ripened so as to coagulate in one hundred and twenty seconds instead of in thirty seconds.

\section{How to Ripen Milk to the Right Point.}

At the beginning of the season's work the cheese maker has nothing to guide him as to the ripeness of the milk, because he does not know the strength of the rennet extract at his disposal. The first day he makes cheese, he must make a rennet test of his milk at the time he sets it and then observe how the milk acts. If the milk is too sweet, he can calculate about how much riper 
it must be to work just right, and in a few days he will have the matter entirely under his control. Cheese makers should never neglect to use the rennet test, for it enables them to judge definitely the condition of their milk.

When a maker is troubled with tainted milk it is often necessary to ripen a little lower than with good milk, for the bad flavor, as we have already learned, is due to some harmful variety of bacteria which crowd out the lactic ferments.

\section{xx. Definition of a Starter.}

A starter is a small quantity of milk in which the lactic fermentation has been allowed to develop; there are therefore millions upon millions of the desired kinds of bacteria in a small quantity of it, and when these are put into the milk in the vat, they increase very rapidly and hasten the ripening of the milk.

\section{Irx. What to Use for a Starter.}

The milk for the starter should be saved from one patron's milk from the morning or evening before, and should be the kest flavored milk available, for the whole vat will be made like it.

From what has been previously said (28) it will be observed that the milk selected as above is the kind of milk desired. If the Wisconsin curd test is used the milk that habitually gives good curds can be selected. Even in that case a bad fermentation may get in. The surest way of obtaining a good starter is to use a pure culture of lactic ferment.

\section{II2. Lactic Ferment Starter.}

Lactic ferment is a culture placed on the market by several manufacturers in this country. It is sold in large and small bottles. The small bottles cost less and are just as good as the large ones, for we can grow the culture ourselves if we once get a start. One or two quarts of milk should be selected as above and heated to $200^{\circ} \mathrm{F}$. for fifteen minutes and then cooled to $70^{\circ} \mathrm{F}$. The contents of the tottle should be added to this pasteurized milk. In twenty-four hours, if kept warm, the milk will be sour and just at the curdling point.

Another lot of milk, in quantity as much as required for a 2 per cent starter in our vat, should be selected as before and 
heated to $200^{\circ} \mathrm{F}$. for fifteen minutes, and then cooled to $70^{\circ} \mathrm{F}$. and the first culture (startaline) added. In twenty-four hours it will be ready to use. A little is saved each day to make new starter. The starter should always be handled in sterile vessels. If care is taken not to contaminate the starter, it can be propagated in a very pure state through a whole season. Carelessness in handling the starter will infect it with other germs, which will spoil it, in which ease it will be necessary to begin over again.

\section{II3. What Not to Use for a Starter.}

A starter should not be saved from the whole vat of milk, nor from the whey, for the starter will then be likely to contain all sorts of germs, good, bad and indifferent, and these will all be transmitted from one day's milk to the next; in fact, a bad disease might be carried through the milk in this way for a whole season. Thick milk may be used for a starter, if one is hard pressed, kut it is better not to let the starter get quite thick. If the starter is thick, it should be strained carefully through a cloth strainer, for if clots of thick starter get into the vat of milk, they will not be colored and may leave white specks in the curd.

By adding about half water to the starter milk in the evening it will not curdle so but that it will mix nicely in the vat.

Milk should be ripened to a point where in two hours from the time the rennet is added to the milk, there will be one-eighth of an inch of acid on the curd (135). This corresponds to .2 per cent of acid.

\section{II4. Milk Must Not be Too Ripe.}

Milk should never be allowed to ripen to a point where it will work too fast. In such eases there will be too great a loss of fat in the whey, and a small yield of cheese.

\section{II5. Adding the Color.}

Until lately cheese color has been made from the annatto seed grown in South America. Cheaper and stronger color is now being made from aniline, a coal-tar product. The public seems to be prejudiced against mineral coloring, but there is so little of it in the cheese that it is doubtful if it is injurious to 
health. Of late years more and more consumers appear to prefer uncolored cheese.

Different markets require different shades of color. It seems to be a general rule that the further south we go the higher color is required. Chicago calls for a straw color. St. Louis wants a deep yellow color, and New Orleans almost an orange color. (217.)

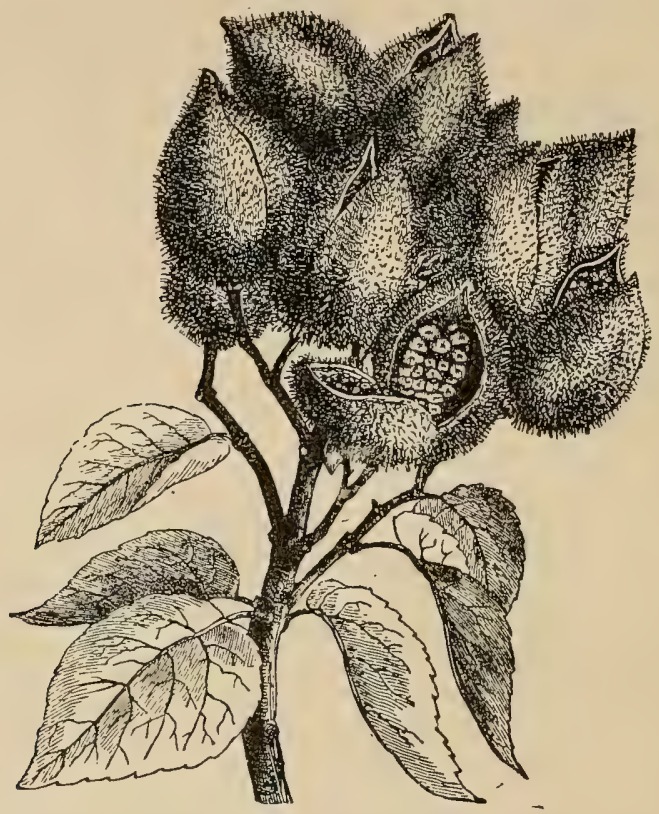

Fig. 24.-Branch of Annatto tree, showing seeds from which cheese color is made.

The color should be added before the rennet. It should be diluted with water and stirred in thoroughly. In the cheese it should not be of a reddish hue.

\section{Ir6. Setting the Milk.}

Having gotten our milk into the proper condition we are now ready to set it. It should be set at $86^{\circ} \mathrm{F}$. It sometimes happens that the milk has accidentally been warmed up to $90^{\circ}$. It is better to set the milk at that temperature than to wait and cool it down, for the milk will be ripening while we delay setting it. The only objection to setting milk at $90^{\circ}$ is that the 
curd hardens too fast to cut it conveniently. If it were not for that fact there would be no objection to setting it at $98^{\circ}$.

There is nothing to be gaimed by setting milk at $82^{\circ}$ and waiting for it to curdle. If milk is over-ripe time can be gained by setting it at as high a temperature as it can be readily handled.

For a fast-curing cheese we should use enough rennet to curdle the milk in fifteen to twenty minutes; and for a slow-curing cheese enough to curdle it in thirty to forty minutes.

\section{II7. Rennet Should be Diluted.}

The rennet should be diluted, not with milk (why?) but with a dipperful or pailful of water, and then poured into the vat evenly from one end to the other. The water should be about $90^{\circ} \mathrm{F}$. If above $100^{\circ} \mathrm{F}$. the rennet will be weakened (74). The milk should be thoroughly stirred just previous to adding the rennet, and the rennet thoroughly mixed with the milk. The stirring should be done gently so that the fat will not separate from the milk.

The milk should be kept in motion for several minutes; the surface should then be stirred gently with the bottom of the dipper so that the cream will not rise on the surface, and the milk will set, or coagulate, and hold it down. The movement of the dipper should be kept up for about half the time it takes the milk to coagulate, and then a cover should be put over the vat to keep the surface of the milk from cooling off.

\section{II8. The Use of Pepsin.}

In substituting pepsin for rennet, only scale pepsin of a strength of 1-3000 should be used. Use a weighed quantity of pepsin at the rate of .5 gram for every hundred pounds of milk in the vat, or for a slow-curing cheese at the rate of .4 gram. Dissolve it in cold water before adding to the milk. Pepsin can be obtained in pound or smaller bottles from dairy supply houses. A pound is enough for 100,000 pounds of milk.

\section{II9. When the Curd is Ready to Cut.}

The curd is ready to cut when it will break clean before the finger. The index finger is thrust into the eurd and pushed along through it about half an inch below the surface. The curd is first split by the thumb, and when the proper firmness 
is reached it will break as the finger is pushed along. If the break is clean, that is, leaves clear and not milky whey in the break, the curd is ready to be cut.

\section{QUESTIONS ON CHAPTER VI.}

1. State the history of Cheddar cheese. 2. Where and by whom was the first cheese factory operated? 3. When and by whom were the first factories in Ohio built? 4. When and by whom were the first factories in Wisconsin built? 5. What are the two processes of manufacture? 6. What is the Cheddar system? 7. How much acid is allowable in milk for Cheddar cheese. 8. Describe Farrington's rapid acid test. 9. To what point by the rennet test should milk be ripened? 10. How can a maker determine at what point to set his milk? 11. What is a starter? 12. How should milk for a starter be selected? 13. What is a lactic-ferment starter, and how is it prepared? 14 . Why should not whey or milk from the vat be used for a starter? 15. From what is cheese color made? 16. Describe the different shades of color required by different markets. 17. At what temperature should milk be set, and why? 18. Why should over-ripe milk be set at a high temperature? 19. Why should rennet be diluted before adding it to the milk? 20. What kind of pepsin is used in cheese making? 21. How does pepsin compare in strength with rennet extract of standard makes? 22. When is the curd ready to cut? 


\section{CHAPTER VII.}

\section{CUTTING AND HEATING THE CURD.}

\section{I20. Firming the Curd.}

Through the action of heat and rennet the curd contracts and expels the whey. In order that this may be more readily done, we cut the curd into small eubes and raise the temperature. The pieces of curd must be of the same size and shape, so that they may expel the whey evenly.

The term "cook" in use for the change brought about in the condition of a curd is not strictly correct, as the curd is not heated hot enough to induce the change ordinarily known as cooking. The term has, however, come into general use by cheese makers in the sense of firming the curd by heat, and is so used in this book.

\section{I21. How to Cut a Fast Working Curd.}

When we have a fast working or over-ripe curd it should be cut finer and heated faster than a normal working curd.

The English cheese-makers formerly broke the curd, first with their hands, and then with wires, but the curd-knife has entirely superseded this method. There are tmo forms of knives used for cutting the curd.

\section{I22. Use of Horizontal Curd-Knife.}

The first is the horizontal knife, which has eighteen or twenty blades. When it is drawn through the length of the vat, it will cut the curd into layers or blankets one-half inch thick, by six inches wide, by the length of the whole vat. Care must be taken not to jam the curd, for if it is jammed it will be lost in the whey. The flat sides of the blades should not be forced into the curd to get the knife into a position to cut it, for they will jam the curd in so doing. 


\section{How to Insert the Horizontal Knife.}

The knife is therefore held in a horizontal position, the upper end near the handle resting on the top of the end of the vat. The knife is then lowered into the curd, the edges of the blades cutting into the curd and taking a circular course till the knife has assumed a vertical position parallel with the end
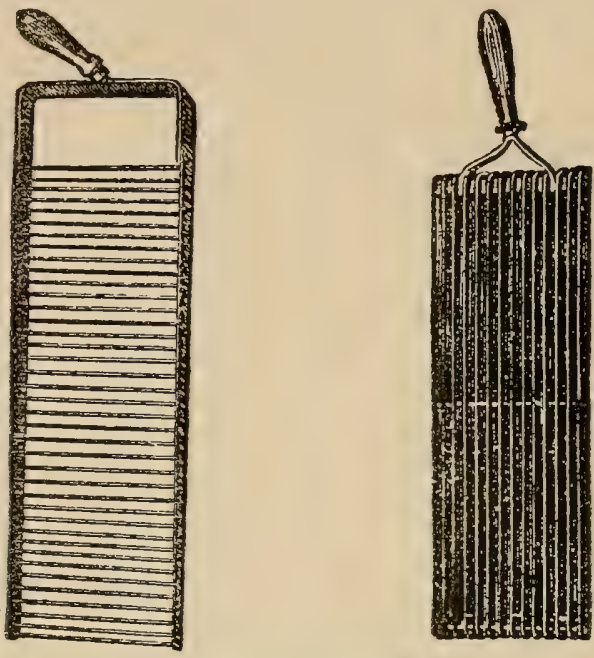

Fig. 25.-Curd knives.

of the vat, the lower end of the knife resting on the bottom of the vat. In this movement we have not jammed the curd, but have the knife in a position to move it through the length of the vat and cut the curd into layers. These layers are only six inches wide and we will have to cut the whole vat of curd into layers. Then keeping the knife in the curd we must turn it without breaking the curd, so that we can run the knife to the other end of the vat. Using the side of the knife next to the uncut curd as a center, we turn the knife around through $180^{\circ}$ of a circle, and we are then ready to draw the knife to the other end of the vat.

\section{r24. How to Take the Knife Out.}

When we have cut the vat of curd all up into tlankets, the knife is taken out in the reverse order to which it went in. 
The horizontal knife is now laid aside and the operation finished with the perpendicular knife. The blades in this knife run in the direction of the longest dimension of the knife.

The cheese-maker should not wait for the whey to rise over the curd before finishing the curd cutting, for the pieces of curd will get out of place, and the curd being harder will not be so easily cut.

\section{How to Insert the Perpendicular Knife.}

One should next start cutting in the same place as with the other knife, inserting it in the curd in the same way, for it has cross braces which are really horizontal blades, and one must avoid jamming the eurd with them. Next draw the knife over the same course that the other knife went, and we have the curd cut into strips one-half inch square and the length of the vat long.

Next cut crosswise of the vat, being careful not to jam the curd, and we then have it cut into half-inch eubes.

If we are making up slow working milk, this amount of cutting may be enough, but if it is necessary to cut finer, it can be done by cutting alternately lengthwise and crosswise. The strokes should now be much quicker, as the curd has been getting harder and finer during the cutting process and will pass between the klades, and it is therefore necessary to use a quick stroke to cut it.

\section{I26. Rapidity of Stroke a Factor.}

When a cheese maker says he cuts a curd a certain number of times, he does not convey the proper idea, for the rapidity of his strokes is a great factor, and if he cuts lengthwise of the vat six times and crosswise six times, and cuts with a slow motion; the curd may not be cut any finer than if it had been cut only four times each way with a quick stroke.

\section{HEATING THE CURD.}

\section{I27. Keep Curd Moving.}

As has been said, the curd is eut to allow the whey to escape, but if the curd is not kept moving, it will settle to the bottom of the vat and mat together again. Therefore, as soon as the curd has been eut, begin stirring it by hand or with a wire basket made for the purpose. 
Do not allow the curd to collect in the corners of the vat, and be sure and rub it off from the sides of the vat or it will scald on. The whey should look clear, and be as free as possible from specks of curd floating in it.

\section{I28. Heating the Curd.}

Curd being a poor conductor of heat, a rise of one degree in five minutes is fast enough to heat normal working milk. If it is heated too fast, it will cook the particles on the outside and retain the whey inside of the curd; the result will be a mottled whey-soaked cheese. (184.)

\section{I29. Cooking an Over-Ripe Curd.}

If the milk is over-ripe, however, it expels the whey faster, and the curd must be heated faster and higher than in the case of a normal working curd, or there will be the required amount of acid on the curd before it is hard enough to remove it from the whey. As a usual thing it is not necessary to cook a curd above ninety-eight degrees, but a curd must be cooked before drawing the whey, no matter if the temperature has to be raised to one hundred and ten degres to do it. (For definition of cooked curd, see paragraph 133.) It is necessary to cook a fast working curd in that way, and if the curd is taking acid too rapidly for the heating in the whey to be sufficient to firm the curd before the acid is too great, the whey can be drawn and the remainder of the firming done in warm water, which is run into the vat in place of the whey. (See, however, paragraph 143 regarding this.)

\section{r30. Stirring the Curd.}

To assist the curd in heating evenly and keep it from matting together, it should be stirred from the time it is eut till it is cooked. Some Canadian factories have a steam stirring apparatus which is very handy, but in most factories stirring is done with a rake.

\section{I3I. Curd Rakes.}

There are two kinds of curd rakes in use, the common wooden hay rake and the McPherson curd rake.

The rake is put into the whey as soon as the steam is turned on, and the curd is started into a rolling motion as though it 
were boiling. The stirring is commenced with the rake, teeth up, at one end of the vat, and the rake is worked down the length of the vat, making the curd roll on the side of the vat opposite the operator; then kack again, making it roll on the side toward him. Care should be taken that curd does not collect in the corners of the vat; nor should it be allowed to roll up into little balls. On the other hand, it must not be jammed, or fat will be lost in the whey at the expense of the yield of cheese.

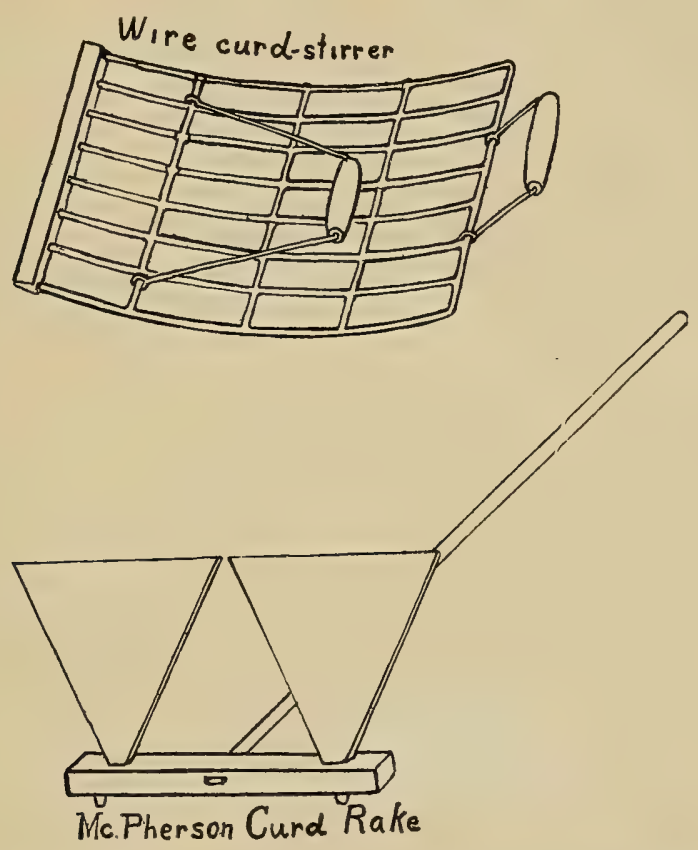

Figs. 26-27.-Wire curd stirrer and McPherson's curd rake.

\section{I32. The McPherson Curd Rake.}

The McPherson eurd rake has large triangular teeth with the base of the triangle forming the end of the tooth. This form of rake makes it much easier to give the curd a rolling motion. Some rakes have only two large teeth, and others several, but smaller ones. It is well to have two short wooden pins about a half to three-quarters of an inch long, in the back of the rake, to prevent its jamming the curd at the bottom of the vat. 


\section{How to Tell a Proper Cook.}

One of the most important steps in the process is to know when a curd is cooked enough. There should be one-eighth of an inch of acid on the curd, when the whey is drawn. Here it will be seen that one's judgment comes into play to know how fast to heat a curd in order to have it just firm enough when the acid comes. The rennet test will help us to regulate this, but if the rennet test indicates that we have a fast working milk it will be necessary to cook faster, and perhaps higher. When the whey is drawn the curd must not be salvy and soft, but when a big double handful is pressed together in the hands, and one hand removed, it should not remain in a mashed-up mass, but should fall apart readily. The particles of curd should be examined from time to time, to see that they are cooking on the inside as well as the outside.

An overcooked curd will give a "corky" cheese, while on the other hand, an undercook will give a salvy, weak-bodied cheese that is in danger of souring.

\section{QUESTIONS ON CHAPTER VII.}

1. What is meant by firming or cooking a curd? 2. How should a fast working curd be cut? 3. Describe the use of the horizontal and perpendicular knives. 4. What effect has the rapidity of stroke on the fineness to which a curd can be cut? 5. Why do we cut a curd? 6. Why do we heat a curd? 7. How soon after cutting should a maker begin heating a curd? 8. How should an over-ripe curd be heated? 9 . Why do we stix a curd? 10. Describe the MePherson curd rake. 11. How can one tell when a curd is properly cooked? 12. What is the effect in the cheese of an overcook? 13. What is the effect in the cheese of an undercook? 
CHAPTER VIII.

\section{DRAWING THE WHEY-DIPPING AND MILLING THE CURD.}

\section{I34. Measuring Acid.}

When there is an eighth of an inch of acid on the curd, the whey should be drawn off. The acidity of the whey will then be .20 per cent. (136.)

Strictly speaking, acid cannot be measured by the inch, but the acid seems to act on the curd in some way, so that when a piece is touched to a hot iron and drawn away, it will leave fine, silky threads behind, sticking to the iron. With normal working milk, when the curd is first cooked, it will not string at all; but when the acid has reached a certain strength, the curd will begin to string, at first barely sticking to the iron, and as the acid increases, the strings will get longer, till they may be several inches in length.

\section{Threads Due to Acid.}

That the threads are in no way due to the rennet, but are dependent on the acid, is shown when milk sours naturally. Such a sour milk curd will usually string on a hot iron. If acid is introduced into the milk in sufficient quantity to curdle it, the curd will be likely to string; in fact, strings of any desired length can ke produced by adding the right quantity of acid to the milk. However, if too much acid is added, it will make a soft, mushy curd, which will not string.

The acid softens the curd so that it readily sticks to the hot iron. About two-tenths of 1 per cent of acid in the whey must be present to make it string an eighth of an inch. As the acid increases, the strings get longer. Any solvent of the casein will produce this result on the hot iron. Borax, which is alkaline in reaction, will bring about this result. 


\section{r36. Use of Acidimeter.}

At the present time the hot-iron test has keen largely superseded by the acidimeter or the alkaline-tablet test. The use of the former test was first advocated by Prof. Dean of the Guelph Dairy School. This is the Manns' acid test.* (See Fig. 28.)

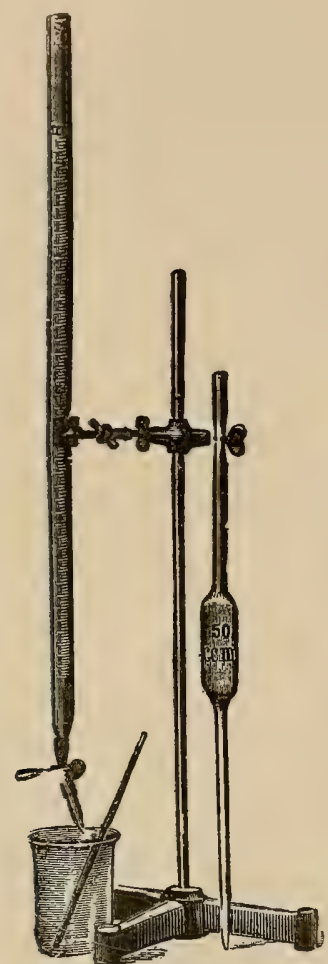

Fig. 28.-The Manns' acidimeter or acid test.

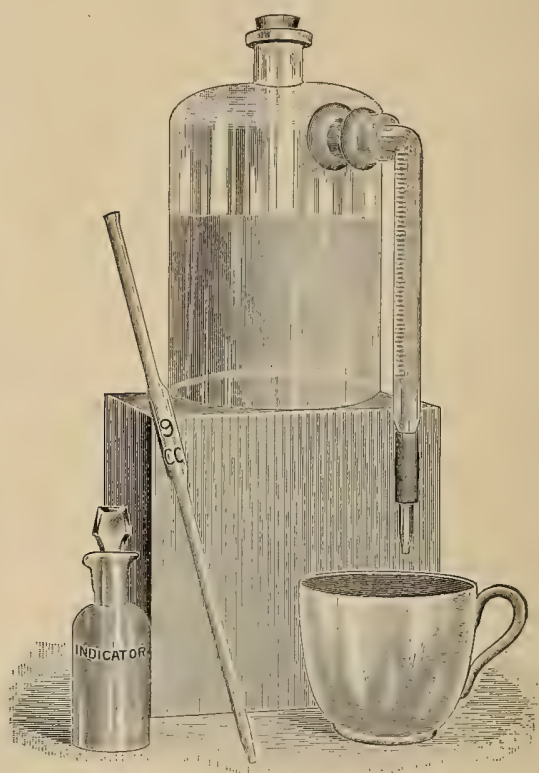

Fig. 29.-The Marschall acid test.

The apparatus consists of a 50 c. c. burette, a solution of phenolphtalein, a Babcock pipette, and a tenth-normal alkali solution. When a pipette of milk or whey is used 1 c. c. of the alkali used is equal to .05 per cent of lactic acid. The Farrington tablet solution* may be substituted for the alkali solution. Use 19.5 c. c. of water for each tablet. Each c. c. of the solution used will be equal to .01 per cent of lactic acid.

*Loc. cst., p. 122. 
The Marschall acid test (see fig. 29) is a convenient apparatus for determining the acidity of milk, whey, etc. It may be used either with a tenth-normal alkali solution, or with the Farrington tablet solution prepared as stated.

In using the acidimeter in cheese making, the milk is set at an acidity of .2 per cent. When cut the whey will have a lower acidity, about .17 per cent. When the acidity in the whey reaches .2 per cent, the whey is drawn. The drawings from the curd will show a rapid increase in acid. This test calls for careful work in titrations, and is preferably used in connection with the rennet and the hot iron tests.

\section{I37. Result of Too Much Acid.}

When too much acid is developed in the whey, there is a great loss of fat, as well as of casein. Experience has taught us, that as a usual thing we cannot let the curd take more than one-eighth of an inch of acid in the whey without disastrous results. If we were to wait but a short time after there are strings an eighth of an inch long, we would find perhaps, that they had increased to an inch in length, and our curd would be ruined. It is therefore necessary that one should work nimbly at this stage of the process. Not only should the whey be drawn off from the curd, but the curd must also be thoroughly drained, for whey in the curd will have the same effect as though the curd were still in the whey. Of course the curd must contain its natural amount of moisture, but there must be no pools of free whey in or on the curd.

Dr. Van Slyke has shown that lactic acid acting upon the curd forms a substance which he calls mono-lactic-acid-paracasein. This is dissolved out of the curd by strong brine. It is this substance which makes the curd cement and string. When a double amount of acid unites with the curd it forms di-lacticacid-paracasein which gives it the characteristics of high acid or sour cheese. The formation of mono-lactic-acid-paracasein affects the subsequent changes in the curing of the cheese.

In the old system of granular cheese making, the curd was stirred in the bottom of the vat, and then a ditch made in the middle for it to drain. In this stirring, considerable fat was lost, and the curds were not uniform in moisture. The reason of 
this was, that it is impossible to stir the curd to the same degree of dryness from day to day, and some day the curds would be drier than another.

\section{I38. Curd Rack.}

In the Cheddar system, which we follow, the curd is drained on racks, which are placed either in the bottom of the vat. or in a curd sink. The racks are made of hard wood, preferably maple. They are constructed of strips rounded on the top, three-fourths of an inch thick, two inches wide, screwed onto

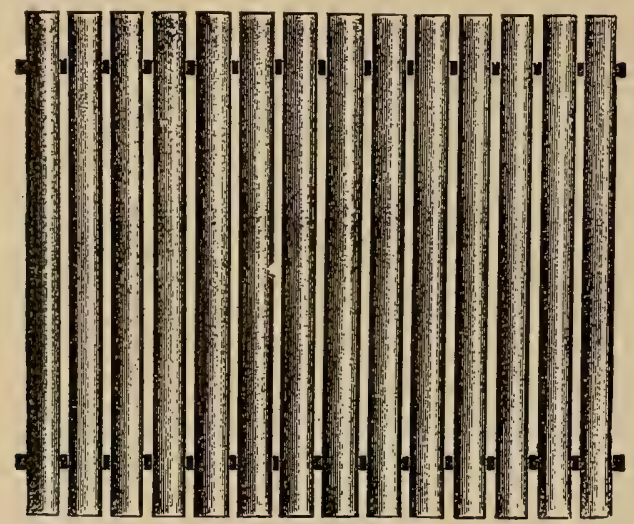

Fig. 30.-Curd Rack.

two other pieces, two inches high, three-fourths of an inch thick, and four feet long. The slats are three-eighths of an inch apart, extend crosswise of the vat, and are long enough, so that not more than a quarter of an inch of space is left between each end and the sides of the vat. The racks are usually in two four-foot sections.

\section{Racks-How Used.}

When the whey is drawn down, so that there is tut very little whey left in the vat to interfere with operations, the vat is tipped so that one end is five or six inches lower than the other, and the curd is shoved down to the lower end till about five feet of the upper end is cleared. The first section of the rack is then put in, and a linen strainer cloth thrown over it. This strainer eloth should be about twelve feet long, and wide enough ( 60 inches) to come up over the sides of the vat. The 
surplus cloth is then tucked under the lower end of the rack, and the curd piled onto it and broken apart to allow the whey to escape.

It should be stirred over several times, and then left to mat evenly about six inches deep. The space, formerly occupied by the curd that has been put onto the racks, is now clear, and the second section of the rack can be placed in the vat. This is put in close to the first section, and the cloth that had been tucked out of the way, is drawn over it and covered with curd, care being taken to stir out the whey, as on the first section. The sides and ends of the strainer cloth are then wrapped over the curd, and the vat covered with a heavy cloth cover to keep the curd warm. The temperature must be maintained, to keep fermentation going on.

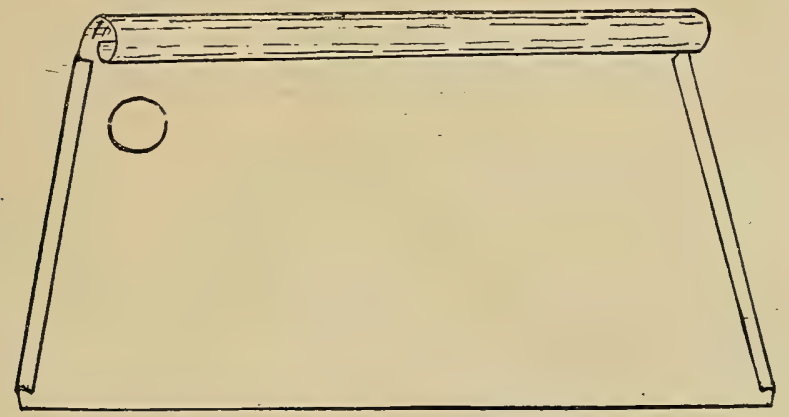

Fig. 31.-The Herrick Curd Knife.

\section{I40. Cutting the Curd into Blocks.}

After ten or fifteen minutes, the curd will have matted together, and can be cut into large blocks, which are turned over.

The best apparatus for cutting the curd that the author has seen is an instrument invented by Mr. B. B. Herrick, assistant in cheese making in the Ohio Dairy School. It is a truneated piece of heavy tin or galvanized iron, ten inches wide by sixteen inches long. It is folded at the ends and has a bead turned on the back to stiffen it. By taking this in both hands it can be pressed down into the curd cutting it quickly without damage to the strainer eloth.

The curd can be cut once or twice down the length of the vat, and across the vat into pieces eight inches wide. 


\section{Turning the Curd.}

Begin at the lower end to turn the curd, for it will ke more convenient to place the hands under the curd on the side toward the upper end of the vat, and roll it over than on the other side. In so doing, it is not necesary to lift the piece, thereby breaking it. Continue turning the other pieces in the same manner, till the last piece at the upper end of the vat is reached, then, by a pull of the eloth, it is turned over. Cover it up and let it stand to mat still closer. By using racks, the whey runs through when the curd is turned over. Watch the curd, and if whey should collect between the pieces, turn them over and let it run off. The curd should be turned from time to time, and much oftener at first than later on, to facilitate the expulsion of the whey. After a while the curd will begin to get a grain to it, and wili tear like the meat on a chicken's breast.

\section{r42. Pin-Holey Curds.}

If we have what is called a "gassy" or "pin-holey" curd, the gas will begin to form in little holes about the size of a pin head. Through the flattening of the curd, these holes are flattened and the gas escapes. Sometimes these pin holes appear before the curd is taken out of the whey, and, if they are plentiful enough, the curd will float on the surface of the whey, and we have what is called a "floater." But this does not occur very often, if we draw the whey in time. It used to occur quite often with bad milk, when the curd was left in the granular. form, and more acid was run in the whey. The pin holes were not flattened, and consequently appeared in the cheese. Such curds are often accompanied by a bad flavor. They are probably caused from bad ferments, but may be due to bad-flavored food. Clover and watercress, when eaten by the cows, have been known to produce a curd with pin holes.

Some of the taints are much more persistent than others. As a usual thing, a taint cannot be gotten entirely out of the cheese.

\section{Washing Curds.}

A poor curd can be greatly improved by washing it. When put onto the racks, and before it has had time to mat, a few pails of water at a temperature of $105^{\circ} \mathrm{F}$. will wash out a great deal of the taint. 
It is not, as a general rule, a good practice to wash curds. A light washing will improve a tainted curd, but the lactic acid is washed out with other substances and without lactic acid a fine Cheddar flavor eannot be obtained. This has been shown by extensive experiments. Sweet-curd cheese made from sweet milk never develops the characteristic Cheddar flavor. Unless two-tenths of a per cent of lactic acid in the whey is developed, this flavor will be lacking in the cheese. Curds that have an excessive amount of acid in the whey may appear to be improved in quality by washing during the first month of curing, but after that time, when it is usually beyond the maker's observation and in the wholesale dealer's hands, it will develop a ragged texture and a bad flavor, like a sweet-cured cheese which has been exposed to a high temperature.*

It has been shown at the Wisconsin Experiment Station that the lactic acid and the milk sugar hold the gas germs in check. If it is necessary to wash the curd very much, cane sugar applied at the rate of two and a half pounds to the hundred pounds of curd will keep the undesirable fermentations in check.

\section{Use of a Curd Sink.}

It is muchl easier to get the eurd onto the racks and expel the whey, by using a curd sink. Nor is as much fat lost in the operation, for where the curd mats together in the vat before it can be gotten onto the racks, it is necessary to break it apart to let the whey out, and the necessary bruising causes a heavy loss of fat.

\section{I45. Proper Form of Curd Sink.}

The common form of eurd sink, with an opening along the whole. length of the bottom, is to be avoided. The sink should be a tin-lined box with a channel bottom. There should te racks in it, and the channel under the racks will leave a place for hot water, to keep the curd warm. There should be a faucet at the lower end that ean be opened to let the whey drain off, and then closed to keep the water under the curd. If the racks are not used, the curd will not drain sufficiently; and if there is

*Under a recent ruling by the Federal Board of Food and Drug Inspection (Oct. 15, 1908), cheese made from curd soaked in water cannot be sold as Cheese, but must be labeled "Soaked Curd Cheese," if sold in inter-state commerce, in the District of Columbia or the Territories. 
an opening along the bottom, there will be a current of air started up around the curd which will thus be cooled. Of course, this is just what must be avoided, because the fermentation will be checked, if the curd cools down.

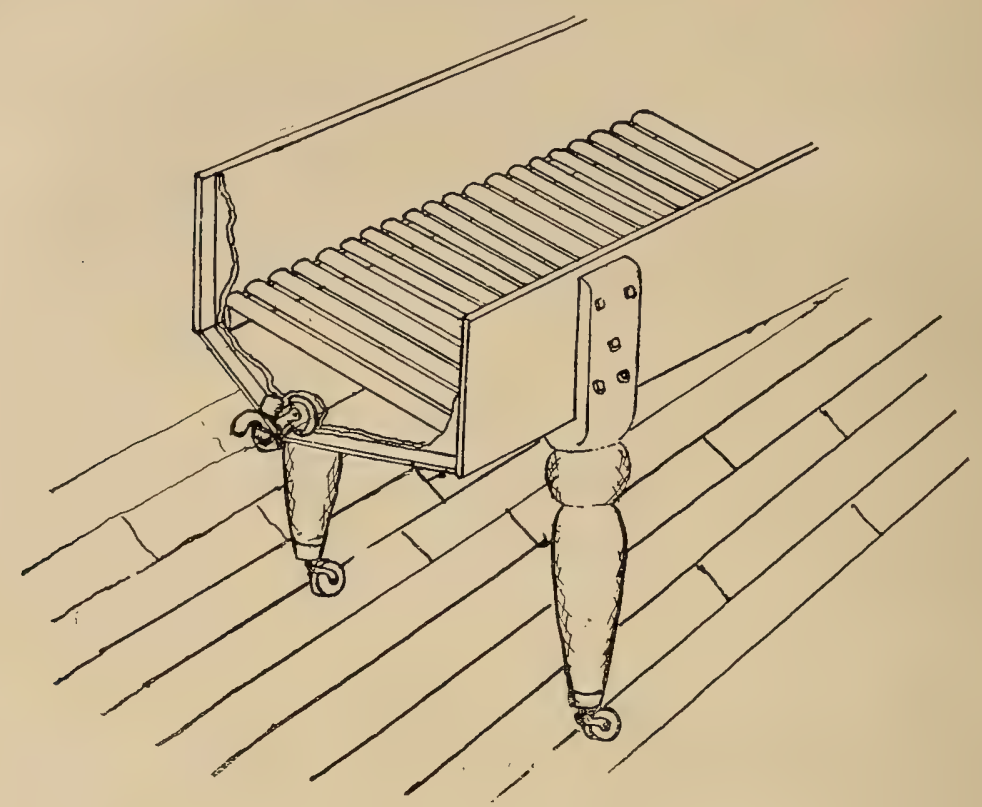

Fig. 32.-Curd Sink.

\section{I46. How to Fill the Curd Sink.}

When the curd sink is used, the whey should be drawn down in the vat till it just barely covers the curd; for while it is covered with whey, it will not mat. The curd sink is then placed in the lower end of the vat, and the curd dipped over onto the racks in the curd sink. All the whey runs through, and the curd is left to dry to mat properly. If the curd is tainted, it can be more thoroughly washed, as the curd is not matted together, and the water will wash all around the particles. As the curd is filled into the sink, this can be moved along, and the curd filled into it evenly.

After the curd has been turned several times, the maker can begin piling up. He can pile it two, three, five or six 
layers deep, but the pieces should be kept together, so that the curd will not spread too much at first.

\section{Keep the Curd Warm.}

The pieces that have been on the outside of the pile should be placed on the inside, so that the temperature may be kept even. We must not forget the fact, that cheese-making is a process of fermentation, and that heat is a great factor in it.
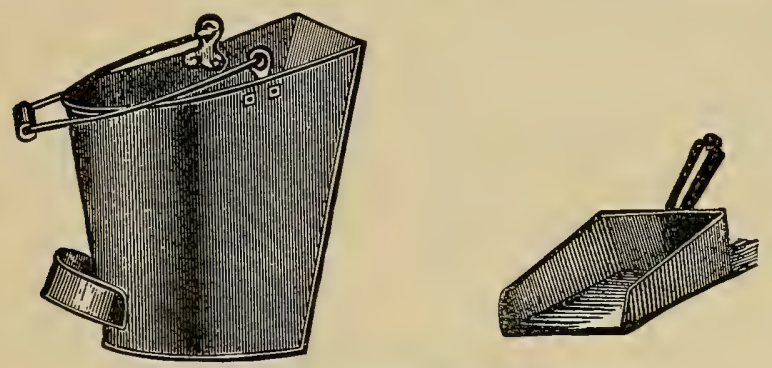

Figs. 33-34.-Curd Pail and Scoop.

\section{I48. Piling Curds.}

Piling the curd has a tendency to make a fast-curing, soft or "weak-bodied" cheese. If a fast-curing, soft cheese is desired, then the curd should be piled, but if a slow-curing, firmbodied cheese is desired, we should pile the curd very little or not at all. In many of the best Canadian factories, the curd is not piled, but is turned over and over. A curd from over-ripe milk, should not be piled very much, as such a curd is likely to produce a "salvy" cheese.

MILLING THE CURD.

\section{I49. When a Curd is Ready to Mill.}

In the course of an hour and a half from the time the curd has been dipped onto the racks, it will have matted down, and assumed a meaty texture. It will not tear out in chunks, but in strips like the meat on a chicken's breast. There will also probably ke half an inch or more, likely an inch, of fine strings, when tried on a hot iron. It is then ready to grind or mill, that is, it is put into a curd mill and cut into small pieces. The acid should be developing well at this stage of the process, but the 
amount of acid is not as important as it is that the curd shall be meaty in texture.

\section{I50. Description of Curd Mills.}

The first curd mills were used in Eng'and. They consisted of a hopper, in the bottom of which was a roller with iron pegs in it. Sometimes there were two rollers. On the side of the hopper were iron pegs, and when the curd was thrown into it, the pegs in the roller would catch it, and carry it against the pegs, and tear and squeeze it to pieces.

The old Roe mill is made on this principle. The old Elgin mill was also on the same plan, only there was less room for the curd to get between the pegs, and the curd was badly smashed and jammed. It caused a great loss of fat, and such a mill ought never to have been used.

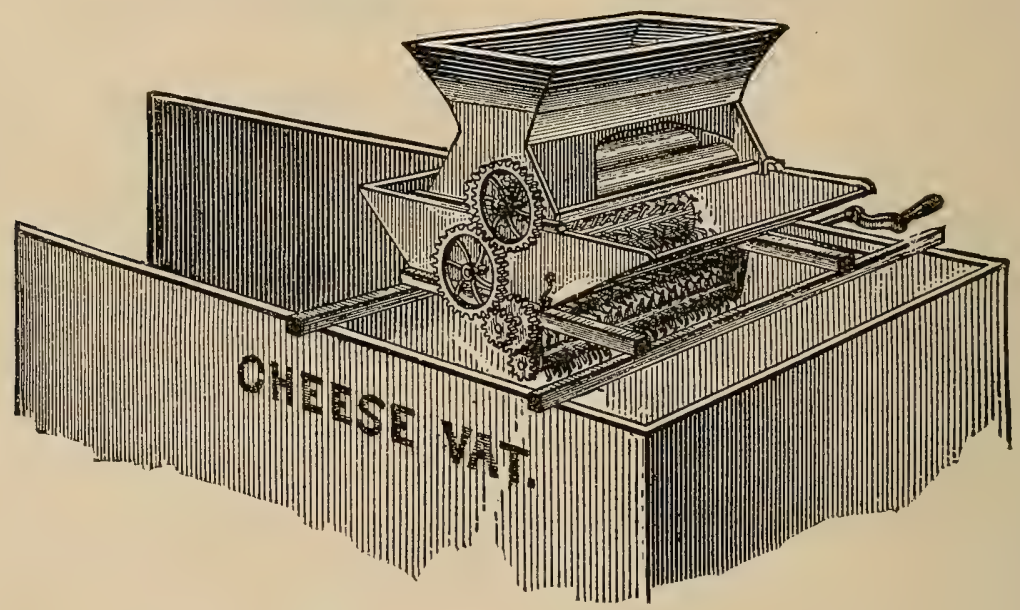

Fig. 35.-The Pohl Curd Mill.

\section{The Pohl Mill.}

The next form of peg mill is the Pohl mill, which has sharp teeth on two eylinders, revolving at different velocities, which pick the curd to pieces. The objection to this mill is, that it does not leave the curd in pieces cf the same size. Some of the pieces will be quite large, while cthers will be sma!l, and when salted the salt will not be evenly distributed. There is a selfsalting attachment to the mill, but this is useless, as a curd is never ready to salt when milled. 


\section{The Whitlow Mill.}

A knife-mill does not jam the curd as much as a peg mill does. It simply cuts it. One of the earliest forms of knifemills was built after the form of peg-mills, as is seen in the Whitlow mill of Canada. There are a number of knives on a shaft which play between knives in the side of the hopper. When the curd is put into the hopper, it is caught between the knives and cut into small pieces. The B. \& W. mill is practically the same mill.

\section{I53. The McPherson Mill.}

The McPherson mill, invented in Eastern Ontario, consists of a wheel with knives in it similar to the blade of a plane. A hopper feeds the eurd down against the wheel, and as it turns.

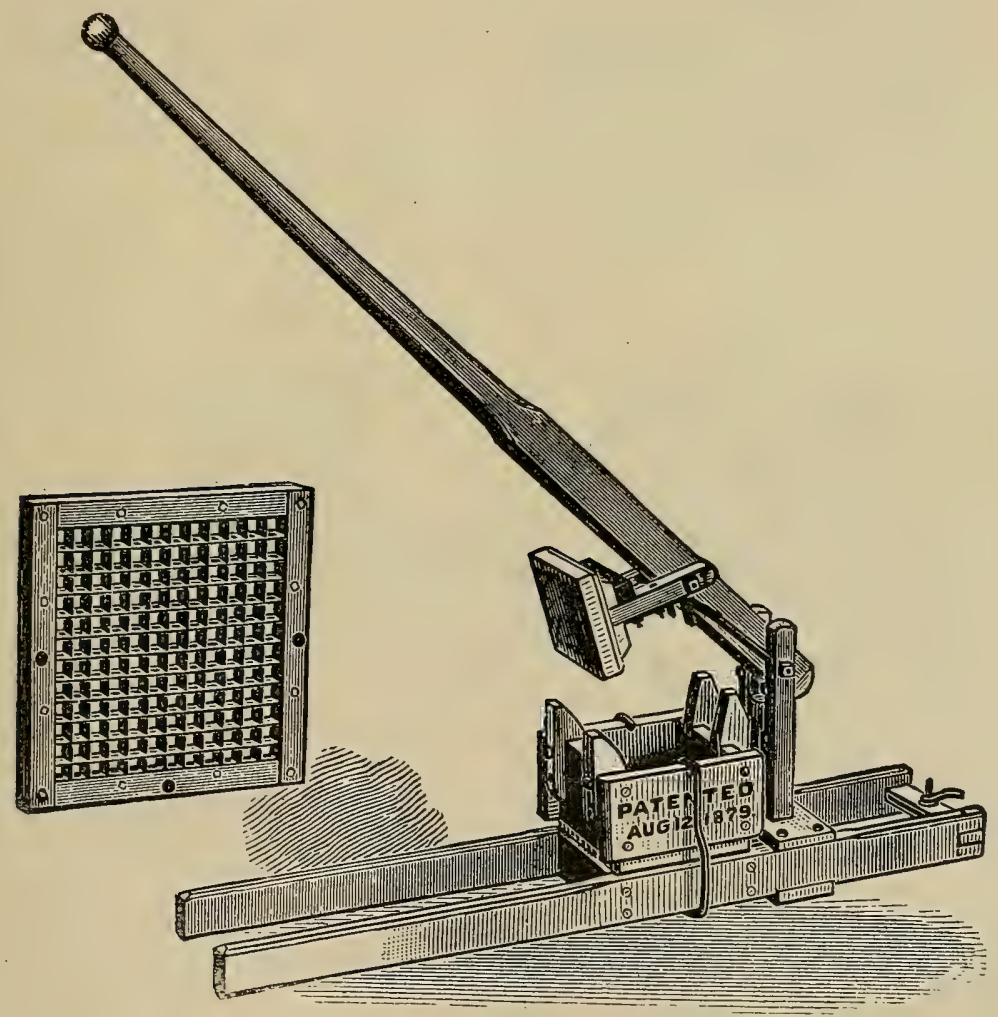

Fig. 36.-The Harris Curd Mill. 
slices of curd are shaved off. The wheel is apt to make the curd fly.

\section{I54. The Gosselin Mill.}

The Gosselin mill is similar to the McPherson, the blade being placed in a cylinder. The curd placed in a hopper rubs against the blades and drops into the cylinder, which being open at the ends, allows the curd to fall out.

\section{The Harris Mill.}

The Harris mill has a network of knives at the bottom of a hopper. A plunger works by a lever into this hopper, and when a lump of curd is dropped into this, the plunger forces it through the knives, leaving the eurd in pieces one-half inch square, and as long as the piece of curd dropped into the hopper.

\section{I56. The Fuller Mill.}

The Fuller mill has two knives with a smaller number of blades than the Harris, placed one on either side of the hopper and the curd is pressed through the knives by a plunger that works back and forth across the bottom of the hopper.

\section{r57. The Barnard Mill.}

The Barnard is similar to the Fuller mill.

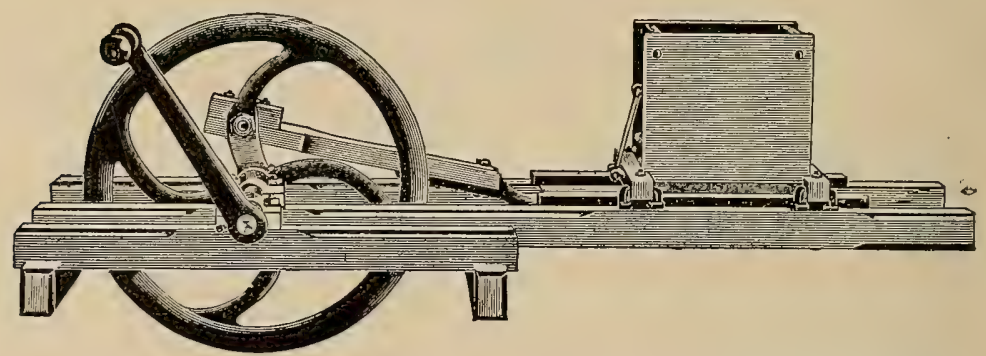

Fig. 37.-The Barnard Hand-Power Curd Mill.

\section{The Kasper Mill.}

The Kasper mill is like the Pohl except that the pegs on the rollers are replaced by a cylinder of knives. The curd is pressed through the knives by means of a wooden roller. The cylinder is in three sections which open automatically and let the curd fall out. (Fig. 38.) 


\section{Advantages and Objections to Knife Mills.}

The advantage of a knife-mill, besides saving the fat in the curd, is that the curd will not mat together on the racks, but can easily be torn to pieces by hand. An objection offered to such mills is, that the eurd will not press together well. This may perhaps be difficult at times, but the trouble in closing the

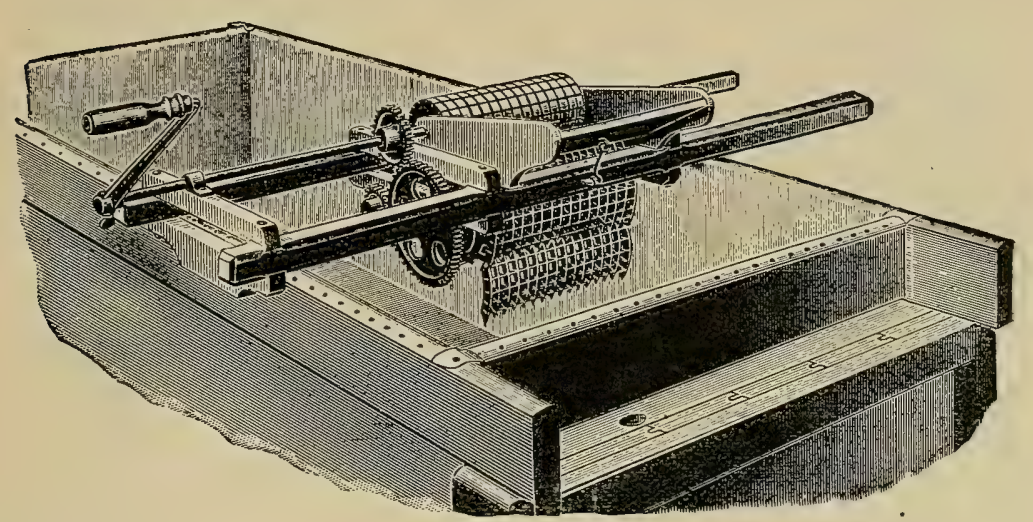

Fig. 38.-Kasper Rotary Curd Mill.

cheese lies somewhere else. It must be remembered that knifemills are used, hardly without exception, in factories where the best Canadian cheese is made, and this cheese is shipped to England, where the bandages are often stripped off from them, and they must necessarily be closed.

If the troukle in closing the cheese be carefully investigated it will be found to be due to the bandage used, or the temperature of the curd. Some makers let the curd mat together again, and grind a second or third time, but so much hacking of the curd is not desirable. The curd should be piled up to flatten the pinholes, and then stirred every fifteen minutes to give it air.

\section{I60. Stirring the Curd.}

A five-tined fork, with the points turned into little loops to prevent catching into the cloth, or sticking into the sink, is a very handy tool with which to stir the curd. It does the work thoroughly, and with much less labor than with the hands alone. 


\section{I6I. Time to Mill.}

The grinding should come about half way between dipping the curd and salting it. There should therefore be an hour and a half from grinding to salting. During all this time the temperature should be kept up.

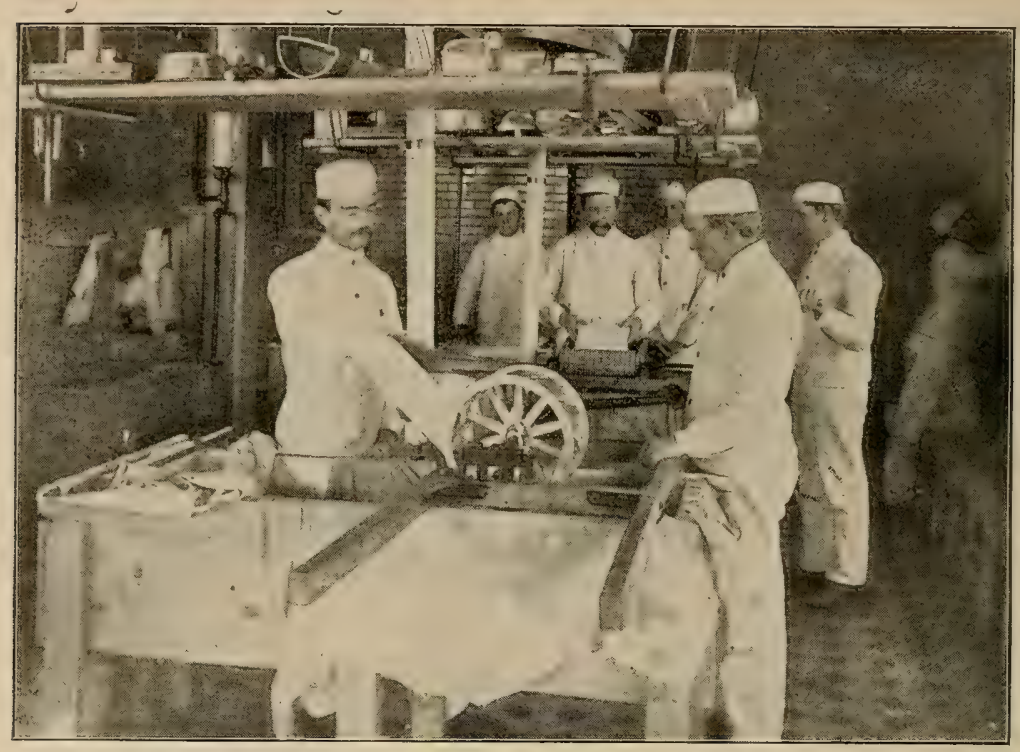

Fig. 39.-Students operating Curd Mill.

The curd should take all the acid it will before salting, which is indicated by strings about two inches long on the hot iron.

\section{Effect of Dry Acid.}

If a fast-curing cheese is wanted, there is all the greater reason for giving it all the acid it will take.

Do not be afraid of getting a sour cheese by giving it all the dry acid it will take. If one has gotten all the whey out of the curd, there is no danger of a sour cheese. It is acid in the whey that makes a sour cheese.

A tallowy cheese may possibly result from a prolonged matting, but this is seldom the case. If the curing room is not under control in hot weather the cheese is safer if well developed on the racks. If the euring room temperature can be held 
down to $65^{\circ} \mathrm{F}$. it will not be necessary to develop so much acid on the racks.

\section{How to Expel Gas.}

If the pin holes are not all flattened out by the time the maker is ready to salt the curd, it can be put into the hoops and pressed up for fifteen minutes. Then take it out and pull to pieces by hand or with the fork. This, however, is not necessary except in very stubborn cases. The gas can usually he expelled by thorough airing and piling.

\section{Steaming Curds.}

The vat or curd sinks should be covered with a heavy canvas cover. A steam hose ean be inserted under it in such a position that the hot steam will not strike the eurd directly. A gentle stream of steam will keep the curd warm; the moisture seems to dispose of taints in the curd.

\section{QUESTIONS ON CHAPTER VIII.}

1. What is meant by an eighth of an inch of acid on a curd? 2. Why do the threads string out on the hot iron? 3. How much acid must be present in the whey to cause strings oneeighth of an inch in length? 4. What is the effect of too much acid in the whey? 5. How are curd racks used in the vat? 6 . Describe the Herrick curd knife. 7. Why and how should the curd on the racks be turned? 8. What are "pin-holey" curds and how should they be handled? 9. What can be said in favor of and against washing curds? 10. How may curds be treated to prevent bad fermentations due to too much washing? 11. What is the advantage of a curd sink? 12. How should a curd sink be constructed? 13. How should the curd sink be filled? 14. Why should a curd be kept warm and how may it be piled to accomplish this? 15. What is the effect of high and of low piling? 16. When is a curd ready to mill? 17. Describe the old peg mills and what is the objection to them? 18. Describe a number of curd mills used in factories. 19. What are the advantages for and objection to knife mills?- 20. How should a five-tined steel fork be fixed to stir the curd? 21. What is the effect of dry acid on a curd? 22. What causes a tallowy cheese? 23. How may gas be expelled from the curd? 24. What can be said about steaming curds? 
CHAPTER IX.

\section{SALTING AND PRESSING THE CURD.}

\section{Condition of a Curd for Salting.}

The curd is ready to salt when it smells like toasted cheese and not like burnt hair when rubbed on the hot-iron. It should not feel harsh, but soft and silky, and when squeezed in the hand, a mixture of half fat and half whey should run between the fingers.

If clear whey runs out, the curd is not ready to salt. White whey should not run from a curd before salting. In that ease it has not been fully freed from whey, and there is a heavy loss of fat. When salted, a clear brine should run from the curd.

Few cheese-makers realize how important a step in the process of cheese making the salting of the curd is, and they salt all their curds according to some fixed rule, learned from their predecessors, without knowing what the salt does.

\section{I66. Salt and Its Impurities.}

Salt is known to chemists by the name of sodium chloride. There are associated with sodium chloride as impurities in salt, potassium chloride, calcium chloride, and sulphates of magnesia and lime. The presence of calcium and magnesium chlorides in salt makes it lumpy and damp, for these chlorides have a great attraction for water, and will absorb it from the air. Calcium chloride and magnesium chloride give the salt a bitter taste.

These impurities, however, as well as the water contained in salt, are a very low percentage of the whole, and when a salt dealer talks about his salt being so much stronger or purer than any other high-grade salt, he has no regard for facts. Do not understand, that common barrel salt is just as good as the best salt for cheese making, for it is not. Common barrel salt contains a great deal of dirt, and salt may take up bad odors, which will be imparted to the cheese. 
Fine salt that has probably been ground, will dissolve faster than a coarser salt in the natural crystalline form, the crystals being broken in the former case.

Salt can easily be tested as to quality, by dissolving it in pure water in a glass cylinder. Use more salt than will dissolve. The best salt is that which leaves a clear brine with no scum or dirt on the top, or bottom of the solutions. Cheese is an article of food and we do not want any dirt in it, so we should avoid dirty salt. If a few drops of a solution of ammonium oxalate is poured into the salt solution, any lime that may be in the salt will be thrown down in the form of a white precipitate of calcium oxalate. By this means we can form an idea of the amount of lime in the salt. It is doubtful if a little lime (calcium oxide) is harmful in the salt, but if the calcium is in the form of chloride, it will attract moisture and make the salt lump. Lumpy salt will not be evenly distributed in the cheese.

AVERAGE COMPOSITION IN AMERICAN DAIRY SALT, IN PER CENT.*

\begin{tabular}{|c|c|c|c|c|c|c|c|}
\hline NAME OF BRAND. & 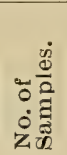 & 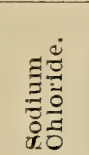 & 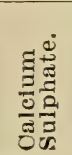 & 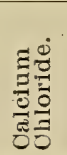 & 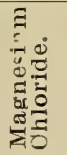 & 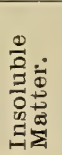 & 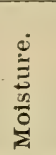 \\
\hline Anchor. & 3 & 97.79 & 1.48 & .28 & .08 & .06 & .31 \\
\hline Ashton. & 3 & 98.01 & 1.42 & .20 & .16 & .03 & .18 \\
\hline Canfield \& Wheele & 4 & 98.18 & 1.21 & .22 & .12 & .04 & .23 \\
\hline Diamond Crystal... & 5 & 99.18 & .54 & .19 & .05 & .03 & .01 \\
\hline Genesee........ & 8 & 98.27 & 1.11 & .24 & .07 & .04 & .16 \\
\hline Kansas... & 3 & 97.87 & 1.50 & .31 & .07 & .05 & .20 \\
\hline LeRoy. & 2 & 98.15 & 1.31 & .39 & .08 & .01 & .06 \\
\hline Vacuum Pan. & 6 & 98.00 & 1.15 & .36 & .15 & .03 & .31 \\
\hline Warsaw..... & 3 & 98.43 & .96 & .40 & .06 & .03 & .12 \\
\hline Worcester. & 5 & 98.57 & .92 & .25 & .07 & .02 & .17 \\
\hline
\end{tabular}

\section{What Salt Does to Cheese.}

In the first place, salt gives taste to a cheese. A cheese without salt has an insipid taste. Salt also takes out the moisture, so that fermentation is checked. A cheese' without salt will cure very fast, in fact fermentation goes on so rapidly that gas holes are formed.

This is seen in brick and Swiss cheese, in which the fermentation starts in the unsalted state, but the salt, which is applied

*See Woll, Bull. 74, Wisconsin Experiment Station. 
to the outside, works its way into the cheese before it spoils. Such cheese must be cured in a cellar, where there is a constant low temperature, as it will otherwise spoil.

\section{I68. Effect of Too Much Salt.}

If a cheese is salted too heavily, it becomes dry and mealy, and cures very slowly. The flavor is also injured. If we have bad milk, we should salt higher to improve the flavor, for up to a certain point, this is accomplished by heavier salting. We believe this to be due to the fact, that as the fermentation is checked by more salt, the gases formed have a chance to diffuse, and escape from the cheese, without filling it with holes and the odor of the gases. Salt may also check the action of the enzymes in their work of digesting the casein. (92.)

To make a fine-flavored cheese it is advisable to salt heavy, say three pounds of salt per one hundred of curd. It must be expected, however, that such a curd will cure slowly. The best kind of cheese cannot be made in a day, a week, or a month. A fast-curing cheese is made by using more rennet and less salt, but the product will not be as good a checse as a slow-curing one. It will not be as close, nor as fine-flavored, for the gases will not have had time to escape from the cheese. If one is making a fine, slow-curing cheese, he need not expect to get as much cheese per hundred weight of milk, as if he were making fast-curing cheese, for the salt expels the moisture and leaves less weight.

In an experiment at the Wisconsin Dairy School, a curd was divided into three equal parts. The first lot received no salt; the second lot, one and a half pounds of salt per hundred pounds of curd; and the third lot three pounds per hundred. The curds were then pressed separately, and the green cheese weighed as follows:

The eheese with no salt.............. 10 ths.

The cheese with one and a balf $\mathrm{ths}$. of salt... $9.75 \mathrm{fbs}$.

The cheese with three pounds of salt...... $9.50 \mathrm{fbs}$.

As the cheese cured, they kept their relative weights. Other experiments have given similar results.

\section{r69. Curds Not Always Salted the Same.}

Curds should not always be salted at the same rate from day to day. A moist curd needs more salt than a dry one, for 
two reasons: First, the excess of moisture must be expelled by the addition of salt; and second, as the expulsion of moisture takes salt with it in solution, enough must be applied to leave the proper amount in the cheese.

\section{I70. Salt Should Be Evenly Distributed.}

It is also essential, that the salt should be evenly distributed through the cheese. If there, is too much salt in the last curd put into the hoop, the rind of the cheese will crack.

\section{I7r. Adding Salt.}

The curd should be spread out evenly in the curd sink, and a part of the salt scattered evenly over it. The curd should then be stirred thoroughly, and again spread out, and the remainder of the salt applied. It ought to be stirred every ten minutes, to keep the salt from settling to the bottom of the pile in the brine.

\section{r72. Temperature of Salting.}

Before salting, the curd should be cooled to $90^{\circ} \mathrm{F}$., for if too warm, the fat may be expelled in large quantities with the brine. The curd should not be put to press till the salt has been thoroughly dissolved and worked into it.

\section{Condition of Salted Curd for Pressing.}

Before pressing the curd will have harsh feeling, due to the undissolved salt crystals, the outside of the pieces of eurd are hardened, so that they will not press together readily; but as the salt works into the curd, it will regain its velvety feeling. When this condition has been reached, which is usually in fifteen to twenty minutes, it is ready for the press.

\section{Removing Fat.}

As indicated in paragraph 172 the fat may run over the surface of the curd and prevent the cementing of the particles. This is especially true of a curd from tainted milk. By throwing two or three pails of warm water $\left(110^{\circ}\right)$ over the curd this fat will be washed off, and then a pail of cold water will harden the curd so that the fat will not run. A little fat is lost, however, in this way. If the curing room is cool enough to permit of it, salting the curd a little earlier will prevent this loss. 


\section{PRESSING THE CHEESE.}

\section{Curd Must Not be Too Warm or Too Cold.}

Before pressing, the curd should be cooled to between eighty and eighty-five degrees. If put to press warmer, the fat runs, and large quantities of it are lost. It also runs between the pieces of curd so that they will not close together, and under the bandage, preventing it from sticking to the cheese. Poorly closed cheese has often been attributed to the curd mill, when the trouble really lay in the temperature at which the cheese was put to press.

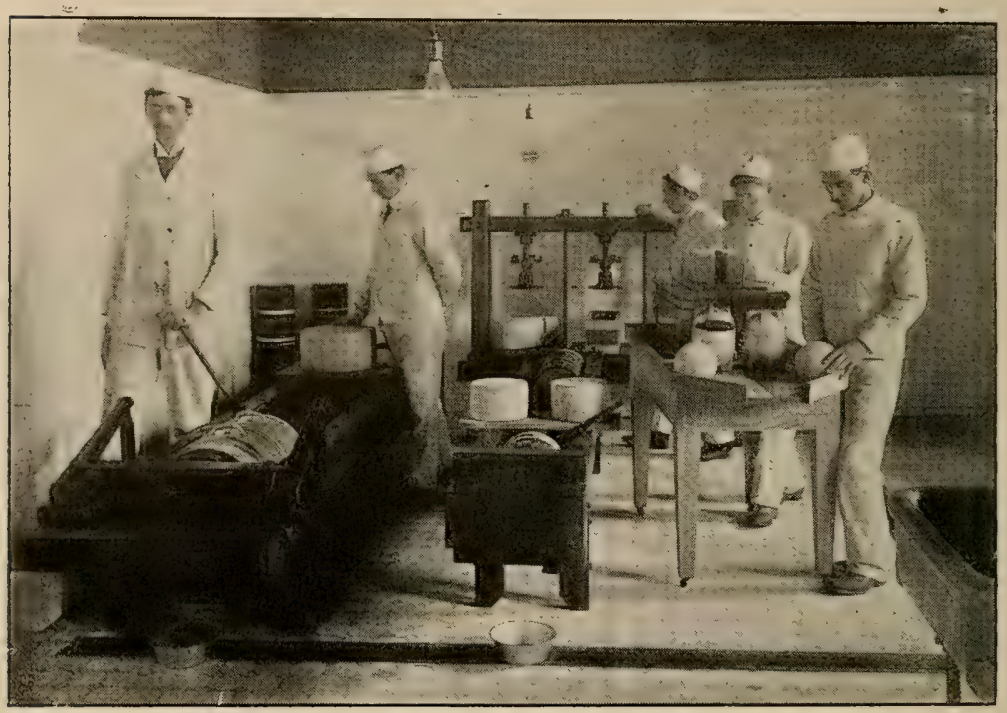

Fig. 40.-Students pressing cheese.

When the eurd is much below $80^{\circ}$, it will not close together, but there is a happy medium which varies according to the temperature of the press room. If the room is cold, the curd will cool down. A cheese-maker must have some brains in his head, and use them, for he is more than a mere machine to be wound up and run down. A proper temperature for the press room is about $70^{\circ} \mathrm{F}$.

\section{I76. Common Packages of Cheese.}

There are four common packages, into which American cheese is pressed, namely, Young Americas, weighing nine or 
ten pounds, Flats and Chedđars, weighing respectively thirty and sixty pounds, and Daisies weighing twenty pounds (Fig. 41).

The common diameter of flats or Cheddar cheese is fourteen and a half inches, and a flat is half the height of a Cheddar.

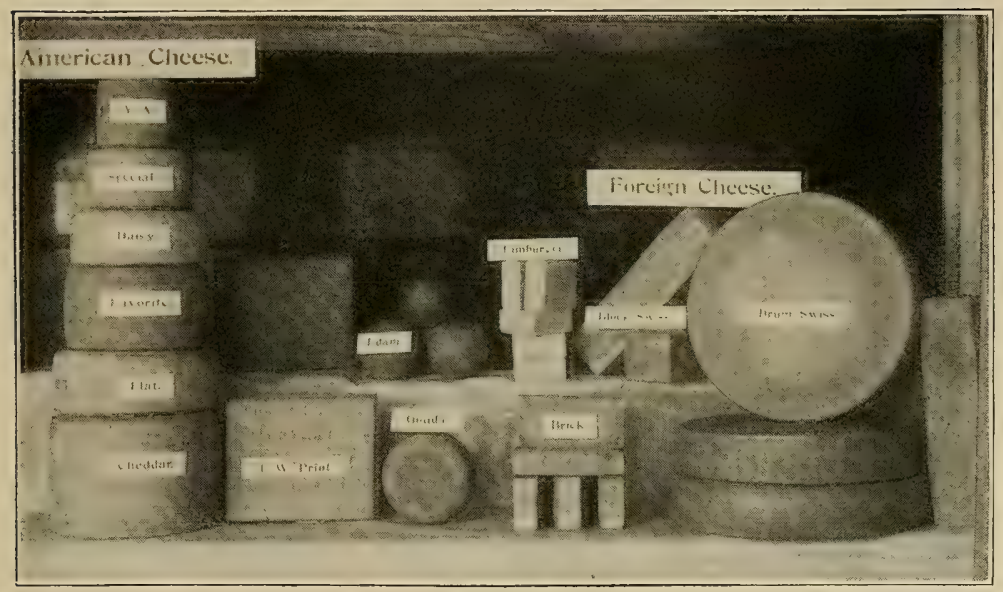

Fig. 41.-Different styles of American and foreign cheese made in the United States.

\section{I77. Cheese Presses.}

There are two kinds of presses used, the gang and the upright. The upright press has the screws in an upright position, and but one screw to a cheese. The gang press has one horizontal screw, which presses anywhere from one to twenty cheese. The hoops (Fraser) are made a little smaller at the bottom than at the top, so that each hoop will fit over the next one in front of it.

It is sometimes claimed for upright presses that the pressure is kept up better, as there is but one cheese under a screw, but they are hard to keep clean and take up a great deal of room.

The Sprague automatic adjustable gang press can be adjusted to fit hoops of different diameters. This press as well as the Helmer is arranged so that a continuous pressure is kept on the cheese. A new factory should certainly be equipped with one of these presses.*

\footnotetext{
*An automatic cheese press is described by J. W. Moore in the 24 th report of the Wisconsin Experment Station (1907), pp. 207-213. See also Farmers' Bull. 329, p. 28
} 
In the Fraser gang hoop, the bandage is held by an iron band, which slips into the top of the hoop. This iron band is called the "bandager."

In pressing the cheese, the maker should aim to turn out a perfect cheese. He should be an artist, and produce an ob-

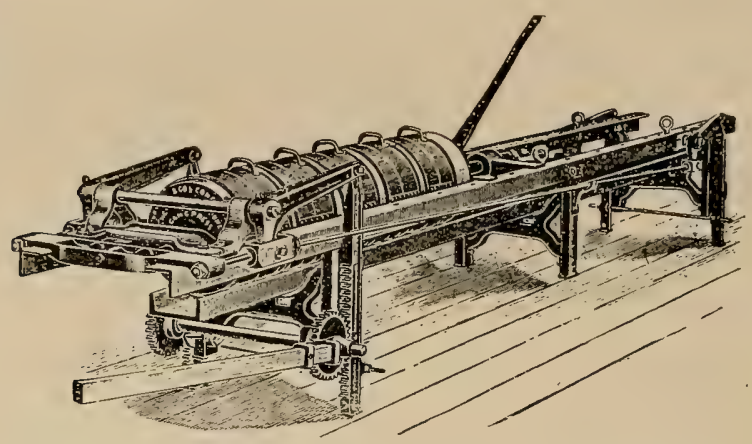

Fig. 42.-The Sprague Adjustable Gang Press.

ject of beauty. The ends should te square with its height, clean, and the bandage turned down evenly at the ends, and closed well on the sides.

\section{Kind of Bandage Used.}

There are two kinds of bandages used, starched and seamless. The starched bandage is made by the cheese maker from

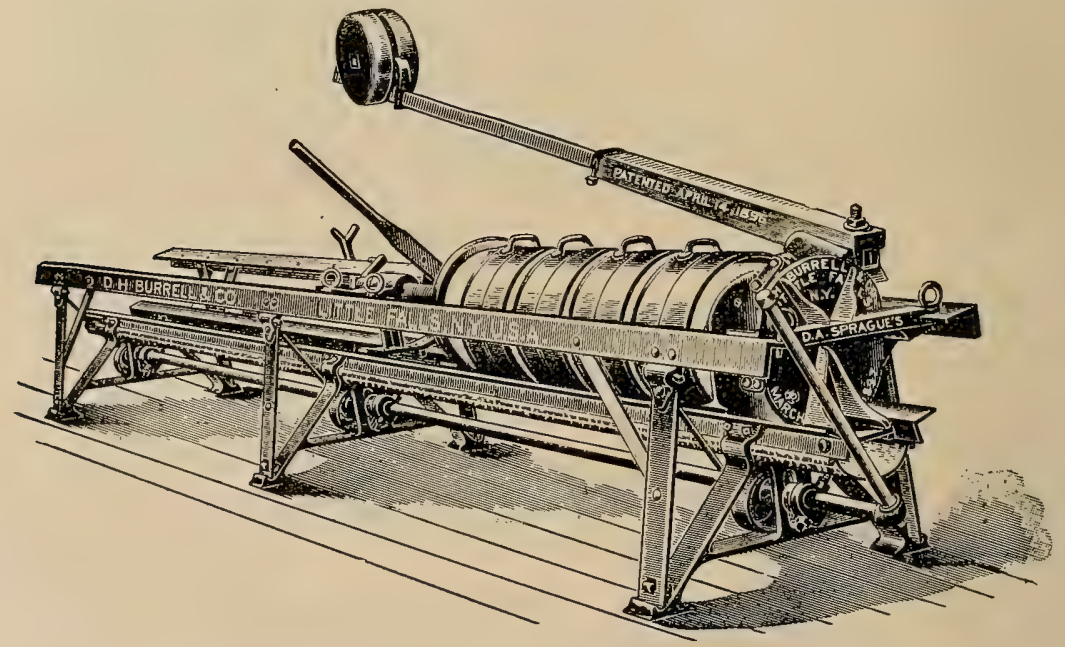

Fig. 43.-The Helmer Patent Continuous-Pressure Press. 
starched cloth. The seamless bandage comes in the form of a long cloth tube, from which the required length for the cheese is cut. But the starehed bandage will not let the whey out properly, and consequently the cheese does not close on the sides. The cheese closes much better with the unstarched, seamless bandage.

Ready-made unstarched bandages of better quality than the seamless bandage and about the same cost are now in the market.

\section{How the Bandage is Put Onto the Cheese.}

When the bandage is put into the hoop, the edge should be turned in evenly, for about an inch and a half on the bottom, and perhaps dampened to hold its place.

Before putting the bandage in, the bottom eap cloth should be put in. It should be round, and as large as the bottom of the hoop (fourteen and a half inches), and should be soaked in hot water. Square cap cloths lap over onto the sides of the cheese, and make bad looking scars.

\section{Cheese Must be of the Same Size.}

Care should be taken to put the same amount of curd into each hoop, so that all the cheese will be of the same height.

The hoops should not be filled so full that the cheese comes above the junction between the bandage and the hoop, for in such cases, there will be a little ridge left at the junction, which will disfigure the cheese.

When the curd has been filled into the hoop, the top cap cloth is put on, and the fibrous ring laid around the edge, to keep the curd from pushing out, and then the follower: put in. Usually the fibrous ring is tacked onto the follower, and while it may fit well, it quite often happens that it does not; and the curd will push out at the places where the ring does not come tight against the hoop. There is another point in having the fibrous ring separate from the follower, which will be noticed later on. (184.)

\section{Tighten the Press Slowly.}

After the hoops have been slipped into place, the screw should be tightened slowly, to let the whey out gradually. A small stream of brine should be kept flowing. If too great pres- 
sure is applied at first, the fat will be forced out. Curd closes together slowly, as will be seen by squeezing it in the hand. If it be squeezed suddenly, and then the pressure released, it will fall apart, but if pressed up slowly in the hand, it will stick together. The full pressure should not be reached for about fifteen minutes.

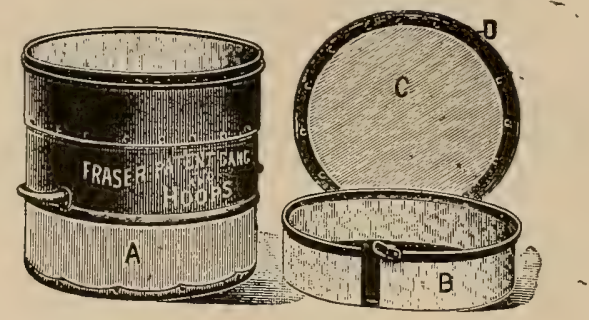

Fig. 44.-Fraser Gang Hoops. A, hoop; B, bandager; C, follower; D, fibrous ring.

In about an hour, the curd will be pressed together, and then the bandage should be turned down around the top of the cheese. This operation is generally called "dressing" the cheese.

\section{I82. Dressing the Cheese.}

Set the hoops in an upright position, and take out the followers, eap cloths, and bandagers. Pull the tandage gently, to be sure there are no wrinkles in it, and then trim off evenly all around, so that it will lap over onto the end of the cheese about an inch and a half. Soak it down into position with warm

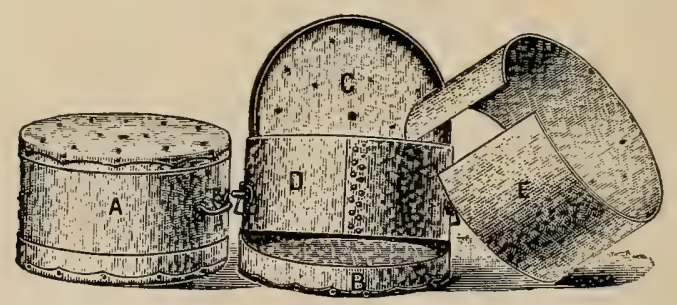

Fig. 45.-Wilsicn Cheese Hoops.

water, and put on the cap, after having wrung it out in warm water. Be sure there are no wrinkles in the cap, for they will leave bad looking marks on the rind of the cheese.

Then put in the bandagers to keep the hoops straight in the press, and the fibrous ring and follower, and close up the press, 
putting on full pressure. Young Americas, however, will not stand as much pressure, for they do not have as much surface as larger cheese, to resist it.

\section{The Wilson Hoop.}

Another form of hoop used largely in Ohio is the Wilson hoop.

\section{DIRECTIONS FOR USING THE WILSON HOOPS.}

Each hoop consists of four pieces, as follows:

$B$. The bottom eover, with the widest flange or rim.

$E$. The open wide hoop.

$D$. The closed or tight wide hoop.

$C$. The top cover with narrow flange or rim.

FIRST-Place the cover with the widest rim $(B)$ on the ways in the bottom of the press.

SECOND-Place the Cap Cloth on the bottom of the cover (B). Said Cap Cloth should be as large as the bottom of the cover.

THIRD-Place within the bottom of cover (A) the open hoop or bandage (E).

FouRtH-Wet one edge of the bandage, adjust with the open hoop and turn the wet edge over the top of the hoop.

FiFTH-Put the closed wide hoop $(D)$ on top of the open one, letting it lap over about one inch, and fasten the hooks which are provided to keep same from slipping down.

SIXTH-Put in the cheese curd as may be desired, for any thickness the cheese are to be made, but always put in enough so that the outer or tight hoop in slipping over the open one when pressing shall not quite be forced down to meet the edge of the lower cover.

SEVENTH-Put on the top cover (C), then unfasten the hooks under the handles, then turn the cheese over, placing the top cover up snug against the head of the press. Proceed in the same manner with the balance of the hoops until are are filled, placing the top cover against the bottom of the previous one, etc. Then proceed to pressing.

ETGHTH-After pressing as usual, or until the time when the bandage is to be turned in or lapped over the edge of the cheese in order to press the bandage down, it is well to remove the cheese from the hoop, and having turned it over, put it back in the hoop with the other face up, and put to press again. This will be found to remove any wrinkles that may have formed in the bandage.

\section{How to Get Cheese Dry.}

The idea that we make a cheese dry by pressing it is an erroneous one. The whey must be removed from the curd while it is in the vat; if it is not, no amount of squeezing in the press will expel it, and the cheese will get sour. 
If the press is not a continuous pressure one, the maker should tighten the press the last thing at night, and the first thing in the morning.

In the morning, the cheese should be taken out of the hoops and examined, to see if they are perfect in shape, and all defects remedied. If the bandage does not stick, the cheese should be washed with warm water, and after being tightened in the press, hot water turned on to warm it up. If the edge of the upper end of the cheese is rongh, it should be turned end for end in the hoop. In either case, the fibrous ring should be left out, so that the edge of the cheese will come out square on the hoop. The cheese must be watched, to see that it does not push out beyond the follower, and its last state be worse than the first; but if the pressure is carefully applied, a nice square edge can te put onto a cheese in this way.

\section{Do Not Pound the Hoops.}

The cheese should slip out of the hoop with very little pounding. Pounding loosens the rivets, and gets the hoops into bad condition, as well as loosens the bandage on the cheese, and sometimes breaks the cheese.

Where a knife is used to loosen the cheese, the bandage is also often loosened. If the cheese does not slip out easily, grease the hoops. The hoops should be kept clean, and when necessary to grease them, clean grease should be used.

Cheese should never be taken out on the floor, but on a press board. We must remember that cheese is an article of human food. Most people like to have clean food to eat, and we should aim to be just as clean in making the cheese as though the consumers were watching all the time.

Wipe the cheese off with a clean cloth, and then put them on the shelves, marking the date neatly. Cheese with great big marks serawled over them do not look attractive.

\section{I86. Greasing the Cheese.}

As soon as the rind has dried off, it should be greased with regular cheese grease. The practice of using the skimmed whey after it has fermented and become full of dirt is nothing less than a dirty trick. Good wholesome grease, prepared for the purpose, can be bought of regular dealers in dairy supplies, and nothing else should be used. 


\section{Cracks in Cheese.}

If the cheese is left exposed to the air too long before being greased, it will crack. Another cause of the rind cracking is too much acid in the whey. A high-acid cheese will, as a rule, crack. A draft of air blowing over the cheese will also cause it too crack. This, of course, is caused by the air absorbing moisture from the rind. The question of moisture in the curing of American cheese has been little considered in the past, but it will doubtless receive more attention in the future.

\section{Cheese in Cold Storage.}

Cheese held in cold storage are very likely to mold. Mold works into the eracks, and for this reason buyers do not want cracked cheese. The rinds of high-acid cheese, held in cold storage, will also begin to rot at the middle.

Sometimes the maker leaves the eaps, or press cloths, as they are sometimes ealled, on until a few days before shipping, and then pulls them off and greases the rinds.

Sometimes salt sacks made out of heavy ducking are used for caps. This leaves a hard but very rough rind, and if the cheese is held in cold storage, and mold grows on it, it is almost impossible to get the mold off, and buyers are strongly opposed to using salt sacks for this purpose.

\section{I89. Cleaning Moldy Cheese.}

Cheese that gets moldy in cold storage is put into a sink of hot water, to which a little ammonia has been added, and scrubbed with a brush. It is put on a shelf to drain and dry, and afterward boxed again.

\section{Cheese Cloth Circles and Press Cloths.}

Sometimes a thin "cap" of cheese cloth, called a "cheese cloth circle," is put on the end of the cheese. The cheese cloth circle does not go on under the bandage where it is turned down on the end, but over it. When circles are used, there is no need of greasing the cheese till they are shipped. The circle is then pulled off and the rind greased.

The circles make the cheese much cleaner, and buyers generally prefer them, and will pay more money for the cheese, usually an eighth of a cent a pound more. The cost is about one-sixteenth of a cent a pound on flats. Sometimes, by special 
agreement, buyers want the circles left on the cheese. When the cheese come out of cold storage they are cleaned, the circles being stripped off, leaving a clean bright rind, which is greased.

The circles should be but twelve or thirteen inches in diameter, as they sometimes do not stick under the edge where they lap over the kandage.

The first one is put on inside the "heavy cap" or "press cloth," before the curd is put into the hoop, and the other one is put in when the cheese is "dressed."

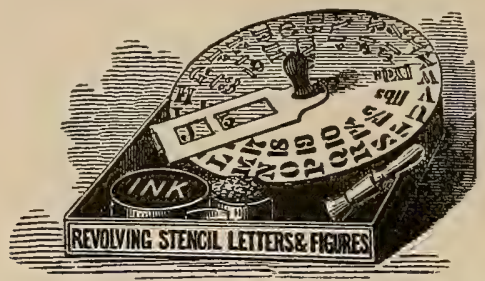

Fig. 46.-Revolving Letter and Figure Stencil.

\section{I9I. Print Cheese.}

An arrangement for molding cheese into print forms similar to one-pound butter prints was designed at the Wisconsin Station in 1898-99.* The cheese is made by the usual Cheddar process, but the curd is placed in a rectangular mold, the bottom or "follower" of which is a carved board. This board makes an impression on each one-pound print of cheese, the groove showing where it is to be cut in order to make each print weigh about one pound. - The dimensions of each block of 15 prints (weighing a little over 15 lbs.), are $11 \frac{1}{2} \times 131 / 4 \times 21 / 2$ inches, each print being $21 / 2 \times 21 / 2 \times 41 / 4$ inches in size.

In making this cheese, the curd is placed in a rectangular metal hoop similar to the Cheddar cheese hoops with fasteners, etc.; the bandage is made to cover the sides and bottom, and come together on the top of the flat cheese; the cloth is cut so as to make smooth, neat corners. The cheese are cured in the same way as Cheddar cheese, and when pressed with a carved board, a trademark may be branded into each pound of the cheese, and thus protect the reputation of cheese from a given source.

*Report 18, pp. 132-135; Report 20, pp. 190-191. 


\section{Keep a Daily Record.}

When the cheese is ready to ship, it quite often happens that a maker finds something peculiar about a cheese which he wishes to avoid or reproduce in the future, but he does not remember the circumstances connected with the making of that particular cheese In the best factories a taily record is kept showing the

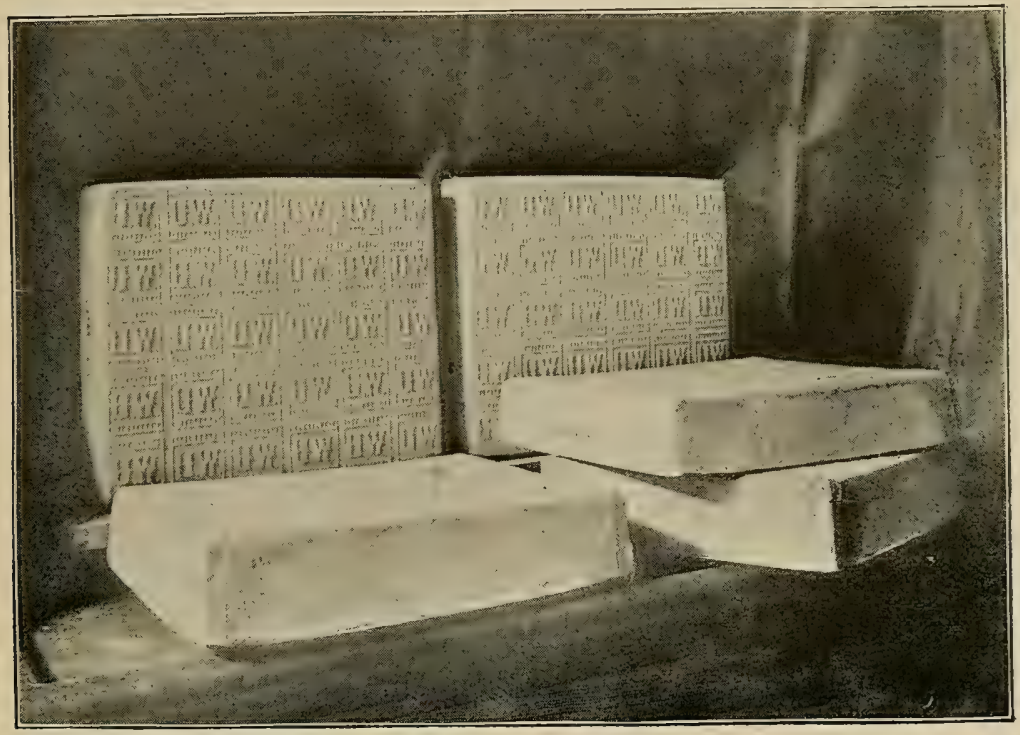

Fig. 47.-Print Cheddar Cheese, made at the University of Wisconsin Dairy School.

conditions under which each cheese is made, and how the milk and curd act. This gives the maker a history of each cheese, and by its aid he is often able to remedy defects and reproduce desirable points.

The following blank is suggested for the purpose:

$$
\text { Date................190. }
$$

Vat used (Number of vat),

Condition of milk,

Per cent of fat in milk,

Pounds of milk in vat,

Rennet (or acidity) test for ripeness,

Temperature set, 
Time set,

Amount of rennet used,

Rate of rennet per 1000 pounds of milk,

Time cut,

Minutes in curdling,

Time steam was turned on,

Time required in raising to ...... degrees,

Hot-iron test (or acidity) when dipped,

Time dipped,

Time from cutting to dipping,

Per cent of fat in whey,

Time ground,

Hot-iron test (or acidity) when ground,

Time salted,

Amount of salt on curd,

Rate of salt per 1000 lbs. of milk,

Time put to press,

Kind and number of cheese made,

Time dressed,

Time pressed,

Weight of green cheese,

Average weight of milk per pound of cheese,

Highest and lowest temperature of euring room for last twenty-four hours.

Percentage humidity in curing-room.

Remarks-

Under this head any important matter not included under the other heads may be noted, such as gassy curd or washing out bad flavors, or any treatment different from the ordinary method of manufacture.

\section{QUESTIONS ON CHAPTER IX.}

1. What are the conditions of a curd when ready to salt? 2. What is salt? 3. What are the impurities in salt, to what extent do they occur, and what are the objections to them? 4. What does salt do to cheese? 5. What is the effect of too much salt? 6. Does salt increase or diminish the weight of cheese, and why? 7. Should all curds ke salted alike? 8. How should 
salt be applied to a curd? 9 . When is a curd ready to press? 10. What prevents cheese from closing, and what is the remedy? 11. At what temperature should curd be pressed, and why? 12. What are the common packages of cheese? 13. How do upright and gang presses compare? 14. How is the bandage held in the Fraser hoop? 15. What are the different kinds of bandage in use? 16. How is the bandage put onto a cheese? 17. How should the eap cloths be cut? 18. How full should a hoop be filled? 19. How fast should the press be tightened? 20. What is meant by dressing the cheese? 21. Describe the Wilson hoop. 23. How is moisture expelled from a cheese? 23. Why should not the hoops be pounded to get the cheese out? 24. Why and with what should cheese be greased? 25. How do high acid cheese behave in cold storage? 26. How can moldy cheese be cleaned? 27. What is a cheese cloth circle, and how are they put on with reference to the bandage? 28. What is a press cloth? 29. What is the advantage of a daily record? 
CHAPTER $X$.

\section{CURING AND SHIPPING THE CHEESE.}

\section{Changes in Curing Cheese.}

When the cheese is coagulated by rennet, the coagulum is called paracasein. In curing, the cheese undergoes changes into the following products in the order named. Paracasein changes by the action of lactic acid into paracasein-monolactate (lactic-acid-paracasein), para-nuclein, caseoses, peptones, amides and ammonia. The first changes are from a substance insolubl: in water to soluble substances. These substances do not havy much flavor, but as the amides develop the characteristic flavor appears. Dr. Van Slyke has shown by careful chemical analyses extending over a period of 35 weeks that the rate of the formation of these decomposition products is dependent upon the temperature.

\section{Curing at Different Temperatures.}

Cheese will cure slowly at low temperatures and improve in flavor and texture. At the Wisconsin Experiment Station a cheese kept at $15^{\circ} \mathrm{F}$. for 5 months was found to have cured perfectly and to be of a very fine quality, with the exception that the freezing had made the texture crumbly. As the temperature is raised the cheese cures faster. At $60^{\circ}$ to $65^{\circ}$ thic most rapid curing takes place at which a good cheese can be obtained. A temperature of $70^{\circ}$ for any protracted length of time will injure the texture and flavor, while a temperature of $80^{\circ}$ will spoil the best kind of cheese.

\section{I95. Curing Shelves, How Made.}

The cheese should be cured on shelves made of good clear pine, one and a half inches thick by sixteen inches wide, supported every four feet. The reason for having the lumber clear is 
that the sap and pitch from the knots will color the cheese rinds. The boards should be wider than the cheese, so that the cheese will not extend over the edge and a mark be left on the face of the cheese. The board ought to be heavy and the supports close together to prevent sagging, which might make the cheese, especially Cheddars, crooked. The cheese should be turned every day, and the shelves wiped with a clean cloth. Pains should be taken not to soil the cheese nor break the corners in turnings them.

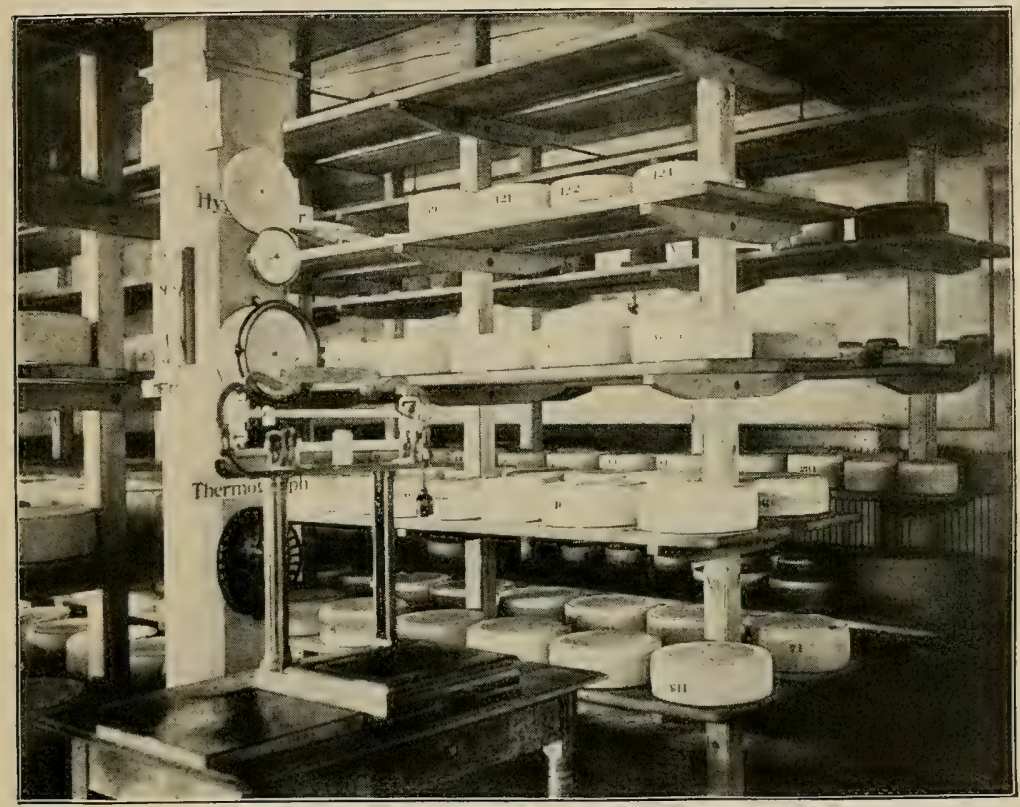

Fig. 48.-View of Cheddar Curing Rocm, Wisconsin Dairy School.

\section{Arrangement of Cheese.}

The older cheese should be kept on the lower shelves, and the younger ones $c n$ the upper shelves, because of the difference in temperature between the upper and lower portions of the room. The upper shelves being warmer, the younger cheese will cure faster and the month's make will be more even than if this rule is not followed. 


\section{Moisture in the Curing Room.}

A matter that has not received proper attention in euring American Cheddar cheese is the humidity of the air in the curing room. There are two instruments for measuring the humidity - the hygroseope and psychrometer.

\section{The Hygroscope.}

The hygroscope is an instrument consisting of a coil of material very sensitive to moisture. As it takes up from or gives off water to the atmosphere the coil moves a hand around a dial which shows the per cent of humidity.

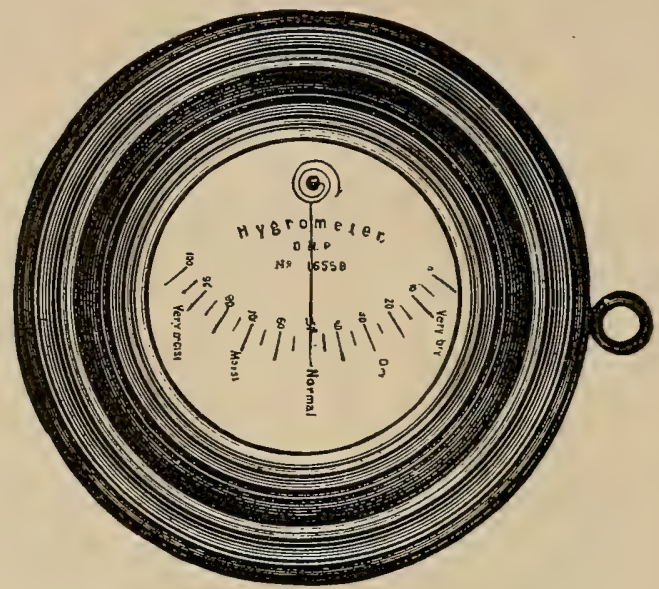

Fig. 49.-Hygrometer or Hygroscope.

\section{The Psychrometer.}

The psychrometer consists of two accurate thermometers. On the bulb of one is a wick which dips in a cup of distilled water. When the air is saturated it has all the water it will hold. If the air is not saturated, water will evaporate from the wick, and the dryer the air the greater the evaporation. As the water passes from around the bulb into the air it lowers the temperature.

The thermometer should be fanned briskly with a good fan for three minutes, and then the reading taken quickly. First find the dry-bulb reading on the chart and then the wet-bulb reading in the next column; in the third column, opposite the 
dry-bulb reading, is the relative humidity, or per cent of saturation, i. e., the per cent of water the air is capable of holding at that temperature.

The psychrometer is not as handy as the hygrometer, but is considered more reliable.

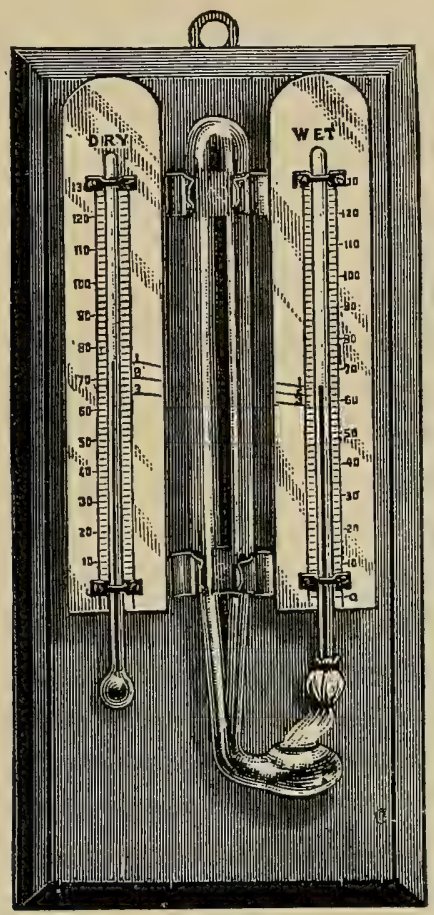

Fig. 50.-Psychrometer.

The United States Weather Bureau has prepared a table of readings with the corresponding humidity. The following table has been arranged for use in curing rooms by Professor F. H. King. 
Table Showing the Relative Humidity in the Air of Curing Rooms.

DIRECTIONS.-Notice that the table is in three column sections. Find air temperature in first column, then find wet bulb temperature in second column, same division. In third column opposite this is the relative humidity.

Example.-Air temperature is $50^{\circ}$, in first column; wet bulb is $44^{\circ}$, in second column, same division. Opposite $44^{\circ}$ is 61 , which is the per cent of saturation, or the relative humidity of the air.

\begin{tabular}{|c|c|c|c|c|c|c|c|c|c|c|c|}
\hline $\begin{array}{l}\dot{\partial} \\
\vec{B} \\
\dot{a} \\
\dot{a}\end{array}$ & $\begin{array}{l}\dot{0} \\
\vec{B} \\
\overrightarrow{0} \\
\overrightarrow{0}\end{array}$ & 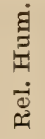 & $\begin{array}{l}\stackrel{0}{\overrightarrow{0}} \\
\overrightarrow{0} \\
\dot{0} \\
\stackrel{0}{A}\end{array}$ & $\begin{array}{l}\dot{\vec{Z}} \\
\vec{F} \\
\overrightarrow{0} \\
\overrightarrow{0}\end{array}$ & 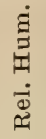 & 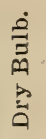 & $\begin{array}{l}0 \\
0 \\
\overrightarrow{0} \\
\overrightarrow{0} \\
\overrightarrow{0}\end{array}$ & 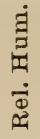 & 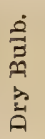 & $\begin{array}{l}0 \\
\vec{J} \\
0 \\
0 \\
3\end{array}$ & $\begin{array}{l}\dot{\Xi} \\
\dot{\Xi} \\
\dot{\Phi} \\
\dot{\Phi} \\
\dot{0}\end{array}$ \\
\hline \multirow{6}{*}{40} & $\begin{array}{l}32 \\
33\end{array}$ & $\begin{array}{l}37 \\
44\end{array}$ & & $\begin{array}{l}36 \\
37\end{array}$ & $\begin{array}{l}48 \\
55\end{array}$ & \multirow{7}{*}{46} & $\begin{array}{l}37 \\
38\end{array}$ & $\begin{array}{l}38 \\
45\end{array}$ & 48 & 47 & 93 \\
\hline & 34 & 52 & & 38 & 62 & & 39 & 51 & & & \\
\hline & 35 & 59 & 43 & 39 & 70 & & 40 & 58 & & $\begin{array}{l}3 \\
39\end{array}$ & $\begin{array}{l}30 \\
3\end{array}$ \\
\hline & $\begin{array}{l}36 \\
36\end{array}$ & $\begin{array}{l}68 \\
76\end{array}$ & & $\begin{array}{l}40 \\
41\end{array}$ & $\begin{array}{l}77 \\
85\end{array}$ & & $\begin{array}{l}41 \\
42\end{array}$ & $\begin{array}{l}65 \\
72\end{array}$ & & 40 & 42 \\
\hline & 38 & 84 & & 42 & 92 & & 43 & 79 & & 41 & 48 \\
\hline & 39 & 92 & & & & & 44 & 85 & & 42 & 54 \\
\hline \multirow{9}{*}{41} & & & & 34 & 29 & & 40 & 90 & & 44 & 67 \\
\hline & 32 & 31 & & 35 & 36 & & & & & 45 & 73 \\
\hline & 33 & 38 & & 36 & 43 & \multirow{10}{*}{47} & & 28 & & 46 & 80 \\
\hline & 34 & 46 & & 37 & 49 & & 37 & 34 & & 47 & 86 \\
\hline & $\begin{array}{l}35 \\
35\end{array}$ & $\begin{array}{l}53 \\
60\end{array}$ & 44 & $\begin{array}{l}38 \\
39\end{array}$ & $\begin{array}{l}56 \\
63\end{array}$ & & 38 & 40 & & & \\
\hline & $\begin{array}{r}50 \\
37\end{array}$ & $\begin{array}{l}00 \\
68\end{array}$ & & $\begin{array}{l}39 \\
40\end{array}$ & 70 & & $\begin{array}{l}39 \\
40\end{array}$ & $\begin{array}{l}46 \\
59\end{array}$ & & & \\
\hline & 38 & 76 & & 41 & 78 & & $\begin{array}{l}40 \\
41\end{array}$ & $\begin{array}{l}52 \\
59\end{array}$ & & $\begin{array}{l}39 \\
40\end{array}$ & 32 \\
\hline & 39 & 84 & & 42 & 85 & & $\begin{array}{l}41 \\
42\end{array}$ & 66 & & $\begin{array}{l}40 \\
40\end{array}$ & $\begin{array}{l}37 \\
43\end{array}$ \\
\hline & 40 & 92 & & 43 & 92 & & 43 & 72 & & $\begin{array}{l}1 \\
4\end{array}$ & $\begin{array}{l}40 \\
40\end{array}$ \\
\hline \multirow{9}{*}{42} & 33 & 33 & & 35 & 31 & & -45 & 86 & 50 & 44 & 61 \\
\hline & 34 & 40 & & 36 & 37 & & 46 & 93 & & 45 & 67 \\
\hline & 35 & 47 & & 37 & 44 & & & & & 46 & 74 \\
\hline & 36 & 54 & & 38 & 50 & \multirow{9}{*}{48} & & & & 47 & 80 \\
\hline & 37 & 61 & & 39 & 57 & & 37 & 29 & & 48 & 87 \\
\hline & 38 & 69 & 45 & 40 & 64 & & 38 & 35 & & 49 & 93 \\
\hline & 39 & 77 & & 41 & 71 & & 39 & 41 & & & \\
\hline & 40 & 84 & & 42 & 78 & & 40 & 47 & & & \\
\hline & 41 & 92 & & 43 & 85 & & 41 & $\begin{array}{l}53 \\
60\end{array}$ & & $\begin{array}{l}40 \\
41\end{array}$ & $\begin{array}{l}33 \\
39\end{array}$ \\
\hline \multirow{3}{*}{43} & 33 & 28 & & & & & 44 & 73 & 51 & 43 & 50 \\
\hline & 34 & 34 & & 35 & 26 & & 45 & 79 & & 44 & 56 \\
\hline & 35 & 41 & 46 & 36 & 32 & & 46 & 86 & & 45 & 62 \\
\hline
\end{tabular}


Curing and Shipping the CheEse.

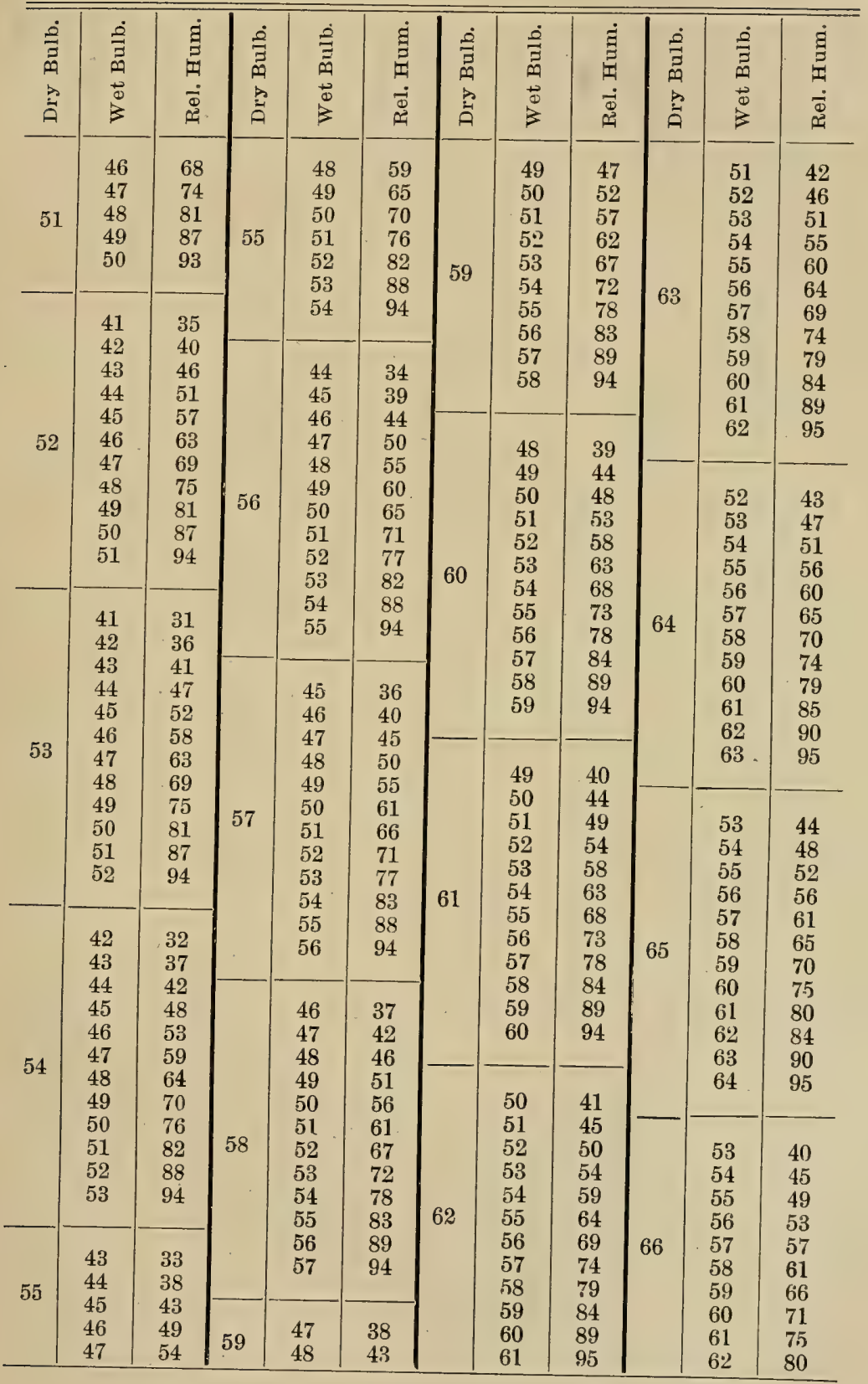




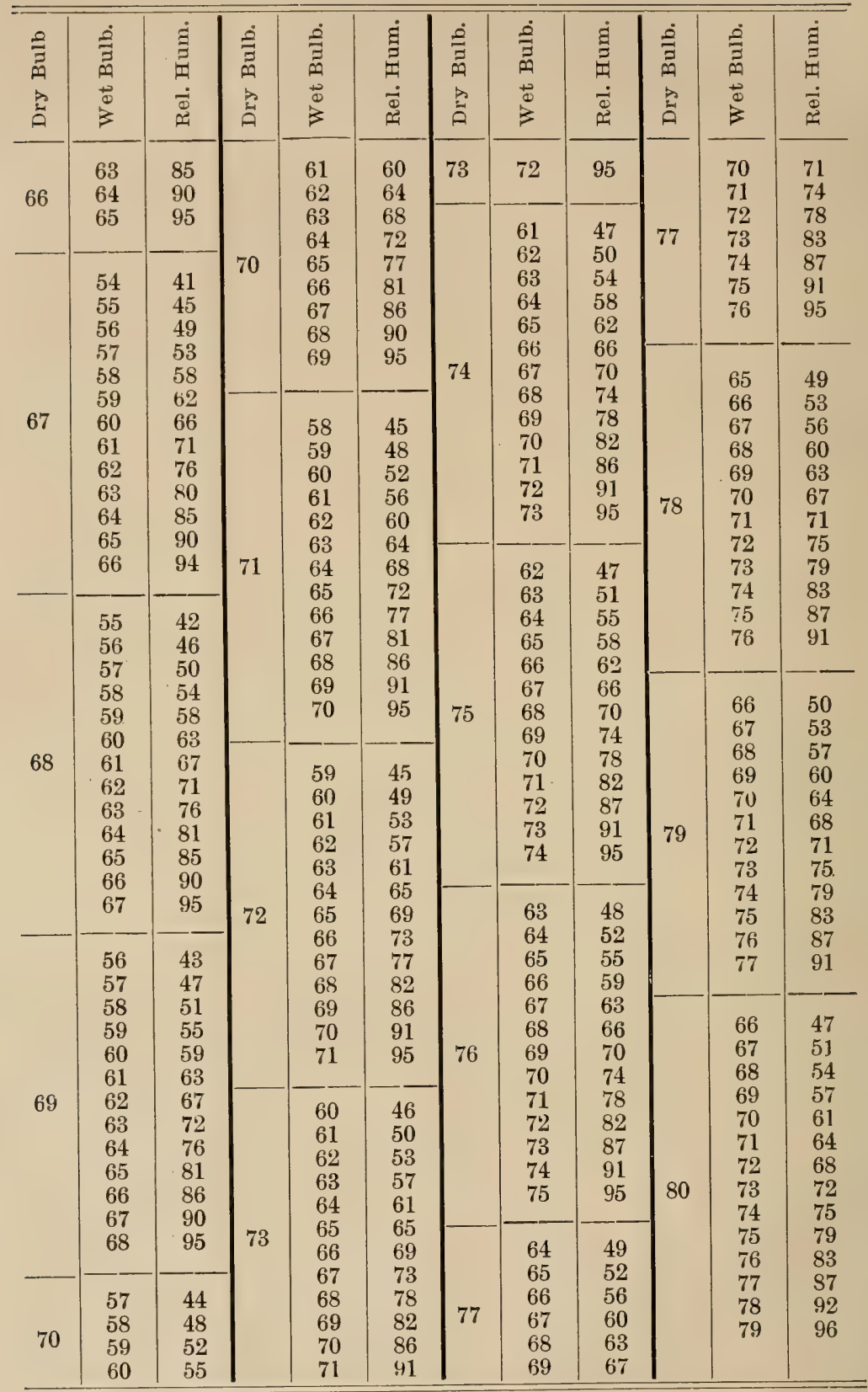


200. Condition of the Curing Room Air.

The air should have as much moisture as it will hold without molding the cheese. Cheese will stand a good deal if the air is kept moving, perhaps as high as ninety per cent. If kept between sixty and seventy per cent it is very fair, but the

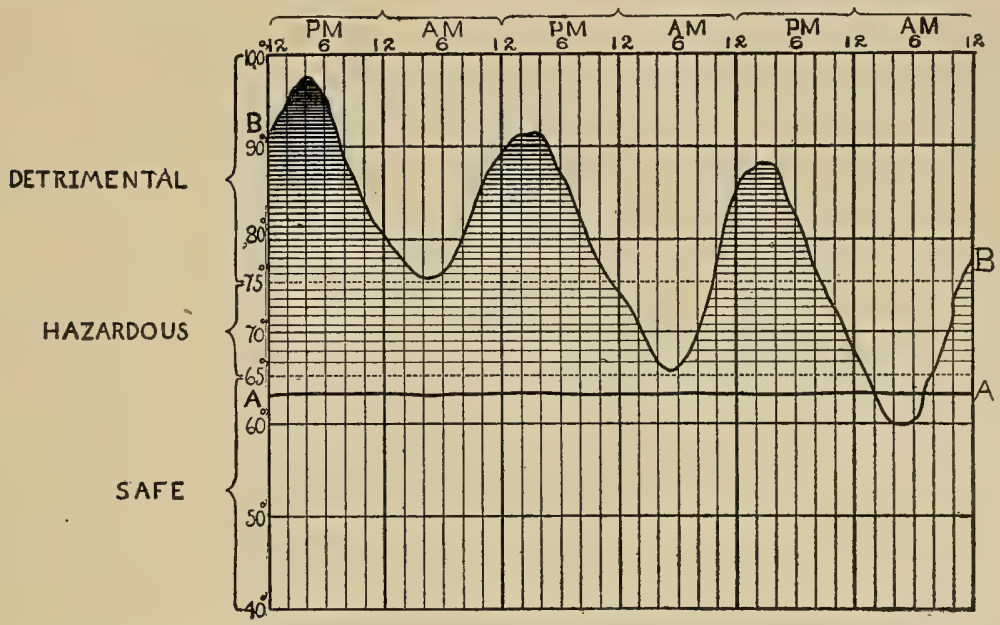

Fig. 51.-Recorded temperature in an ordinary cheese curing room (curve $\mathrm{B})$, and the same in a cellar cheese curing room (curve A).

instruments show that the relative humidity in American curing rooms often gets down to twenty or thirty per cent and the cheese then will dry out rapidly and crack.

\section{I. Supplying Moisture.}

Moisture can be supplied by sprinkling the floor, or better still, by hanging up wet sheets that are constantly supplied with water.

To supply a curing room of five thousand cubic feet capacity, at least three cloths thirty inches wide by twelve feet long are needed. These cloths cannot be supplied from a tank by means of wicks, but if there is plenty of running water a pipe with fine holes drilled on the upper side might be arranged on which to hang the cloths; water run through the pipe will keep the cloths saturated. A gutter should be arranged at the bottom to carry off the surplus water. 
After a while the cloths will get stiff from the sediment in the water. They should then be boiled in water to which a little hydrochloric acid has been added. Do not use enough acid to injure the cloth.

\section{Shrinkage in Curing.}

The loss of weight in euring is due to the evaporation of the water of the cheese and to chemical changes. The factors affecting the rate of loss in curing are:

1. The temperature of the euring room.

2. The relative humidity of the air of the curing room.

3. The size and the form of the cheese.

4. The moisture content of the cheese.

5. The protection to the surface of the cheese.

The following table shows the effect of both the size of cheese and the temperature of the room on the shrinkage:*

PER CENT OF LOSS IN TWENTY WEEKS.

\begin{tabular}{c|c|c|c}
\hline $\begin{array}{c}\text { Weight of } \\
\text { Oheese. }\end{array}$ & \multicolumn{2}{|c|}{ Temperature of Ouring Rooms. } \\
\cline { 2 - 3 } & 40 degrees. & 50 degrees. & 60 degrees. \\
\cline { 2 - 4 } $70 \mathrm{lbs}$. & 2.5 & 2.4 & 4.2 \\
$45 \mathrm{lbs}$. & 2.7 & 3.7 & 5.1 \\
$35 \mathrm{lbs}$. & 3.9 & 5.9 & 8.5 \\
$121 / 2 \mathrm{lbs}$. & 4.6 & 8.1 & 12.0 \\
\hline
\end{tabular}

The low-temperature cheese was better in texture and milder in flavor than the cheese cured at higher temperatures and the low temperatures therefore returned more money, as shown in the following table:

SHRINKAGE IN TWENTY WEEKS.

\begin{tabular}{l|c|c|c}
\hline Temperature & $\begin{array}{c}\text { Per cent. of } \\
\text { Shrinkage. }\end{array}$ & $\begin{array}{c}\text { Scores of } \\
\text { Oheese. }\end{array}$ & $\begin{array}{c}\text { Value of 100 } \\
\text { pounds at 10c } \\
\text { per pound. }\end{array}$ \\
40 degrees. & 3.8 & 95.7 & $\$ 9.62$ \\
50 degrees. & 4.8 & 94.2 & 9.52 \\
60 degrees. & 7.8 & 91.7 & 9.22
\end{tabular}

At the end of twenty weeks the cheese cured at $40^{\circ} \mathrm{F}$. was worth $221 / 2$ cents more per 100 pounds than that cured at $50^{\circ} \mathrm{F}$., and 60 cents more than that cured at $60^{\circ} \mathrm{F}$.

*Bulletin 234 of the Geneva Experiment Station. 


\section{Central Curing Rooms.}

Central curing rooms appear to te the most economical method of handling cheese. A small building containing the machinery for making cheese can be erected at little expense. Once or twice a week the cheese from a number of such makerooms can be transferred to the central euring room which can

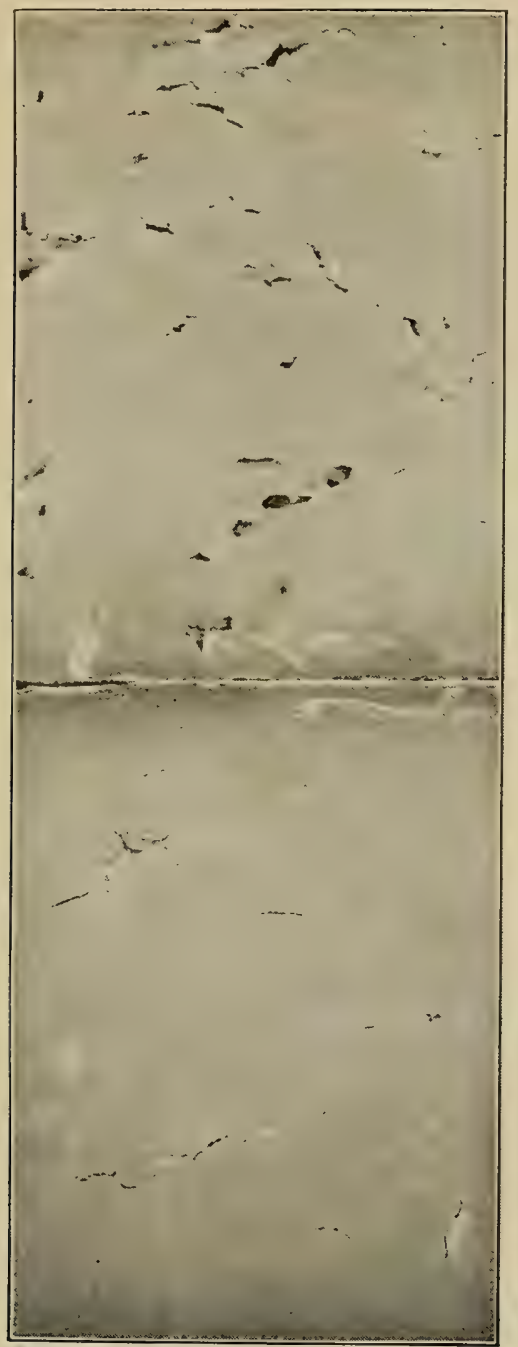

Fig. 52.-Texture of cold-cured cheese; upper cheese cured at $60^{\circ} \mathrm{F}$., lower at $40^{\circ} \mathrm{F}$. 
be a large building-very likely cooled by artificial refrigeration. This arrangement will reduce the labor at the factories very materially and an expert ean give his attention to the curing of the cheese.

The quality of cheese is not only enhanced at low temperatures, but the life of usefulness of the cheese is greatly extended.

Combining the improved quality and increased quantity of the cheese cured at $40^{\circ}$ for twenty weeks over that cured at $60^{\circ}$

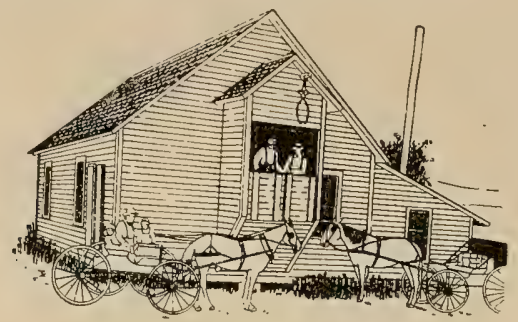

Fig. 53.-Cheese Factory at Chimney Rock, Wis. The cheese is not cured at the factory, but is shipped twice a week to a central curing room at La Crosse.

for the same length of time, the saving will, according to Dr. Van Slyke, be $\$ 1.08$ per 100 pounds of cheese. For a factory receiving 5,000 pounds of milk per day this would mean $\$ 5.40$

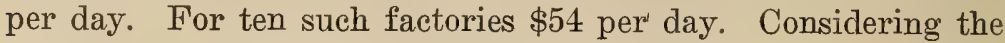
decreased cost of handling at the make-rooms and the smaller cost of one good curing building in the place of ten, it is quite evident that the central curing room makes it possible to cure cheese in the most economical manner.

\section{Cold Curing of Cheese.}

During late years the method of cold-curing Cheddar cheese has been adopted quite generally by large manufacturers and wholesale cheese dealers. The cheese are kept at the factory for a week or ten days, and then brought to the cold-storage ware-house, where they are parafined (see below), and kept in cold-storage at below $40^{\circ}$ for 2 months or more, according to the conditions of the market and the locality where they are to be sold. On account of the improved quality and the minimum losses through shrinkage in the case of cheese thus eured, this method is likely to beenme of greater importance as our cheese 
industry is developed and central curing rooms are becoming still more general than they are at the present time.

\section{Paraffining Cheese.}

The evaporation of moisture from the cheese can be prevented by applying a coat of paraffine which is practically impervious to moisture. If applied at a temperature of at least $200^{\circ} \mathrm{F}$. the cheese will remain bright, as the mold spores are killed at that temperature and the paraffine adheres firmly to

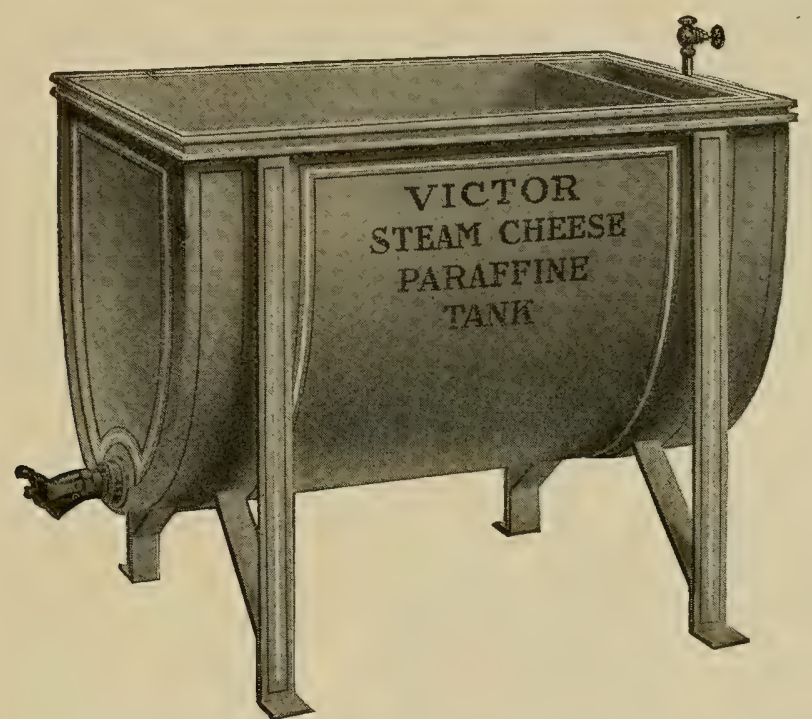

Fig. 54.-Tank used for paraffining Cheddar cheese in factories. The steam is admitted into the jacket around the tank and keeps the paraffine at the proper temperature. By means of such a tank and a pair of dipping tongs cheese can be paraffined easily and rapidly.

the surface of the cheese. Applied hot, less paraffine is necessary, thus reducing the expense of coating. About $4 \mathrm{oz}$. of paraffine will adhere to an 80-pound cheese if the paraffining is done at $210-220^{\circ}$ F. Semi-refined wax of a melting point below $116^{\circ} \mathrm{F}$. should be used.**

The vat in which the paraffine is melted is similar to a cheese vat but much smaller. A partition three inches from

*Report 1906, Dairy Commissioner of Canada, p. 14, where a convenient form of apparatus used at Canadian curing rooms for waxing cheese is shown. See also Mich. Sta. Special Bull. 21, Farmers' Bull. 190, and Melick, Dairy Laboratory Guide, p. 66. 
one end does not reach quite to the bottom; the large cakes of paraffine are slipped behind this when placed in the vat. The paraffine is colored a light yellow with a little cheese or butter color. A frame for holding the cheese hangs above the vat and is counterbalanced by a weight hanging over pulleys. The cheese is placed in the frame over the vat and then immersed 10 to 20 seconds in the hot paraffine. Then it is allowed to hang for a few minutes to harden sufficiently to handle.

Dr. Van Slyke makes the following statement regarding paraffine in Bulletin 234 of the Geneva Experiment Station:

"At the end of seventeen weeks, cheese covered with paraffine had lost only .3 pound for 100 pounds of cheese placed in storage at $40^{\circ} \mathrm{F}$., .5 pound at $50^{\circ} \mathrm{F}$., and 1.4 pounds at $60^{\circ} \mathrm{F}$. The saving thus effected, based on the uniform price of cheese at 10 cents per pound, would average about 35 cents for 100 pounds of cheese cured at $40^{\circ} \mathrm{F}$., 43 cents at $50^{\circ} \mathrm{F}$., and 64 cents at $60^{\circ} \mathrm{F}$; or comparing cheese kept at $40^{\circ} \mathrm{F}$. covered with paraffine, with cheese cured at $60^{\circ} \mathrm{F}$. not so covered, there would be a difference of 75 cents a hundred in favor of the paraffined cheese."

The objection has been made that by paraffining cheese water is being sold for cheese, which is a fraud. The objection is answered by saying that it is retaining not an excess of moisture but the moisture that ought to be kept in the cheese. The English trade has objected to coated cheese and Canadian makers are conservative about adopting the method. Some factories have adopted the method of coating green cheese fresh from the hoop. Some Wisconsin dealers have had trouble with some such cheese turning sour and going off flavor. Cheese should not be paraffined before about 2 weeks old. Most wholesale houses are paraffining all cheese received, but this is usually two or three weeks old. The cheese-maker should be careful not to paraffine green or soft cheese.

\section{Cheese, How Boxed.}

Young Americas are shipped four, Cheddars one, and flats generally two, in a box. 
Where flats are shipped two in a box they are placed one on top of the other, and are in that case termed "twins." When shipped one in a box they are called "singles."

\section{Scale Boards.}

That the rinds of the cheese may be well protected "scale boards," or very thin basswood or whitewood boards, are placed in the box. Two or three are placed on each end of the box, and two or three between twins. This number is more than is generally used, but cheese in this way keep better when placed in cold storage. If flats are put together without scale boards, and left for any great length of time, they will stick together so tight that they can only be pulled apart with difficulty. The rinds sweat and are easily broken. They therefore need plenty of scale boards. The boxes should be trimmed to one-eighth of an inch less than the height of the cheese, so that it will hold its place and arrive in the market in good condition. They should not be more than al quarter of an inch larger in diameter than the cheese; if there is too much room in the box the cheese will be likely to shift around and break the box. On the other hand, the box should not be so tight that the cheese will stick in it.

Boxes that are split or poorly nailed should be rejected, as they will be sure to arrive in the market in a dilapidated condition. Cheese makers do not realize that boxes that may be in fair condition when filled may be entirely useless at the end of the journey.

When the cheese is hauled to the depot the boxes should be covered with blankets to protect it from dust and the hot sun.

\section{How Cheese are Weighed.}

In weighing cheese nothing but full pounds are counted. For instance, if the weight is $603 / 4$ pounds, it is recorded as 60 , or if the beam barely rises at 61 pounds, it is recorded as 60 pounds, as it would likely lose weight in transportation and be cut in weight when in the hands of the buyer. In the large warehouses, where hundreds of boxes arrive in a single day, they cannot stop to weigh every box, but weigh a few boxes, and if the weight falls short the whole lot is docked accordingly. Such weighings are referred to an official weighmaster. 


\section{Marking of Weights.}

The weight should be stenciled, or plainly marked, on the box (not the cover) next to the seam, where it can readily be found. A lead pencil hardly makes a sufficiently plain mark on a cheese box. The brand of the firm to whom the cheese is shipped should be stenciled on the side of the box.

\section{2ro. Buyer's Stencil.}

The buyer generally furnishes a stencil for marking the boxes. Each stencil, so issued to a shipper, has a distinguishing number, which is recorded in the buyer's office, and by referring to the number the latter will know who shipped the cheese. This is especially necessary where several factories make up a carload of cheese for one firm.

If a cheese-maker has any cheese that is not first-class he should put a distinguishing mark on them and notify the buyer, who will usually deal fairly with him, when he understands that the maker is not trying to take advantage of him.

\section{II. How to Sell Cheese.}

Cheese is sold mostly on the dairy boards of trade. The buyer, after he bargains for the cheese, should be required to inspect the cheese at the factory and accept or reject it. He should then give a draft on a local bank for the amount due. The bank draws on the firm for this amount, at the place of business of the firm, and the cheese belongs to the bank till the draft is honored. This is a strictly eash basis, and is fair to both partics.

\section{QUESTIONS ON CHAPTER X.}

1. What is the curing process in cheese? 2. At what temperature should cheese be cured? 3. What has been learned by experiments in curing cheese from the same lot of milk at different temperatures? 4. How should the curing shelves be made? 5. How should the cheese be arranged on the shelves? 6. What two instruments are used for measuring the humidity of the atmosphere, and what can be said as to their accuracy? 7 . What precautions should be taken in reading the psychrometer? 8 . What is meant by relative humidity, or per cent of saturation? 9. What should be the relative humidity of the curing room? 
10. How may moisture be supplied to a room artificially? 11. How much cloth surface is required for a room containing five thousand cubic feet of space? 12. How should cheese be boxed? 13. What five factors affect shrinkage in euring? 14. What are the advantages of central curing rooms? 16 . What is the purpose of paraffining cheese? 17. At what temperature should paraffine be applied? 18. How does the shrinkage between paraffined and unparaffined cheese compare? 19. What are the objections to paraffining? 20. What are scale boards and how should they be used? 21. How should cheese be weighed? 22. How and where should the weights be marked on the box? 


\section{CHAPTER XI. \\ JUDGING CHEESE.}

\section{2r2. Ideal Cheese.}

One trouble which cheese-makers meet with is that they do not have the proper idea of a perfect cheese in their minds. This arises largely from the circumstances under which they are placed. The cheese are shipped out of the factory as soon as the buyer will take them, the youngest being but a week or ten days old. The cheese may have defects, but the maker does not get a chance to see how it will turn out.

The requirements of a certain market with regard to a perfect cheese are embodied in a "Cheese Score," which shows the number of points on a scale of 100 , given to the various qualities of the ideal cheese, as flavor, texture, color, etc.

\section{2r3. Scale for Scoring Cheese.}

The scale of points now generally used in scoring cheese at dairymen's conventions and dairy shows in this country is as follows :

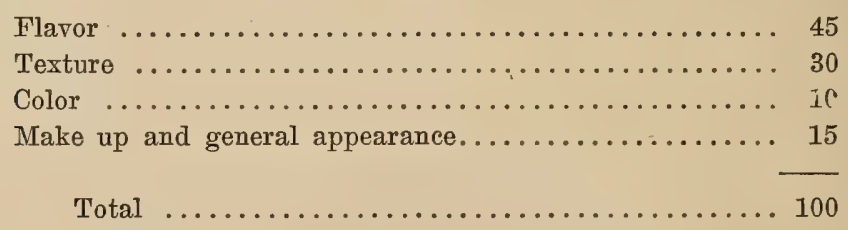

In this scale salt is judged with flavor and texture where it belongs, while the very important item of the neat way in which the cheese is put up gets proper consideration. In the score formerly used, flavor was given 50 points, texture 30 , and salt and color 10 points each. Under this score a dirty, poorly bandaged, crooked cheese might get as high a score as a neat square one. 
Prof. Dean suggests the following scale of points for judging Canadian cheese:* Flavor 40, texture 20, closeness 15, even color 15, and salt 10, total 100 .

The English scale of points for scoring cheese is also given here:

Flavor, 35; quality, 25; texture, 15; color, 15; make, 10; total 100.

In this scale quality, which means that the cheese should be mellow, rich, melting on the tongue, applies to an old, wellcured cheese. The cheese that goes on the market in this country does not have this quality.

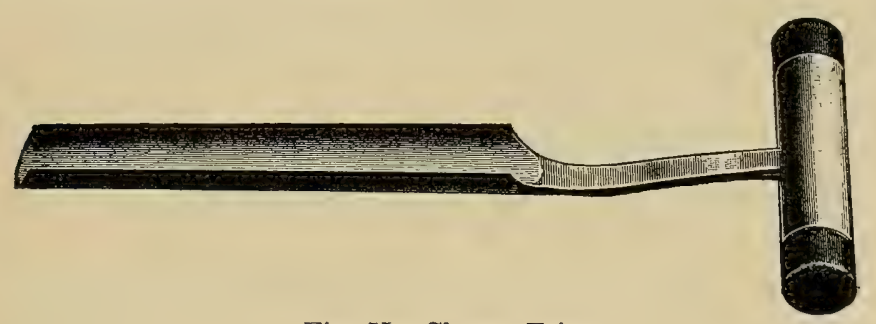

Fig. 55.-Cheese Trier.

In scoring a cheese, this is sampled (tried) by means of a cheese trier, and the plug thus obtained carefully examined. The trier should be thin, round and a little tapering, so that it will pull a round smooth plug. A plug should always be taken from the top of the cheese. Never plug it through the bandage. When the plug has been replaced in the cheese, the place should be greased over, to keep the cheese from drying out, and skippers from getting into the same.

We shall now discuss the various qualities of Cheddar cheese, as expressed by the score given above.

\section{Flavor.}

Flavor is the most important item in the quality of a cheese. No matter how gocd the other points may be, if the flavor is bad, the cheese will be condemned. It would be a difficult matter to describe accurately just what the flavor should be like, for there are different flavors in cheese, which may be equally good. This comes about from the different ferments in the

* Canadian Dairying, p. 178; see also Canadian government score, Appendix, p. 207. 
cheese which we cannot as yet entirely control. Bacteriological research may overcome this difficulty in the near future.

The old saying that "the proof of the pudding is in the eating of it," is true of cheese. If the cheese tastes good and we want more of it, the flavor is satisfactory. It should not be sharp enough to bite the tongue, but of a mild lasting taste. A great many cheese, in which the flavor cannot be termed bad, are still on the negative side; they do not have that fine lasting aroma, although we can eat them quite agreeably, but we do not feel that it is a matter of very great importance, whether we can have more of the same cheese or not.

Where experts are judging cheese, they seldom taste it. They get the flavor simply by the smell, for if they tasted of every plug they would soon be confused as to flavors.

If a cheese is cold, it should first be warmed in the fingers, before judging the flavor.

\section{Texture.}

While flavor stands first in importance, the texture of a cheese comes next. The plug should be smooth, nut fuzzy. If the cheese is not fully cured the plug should bend a little before breaking. When held between the eye and the light it should be slightly translucent. If the light does not come through, it is a sign that the texture has been injured in the manufacture, probably by too high acid. When a piece is broken from the plug, it should not crumble off, but should show a surface such as flint does when broken; this texture is therefore termed a "flinty break." When pressed between the fingers it should not stick to them but should mold like wax. Cheese that is tough and will not mold down readily between the fingers, is said to be "corky," this is probably due to over-cooking or use of an insufficient quantity of rennet to cure it properly. Cheese should not be mealy, as is the case with high acid or too highly salted cheese.

A Cheddar cheese with good texture should not have any round, smooth or ragged holes in it; but should be perfectly solid. (See Fig. 52.)

Cheese with the round holes, or one that is soft and pasty, will go "off flavor" on further keeping. 


\section{Salt.}

As was said under the subject of salting the curd, salt gives flavor to a cheese. In fact, the entire flavor is affected by the salt. Cheese that are a little soft and somewhat inferior in flavor could te improved by using a little more salt. It has also been stated that a free use of salt may injure both the texture and flavor of the cheese. The influence of salt is, therefore, partly considered under texture and flavor.

\section{2r7. Color.}

The color of a cheese, like salt, is another way of judging its texture and flavor. A cheese without any coloring matter added to it is improperly termed "white." An uncolored cheese should never be white, but of a light amber color. If it is a dead white, it is so because the acid has cut the color out of it. In a colored cheese, these defects will be more easily seen.

The color should be even from one end of the plug to the other. A high acid cheese will give a distinct odor to the trier, the same as when acid attacks steel.

In judging cheese, unless some particular market is in view, the shade of color cannot be taken into consideration. As already stated, New Orleans requires a very high color, St. Louis less, Chicago still less, while Boston in this country, and Bristol in England, want no artificial coloring. The tendency toward making uncolored cheese seems to be increasing.

\section{2r8. Gross Appearance.}

A good judge can usually form a correct opinion of quality of a cheese from its outside appearance. It should be square, and the rind without cracks, for cracks indicate high acid. When the fingers are run over the surface, it should be springy, that is, it should give readily under the pressure and regain its position. If the finger sinks into a place which does not spring back, it indicates a hole or soft place in the cheese. The rind should not have any white spots on it, as these indicate whey. Sometimes the white spots will disappear in time, but it is a weak point in the quality of the cheese.

\section{2r9. Corky Cheese.}

A corky cheese, as its name implies, has a texture resembling that of cork. It does not break down and probably will 
crumble in the fingers. There are two general causes of corky cheese, over-cook and too little rennet. In case of the latter cause the cheese will improve with age.

\section{Hard, Crumbly or Mealy Cheese.}

Too much salt will make a hard cheese that will probably be mealy. A high acid cheese will have a similar texture, but the color will be cut and the flavor affected by the acid so that the cause can be distinguished.

\section{Weak Bodied, Pasty or Cracked Cheese.}

Cheese that has too much whey left in it either by undercook or insufficient stirring when dipped, will be soft, and will not mold properly, but stick to the fingers. Such a cheese will show mottled spots on the rind. Too much piling on the racks will make a weak-bodied cheese. In extreme cases the whey will run out causing what is termed a leaky cheese. The danger of weak-bodied cheese is that they may become sour.

Cracked cheese are caused either by sour curds or by insufficient closing in the press. The latter probably comes from fat covering the particles of curd and preventing their cementing into one mass. It may also be caused by over-cook or by a draft of air blowing over a cheese and drying it out rapidly. Any cheese will be apt to crack in a dry curing room in dry hot weather.**

\section{Rusty Spots in Cheese.}

Rusty spots in cheese are caused by bacillus rudensis, first discovered by W. T. Connell in 1896 in a Canadian factory. Spots of the size of a pinhead or larger, can te seen at a distance of several feet. In bad cases the cheese is colored as highly as if annatto had been used, but unevenly distributed. It is more prevalent around gas holes and moist spots. A warm curing room hastens and a cool room retards them. They usually appear in four to eight days. If they do not appear in ten days there will be no cut in price. They do not injure the texture or flavor, but the consumer objects to the appearance of such cheese.

\footnotetext{
* Defects in American Cheddar Cheese are discussed in detail, and causes and remedies given in each case, in a special article in the Appendix (see p. 199).
} 
Red spots broke out first in 1883 in a mild form in St. Lawrence County, N. Y. In 1884 it was worse, occurring mostly in the fall months. It developed at a factory at Hailesboro in 1892 and the factory was eventually abandoned for cheesemaking. Other factories in New York and Canada have been troubled but it has not appeared in other parts of the country. Harding and Smith of the Geneva Experiment Station have carried on investigations which show that the factory is usually the main seed bed, though the bacillus is found in the milk of certain dairies.

If all of the apparatus is put into the cheese vat, then covered tightly and a jet of live steam turned on the utensi's for an hour, and this operation repeated three times a week, the trouble can be practically eliminated.

\section{Poison Cheese.}

There are occasional reports of people being poisoned by eating cheese. Fortunately these cases are quite rare, but as they are isolated it is difficult for scientists to trace the full history of the cheese. Professor Vaughan, of Michigan, some years ago carried on quite an extensive investigation of the chemical nature of such cheese and isolated a poison called tyrotoxicon. This poison causes cramps, acts as a purgative and paralyzes the lower limbs. The author's attention was called to the case of a factory in which some poison cheese had been made. The factory was kept in a neat and tidy manner so that it is not probable the poison resulted from carelessness at the factory. The maker stated, however, that every cheese containing poison had been made when the milk was held several days before making into cheese, and in no case was poison formed in the cheese when the milk was made up each day. The great majority of cases of ice cream poisoning have been traced to church socials, where the cream was gathered and held several days before freezing. This evidence would indicate that the poison is more likely, to occur when the milk is held several days before being made up. 


\section{QUESTIONS ON CHAPTER XI.}

1. What are points in judging cheese and what importance is attached to each? 2. Describe the flavor of a good cheese. 3. Deseribe a good texture. 4. How does salt affect flavor and texture. 5. Describe a good color. 6. What can be learned from the gross appearance of a cheese? 7. What are the English standards for cheese? 8. What is a corky cheese and its two principal causes? 9. What are the causes of hard, crumbly or mealy cheese? 10. What is a weak bodied or pasty cheese and how is it caused? 11. What are the causes of cheese cracking? 12. What are rusty spots in cheese and how caused? 13. How extensive has the trouble of rusty spots been? 14 . What is the method of combating rusty spots? 
CHAPTER XII.

\section{HINTS ON THE CONSTRUCTION AND OPERATION OF CHEESE FACTORIES.}

\section{Independent Factories.}

In the closing pages of Chapter $\mathrm{X}$ the advantage of the central curing room has been set forth. This will apply only where one person or firm controls a large territory ${ }^{n} r$ where factories combine to sell their products. The problem of successfully operating the single factory still remains; in this chapter the construction and operation of such independent factories will be discussed.

We will assume that the factory is to be equipped for handling ten thousand pounds of milk a day, which is small enough.

\section{Good Foundations.}

In the first place there should be good solid foundations of stone piers, which allows the ground to heave and settle, without raising or lowering the building. The supports should be close enough together to hold the sills in place.

\section{Dimensions.}

The plans may call for a making-room 20x30 feet, with an office ten feet square taken out of one corner of it, a boiler room $10 \times 16$ feet attached, and a curing house 20x40 feet, two stories high.

\section{Store Room.}

The upper story should never be used for curing cheese, but for storing cheese boxes and other supplies.

\section{Curing Room.}

Some Canadian factories have the euring rooms in a building separated from the rest of the factory, but they can be built together and the lumber and material thus saved which would be needed for a second wall if they were separated. 


\section{Sills.}

We should have $8 \times 12$-inch sills around the outside of the building. There should be two $6 \times 8$-inch stringers, running across the make-room, and one of the same dimensions running through the middle of the long way of the curing room. Tenfoot joists can be put between the sills and stringers. The dimensions of these joists should be $2 \times 10$ inches, and they ean be placed eighteen inches apart.

\section{Curing Room Floor.}

The joists under the euring room should have rough boards nailed close together on the under side, and a five-inch layer of tanbark put in between them. There will then be a five-inch

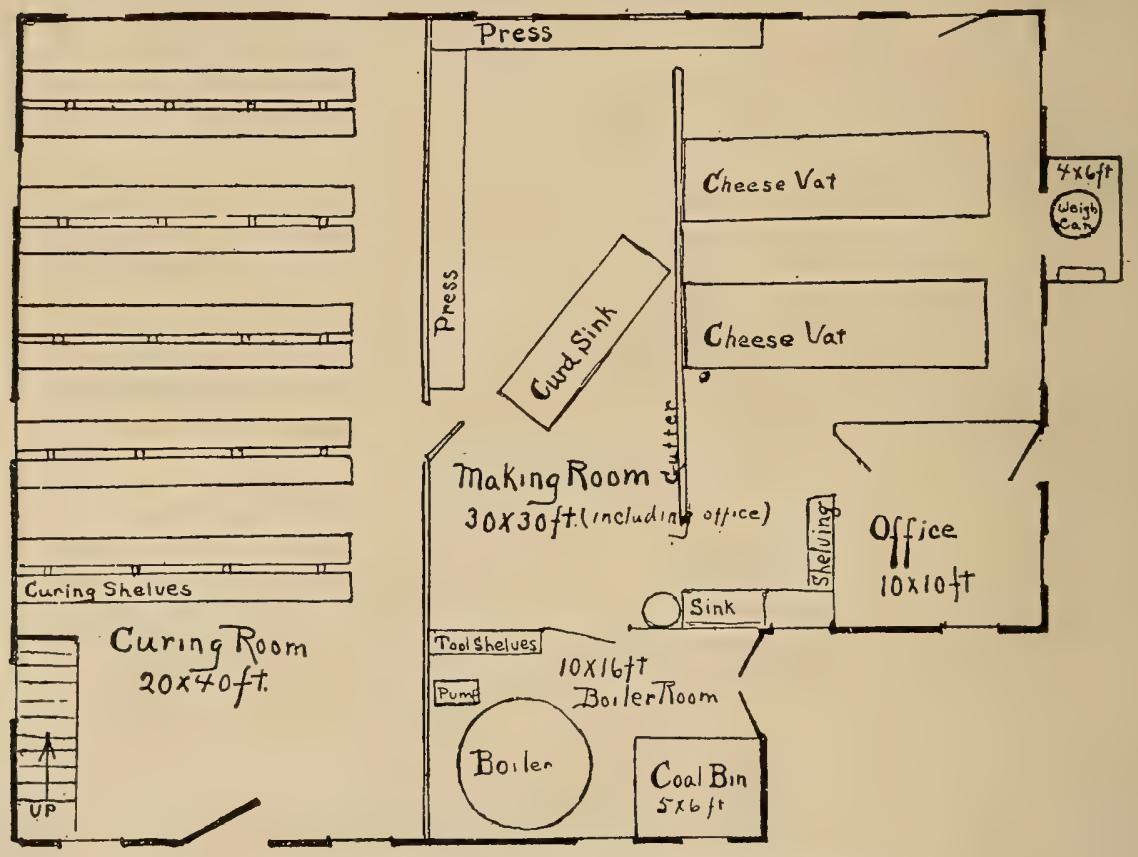

Fig. 56.-Plan of a Cheddar cheese factory.

space left above the tanbark, over which a tight, heavy floor is to be laid. This may be made, by first laying rough boards, and covering with paper, and then laying the regular flooring. The tanbark, air space and tight floor are a protection against the outside temperature. 
Construction and Operation of Cheese Factories. 119

\section{Vat Room Floor.}

The making room should have a heavy two-inch floor, preferably of maple. It must slope at the rate of one inch in five feet, toward a ditch at the lower end of the vats or twenty feet from the front end of the room.

\section{Curing Room Walls.}

Paper can be put on the studding under the siding, and the walls lathed and plastered. The studding is of $2 \times 4$, such as is generally used, and if tanbark can be easily obtained, it can be filled in between the studding. Tanbark is better than sawdust for filling in such places, as mice are not inclined to work in it. It is hardly necessary to say, that the top of the room should either be ceiled or plastered.

The curing room must practically be a large box, with walls so constructed that the temperature inside will be affected as little as possible by the outside temperature; some means of introducing cool, fresh air into the curing room is highly desirable.

The walls and ceilings will therefore have to be of several thicknesses, with air spaces between, like the floor which we have already described.

\section{Door and Windows.}

We must not forget, after we have built such walls, to have the windows fit tightly and have shutters on the outside. The doors must be heavy, with air spaces in them, and close tightly with a lever latch like a refrigerator door.

To construct our walls, we may put the $2 \times 4$ studding two feet apart, which is to be lathed and plastered inside. On the outside, rough boards and paper may be put, and then another row of studding, and paper nailed on with boarcls on the outside of these. In the spaces in the outer row of studding, tanbark may be filled in.

\section{Joists.}

The joists in the ceiling should be $2 \times 6$, ten feet long, eighteen inches apart, supported by $4 \times 6$ running crosswise of the room. If the rorm is ceiled overhead, tanbark three inches. deep can be filled in between the joists, and then a layer of paper put down before the floor is laid. If the room is lathed 
and plastered, boards must be put in to hold the tanbark. 'The second story, which is used only as a store room, need not have double walls. A tight-fitting trap door should be made between the store room above and the curing room below, through which to get the cheese boxes down.

\section{Stone Cellar.}

A better wall for the curing room in the first story nitay be made of stone, and built into the side of a hill, for still greater protection from outside temperatures, as in the case with cellars for curing of brick and Swiss cheese. The stone and earth help to keep down the temperature of the air in the room.

\section{Curing Cellars.}

In some places cellars made for curing brick cheese have been used with splendid results for Cheddar cheese. Such o cellar is built into the side of a hill, it is stoned up on the sides and rises above the ground just far enough for small windows around the top. One trouble with these cellars is that they are sometimes so damp that cheese molds rapidly.

\section{Ventilation of Cellar.}

Dampness in the cellar can be obviated by ventilation. At each end of the room is an eight-inch pipe running up through the roof. One of these has a cone above it to prevent the rain coming in through it. On the top of the other is a hood with a tail that keeps the hood always facing toward the wind, and the wind striking into the hood carries a current of air down into the room, while another current of air goes out of the other pipe. Dampers similar to those put into stovepipes ean be arranged in these pipes to regulate the flow of air. If the air should get too dry, moisture can be supplied by means of wet sheets. I have seen such curing cellars where the inside temperature did not go above sixty-five degrees, while that outside was eighty-five to ninety. We would have to change the plans of the factory here given for such a curing cellar.

\section{Sub-Earth Ducts.}

In the first edition of "Cheddar Cheese Making," published in 1893, the use of sub-earth ducts for cooling curing rooms was advocated. Since then the system has been put into use and is very successful. As one descends into the ground the effect 
of the sun's heat is left behind. Lower down the internal heat is felt, but in a zone said to be between twenty and eighty feet below the surface there is a constant temperature of $48^{\circ}$ to $50^{\circ}$, or possibly colder. This is indicated by the temperature of the spring and well water that comes to the surface. By conducting air down into the ground and then through a system of tubes ten or twelve feet below the surface for a hundred feet or more, the air can be carried into the curing room at a temperature of not over $60^{\circ} \mathrm{F}$. If the curing room is well insulated the air cannot get in at any other place and will be cool. The air is forced into the duct by means of a cowl, which always faces

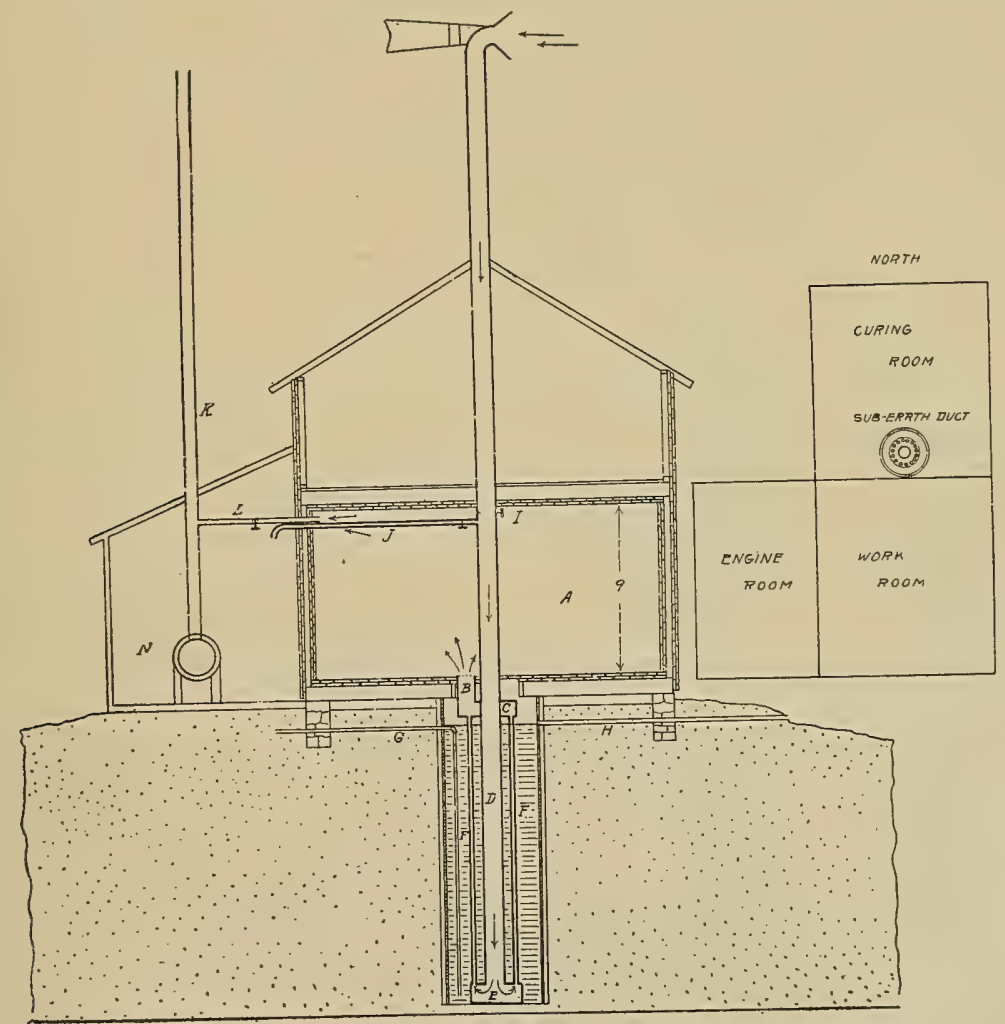

Fig. 57.-Method of cooling air with cold cold water. A, curing room: $\mathrm{B}$ duct Ieading into curing room; C, E, galvanized iron drums, air and water tight; $F$, thirteen or more 5 -inch flues of galvanized iron, $10 \mathrm{ft}$. long, soldered water tight to drums to cool air; $D$, main air duct from funnel; $G$, water pipe from pump; $H$, over-flow pipe; $I$, damper in main shaft; $J$ 4-inch pipe leading from blower to use when there is no wind; $K$, smoke stack of boiler; L, ventilator irom curing room to smoke stack; $N$, boiler. 
the wind, and the air is thereby forced down the tube into the duct. An outlet from the top of the curing room allows the warm air to escape. A curing room if built as described, would be right to use with a sub-earth duct, but double windows and doors should be put in to make the room perfectly tight. The
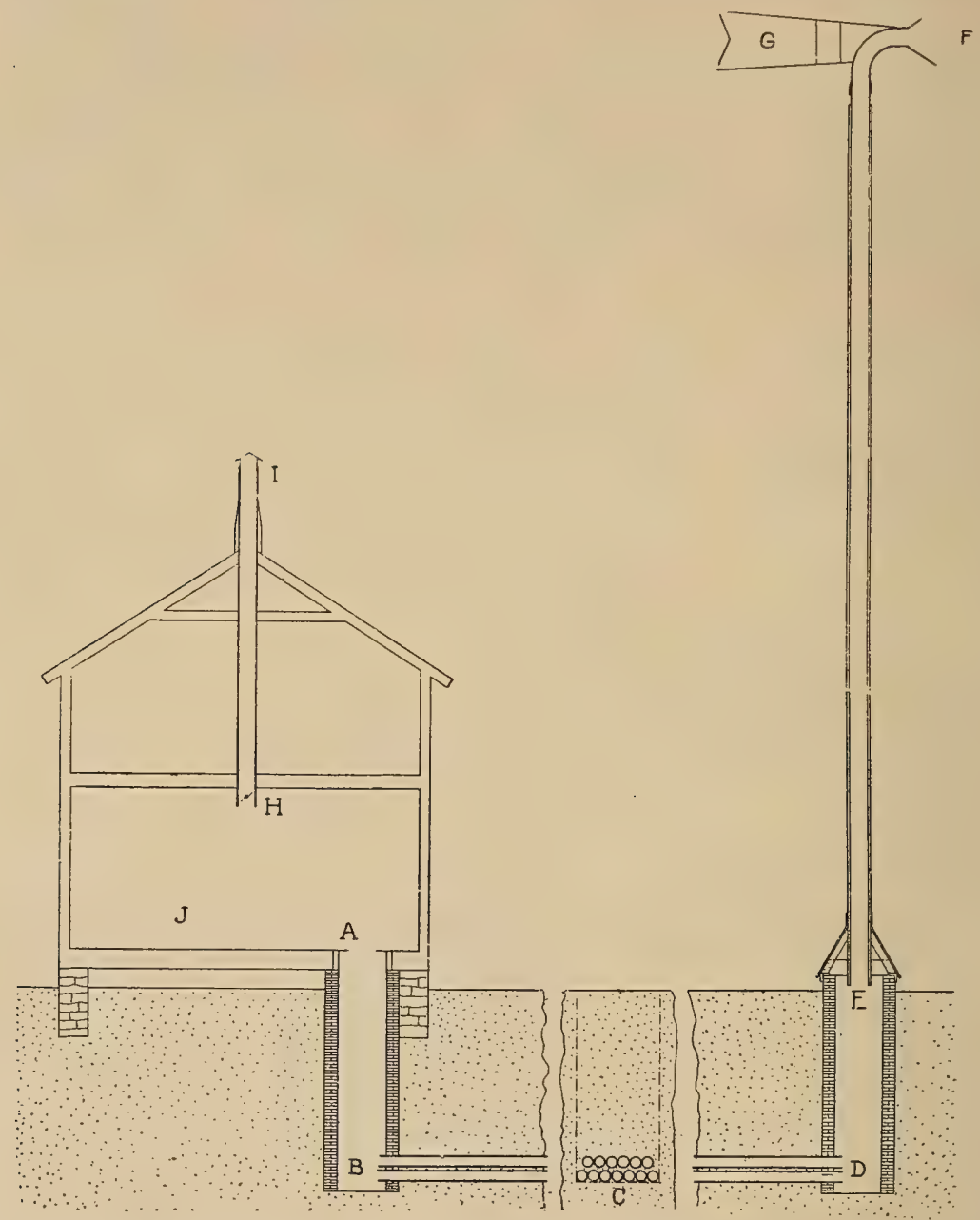

Fig. 58.- Section of cheese-curing room and horizontal multiple subearth duct. $A$, inlet to curing room; $B$, end of sub-earth duct in bricked entrance to factory; C, cross-section of the multiple ducts as placed in a factory at Neenah, Wis. D, E, bricked entrance under funnel at outer end of subj-earth duct; $F$, funnel with mouth 36 inches across; $G$, vane to hold fun-
nel to the wind. 
Construction and Operation of Cheese Factories. 123

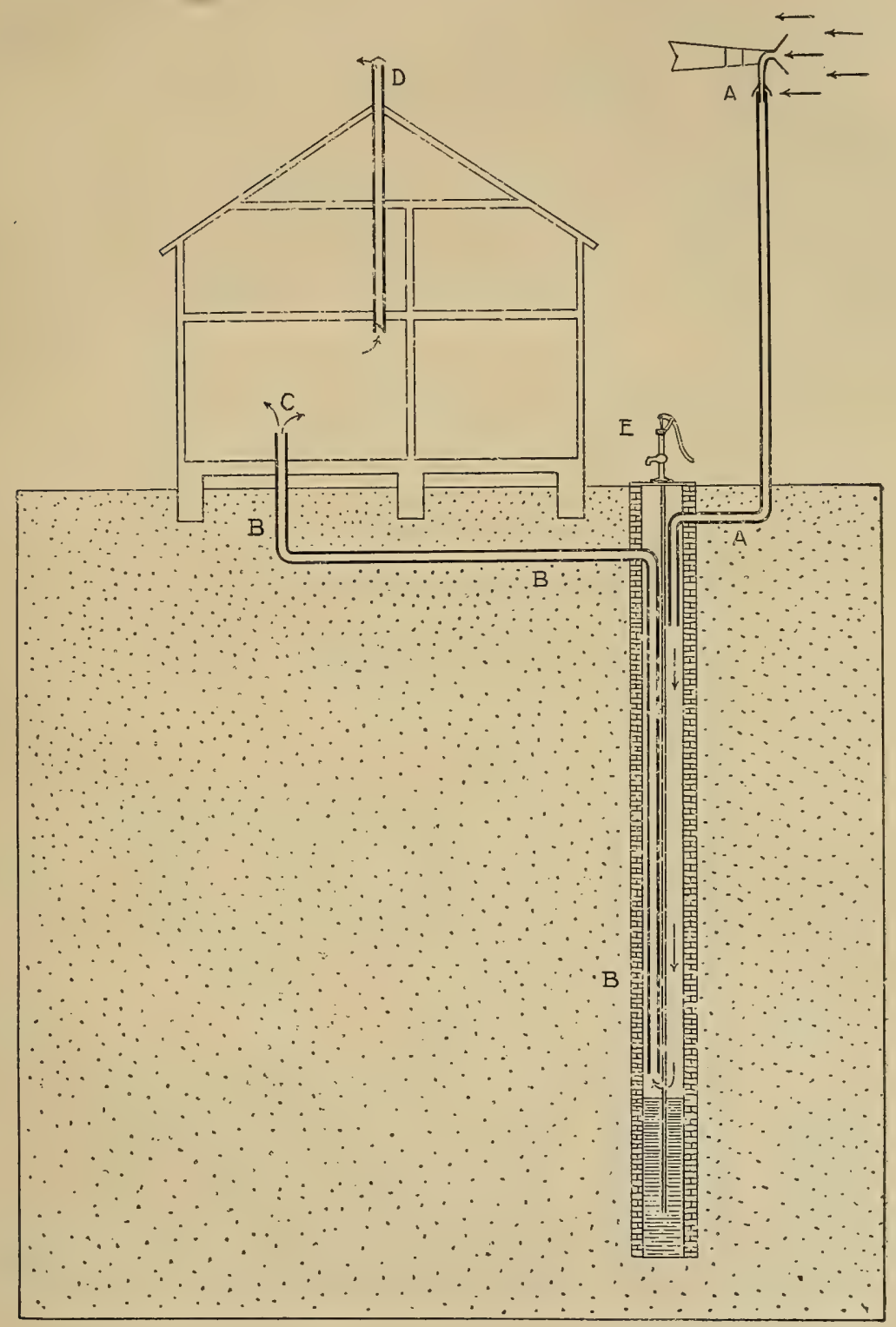

Fig. 59.-Vertical section of a cheese factory and sub-earth duct in well at Colby, Wis. A, A, funnel taking air into well; B, B, B, duct leading air from well to curing room; C, D, ventilator. 
illustrations here given of the construction of cheese curing rooms and of a ventilating duct are taken from Bulletin 70, of the Wisconsin Experiment Station, by Prof. F. H. King.

\section{Number and Size of Tiles.}

The first ducts constructed were single tubes, but they were too near the surface and therefore unsuccessful. The first successful duct was made by placing thirteen rows, one hundred feet long, of six-inch tiles eight to ten feet in the ground. These tiles were, however, somewhat small in diameter, and by friction hindered the passage of air on still days when most needed.

Professor King recommends not less than three ten-inch tiles one hundred feet long for a curing room of 5;000 cubic feet of space. Longer tubes and more of them twelve feet down would be better.

\section{Use of a Well.}

The illustration (Fig. 59) shows how a well may be used for cooling the air of a curing room. It is one of the most successful plans proposed for this purpose.

\section{4x. Water Motor Fans for Driving Air.}

The weak point in the sub-earth duct is that there may be several days of hot weather with little wind when the cowl will not work. At such a time a fan driven by water motor will circulate the air. The Triumph Dairy Co., Triumph, Ohio, has such a contrivance. A five-barrel tank of water on top of the building will run the fan most of the night. The tank is filled with water by a steam pump.

\section{Boiler Room.}

The boiler room should have a cement floor laid on the ground, and the walls and ceiling should be lined with corrugated sheet iron, to insure against fire.

\section{Building Should be Raised.}

The rest of the building should be raised about a foot above the ground, so that air may circulate beneath and keep the sills from rotting.

\section{Water Supply.}

A good well is an absolute necessity for a cheese factory. Water can be pumped into a galvanized iron eistern placed 
above the curing room. This cistern should be set in a drip pan, which will catch any leak or sweat from it, and carry it outside without leaking through into the euring room.

\section{Hot Water.}

From the cistern, water may be carried in pipes to the different parts of the building. The water pipes should be galvanized so they will not rust. A steam pipe can be connected to the water pipe by a $\mathrm{T}$, and the flowing water thus heated by turning steam into it.

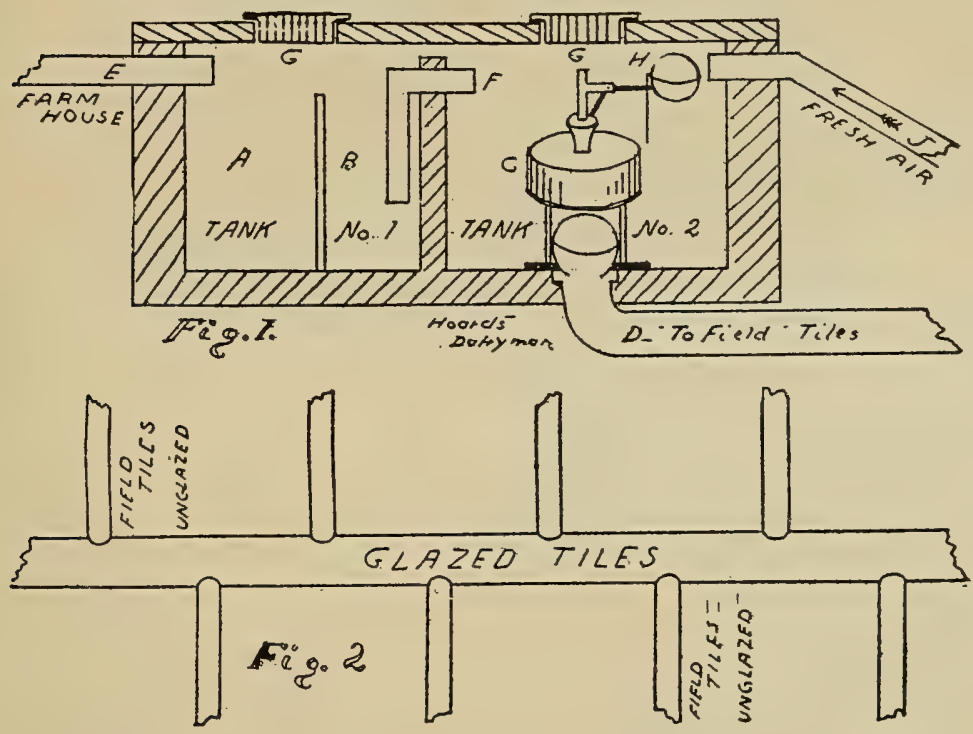

Fig. 60.-Plan for a septic tank.*

This is a cement tank 8 feet long, 4 feet wide and $21 / 2$ feet deep, with a partition reaching nearly to the top and dividing it into two sections. The top has two manholes $G$ opening into the sections. The sewage enters Section 1 through pipe $E$, into part $A$, which is separated from part $B$ by a plank partition having 1 -inch spaces between the planks, to keep solid matter in part A. Solid matter collects on the top by formation of gas. The liquids flow from the bottom through pipe $F$ into section 2. When this fills the trap valve is sprung and lets the liquid run out into the underground system of tiles. The tiles should not be more than a foot below the surface of the ground, and should be level. Their volume should be a little more than the volume of the section of the tank emptied into the tile. While the tank is filling again, the liquid soaks into the soil and bacteria near the surface decompose the organic matter.

Prof. John Michels of N. C. College of Agriculture has experimented with septic tanks and finds the tanks, without the tiles, to be sufficient to decompose creamery slops.

*Foard's Dairyman, January 1, 1904. 


\section{Septic Tank.}

Much difficulty has been experienced in getting rid of the sewage around cheese and butter factories. The blind well has been a source of contamination of the water supply, and pollution of streams has been the occasion for law suits and neighborhood quarrels.

The septic tank offers a simple, cheap and efficient means of sewage disposal. It has been presented in a number of dairy papers. (See Fig. 60.)

It is two feet deep and above ground, though it may be covered with earth. The factory must therefore be built high enough to empty the drains into the top of the tank. The system of tiles into which the tank empties should not be over one foot kelow the surface and should be perfectly level.

\section{Sewer Trap.}

At the mouth of the factory drain there should be a sewer trap, which is simply an w shaped pipe, in which water constantly stands and keeps gas from coming up from the septic tank.

\section{Whey Tank, How Built.}

The whey tank should be lined with galvanized iron, and be placed high enough for a wagon to drive under, and draw off the whey by simply opening a valve. The ground ought to be paved in such a way that the drip will run off into the sewer. A skim-milk weigher will facilitate an equal division of the whey.

\section{Elevating Whey.}

To get the whey from the vat into the whey tank, it can be drawn into a box or barrel, and from there forced by a steam jet into the whey tank. The whey should be scalded to keep it sweet, and after the patrons are gone every morning, the tank should be scrubbed out and steam turned into it to scald it. There should be a platform around the tank and steps leading up, so that a person can get into it easily.

\section{Sink, How Made.}

Another necessary thing, which is seldom found in a factory is a good sink. It should be iron or galvanized-iron lined, and plenty large enough-say three feet long, by twenty inches 
wide, by twelve inches deep, properly connected with the sewer. At the end of the sink there should be a wide shelf or table inclined toward the sink, so that drippings will run off into the sink. This shelf is used to drain tinware, and a steam jet projecting through it, can be used to sterilize utensils.

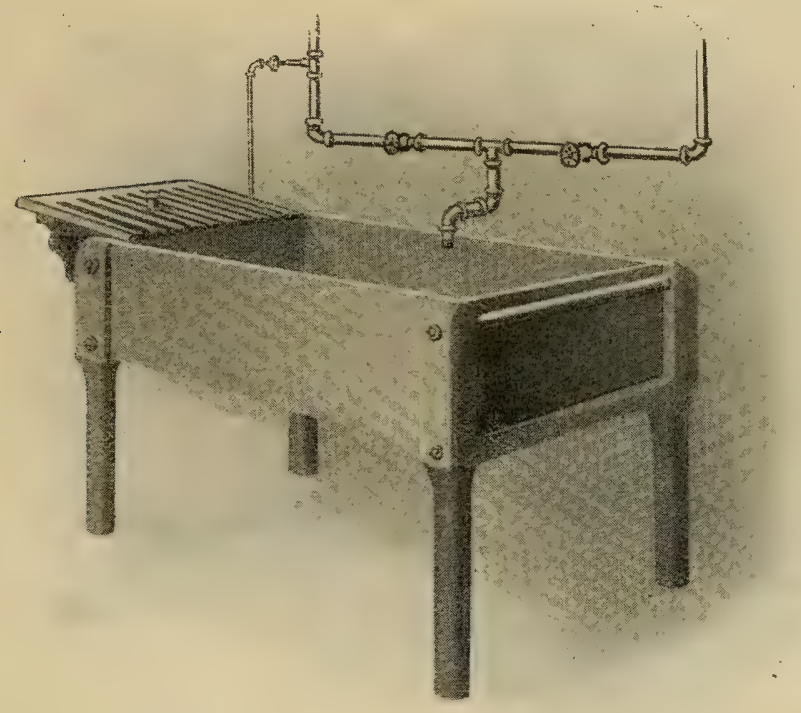

Fig. 61.-Wash Sink.

Hot and cold water connections at the sink should be provided, and perhaps a hot water barrel beside it. This barrel may be made of galvanized iron, and should be used for a supply of clean, hot water, rather than a place to wash dirty tools, which should be cleaned in the sink.

\section{I. Bath Room.}

One thing that a factory should have, though generally unthought of, is a bath room. This can be placed above the curing room. A room, five by eight feet, can have a floor covered with galvanized iron, to eatch any drip or slop, and a bath tub put in. Hot and cold water can be connected with it, and a most desirable convenience thus supplied. 


\section{Equipment.}

For a factory of the capacity previously mentioned, an eight-horse power boiler will be required. A horizontal brick arch boiler is preferable to a vertical one, as it will hold the heat better, and a person can more easily clean the flues.

There should be a good steam pump, and possibly an engine, though the latter is not absolutely necessary. For ten thousand pounds of milk two vats of a capacity of 5,200 pounds will be needed; these ought to be provided with whey gates for emptying them.

\section{Water Boxes of Vats Should be Lined.}

It is quite essential also to have the water roxes of the vats lined with galvanized iron, or they will leak, making a bad muss on the floor.

\section{Curd Sink, Presses, and Hoops.}

It will be remembered that a curd sink is a necessary piece of apparatus in getting the curd drained properly; we must, therefore, have a curd sink constructed in the way suggested.

For the curd from 10,000 pounds of milk, two gang presses, and either twenty. Cheddar or forty flat hoops will be required.

\section{Pressing Flats.}

One should not attempt, as is quite commonly done, to press two flats in a Cheddar hoop by putting a divider between. Artistic looking cheese cannot be made in that way

Flat hoops do not cost nearly as much as they formerly did, and the expense will be but slightly increased by providing the necessary number of hoops.

\section{Milk, How Lifted.}

If the roadway is not high enough to empty the milk directly into the weigh can, a large wheel fixed tight on an axle is probably the best appliance for lifting the milk. An endless rope runs over the wheel, and by pulling this rope the wheel turns and winds up another rope on the axle. This rope has tongs on it, which take hold of the milk can.

The weigh ean is placed on an 800-pound double-t,eam scale, which stands in a receiving room or covered platform. This platform is built out on brackets in front of the factory. On 
one side of the room is a shelf for the milk book, and another for the sample jars. The milk is run from the weigh can to the vat, through an open tin conductor.

\section{Milk Testing.}

For testing the milk, we should have a thirty-bottle steamturbine Babcock tester, and a Quevenne lactometer. The Quevenne lactometer gives a direct reading of the specific gravity, and is used in connection with the Babcock fat test for detection of watered milk (62).

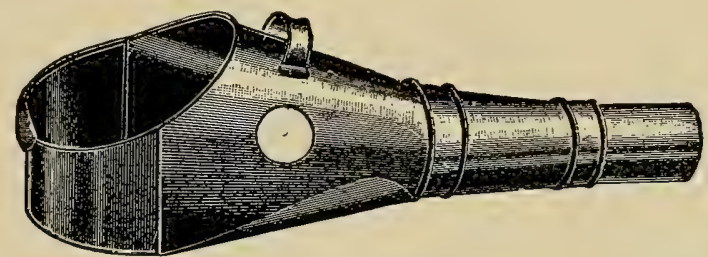

Fig. 62,-Milk Conductor Head, for running milk from weigh can to vat.

\section{Appliances Needed.}

Some of the minor articles needed in the factory, are usually lacking, and sometimes there are not enough of the articles to enable one to work handily.

There ought to be two curd knifes-horizontal and perpendicular-and these should be six or eight inches wide and twenty inches long.

A rennet test will be required, and two or three reliable thermometers, for these are easily broken, and we must not run the risk of being without one.

wash dish, two curd pails, three or four twelve-quart tin pails, several dippers, one of which has a flat side, and a perforated tin bottom, for skimming specks off the milk.

\section{Curing Shelves.}

The shelves in the curing room are supported by crosspieces, attached to wooden posts. These posts are $4 \mathrm{x} 4 \mathrm{~s}$, reaching from floor to ceiling. The er $\mathrm{ss}$ pieces are $2 \times 4 \mathrm{~s}$, set into the $4 \times 4$, to keep them from tilting, and a bolt put through to hold them in place. The shelves are sixteen-foot boards; sixteen inches wide, and one and a half inches thick. They should be the clearest pine lumber obtainable.

The shelving can run crosswise of the room, and if the 
boards are sixteen feet long, there will be a four-foot passage on the side of the room next to the making room. At the further end of the room from the door to the making room, ten feet of space can be left for boxing cheese.

\section{Cost of Factory.}

The factory we have suggested will cost more than the ordinary run of factories, for it is much better. Nothing that will be a waste of money has been suggested. Certain firms put up factories which are inferior to this, for which they get a third more money than this will cost.

As the cost of material in different localities varies so much, we have not set a price on this factory, but the necessary facts are given, so that anyone can figure on the cost of the building for his own locality, and reliable firms will furnish machinery at reasonable prices.*

\section{QUESTIONS ON CHAPTER XII.}

1. What is the necessity of good foundations for a factory? 2. How should the curing room wall be constructed? 3. Why are double windows needed in the curing room? 4. How should the curing room door be built? 5. What is the advantage of a curing room in a cellar? 6. How may such a room be ventilated? 7. What is the principle on which a sub-earth duct works? 8. How many and how large tiles should be used? 9. How deep should the tiles be placed in the ground? 10. How long should a duct be? 11. How may air be forced through the duct? 12. How large should the cowl be and how high should it be placed? 13. How can a well be utilized as a duct? 14. How ean hot water be secured? 15. Why should the water pipes be galvanized? 16 . What can be said of good sewer connections? 17. What is a septic tank? 18. How should the whey tank be constructed? 19. How should the whey be drawn off? 20. How can the whey be elevated? 21. Why should the water tanks of the vats be lined? 22. How should the curd sink be constructed? 23. Why should flats not be pressed in Cheddar hoops? 24. How should a wash sink be made? 25. How should the curing shelves be constructed?

*For plans of cheese factory buildings and equipment, see also Dairy Commissioner of Canada, Rept. 1906, pp. 25-34; Dean, Canadian Dairying, pp. 245-8; Mont. Exp. Station Bull. 53; and Mo. Exp. Station, Circ. of Inf., 18. 


\section{CHAPTER XIII.}

\section{ORGANIZATION OF CHEESE FACTORY ASSOCIATIONS.}

\section{6r. Plans of Operation.}

Cheese factories are operated on two plans, namely, the private and the stock company systems. In the first named plan the factory is owned by an individual who furnishes everything needed in the manufacture, and receives a certain price per pound for such manufacture, the milk and the cheese being considered the property of the patrons. The patrons then have some form of organization for the purpose of selling the cheese and dividing the money, and looking after the interests generally.

Under the other system the farmers' organization owns the factory, and the officers do all business and hire a cheese maker to manufacture the cheese. Co-operative associations are usually not successful unless a business manager is given full authority to manage the business.

The following by-laws will give a general idea of how to organize such an association:

\section{By-Laws for a Cheese Factory Association.}

ARTICLE I. Name-This Association shall be known as the........

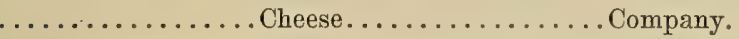

ARTICLE II.-Capital Stock-The capital stock of the Association shall be $\$ 4,000$, divided into two hundred shares of twenty dollars each

ARTICLE UII. Officers-The officers shall be a president who shall have general oversight of the business of the Association and prosecute any case at law that may arise. A treasurer shall receive and disburse all money and keep a proper set of books which shall be open to inspection of any member of the Association at any time. He shall be the salesman for the Association. He shall receive \$- per annum for his services. There shall be a secretary who shall figure all milk dividends. He shall be Chairman of the Test Committee.

ARticle IV. There shall be semi-annual meetings of the Association 'on the first Tuesday in March and October, three days' notice of the time 
and place of meeting to be given by the president. Special meetings may be called by the president, three days' notice of the time and place to be given, and upon the written request of ten members of the Association the president shall call such a meeting.

ARTICLE V. The division of money for cheese sold shall be determined by the fat test of the milk, after expense of making has been deducted. The remaining amount of money shall be divided by the number of pounds of butter fat delivered during the time said cheese was made, to determine the price per pound of butter fat, and each patron shall receive that price per pound for the butter fat delivered by him during that time.

ARTICLE VI. Test Committee-There shall be a test committee of three members beside the secretary who shall assist the cheese maker in testing the milk.

ARTICLE VII. The price for making cheese shall be one and a half cents per pound.

ARTICLE VIII. The cheese maker may reject any milk that in his judgment will not make first-class cheese.

ARTICLE IX. No milk will be received at this factory that has not been properly strained and aerated.

ARTICLE $X$. These by-laws may be altered at any legal meeting by a two-thirds vote of the members present, providing there are at least ten members present at such meeting.

The above by-laws can, of course, be changed to suit any particular locality or conditions. The amount of eapital stock may be altered, or such articles changed to make them suit a private factory.

\section{Test Committee.}

Article VI, which provides for a test committee, is for the purpose of preventing dissensions. We quite often hear it stated that the maker reads the tests low to get a larger yield, or that he favors one patron more than another. Such statements may be founded on facts, but are often the result of suspicions. If the patrons have a committee of their number to see the tests made, such a committee cannot fail to secure justice.

\section{Quorum.}

The number that shall constitute a quorum has been purposely left out, for in such an association it is not very important, and might hinder the business of some meetings. The article on the revision of the by-laws contains a clause that practically names a quorum in such a case. 


\section{Rates for Making.}

In some Canadian stock companies there are two rates charged for making the cheese, a stockholders' rate and a patrons' rate, which is higher than the former. The patron is not entitled to whey. It belongs to the corporation, to be fed to hogs owned by the association, or disposed of as the stockholders see fit. Each share of stock entitles the owner to have fifteen thousand pounds of milk made up at stockholders' rates, and after that he must either get another share of the stock or pay patrons' rate for all milk made up above that amount. The object of this rule is to make each patron take a financial interest in the factory.

\section{Figuring Dividends.}

As is indicated in one of the by-laws the price per pound of butter fat should be found, and each patron paid for the pounds of fat delivered by him.

Cheese may be sold each week, but the dividends are made for the month.

The composite samples of milk are saved as described under the head of milk testing; these are tested once a week. The pounds of milk delivered by the patron multiplied by the per cent of fat, gives the pounds of fat deliverec by him. The amount of money left after paying all expenses is then divided by the total pounds of fat for the month to get the price per pound of fat. The number of pounds of fat delivered by each patron, multiplied by the price per pound, gives the amount due him. Theoretically, the pounds of milk delivered each week should be multiplied by the weekly test, but if the tests from week to week are averaged for the month, and the average test multiplied by the amount of milk for the month, the result will come very close to the amount obtained if each week's fat is found and added together for the month, and a large amount of labor will be saved in the calculations.

If there is a small surplus or shortage of money in figuring, it can be added to or subtracted from the next month's money before determining the price per pound.

For an example of dividing the money suppose there are three patrons, and during the month they delivered milk as follows : 


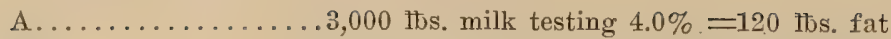
B............. $2,200 \mathrm{lths}$. milk testing $3.5 \%=77 \mathrm{lts}$. fat C.............. milk testing $4.5 \%=45 \mathrm{lbs}$. fat

Total for month.....6,200 Ibs. milk testing $390 \%=242$ ibs. fat

By dividing the pounds of fat by the pounds of milk for the month, and multiplying, by 100 we get the average test of all the mill for the month. This is not needed in the figuring of the dividends, but it is interesting to know what the average test is.

Suppose the cheese made from the milk was 620 pounds and sold at 10 cents per pound. We then have $\$ 62.00$. The cost of making was $\$ 9.30$, and we have left $\$ 52.70$ to be divided among the patrous. By dividing this amount by the 242 pounds of fat we get 21.7 cents per pound. Then

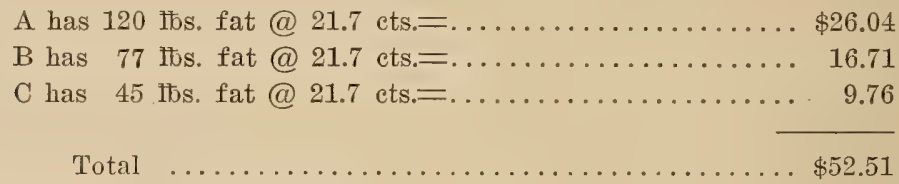

We had $\$ 52.70$ to be divided; the 19 cents surplus may be added to next month's money to be divided among the patrons. One should always prove his figures to be sure they are correct.*

\section{Three Methods of Figuring Dividends.}

Prior to the invention of the Babcock test, milk delivered at the cheese factories was always paid for according to the socalled pooting system, by which method the milk from all the patrons received the same price per cwt., regardless of its quality and value for cheese making. This plan is still in use in many cheese factories, although it is readily seen that it is unfair to the patron furnishing rich milk, or milk testing above the average for the factory.

The method of payment explained in the preceding is based on the test of the milk furnished by the different patrons and is believed to be the most equitable and convenient plan for paying for milk at a cheese factory, since the fat content of the milk determines the quality of the cheese, as well as the amount of cheese made per ewt. of milk. The objection to this system is that a milk rich in butter fat does not yield quite as much

*The methods of calculating dividends at cheese factories are discussed in more detail in "Testing Milk and Its Products," 18th ed., pp. 199-203. 
more cheese than a milk low in butter fat as is indicated by the differences in the tests, but the quality of the cheese from rich milk is enough better to make up for the small difference in the yield per pound of butter fat.**

As a compromise between the pooling system and the plan of payment by the test, Professor Dean of Guelph (Ont.) Agricultural College, has suggested the method of adding two to the test; ; thus, if patron A's milk tested 3 per cent, adding 2 makes it 5 - per cent; if patron B's milk tested 4 per cent, adding 2 makes it 6 per cent, thus changing the ratio of the relative value of the two milks for cheese-making purposes from $3: 4$ to $5: 6$. This method of payment which has been adopted at some Canadian factories, gives an advantage to the patron furnishing milk of the poorest quality and renders it advantageous to adulterate the milk by watering. An example will illustrate how this works out: Let us suppose that a patron furnishes 100 pounds of 4-per cent milk; if he adulterates this with 100 pounds of water, to take an extreme case, he will have 200 pounds of milk testing 2 per cent; by adding 2 to the milk testing 4 per cent, he will receive eredit for 6 points in his dividends, while if the milk is adulterated as suggested, he will receive credit for 4 pounds per hundred weight, or 8 points for his 200 pounds of adulterated milk. By basing the dividends on the fat test he would receive credit for 4 pounds in both cases, as he has not increased the amount of butter fat in his milk by watering it.

\section{Factory Statement.}

A statement containing all necessary items should be given each patron so that he can figure the dividend himself. There should be a printed form for this. The following may be used:

MUSCODA CHEESE ASSOCIATION FACTORY.

Statement for

Month of

Sales include following dates.

No. pounds of cheese sollt...

* See frontispiece Value of fat in milk for chese production. The vie of cheese from 200 pounds of fat in milk for cheese production. The yields Separator skim milk pounds of milk of different fat contents were as follows: cent, 16.0 lbs.; 3 per 11.0 lbs.; milk containing 1 per cent fat, $13.1 \mathrm{lbs}$; 2 per 24.8 lbs. $1 \mathrm{bs}$; 3 per cent, 18.3 lbs.; 4 per cent, 21.6 los., and 5 per cent,

tSee Bull. 114, Ont. Agric. College; also Dean, Canadian Dairying, p. 146. 


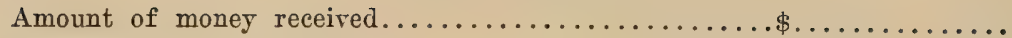

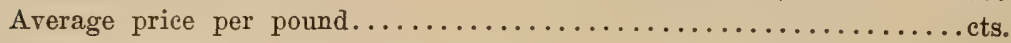

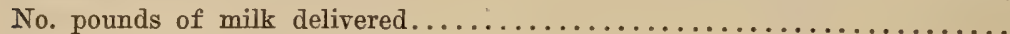

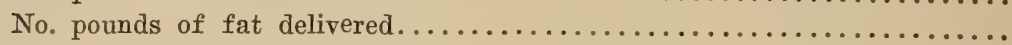

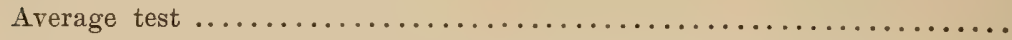

Expenses

Money to be divided.

Which leaves.

.cts. per pound of rat

No. pounds of milk delivered by you

Your average test.

Pounds of fat delivered by you.

At. . .

cents per pound

Dr. by......... pounds of cheese at.

$\$$

Money due you.

No. pounds of fat required for 1 pound cheese.

No. pounds of cheese from 100 pounds milk.

Sec.

QUESTIONS ON CHAPTER XIII.

1. What are the two general plans on which a factory may be operated? 2. What is a common cause of the failure of cooperative companies? Describe how dividends are figured. 4. Why should a statement be made to each patron when a dividend is declared? 5. What are the important points in such a statement? 


\section{CHAPTER XIV.}

\section{SWISS CHEESE-ITS CHARACTERISTICS.}

\section{Sweet Curd Cheese.}

It will be remembered that Cheddar cheese was first made in England and was introduced into America by the emigrants from England. In like manner the manufacture of a number of other styles of cheese has been introduced. These styles are what are generally termed sweet-curd cheese. The Cheddar is made from ripened milk and a certain amount of acid is developed in the whey. With the sweet curd varieties, however, the milk must be sweet, the milk being curdled and cooked up as rapidly as possible and then put into the molds before salting. The salt is nearly all applied to the outside of the cheese by means of dry salt rubbed on the surface or by soaking the cheese in a strong brine.

Among these cheese are "Swiss," of the round and block varieties, also brick and Limburger. Swiss cheese has been made in this country quite as long as has the Cheddar and with the brick and Limburger, will soon be, if it is not already, entitled to the name "American."

\section{Swiss Cheese, Where Made.}

American Swiss, or "Sweitzer," as it is called, is made to the greatest extent in this country in Green and Dodge counties, Wisconsin; in Wayne, Stark and other counties in Ohio; and in New York State. The makers are mostly natives of Switzerland, who have emigrated to this country and brought their methods of making with them. These methods can probably be improved upon in a number of ways, as will be indicated.

\section{Description of Swiss Cheese.}

Swiss cheese is known in the old country by the name of Emmenthaler. Its origin is not definitely known, but it has 
been made in the canton of Bern since the fifteenth century. In this country it is made in two forms, the round or drum Swiss, and the block Swiss.

The drum Swiss is pressed in large round cakes, twentyfour to possibly thirty-six inches in diameter, and four to six inches in thickness. Such a cheese will weigh, on the average,

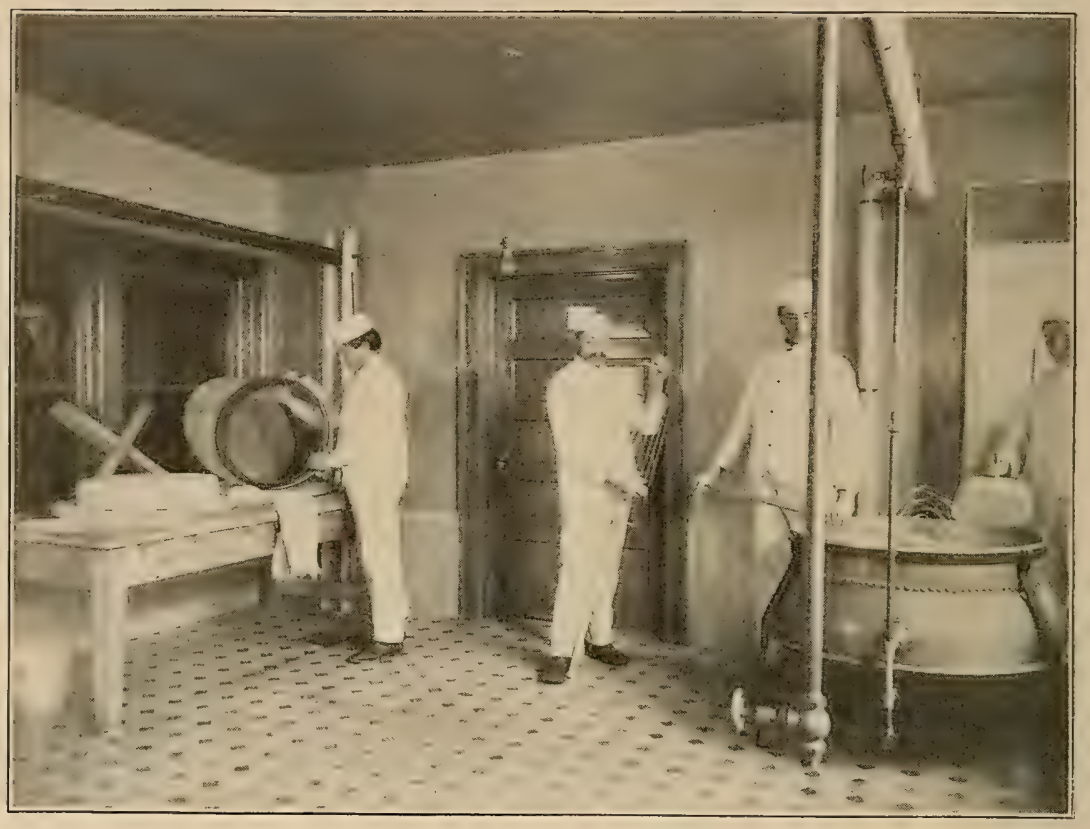

Fig. 63.-Students making Swiss cheese.

about 180 pounds. The block Swiss is six inches square by twenty inches long, and weighs twenty-five to thirty pounds. The illustration (Fig. 64) shows a drum Swiss cheese cut open. On top is laid a square which indicates its size. The illustration of two block Swiss on page 142 will give an idea of their proportions.

\section{Determining Quality of Swiss Cheese.}

In order to intelligently discuss the manufacture of the cheese, we should know what is required in a Swiss cheese to make it of the best quality. 


\section{Flavor.}

First as to flavor. The flavor of the Swiss cheese is a hard thing to describe, the same way as it is difficult to express in words the flavor of a Cheddar cheese. It can be said, however, that the Swiss cheese has a slightly salty taste peculiar to itself, a taste that is very pleasing. A cheese that is bitter to the taste is to be condemned.

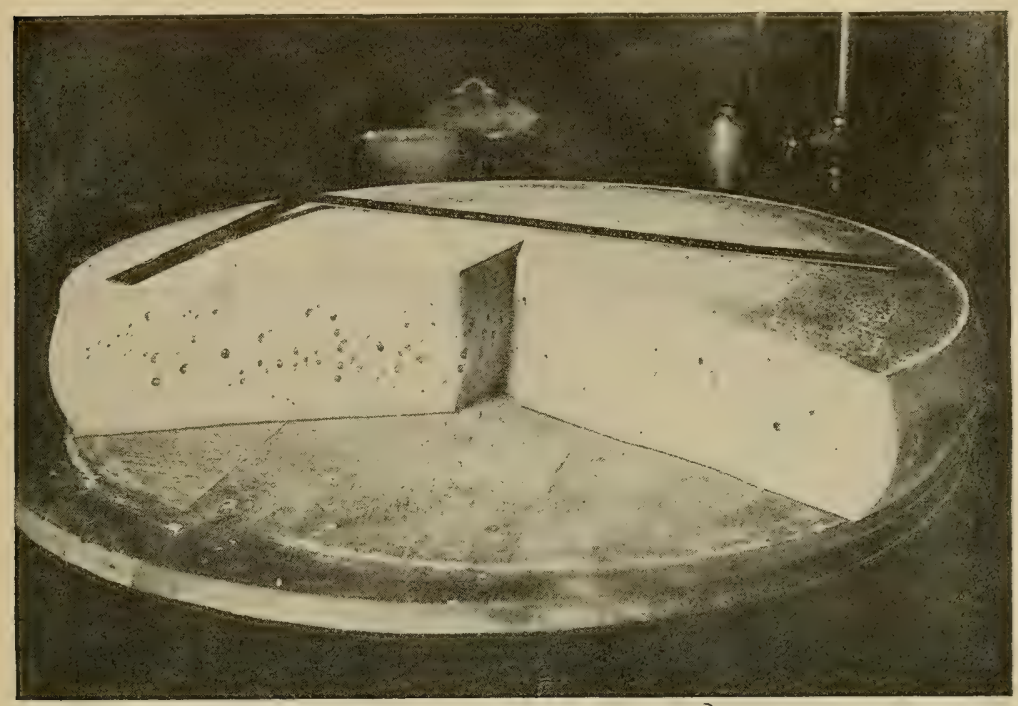

Fig. 64.-A typical Swiss cheese, showing characteristic holes or "eyes." A square on top of it shows its size. The eyes reflect the light, showing that they have a shiny surrace.

\section{Texture.}

A good Swiss cheese should have the right dough, that is, it should not stick to the fingers, nor, on the other hand, be too dry, but it should mold in the fingers like wax, or as the term indicates, like dough. It should also have plenty of even-sized eyes or holes about a half an inch in diameter, evenly distributed through the cheese, as is seen in the illustration. These holes should have a glossy surface, which is again an indication that the dough is right. If it is too soft, these holes will have a dull surface. In an old cheese drops of brine may be found in the holes. 


\section{Color.}

The color should be white. The native Swiss cheese is very light colored, probably on account of the feed that the cows get, which may influence the character of the fat given by the native cows (we know that Guernsey milk is exceptionally yellow, while Holstein milk is light-colored), and by the length of time a cheese has cured. American Swiss cheese that are quite yellow will turn white with more age and cannot be distinguished from the foreign article, and except for the name "imported," may be just as fine. One reason why foreign cheese meets with so

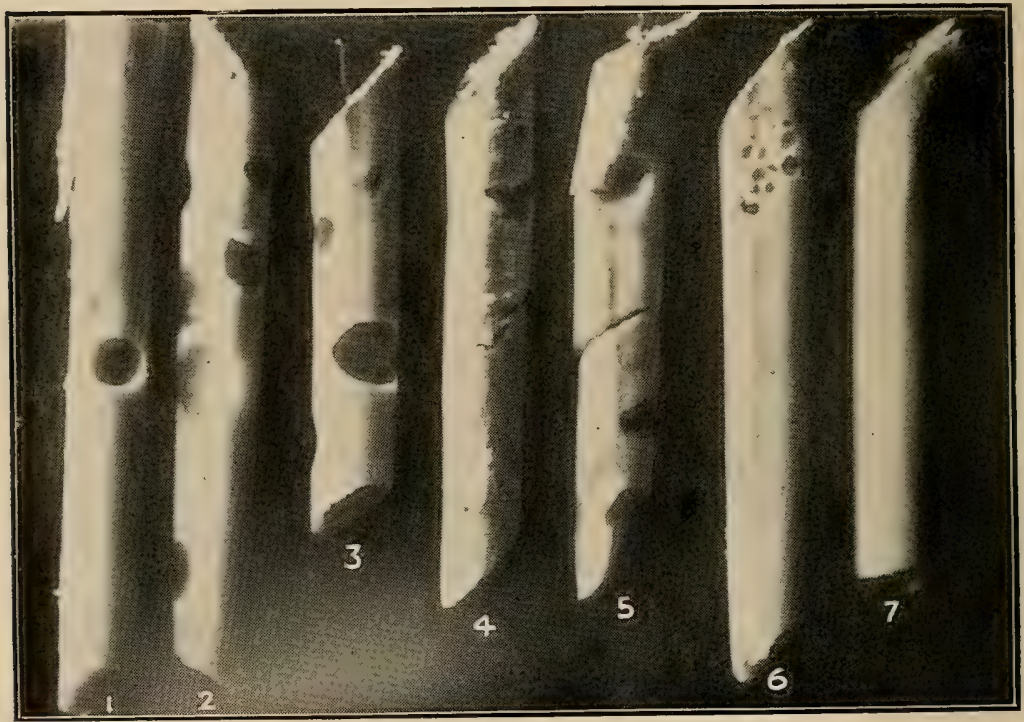

Fig, 65.-A series of plugs from Swiss cheese of different quality. Nos. $1,2,3$ would be classed as No. 1 cheese, though 2 has rather too many holes. Nos. 4 and 5 show the cracks of a glaesler and the corresponding pasty appearance. No 6 at the upper end indicates a niszler, though a typical niszler would have small holes the entire length of the plug. No. 7 is what would be termed a blind cheese as there are not "eyes" or holes.

much favor in this country is that it does not reach the consumer till it is thoroughly cured; if good American cheese of the various kinds are allowed to get thoroughly cured they will meet with the same favor.

\section{Grades of Cheese.}

There are, however, poorer grades of this Swiss cheese that are not represented by our illustration. Cheese are classed in 
three grades, No. 1, No. 2 and No. 3. Cheese like the one shown on page 139 with the right dough and flavor, and the right kind and distribution of holes is classed as No. 1 cheese. Cheese without eyes or holes is termed blind and classed as No. 2. A cheese with little gas holes (called pin-holes in Cheddar cheese) is termed a niszler, meaning "a thousand eyes." One that is pasty and will stick to the fingers usually has few round holes, and if it does have them they are not glossy on the surface. Such a cheese is likely to have checks or cracks, running usually in a horizontal direction, through it. These cracks are supposed to resemble the fracture of a piece of glass and hence the cheese is called a glaesler.

\section{How Cheese is Tried.}

When a buyer goes into a factory to buy cheese he cannot cut any of the cheese open, as shown in the illustrations. He sees the inside of it by drawing a plug with a cheese trier, as is done in buying Cheddar cheese. The picture on page 140 is a photograph of typical plugs of Swiss cheese. Plugs 1, 2 and 3 have the proper kind of holes, though No. 2 has rather too many to be classed as No. 1 cheese. Again, the holes in No. 3 or at least one hole, was too large, for it cut the plug entirely off. It would, however, probably pass for No. 1. Plugs 4 and 5 have the cracks of a glaesler, and the little particles of curd roughed up show it to be pasty. Plug No. 6 shows a niszler at the upper end, while plug No. 7 is blind.

Requirements of Swiss Cheese.-Now to review the classes of Swiss cheese, the requirements for No. 1 are that:

1. The flavor shall be good.

2. The texture shall have the right dough, i. e., it must not be too dry, neither stick to the fingers, but mold like wax. It shall have the right kind of eyes evenly distributed.

3. The color should be light.

No. 2 Cheese would include:

1. Cheese of a second rate flavor.

2. Glaesler or blind cheese.

3. Cheese with a very uneven or abnormal development of eyes.

4. Niszlers. 
No. 3 Cheese would include:

1. Cheese of bad flavor.

2. Cheese damaged by rats or mice.

3. Cheese cracked open.

Cheese damaged by rats or mice $0 r^{*}$ cracked are very likely to rot at such points.

The buyer in the presence of the cheese maker determines the grade of the cheese, and marks it on the edge with his trier

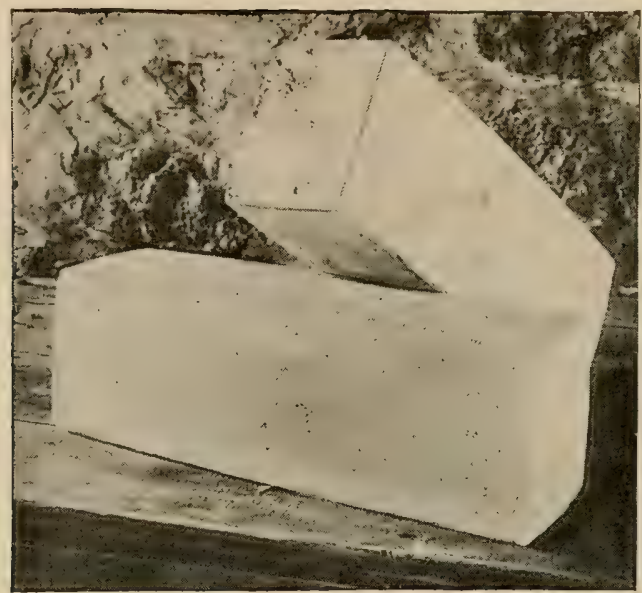

Fig. 66.-Block Swiss cheese as it appears when of fine quality.

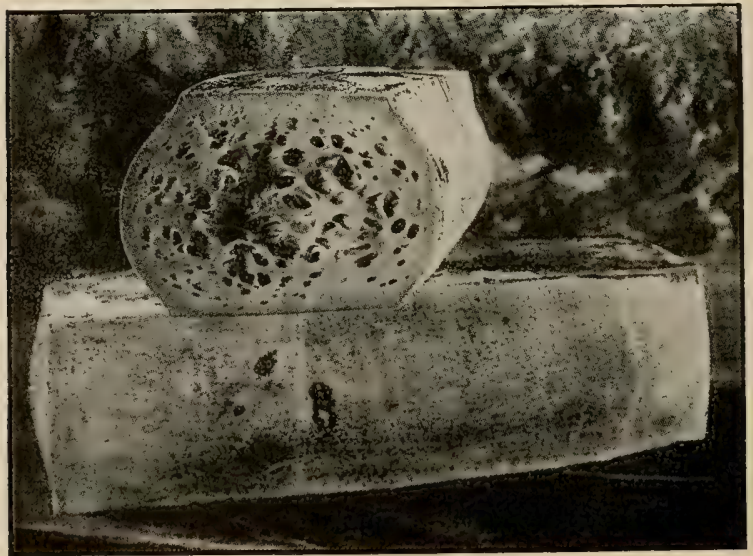

Fig. 67.-Block Swiss cheese bulged at sides from too rapid formation of gas. The salt did not work to the center fast enough. 
by gouging out I, II or III marks. He afterwards brands it with a hot branding iron, the brand being usually his initials. When the price of No. 1 is $91 / 2$ cents, the price of No. 2 will likely be 8 cents, and No. 3 will sell for from 3 to 5 cents.

Italians like glaeslers better than cheese with the eyes in it, and will often pay No. 1 price for the glaesler and reject a No. 1 cheese. Some makers regularly turn out cheese of No. 1 quality, while others have considerable difficulty in so doing, and the difference in price makes a very large difference in the size of the maker's pocketbook. The criticism that is often heard regarding our Cheddar cheese is, that there is not enough distinetion made in price between good, indifferent and bad cheese. That criticism eannot apply to the Swiss cheese markets for the judgment in buying is very rigid.

\section{QUESTIONS ON CHAPTER XIV.}

1. What are the two kinds of cheese which are made with reference to the amount of acid developed? 2. Under what class does Cheddar fall? 3. Under what class does Swiss cheese fall? 4. How is the salt usually applied to sweet-curd cheese? 5. Where is American Swiss made in greatest quantities? 6. By what name does Swiss cheese go in Switzerland? 7. What are the two kinds of Swiss cheese made in this country? 8. What is a good flavor in a Swiss cheese? 9. What is a good texture in a Swiss cheese? 10. What is meant by the eyes of a cheese? 12. What should te the size of these eyes, how should they appear on their surface and how should they be distributed? 13. What should be the color of a Swiss cheese and what conditions influence it? 1. What are the three grades of cheese and what conditions determine the grade into which a cheese goes? 15. What is a niszler cheese? 16. What is a glaesler cheese? 
CHAPTER XV.

\section{SWISS CHEESE-FROM MILK TO CURING CELLAR.}

\section{Selection of the Milk.}

As has been previously explained, Swiss cheese is made from sweet milk. So important does this seem to be that the milk is delivered to the factory twice a day and immediately made into cheese. It is believed by a good many makers that the rennet should under all circumstances be gotten into the milk as soon as possible.

\section{Cause of Glaesler Cheese.}

Exception may, however, be taken to the opinion that all milk for Swiss cheese should be set immediately when received at the factory, for as may have been observed in the experiments with rennet, a very sweet milk does not curdle rapidly nor is the curd as firm as the curd from riper milk. It takes a certain amount of acid (probably about .17 per cent) to make the rennet expel the whey properly. With too sweet milk, such as is obtained in the cool weather of the fall months, it is hard to get a good cook on the curd and such cheese will have a pasty texture, and a pasty texture will make a glaesler cheese.

\section{Rennet Test Should be Used.}

The milk for Swiss cheese should not be as ripe as for Cheddar cheese, but the rennet test should be used to determine the condition of the milk, and then the milk, if it is too sweet, should be brought to the same degree of ripeness each day, by holding or by the addition of a small starter. One of our students reports that with the Marschall rennet test used in his factory, a milk that tests five or six will be sure to give a glaesler cheese, while milk at $31 / 2$ will not do so. It should be remembered that Marschall tests may vary (86), so that each maker will necessarily have to determine at what point the milk should be set by his particular test. 


\section{Use of a Starter.}

Swiss makers generally use a homemade rennet, which is made up by them each day by soaking strips of rennet in whey. It is even claimed that commercial rennet extract is not as good as the whey rennet, as the eyes cannot be obtained with it. The explanation for this probably is, that the whey used acts as a starter which supplies the necesary acid in the milk to make the rennet expel the whey sufficiently. At the same time gas germs may be added which will make a niszler cheese (276). Freudenreich has shown that the lactic-acid germ is desired in making good Emmenthaler. By using a commercial rennet extract, after adding a good lactic acid starter, a cheese with a good development of eyes can be obtained. As this is being done in actual practice it shows that the idea, prevalent among Swiss makers to the extent that it is almost a law is incorrect, that good eyes cannot be obtained with commercial rennet extract. The amount of starter required will not be as much as for Cheddar cheese (113).

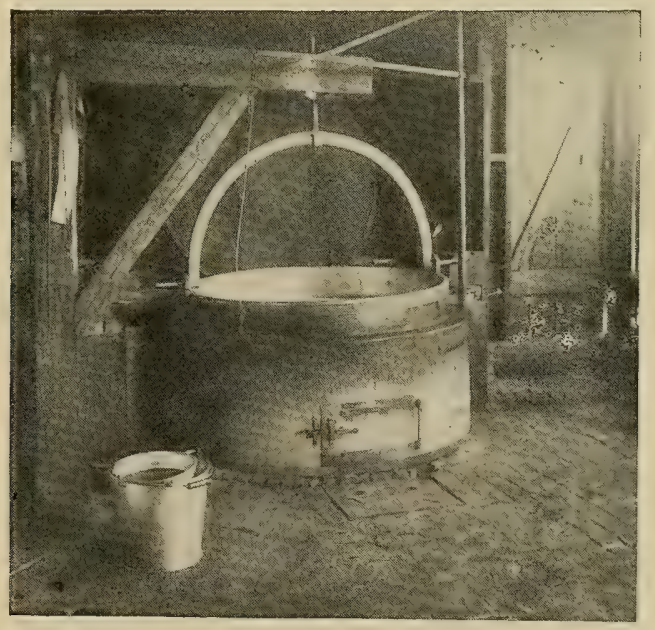

Fig. 68.-Cheese kettle in a Swiss cheese factory near Monroe, Wis. The kettle hangs on a heavy wooden crane. The front of the fire place over which the kettle hangs also hangs on a crane and can be swung out so that the kettle can be swung away from the fire. The opening below the grate will be seen in front of the kettle. The round cover is dropped over the top when the kettle swings forward. 


\section{Test of Homemade Rennet Solution Not Correct.}

When a maker prepares his whey rennet, he tries a certain quantity of it on a sample of milk to see that it is of the right strength. If the acidity of the milk were the same each time, as well as the acidity of the whey used, this might be correct, but as a different lot of milk with a difference in acidity is used, it will be seen that this is not a correct way of determining the strength of the whey rennet. It is, therefore, better to use a commercial extract that will be of the same strength each day.

\section{Swiss Kettles.}

Swiss cheese is made in large copper kettles that vary in size from a capacity of 600 pounds to 3000 pounds of milk. There are two kinds, the fire kettle and the steam kettle.

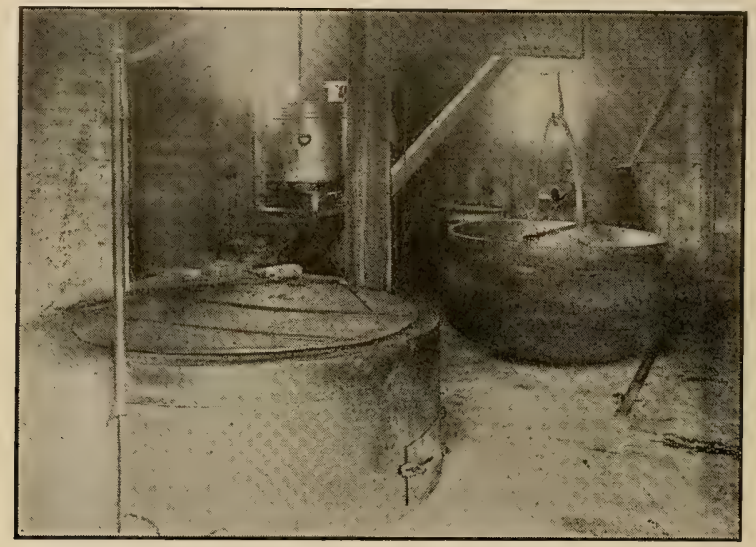

Fig. 69.-View in a Swiss cheese factory, near Monroe, Wis., showing the kettle.swung around in front of the weigh can. "The cover to the fireplace has been dropped.

The fire kettle hangs on a strong wooden crane and the height of the kettle is adjustable. The adjustment is obtained by means of a strong iron serew on which it hangs, and which which may influence the character of the fat given by the native cows (we know that Guernsey milk is exceptionally yellow, while passes through a nut in the crane. The kettle hangs over a fireplace. This fireplace is built in a semi-circular form just large enough to receive the kettle, and connects with a chimney for the exit of the smoke. The front of the fireplace is built of 
sheet iron, and is semi-circular in form, so that when ciosed it just fits around the front side of the kettle. It is hinged on the brick work on one side (the side oppcsite the kettle crane) and the further end of it hangs from an iron crane which is also placed on the side of the fireplace opposite the wooden crane. By turning this crane the sheet iron front can be swung out of the way so that the kettle can be swung out into the room. When the kettle is swung out of the fireplace, this front can be closed and a sheet iron lid, hinged against the chimney, can be

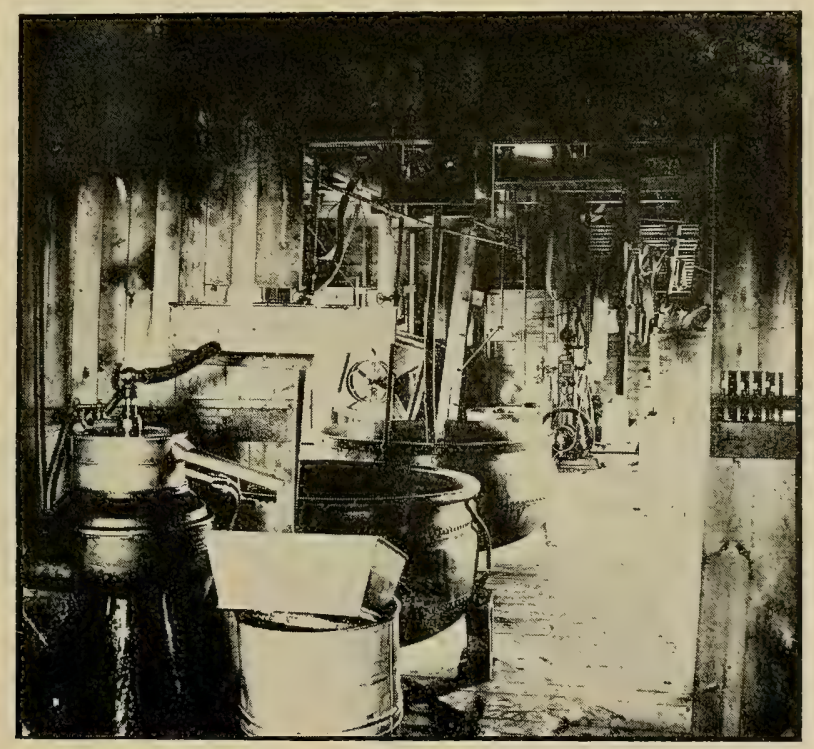

Fig. 70.--Interior of Swiss cheese factory at Florence, Ohio. Steam kettles are used and the whey is skimmed with a centrifugal separator.

dropped to cover up the hole for the kettle. A grate is placed in the bottom of the fireplace, and a fire door in the sheet iron front gives a place for the operator to tend the fire on the grate.

The steam kettles are set permanently on the floor. A steam jacket is riveted on the lower part so that steam can be used for heating the milk. A plug in the bottom connects with a pipe for carrying off the whey.

\section{Filling the Kettle.}

The milk is strained into the kettle the same as into a vat for Cheddar cheese. If a fire kettle is used the kettle may be swung in front of the receiving window. 
Milk for Swiss cheese should be paid for by fat test, the same as for Cheddar cheese. It is sometimes claimed that rich milk does not give as good eyes as poor milk. This opinion probably comes from the milk being richer in the fall when the weather is also cooler, which of course keeps the milk sweeter with the attendant result of very sweet milk. (281). Rich milk will make more and better Swiss cheese than poor or skimmed milk.

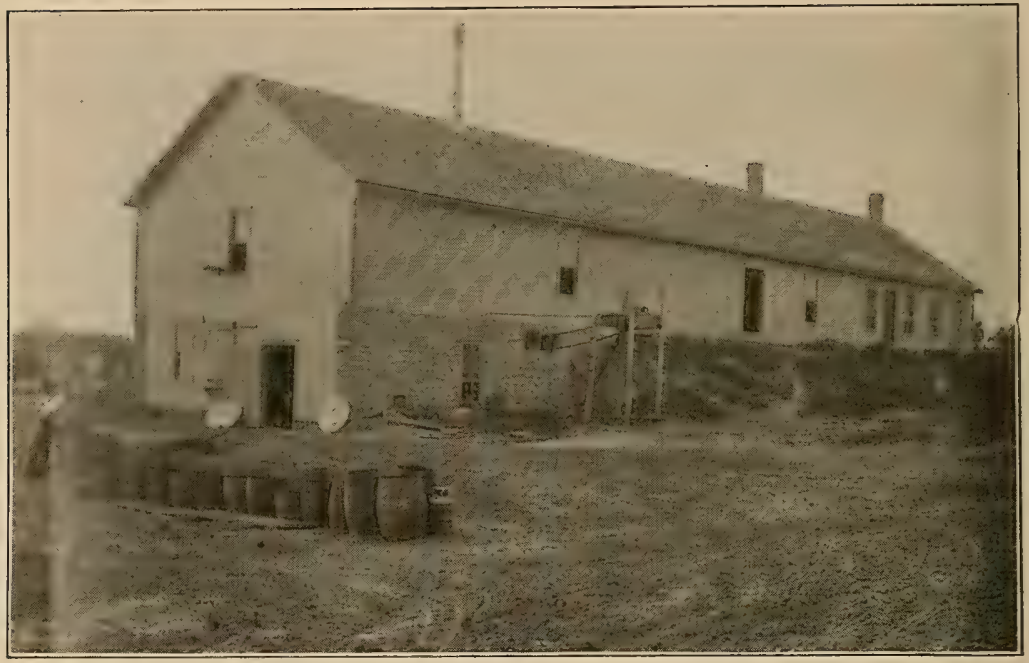

Fig. 71.-A Wisconsin Swiss cheese factory; patrons' whey barrels in the foreground.

\section{Setting the Milk.}

When the milk is all in the kettle the temperature should be noted. The milk has probably not been cooled at home, though it ought to have been aerated. (31.) It is therefore very likely warm enough for setting. If, however, the temperature is found to be below $86^{\circ} \mathrm{F}$., the milk should be warmed to that point. The rennet is then added and stirred in with a large wooden or tin scoop. The milk is put into a whirling motion in the kettle by this operation, and after stirring for four or five minutes the motion should be stopped, so that the coagulum, when it begins to form, will not be broken by the 
force of the current. In the course of twenty to thirty minutes the curd should be ready to cut.

\section{Cutting Swiss Curd.}

A Swiss curd when ready to cut should be of about the same consistency as a Cheddar curd. That is, it should make a clean break over the finger when it is inserted (119). There ought to be a cover for the kettle so that the surface of the milk will not cool off. It will be remembered that rennet will not act as rapidly when the temperature is reduced (74), and one should aim as far as practical to keep the heat from radiating from the surface. At first the curd is turned over with the scoop so that the surface coming in contact with the lower layers will warm up. After the surface has been turned over very carefully a scoopful at a time, it is ready to be cut with the Swiss harp.

\section{The Swiss Harp.}

The Swiss harp is so called, because it is shaped like a harp. It is an iron frame with a long wooden handle. Fine wires are strung lengthways of it about an inch apart. This is carefully inserted in the curd and by circular motions across the kettle the curd is broken into pieces about an inch in diameter.

\section{The Wire Stirrer.}

The wire stirrer is a stick five or six feet long, through one end of which a group of wires are worked into a spherical form. This is next inserted into the curd, which is brought into a circular motion around the kettle. The curd is stirred gently for a few minutes to keep it apart while it firms a little.

\section{Another Method of Cutting.}

By means of the stirrer the curd has become about as fine as Cheddar curd. With the knives used in making Cheddar cheese (122), the curd can at once be brought to this condition without breaking and jamming it. It is from this cause that so much fat is lost in Swiss cheese making. (18)

\section{Inserting the Wooden Brake.}

A wooden brake that is about four or five inches wide, made to fit the side of the kettle closely, is now fastened to the kettle. This breaks the current, causing an eddy in the whey 


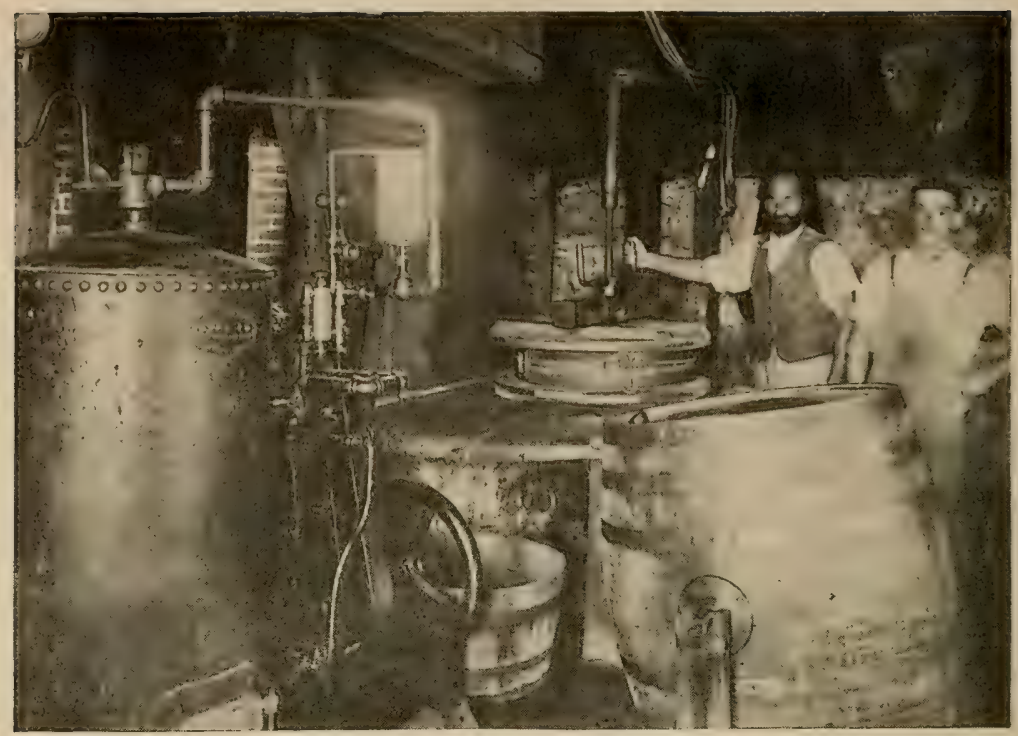

Fig. 72.-Interior of a Swiss cheese factory, showing a cheese in the press and the means of adjusting the pressure. The small engine and churn are for making whey butter.

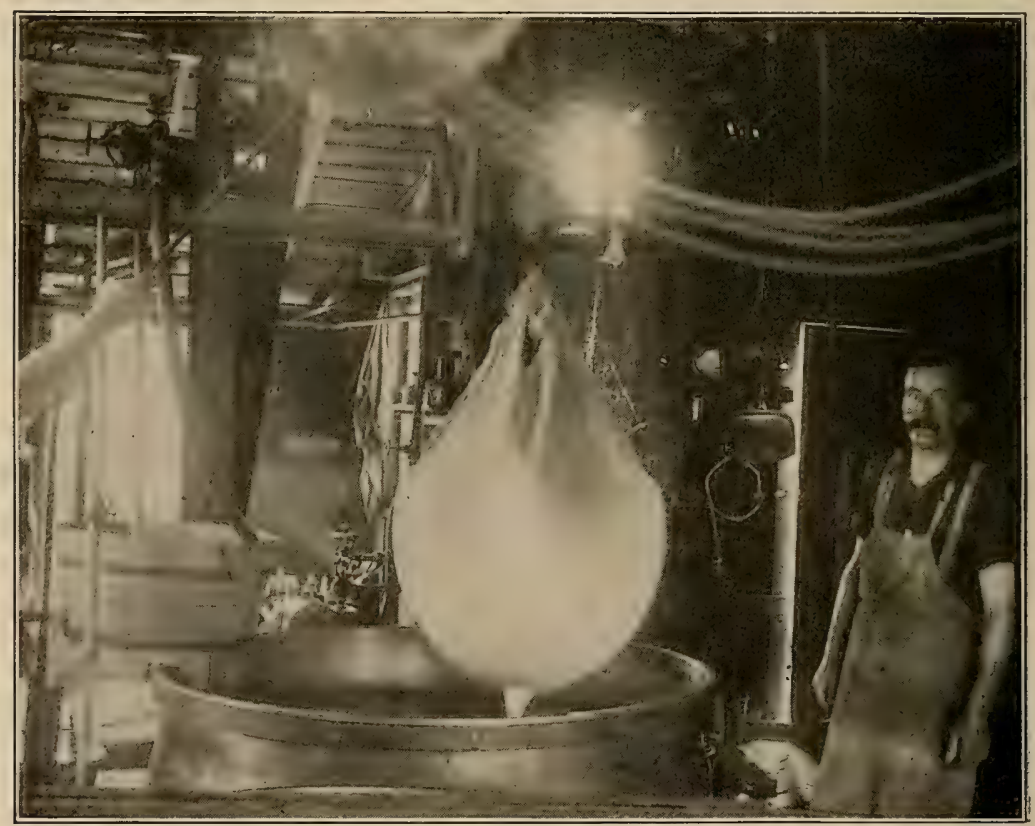

Fig. 73.- Taking a curd out of the kettle. The block and tackle with curd attached is run on a track over the press. 
as it flows around the kettle and the heat is more evenly distributed.

\section{I. Cooking the Curd.}

The kettle is next moved over the fire, or the steam is turned on if it be a steam kettle. The operator stirs it vigorously with the wire stirrer mentioned above, and the curd breaks and contracts into pieces as fine as wheat. It is stirred until the temperature has been raised to $40^{\circ}$ or $42^{\circ}$ Reaumur.* After

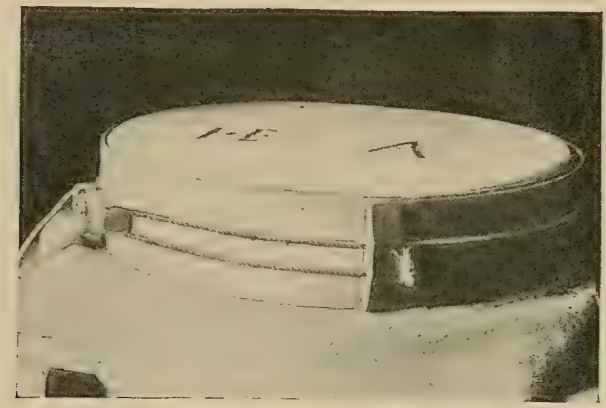

Fig. 74.-A round Swiss cheese in the hoop. The cheese is made the thickness of the hoop, and the diameter is adjusted accordingly by the rope which runs around it. A round board lies on top and presses the cheese into the hoop.

the whey has reached this temperature the kettle is swung away from the fire or the steam is turned off, as the case may be. The stirring is, however, contined until the curd is quite firm, when it is allowed to settle.

\section{Testing Curd for Firmness.}

A curd is considered firm enough for dipping when it ceases to feel mushy and will not squeak between the teeth. Some makers test the cook by squeezing it into a roll in the hand and then noting when it will break short.

This is a point where the maker's judgment is very important. If the curd is not cooked enough, it will result in a glaesler, and if cooked too much the fermentations will work so slow that eyes will not form.

* Reaumur thermometers which start with the freezing point of water as $0^{\circ}$ and run to $80^{\circ}$ at the boiling point, are used almost entirely by Swiss makers. $40^{\circ}$ and $42^{\circ}$ are therefore equal to $130^{\circ}$ and $135^{\circ}$ Fahrenheit. 


\section{Dipping the Curd.}

When the curd is finally firm enough, the wooden brake in the side of the kettle is taken out and the curd is set whirling in the kettle so that when it settles it will collect in a lump in the middle of the kettle. It is then gathered up into a linen strainer cloth for pressing. The eloth is gathered at one edge in the hand and wet in the whey; it is then spread out and rolled onto a flexible iron band. The opposite end is held by an assistant, or if the operator is alone, he holds it in his teeth, and then the iron band is bent into an arch and slid under the lump of curd.

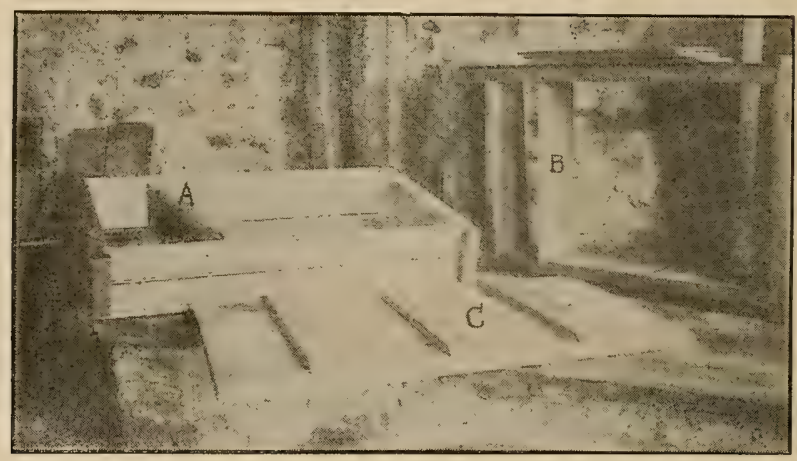

Fig. 75.-Block Swiss molds. A, tne adjustable end, muved by a screw. $B$, the partition which fits into the grooves, making the right sized molds after the blocks are cut. C, the cover or tollower.

The corners of the cloth are then tied together and the whole thing drawn up with a rope and tackle which runs on a pulley and track, like a hay fork, to the pressing table.

It is claimed that if the pieces of curd that are collected at last are put into the center, they will cause the cheese to crack and from the crack a rotten place will start. The curd should therefore be put into the hoop in a lump, and as quickly as possible, so that it will not become cool and brittle and therefore crack. Where there is curd enough, the lump in the kettle may be eut in two and put into two hoops in different dippings.

We have seen that the curd is cooked to $135^{\circ} \mathrm{F}$.; this would seem a very high temperature for a man to put his arms into, as the maker has to do when he scoops the curd into the cloth. Some observations on this point will show that the whey cools 
down to $115^{\circ}$ or $120^{\circ}$ before the curd is taken out, and is quite different from the other high temperature which would probably seald him.

\section{Pressing Drum Swiss.}

The pressing table is usually on a brick or stone wall and is slightly inclined so that the whey will drain off. The curd cloth with the eurd in it is put into a hoop made of a band of elm wood held in circular shape by means of a cord that runs around it. The illustration shows such a hoop with a cheese in it. The hoop rests on a circular press board while a similar

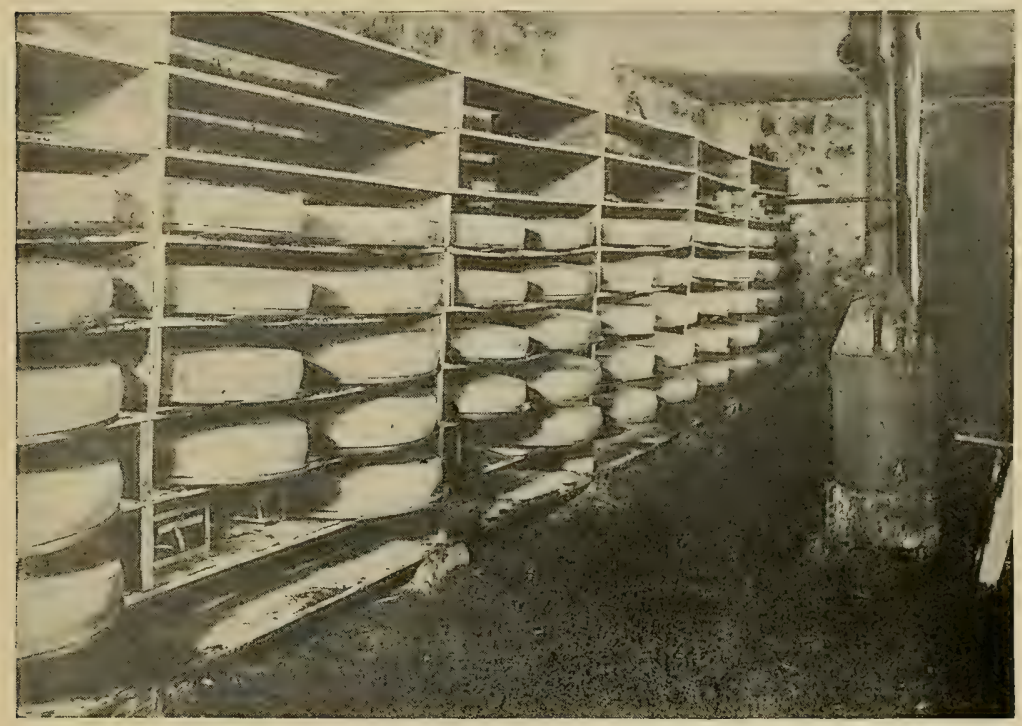

Fig. 76.-Curing cellar in a Swiss cheese factory, near Monroe, Wis. The large drum Swiss cheese are on the shelves. The small boiler supplies steam for moisture when too dry.

board is placed on the top of it. The hoop is adjusted in diameter by means of the cord so that the curd a little more than fills it.

For the first fifteen minutes it is pressed lightly, then a little more pressure is applied, and in half an hour full pressure is put on. It is turned several times a day, the eloth being taken off and readjusted each time. There are usually two eloths used in the operation, one cloth lying underneath, and the other 
spread over the top and tucked in between the hoop and the cheese. Dry cloths are put on several times during the day. The cloths should be kept clean by thorough washing and scalding. The press may be worked partially by means of a screw as shown in the illustration, but the main pressure is ottained by placing a post between the cheese board and a heavy beam. The post is close to the fulcrum end of the beam, while the long, heavy end of the beam gives the pressure.

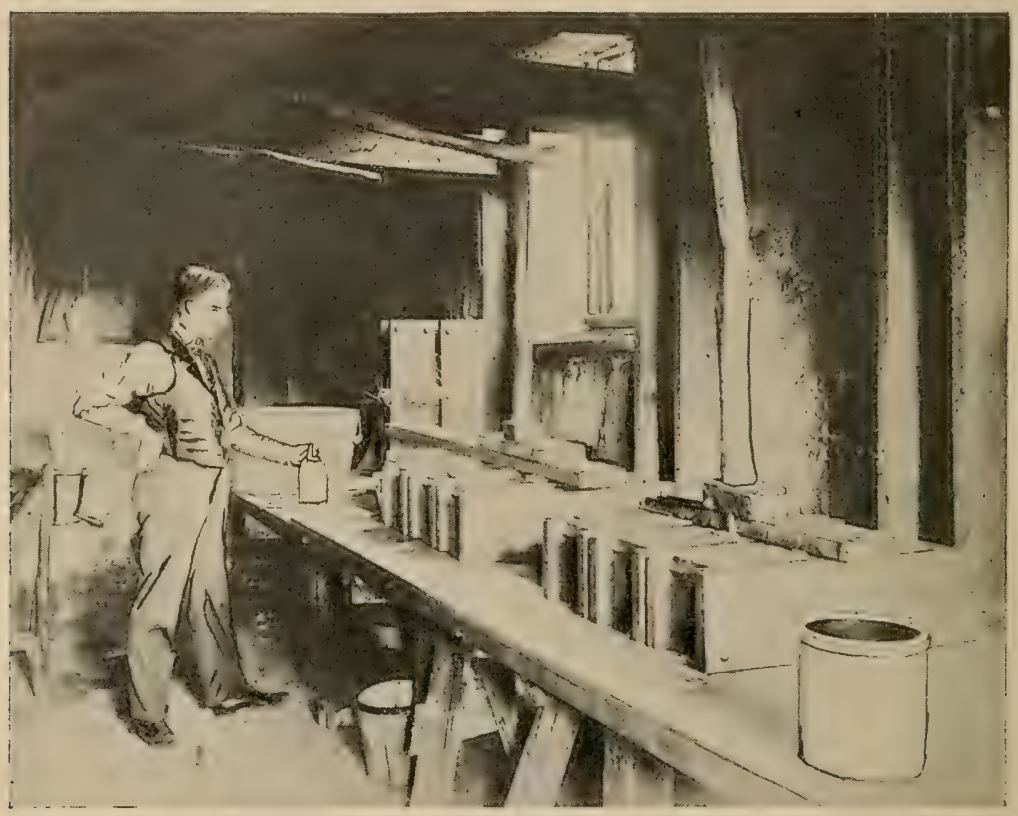

Fig. 77.-Block Swiss under pressure in individual molds.

\section{Pressing Block Swiss.}

Block Swiss is practically the same as a round Swiss in every way but the form in which it is pressed. It is first pressed into a rectangular eake twenty inches wide and six inches thick. A sliding end regulated by a screw adjusts the volume of the mold to the quantity of the curd. It is turned and pressed in this mold just like a drum Swiss for the first twelve hours. It is then eut into blocks six inches wide and put into another mold with partitions in it just large enough for each piece. Some- 
times, however, the curd is pressed from the start in a mold six inches wide by six inches deep and twenty inches long.

\section{Marking Cheese.}

When a cheese has been in the press twenty-four hours it is taken out. It should be perfectly square at the edges with no wrinkles left in it by folds in the cloth. A black paste made of butter and lampblack is used for marking the date on the cheese. It is just as important to keep a record of the way a Swiss curd may act as it is with a Cheddar eurd (192). Such a record will enable the maker to follow the cheese in the curing cellar.

\section{Salting the Cheese in Brine.}

Most makers salt their cheese in a brine bath. A tank of brine is kept in a cool room, sometimes in the cellar. The brine is made up by dissolving salt in water until the brine formed is dense enough to float an egg. As cheese are salted in the bath and absorb the salt, it is necessary to renew the salt quite often. The cheese is immersed in the brine, turning it over

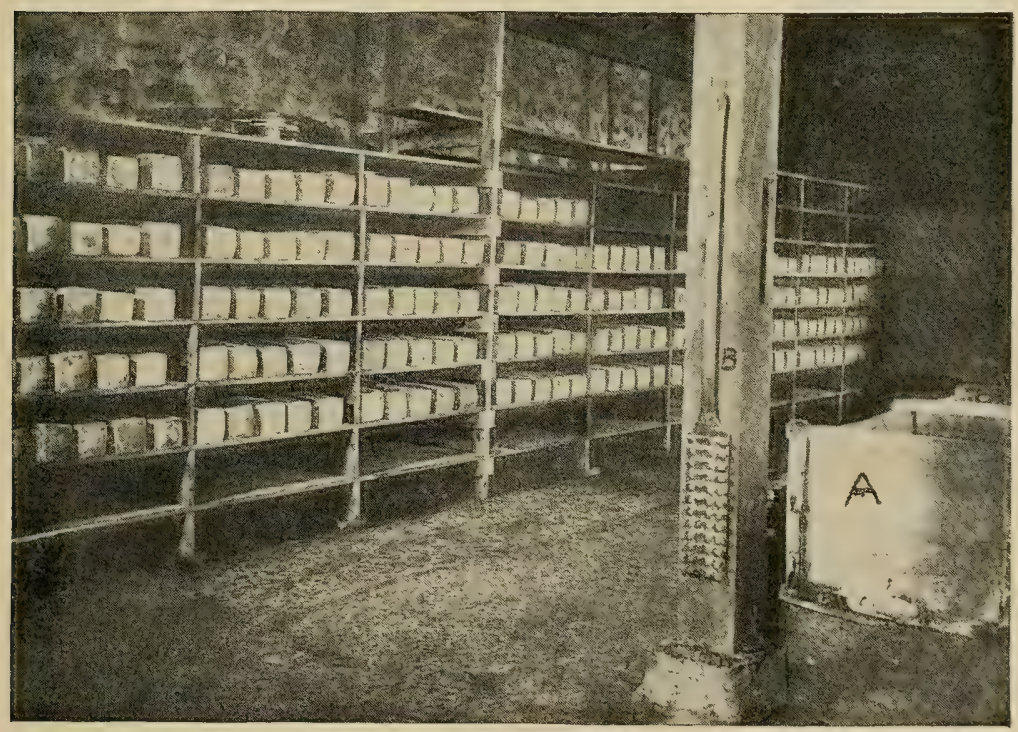

Fig. 78.-Block Swiss cheese in cellar at a factory, near Monroe, Wis. The large trush $\mathrm{B}$ on the post is used for washing drum Swiss cheese. The brine tank $A$ is seen in the illustration. 
occasionally, as the cheese will float and the top rise a little above the surface. A cheese is kept in the brine for three or four days, according to the amount of salt it is desired to work into it.

\section{Salting with Dry Salt.}

Some makers do not use a brine bath for salting, but seatter coarse salt on top of the cheese. The cheese is kept on a shelf in the cellar, with a salting hoop around it. This hoop is used simply to keep the cheese from spreading while it is soft. The salt draws moisture from the cheese. This moisture dissolves the salt and acts as a medium for the transmission of the salt to the interior of the cheese. No more salt should be applied than can be absorbed over night, so that the cheese will be dry next morning. It is claimed that with the brine method the salt is applied more evenly to all parts of the cheese. A cheese is salted with dry salt from three to five days. If gas shows in a cheese by its huffing or bloating, a little more salt applied to that locality will check the gas.

QUESTIONS ON CHAPTER XV.

1. What is the cause of glaesler cheese? 2. How much acid should milk for Swiss cheese have before setting? 3. How may the acidity of milk for Swiss cheese be determined? 4 . Why are makers more likely to have glaesler cheese in the fall months than in summer? 5. What is the effect of whey rennet with regard to the acidity of milk? 6. What danger is there with regard to gassy fermentations when whey rennet is used? 7. What is the probable cause of glaesler cheese when commercial rennet is used and how may this be remedied? 8. How much lactic acid starter may be used in milk to be made into Swiss cheese? 9. Why is the test for strength of whey rennet as generally practiced in factories not correct? 10. To what other cause than rich milk can glaesler cheese in the fall be attributed? 11. What effect on yield and quality of cheese does the butter fat have? 12. At what temperacure should milk for Swiss cheese be set? 13. What are the two classes of copper kettles used? 14. How are the fire kettles kindled? 15. Why is the current of milk around the kettle stopped in a few 
minutes after adding the rennet? 16. When is a Swiss curd ready to eut? 17. How much rennet should be used in making Swiss cheese. 18. How is a Swiss curd cut? 19. Describe a Swiss harp. 20. Why is a Cheddar curd knife better for eutting a Swiss curd than a Swiss harp? 21. What is the purpose of the wooden brake placed in the side of the kettle while heating the curd. 22. At what temperature should a Swiss curd ke cooked? 23. How do the Reaumur and Fahrenheit seales compare? 24. When is a curd sufficiently firm for dipping? 25. What is the effect of an over-cook? 26. What is the effect of an under-cook? 27. How is the curd gathered into a lump or eake when firm enough to dip? 28. How is the press cloth put around the cake? 29. How is the curd transferred from the kettle to the pressing table? 30. How is a drum Swiss pressed? 31. How is the hoop or mold adjusted? 32. Why should care be taken in putting the last pieces of curd with the lump on the press? 33. What trouble may result if the curd cracks? 34. How are the eloths adjusted on the cheese? 35. How is a cheese marked? 36. What are the two methods of salting Swiss cheese? 37. How strong should the brine be made? 38. How long is a cheese left in the brine? 39. How is a cheese dry salted? 40. What advantage is claimed for brine salting over dry salting? 


\section{CHAPTER XVI.}

\section{SWISS CHEESE-WORK IN THE CELLAR.}

\section{Starting the Eyes.}

From the salting shelf or brine tank the cheese is taken to the curing cellar. The curing covers two stages and the cheese should be handled in two cellars to secure the proper conditions for a perfect curing. The first curing cellar should be kept at a temperature of about $70^{\circ} \mathrm{F}$. At this temperature the gassy fermentations set in and start the eyes. By tapping the cheese with the finger, the eyes can be located, for the cheese will begin to sound hollow. Care should be taken to prevent the eyes from forming too much in one part. Eyes may be checked by salt, or they may be developed by a little higher temperature and more moisture. As a cheese dries out the eyes are checked. A steam jet in the cellar will provide desired moisture.

\section{Reason for Making Block Swiss.}

Block Swiss are handy for eutting. Sometimes where the fermentations are hard to control, block Swiss is made instead of the round variety, for the blocks being smaller, gassy fermentations can be checked quicker, and on the other hand, where the eyes are slow in forming they can be coaxed easier.

\section{I. Handling on the Shelves.}

The large round cheese is kept on a round cheese board. By this means the cheese ean be easily handled. It is kept free from mold by frequent scrubbing with a long-handled brush made for the purpose. When it becomes necessary to turn a cheese, it is carried on the board to a table, where it is flopped over onto another board of the same kind. The turning of the cheese at the press is done in like manner.

\section{The Second Cellar.}

After the eyes have been well started, the cheese is transferred to a second cellar which is kept at about $60^{\circ} \mathrm{F}$. Here 
the eres may still develop slorly, but they should not bloat the cheese. If a maker attempts to cure cheese in one cellar, he will be likely either not to get the eyes started, or if they do start they may develop too far.

\section{Handling Block Swiss in Cellar.}

Block Swiss being smaller than the drum cheese are more easily handled. They should be washed often enough to keep them clean from mold. Care should be taken, however, not to keep them wet, for in that case the rinds will soften.

\section{Length of Curing Period.}

Swiss cheese cures slowly. As previously explained, the enzymes in the milk break dorm the hard curd into soluble peptones. This process takes a number of months and a fine Swiss cheese should be at least eight or ten months old before it is ready for consumption.

\section{Boxing Drum Swiss.}

Drum Swiss are shipped in large tubs. The tub is made a little tapering, and to fit the diameter of the cheese. First a large round scale board is put in the bottom of the tub. A cheese that just fills the tub in diameter is lifted in and pressed tight against the bottom. Another scale board nest follows and on top of this another cheese is crowded. In this way probably sir cheese are put in a tub. On top of the last a seale board is placed and then the circular cover is forced down on top, by the maker standing on it and gently crowding on all sides. With this pressure on it the eover is nailed into place. In this way the cheese will be prevented from moving and injury during transportation. Quite often a thousand pounds of cheese will be filled into one tub. If the cheese has to stand in storage a long time, especially if rarm, it may streat some and the scale boards will prevent the cheese sticking together and spoiling the rinds.

\section{Boxing Block Swiss.}

Block Swiss is put up in boxes six inches deep, trenty inches wide and three feet long. Such a bor will hold a row of six cheese. A paper is put in the bottom of the box. scale boards between the cheese, and another paper on top.

The method of grading cheese has been explained (276). 


\section{Whey Butter.}

It has been explained that in the methods of making Swiss cheese more fat is lost in the whey than in the manufacture of Cheddar. It is the general practice in Swiss factories to make butter from the whey. In the great majority of factories this butter is little more than grease. The reason for this is that very erude methods are employed in its manufacture. The fat as it rises on the whey is soft because it is warm. Under these warm conditions bad fermentations are at work causing poor flavors. The cream obtained is churned without being properly cooled with ice and the grain of the butter is therefore soft and greasy. The grease thus obtained sells for about ten cents a pound.

By the use of a separator a much more efficient skimming can be done, and the cream will be thick. With ice and a proper vat for holding the cream, the butter fat can be hardened and the eream ripened slowly, thereby securing fairly good flavors. If the cream be churned at a low temperature, an efficient churning will be possible, and a good grain and a fair flavor be obtained in the butter. If this butter is held in a refrigerator until shipping, a much better price can be obtained for it than for the grease now often sold as whey butter. A number of factories where the whey is skimmed by a separator and the cream properly ripened, are turning out butter that sells for full market price, whereas the factories that are making whey butter in the old way receive only half this price. It pays to do things right.

\section{QUESTIONS ON CHAPTER XVI.}

1. At what temperature should Swiss cheese be kept to start the eyes? 2. How may the location of eyes in the cheese be determined? 3. How may an over development of eyes in local points in a cheese be checked? 4. What is the effect of a dry atmosphere on the development of eyes? 6. How may moisture be supplied to a cheese cellar? 7 . What is the advantage in making block Swiss instead of drum Swiss. 8. How are drum Swiss handled on the shelves? 9. How is a drum Swiss cheese turned? 10. Why are two curing rooms neccssary 
in manufacturing Swiss cheese? 11. At what temperature should the first and the second cellar be kept? 12. Why should old and new che'ese not be kept in the same cellar? 13. How often should Swiss cheese be washed? 14. What will be the effect of keeping the cheese too damp? 15. How long is it necessary to cure Swiss cheese? 16. How are drum Swiss cheese shipped? 17. What is the use of the scale board between the rinds? 18. Why should the cheese be crowded into the tub? 19. How many cheese are placed in a tub and what is their aggregate weight? 20. What is the size of a box for block Swiss? 21. How many cheese are put in a box? 22. How can whey butter be made to bring a much better price than is now usually obtained for it? 


\section{CHAPTER XVII.}

\section{BRICK CHEESE.}

\section{Characteristics of Brick Cheese.}

Brick cheese is probably so called because it is made in the form of a brick, and bricks are used for pressing the cheese in the mold. Brick eheese has a milder flavor than Cheddar; it is moist and suits a large number of people who are especially fond of mild cheese. It can be eut into thin slices which do not erumble and this brings it into favor.

It generally contains small holes, but does not have the large eyes of Swiss cheese. It is softer than Swiss, but not so soft as Limburger. The real difference between brick and Limburger is that the former contains less moisture and is cured in a drier atmosphere than the latter; these conditions of moisture inside and outside the cheese influence the character of the fermentations in it.

\section{Quality of Milk Required.}

For brick cheese, the milk should not be as ripe as milk for Cheddar, and on the other hand it should not be so sweet that the rennet will not expel the whey properly, for it will then have a tendency toward Limburger in the softness of the texture and the gas germs may get more of an ascendency in the cheese than when the milk is ripened further before setting. If the milk is ripe enough so that the curd will string on the hot-iron before it can be gotten out of the whey, a Cheddar flavor will develop. One of the finest Cheddar flavors that the author has ever observed, was in a brick cheese in which one eighth of an inch of acid was developed on the curd at the time of dipping.

\section{3ro. Milk, When Received.}

It is evident that milk may be received but once a day if it is properly cared for, in fact it will be less liable to develop 
gas in the cheese if the milk is a few hours old. On the other hand, milk that is over-ripe cannot be used without destroying the peculiar character of brick cheese.

The rennet test and the acid test previously described ( 82 and 136) are of importance in obtaining milk of the proper acidity for brick cheese. If the milk is found to be very sweet, a lactic ferment starter may be added, so that a pure lactic acid fermentation may predominate over the gas forms, and thereby secure a cheese with fewer holes.

\section{3xI. Quantity of Rennet Required.}

Brick cheese is a quick euring cheese, and a little more rennet is used than for a medium curing Cheddar. The milk will, of course, be a little sweeter than for Cheddar and enough rennet is used to coagulate it in twenty minutes.

\section{How Cooked.}

Brick cheese is made in a steam vat; it is set at $86^{\circ} \mathrm{F}$., the curd cut and the temperature raised for firming, the same as with Cheddar cheese. The temperature at which the firming takes place depends on the acidity of the milk. With milk nearly as ripe as for Cheddar, $108^{\circ} \mathrm{F}$. will do, while $118^{\circ}$ or $120^{\circ}$ may be required for very sweet milk. The temperature usually employed is about $114^{\circ} \mathrm{F}$.

\section{3r3. Testing Curd for Firmness.}

Curd, when ready to dip, should feel as firm as curd for Cheddar cheese. An over cook will make the cheese dry and corky, and an under cook will make a soft cheese approaching a Limburger.

\section{3r4. Dipping the Curd.}

When the curd is firm enough, the whey is drawn off so that only enough is left in the vat to keep the eurd from matting together. A few handfuls of salt per 1000 pounds of milk are then added to the curd for the supposed reason of checking gas fermentations, but as the salt dissolves in the whey and runs away, this operation can be of little use. Some makers are in the habit of salting the milk by placing salt in the strainer when the milk is running into the vat, to check the development of acid and gas. This, however, is positively injurious to 
the milk as it retards rennet action (92) and does not accomplish the object sought.

\section{Brick Cheese Molds.}

The brick cheese mold is a rectangular box without bottom or top. The common size is ten inches long by five inches wide and eight inches deep. In some localities they are eight and a half instead of ten inches in length.

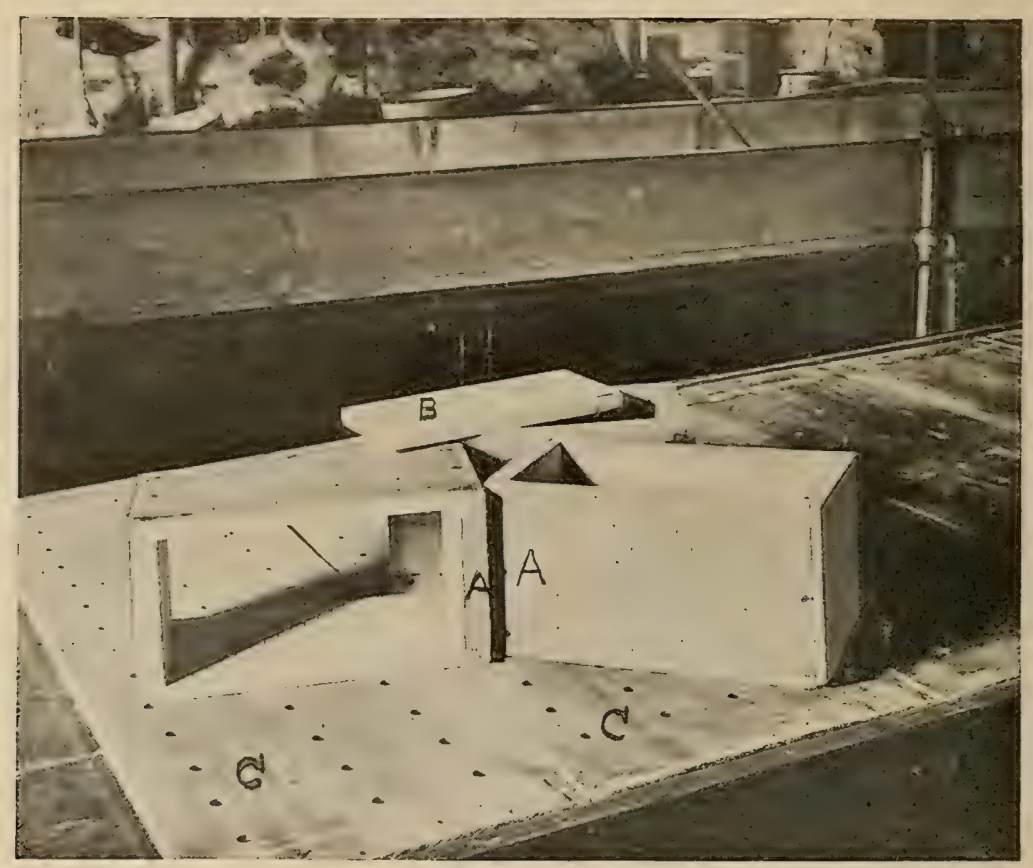

Fig. 79.-Brick and Limburger cheese molds. A, molds. B, follower. C, draining board.

Slits sawed on the inside enable the whey to more readily escape. Sometimes molds are made of perforated tin, but they do not hold the temperature as well as wood.

\section{I6. Draining Table.}

These molds are placed on a draining table. The table is about thirty inches wide, by six, eight or ten feet long, and inclined toward one end. A guard two inches high is fastened to the upper end and sides. A half-inch strip is fastened along the inside of this guard on which to rest the draining boards. 


\section{Draining Boards.}

These draining boards are a foot or sixteen inches wide and have several rows of inch holes bored through them. These boards are laid in the drainage table with their ends resting on the half-inch strips referred to above. A eloth, such as is used on the racks in Cheddar cheese manufacture, is thrown over the draining board, and the molds are set side by side on top of this eloth.

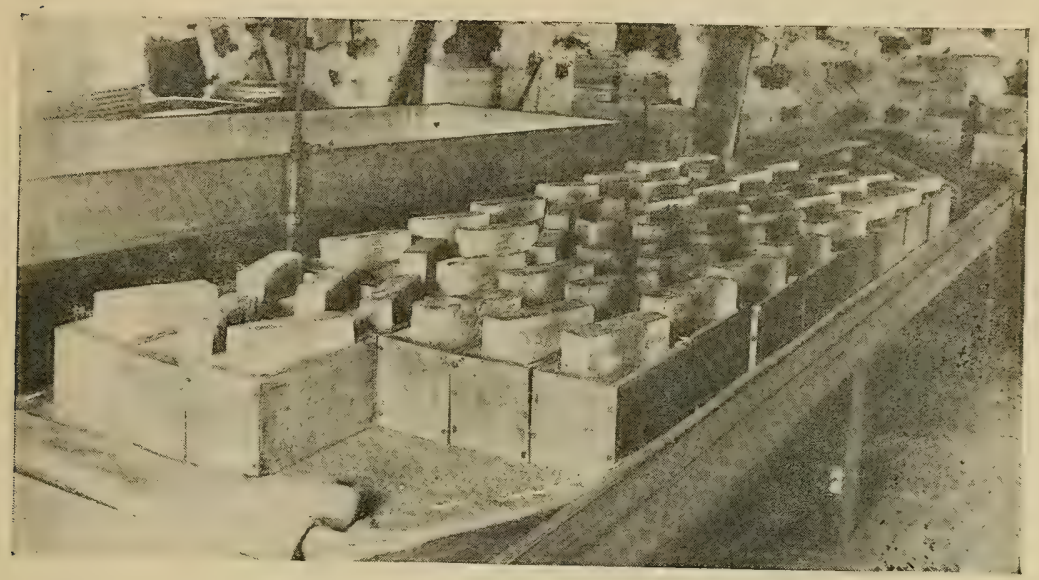

Fig. 80.-Brick cheese in the molds. A cloth is placed under the molds.

\section{I8. Filling the Molds.}

The table is placed close to the vat, and the operator stands between it and the vat. With a eurd pail he dips the curd out of the vat and fills it into the molds. The whey goes through the eloth and the holes in the draining boards, and runs down the table into a whey gutter. Care should be exercised to get just the same amount of curd into each mold so that the cheese, when the curd is all pressed tight together, will be atout three or four inches thick, and will weigh six pounds while green. Wooden followers that just fit in the molds are then put on top of the curd.

\section{Pressing the Cheese.}

One or two bricks are placed on top of the follower in each mold for pressure. In an hour or two the mold is turned over and the pressure applied to the other side. This may be done 
several times during the twenty-four hours the cheese is in press.

\section{Salting the Cheese.}

At the end of twenty-four hours, the cheese is taken out of the molds and salted in a salting room, which is really a cellar room between the making room and the curing cellar.

The salting table is built like the draining or pressing table; with the exceptions that the sides are ten or tweive inches high and there are no draining boards laid on it.

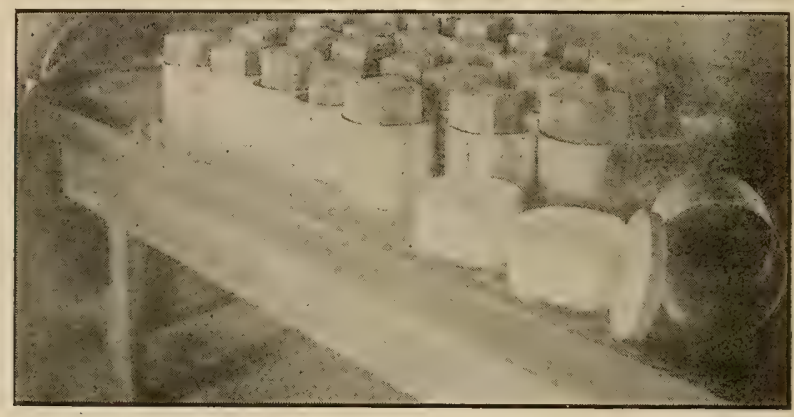

Fig. 81.-Round Brick or Imitation Munster cheese in the tin molds.

Each cheese is rubbed with salt on all sides of it.

The salt dissolves and penetrates to the interior of the cheese, at the same time expelling moisture which runs off from the table. When the cheese is partially salted, the surface is scraped with a tool which is much like a piece of a saw blade. The small teeth scrape up small particles of the curd which are rubbed into the little erevices left between the particles of curd, and in this way a smooth rind is formed. The saiting usually extends over three days, the cheese teing turned each day and a little coarse salt being laid on the upper side.

The cheese are piled two or three layers deep, being laid on their broad sides. They may be piled deeper each day.

\section{I. Curing the Cheese.}

From the salting table the cheese is carried to the curing cellar, where it is laid on tiers of sheives arranged around the room. These shelves are ten or twelve inches apart. The cheese 
are laid on their broad sides for a week or two until they begin to cure, when they may be laid on their edges.

The cellar should be kept at a temperature of about $60^{\circ} \mathrm{F}$. and the relative humidity should be 80 to 90 per cent. This, it will be seen, is a little higher than is best for Cheddar cheese. With such a humid atmosphere the cheese will probably mold, and the maker is kept busy washing the mold off from the cheese. He should get around to wash each cheese once or twice a week, and if necessary oftener. The water used may be clear water, or it may have a little salt dissolved in it.

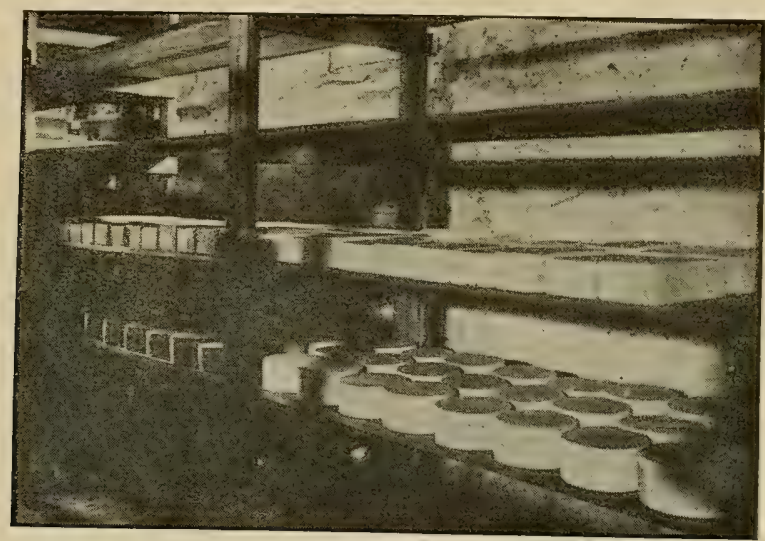

Fig. 82.-Brick and Munster cheese in curing cellar.

\section{Appearance of Gas, Remedy.}

If gas appears in the cheese it will huff up and bulge out at the ends, sides and edges. Where this occurs to any great extent the value of the cheese is reduced, and the best remedy is to apply the Wisconsin curd test to the milk and eliminate the cause. The value of this test was first demonstrated in brickcheese factories.

\section{Curing Process.}

A plug from a green cheese will be very harsh to the feel, and the plug will bend like rubber. In the course of about two weeks the harshness begins to disappear, and the cheese will break down in the fingers, and mold like wax, though it is somewhat softer and the plug more elastic than Cheddar. 
Brick cheese is usually shipped when it is a month old. If cured slowly, it is better at two months old, but being softer it is not as long lived as Cheddar.

\section{How the Cheese is Shipped.}

When brick cheese is ready to ship, it is wrapped in a good quality of Manilla paper and packed in rectangular boxes that are twenty inches wide, five inches deep, and three feet long, the same size as a Limburger box and one inch shallower than a block Swiss box. Each box will hold twenty to twenty-five cheese, and the net weight of the cheese in the box will be one hundred and five to one hundred and twenty pounds. The box weighs about fifteen pounds more.

\section{Fancy Styles.}

It has been pointed out that the market calls for odd sizes and shapes of Cheddar at higher prices than for the large Cheddar form. The same thing is true of brick cheese. A round cheese called a Munster is made in the same way as brick, excepting that the molds are round, and made of tin with holes punched in the sides for the whey to more readily drain out. Being round they are always laid on the flat ends to keep them in shape. The salting and curing is the same as for brick, as is also the method of shipping.

\section{QUESTIONS ON CHAPTER XVII.}

1. Why is brick cheese called by that name? 2. What are the characteristics of brick cheese? 3 . What quality of milk is required for brick cheese? 4. How often should milk be received? 5. What ean be said about the use of a lactic ferment starter in milk for brick cheese? 6. How much rennet should be used to set milk for brick cheese? 7. In what kind of a milk receptacle is brick cheese made? 8. How does the temperature, at which the curd should be cooked, vary with the acidity of the milk? 9. How firm should the curd be for dipping? 10. What would be the effect in the cheese of an over-cook? 11. What would be the effect of an under-cook? 12. How far is the whey drawn off from the curd before dipping? 13. Describe a trick cheese mold. 14. Describe a draining table and draining boards. 15. What kind of a cloth is used to cover the draining boards? 
16. How is the curd filled into the molds? 17. What are the dimensions and weight of a brick cheese? 18. How is the pressure applied to the cheese? 19. How long is the cheese kept in the molds. 20. Describe a salting table. 21. How are brick cheese salted? 22. How are the little crevices on the surface between particles of curd filled in? 23. How long is the cheese salted? 24. At what temperature should brick cheese be cured? 25. What should be the relative humidity of the air in the cellar? 26. Why and how often should the cheese be washed? 27. What physical change does brick cheese undergo in curing? 28. How is brick cheese packed for shipment? 29. How long should brick cheese be cured? 30. How does the life of brick cheese compare with that of Cheddar and Swiss, and why? 31. What is Munster cheese and how is it made? 


\section{CHAPTER XVIII. \\ LIMBURGER CHEESE.}

\section{Origin of Limburger.}

Limburger cheese is of foreign origin, having come from the province of Lüttich in Belgium. Its manufacture in this country is, however, earried on by Swiss and German rather than by Belgian emigrants.

\section{Characteristics of Limburger.}

Limburger is perhaps more generally known by its odor than by anything else. Many people who have never tasted it recognize the odor. But while it is kept cool it does not have such a pronounced odor as when warm. It is found on the market in blocks five inches square and about two inches thick, wrapped in Manilla paper and tinfoil. It has a soft texture and a yellowish color.

\section{Kind of Milk Required.}

Limburger is made from sweet milk. Except where the milk is gassy, very sweet milk is not an objection as with Swiss or brick cheese, for the reason that it is to be made soft and pasty anyway, and if the milk were too ripe the rennet would expel too much moisture.

\section{Utensils Used.}

A steam vat and eurd knives, like those used for Cheddar and brick cheese are used in the manufacture of Limburger. A draining table like those used for brick cheese is also used but the molds and subsequent handling are different than for brick.

\section{Setting the Milk.}

As the milk used may be sweeter than for brick it should be set at $90^{\circ} \mathrm{F}$., which is a little higher temperature than is used in making brick cheese. It is probably made up twice a day 
and its temperature when received may be a little higher than this. If it happens to be higher it can be set at the temperature it has without cooling to $90^{\circ}$. Enough rennet should be used to coagulate the milk in twenty to thirty minutes.

\section{I. Cooking Limburger Curd.}

The curd is eut when as firm as for Cheddar and brick, that is, when it will break over the finger with a clean fracture. The eurd is stirred and the temperature raised in the same manner as for the above mentioned kinds with the exception that the firming is done at a lower temperature. Ninety-six degrees is the temperature at which it is usually cooked. If the milk is very sweet the temperature must necessarily be a little higher than when some acid has developed. The curd is dipped when a little softer than in making brick cheese.

\section{Dipping the Curd.}

When the curd is firm enough the whey is drawn down so that it just covers the curd as is done in making brick cheese. The Limburger mold is made just like the brick mold with the exception that it is twenty inches long instead of ten. The curd is dipped into these molds and allowed to settle together, brick pressure being applied. After about half an hour it may be turned over. After resting in this position for fifteen or twenty minutes the mold is lifted from the cheese, which is then a block five by twenty inches, and two and a half to three inches thick. It is next divided into four sections so that each section will be five inches square. The cutting may be done with a common large bladed knife, but a ketter contrivance is a knife with three blades five inches apart. It is made in the following manner: A heavy piece of tin five inches wide and fifteen inches long is reinforced by a strong wire in the edge. Three pieces of heavy tin, four inches wide by five inches long, with the ends turned over to stiffen them, are soldered five inches apart on one side of the large piece of metal. By simply pressing this instrument down on the block of curd, the three blades cut it into four equal sized cakes.

\section{Limburger Pressing Table.}

The cakes are next transferred very carefully to the pressing table. This can hardly be called a press, as the cheese get 
no pressure beyond their own weight. The table is like the draining table with sides four inches high, but no draining boards are used. A rectangular frame the size of the table fits inside the table. The rows of the cakes are placed along one side and are divided by wooden partitions four inches high and five inches long. When the row is completed a long strip, the length

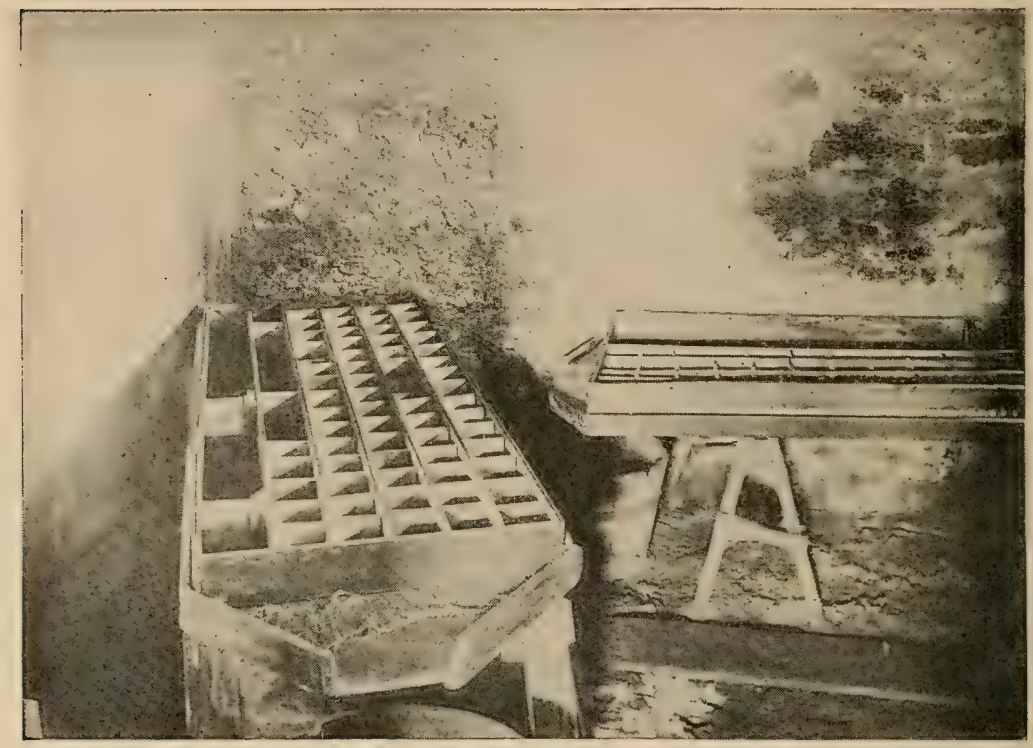

Fig. 83.-Limburger molds on pressing table, shcwing the long pieces and the short partitions between.

of the table, is placed against the row and another row is laid down. In this manner several rows are laid down and the last long strip held in place by several sticks wedged in between the strip and the opposite side of the table. The cakes are turned a number of times in order to drain them and firm the surfaces. The temperature of the room should be about $60^{\circ} \mathrm{F}$. In twenty-four hours the cheese go to the salting table.

\section{Salting Limburger.}

Limburger is salted in much the same way as brick cheese. First the edges are rolled over in a box of salt and then salt rubbed on the two broad surfaces. It is laid on the draining takle in single layers for the first day. The second day it is 
salted again in the same way and piled in two layers; the third day it is salted again and piled three or four layers deep. Limburger is salted on the average about four days.

\section{Curing Limburger.}

The curing of Limburger is a putrefactive fermentation. It goes from the salting table to the curing shelves, where the cakes are laid on their broad sides. They are washed every day with water to keep them moist and free from mold. The atmosphere of the cellar should have a relative humidity of 95 and the temperature should be about $58^{\circ}$ to $63^{\circ} \mathrm{F}$. Under these conditions the surface soon begins to get shiny and soft and change from white to a reddish yellow. This works its way to the center, changing the harsh curd to a soft condition. After about ten days the cheese may be set close together on their edges. This change requires from four to six weeks to work to the center, and the cheese is then ready to ship.

\section{Shipping Limburger.}

The cheese is first wrapped in Manilla paper and then in tinfoil and is packed in boxes twenty inches wide, five inches

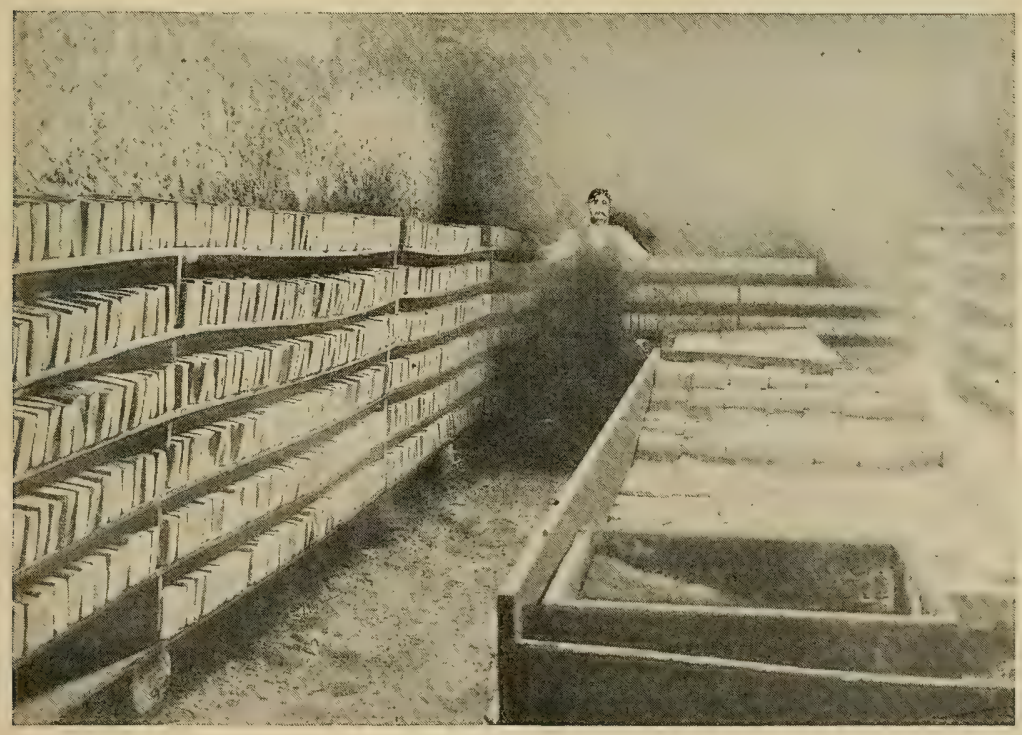

Fig. 84.-Limburger cellar. In front is the salting table with the cheese in the salt. In the foreground is a tox containing salt. The cheese may be seen on the shelves. 
deep and thirty-six inches long. It may be held in storage for a month or two longer before it reaches the consumer, but being soft it is not long lived.

\section{Cause of the Putrefactive Fermentation.}

The main cause of the putrefactive fermentation is the extremely moist condition in which it is kept. It may be brought about in harder cheese like brick and Cheddar, if they are kept wet, or come in contact with each other or a moist wall, in a very moist atmosphere.

QUESTIONS ON CHAPTER XVIII.

1. Where did Limburger cheese originate? 2. What are the characteristics of Limburger? 3. In what kind of packages is Limburger found in the market? 4. What quality of milk is required for Limburger cheese? 5. What kind of vat and eurd knives are used? 6. At what temperature is the milk set? 7 . At what temperature is the curd firmed? 8 . What would be the effect of over-ripe milk on the cheese? 9. How firm should the eurd be when ready to dip? 10. What kind of a mold is used and what are its dimensions? 11. How much pressure is applied to the curd in the molds? 12. What is the treatment of the curd in the molds? 13. Into what sized blocks is the curd cut when the mold is removed? 14. How is the curd cut into blocks? 15. Describe a pressing table. 16. How long is the cheese left on the pressing table? 17. How is the cheese salted? 18. How long is the cheese left in the salt? 19. How is Limburger handled in the euring room? 20. How long is Limburger in curing and what is the physical change that takes place? 21. How is Limburger packed for market? 22. What conditions especially favor the characteristic fermentation of Limburger? 


\section{CHAPTER XIX.}

\section{EDAM CHEESE.}

\section{Characteristics of Edam Cheese.}

In our best grocery stores one sees cheese put up in the form of round balls about six inches in diameter. They are colored a dark red or are of a bright yellow color, or may be wrapped in tinfoil. Each cheese weighs about four pounds and sells for a dollar, or at the rate of twenty-five cents per pound. The texture is perfectly solid and has a flavor much like an old Cheddar excepting that it is a little more salty and is a little harder.

\section{Origin of Edam Cheese}

By referring to a map of Holland it will be seen that North Holland is the portions of the country lying east and west of the Zuyder Zee. Edam is situated on the Zuyder Zee, about twelve miles northeast of Amsterdam. Edam cheese, together with Gouda, is made in other parts of Holland,

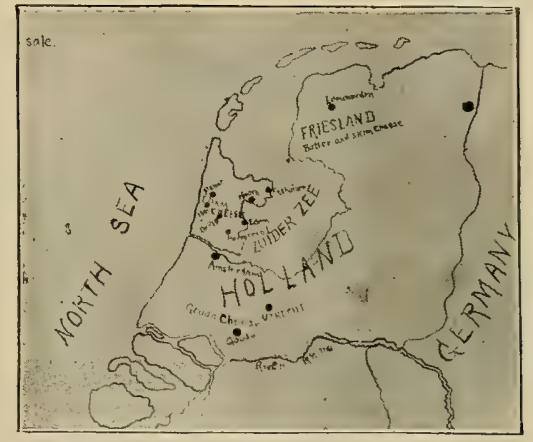

Fig. 85.-Map of Holland. but that portion north of the North Sea canal on which Amsterdam is situated, and west of the Zuyder Zee, is especially devoted to Edam cheese. Every week markets are held at Edam, Purmerend, Alkmaar and Hoorn for the sale of cheese.

\section{Farming in Holland.}

A large part of the country is below the sea level. Shallow lakes or seas like the Zuyder Zee have been surrounded by dikes, and the water pumped out, leaving level stretches of land that grows luxuriant crops. The cattle are of the breed 


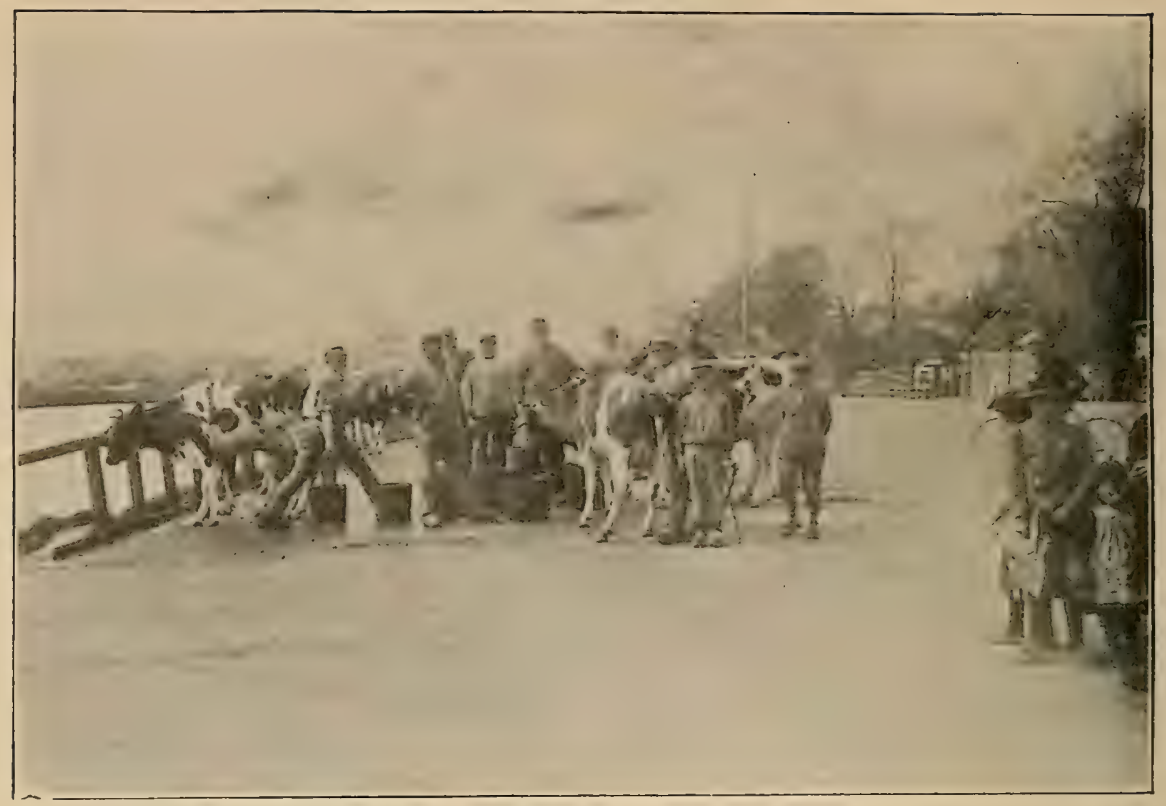

Fig. S6.-Dutch farmers washing cattle at the canal in Purmerend.

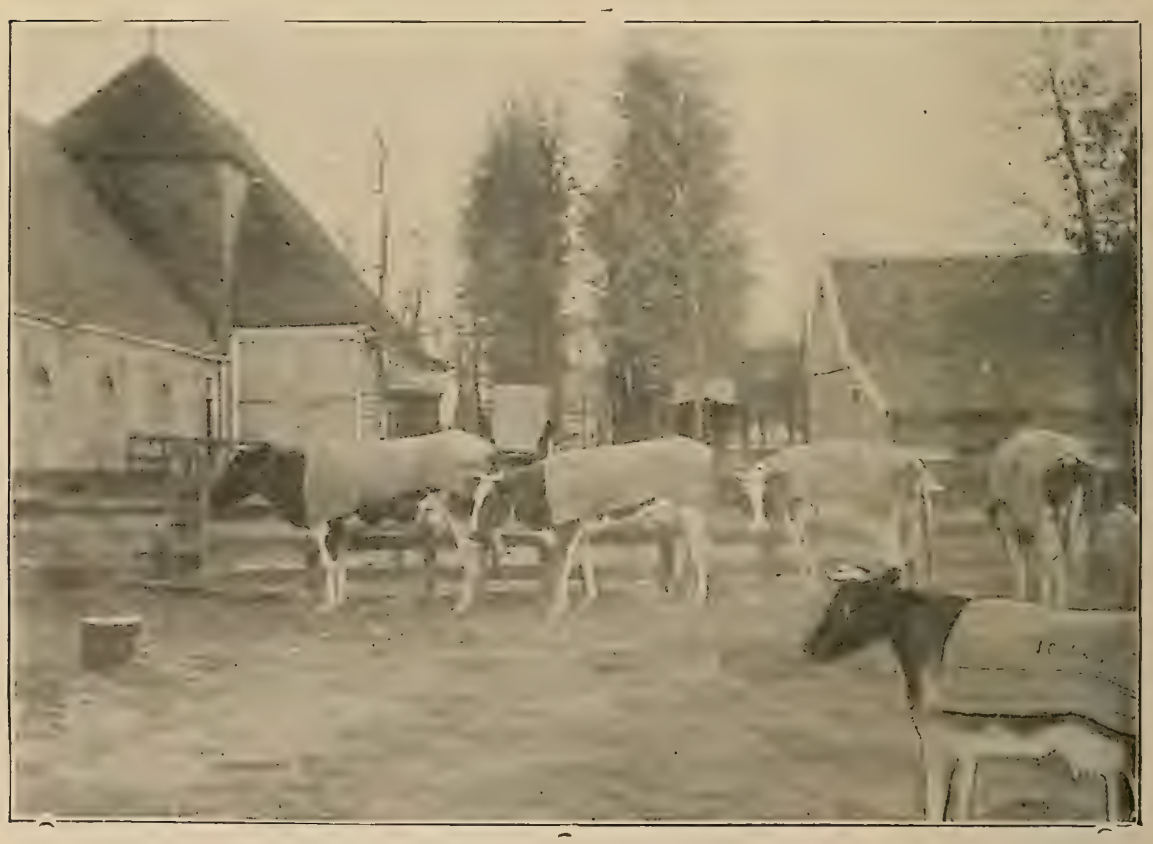

Fig. 87.-A Dutch farm scene in the Beemster Polder. Cattle in the barnyard just before milking time. 
known in this country as Holstein-Friesian. There are a few cheese factories, but the farmer visually makes his milk into cheese in his own dairy. The utensils are crude, the milk being set in a wooden tub and the necessary rises in temperature secured by heating a part of the milk or whey in a kettle and adding it to that in the tub. The cheese room, stable, living apartments and tool rooms are usually all under one roof. In May the cattle are turned out in the fields until November, and the stables are cleaned out and generally used for curing rooms. As there is a lack of wood for lumber the houses are built of stone or brick, which holds the temperature, and as the country is surrounded and tempered by the sea, ideal conditions are naturally present for curing eheese.

The factories have vats which are heated by steam as in this country.

\section{I. Edam Cheese in Holland.}

Edam cheese has been classed with the sweet-curd cheese, but the best quality of it approaches very closely to Cheddar cheese. Hollanders have considerable troutle with the gassy fermentati ins, and use a starter of sour whey which contains

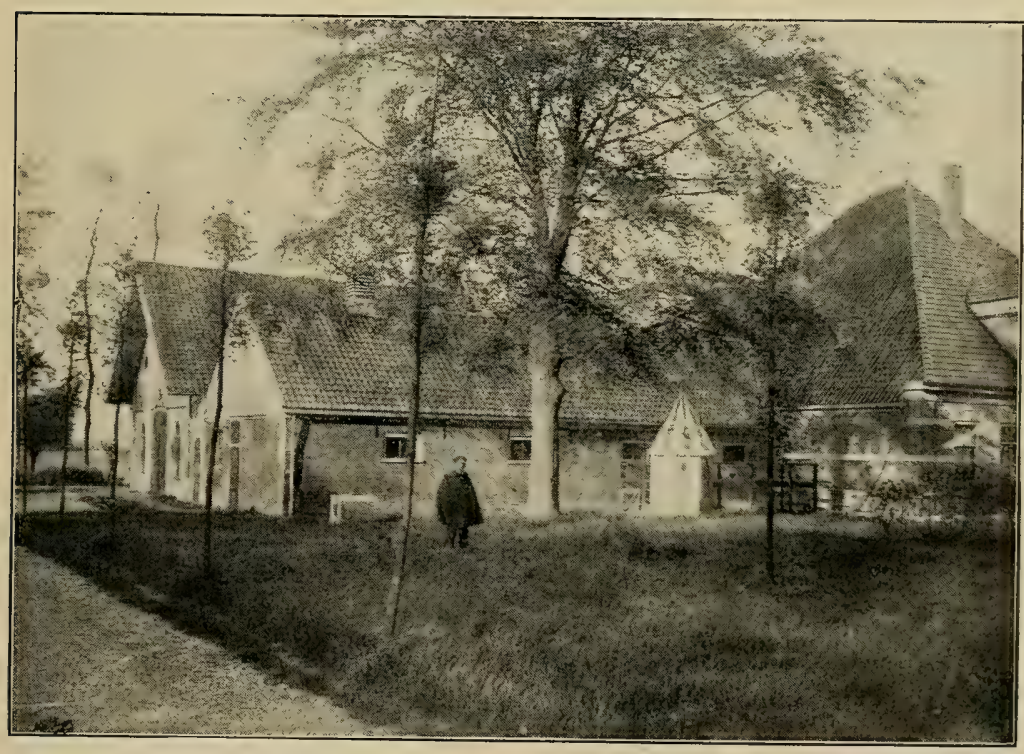

Fig. 88.-Farm tuildings at De Rijp, North Holland. 
a lactic-acid germ. The milk is made up once a day, which gives the night's milk a chance to ripen. The author observed sour Edams in the factories and dairies, and on the markets, which shows that the lactic acid sometimes gets the start of the makers. The purpose of the whey starter is to check the gaseous fermentations.

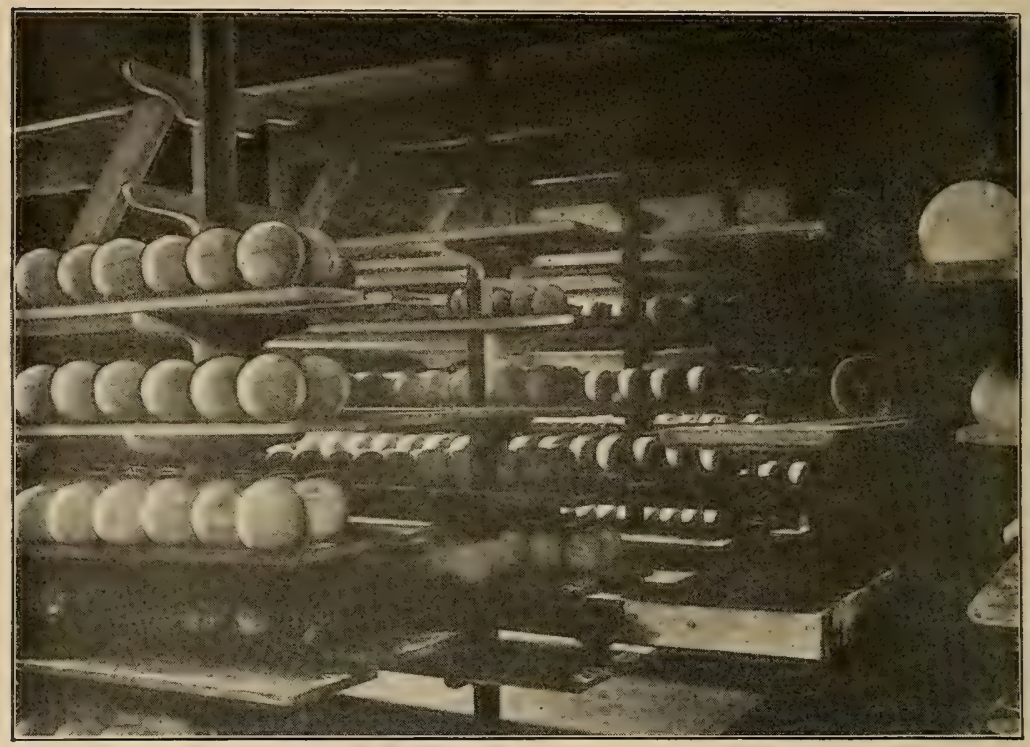

Fig. 89.-Curing-room of an Edam cheese factory at Hoogskarpsel in North Holland.

\section{Treatment of Cheese for Market.}

The cheese is marketed when it is about a month old. It may mold some on the shelves, and is therefore washed and then dried. A coat of linseed oil is rubbed over the surface making the cheese shine. It is loaded into carts without boxing and carried to market.

\section{Description of an Edam Market.}

On arriving at the market, which is a large open space, paved with stones, in the middle of the city, straw is first laid down on the pavement and the cheese piled on it in pyramidal pile like so many cannon balls. The pile is covered over with a cloth to protect it from the heat of the sun. When the market opens, buyers pass among the piles and try a sample from 
each pile with a trier the same as is done with other cheese. If the bargain is closed the salesman and buyer shake hands as if they would never let go, but if on the contrary no bargain is made, the buyer goes on and the salesman turns the plugged cheese over and places it in the bottom of the pile, and awaits the next inspection of his goods. When the cheese is sold, it is placed on skids, which will hold about 150 cheese, and official

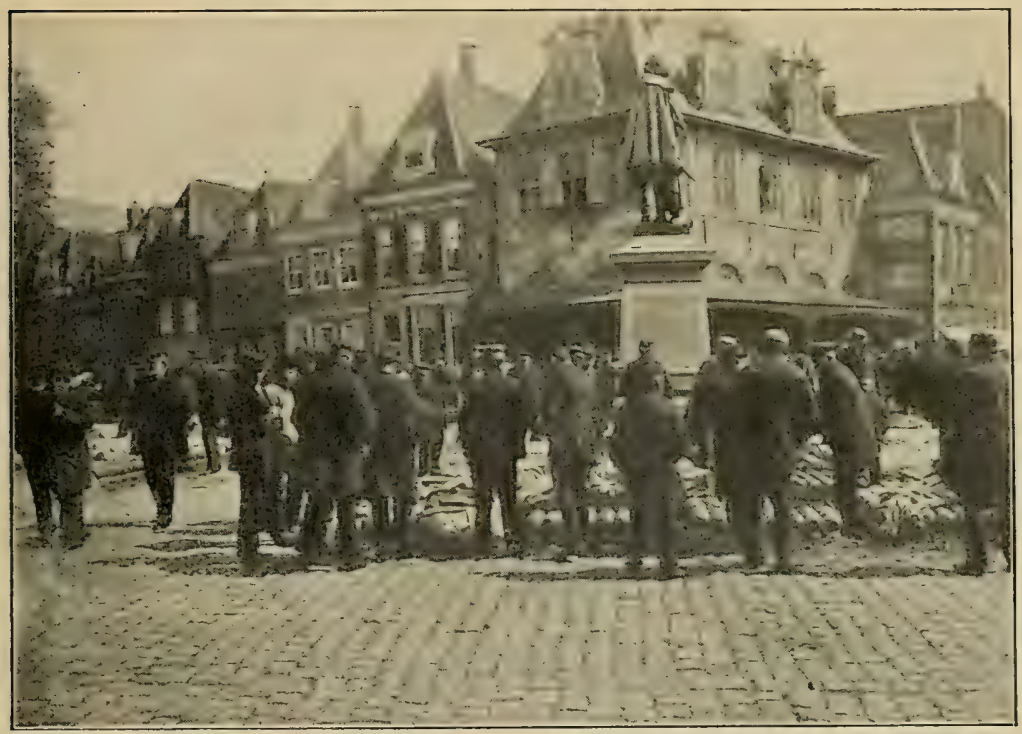

Fig. 90.-The weekly cheese market at Hoorn, North Hol'and. The market buildings where the cheese is weighed is just beyond the statue.

weighers place it upon large balances in the market building and balance the cheese with official weights. The buyer then takes possession of his cheese. The price paid will probably correspond to the price paid for Cheddar in this country. The best cheese reach this country, but are not consumed until they are eight, ten or possibly twelve months old. The fine characteristic flavor cannot be developed in less time, and it must be developed at a temperature not to exceed $65^{\circ} \mathrm{F}$. When it is cured, the cheese may be smoothed down in a turning lathe. The red color is obtained by immersing it for half a minute in an alcoholic solution of earmine. 


\section{Possibilities of Manufacture in America.}

As the milk in America is generally richer, the sanitary conditions better, and the climate conditions can be artificially supplied, it is possible to make an Edam in this country that is fully equal, if not superior, to the best imported Edam.

\section{Market for Edam in America.}

Edam as sold at wholesale in this country, is packed in cases of one dozen cheese each or about fifty pounds, and sells

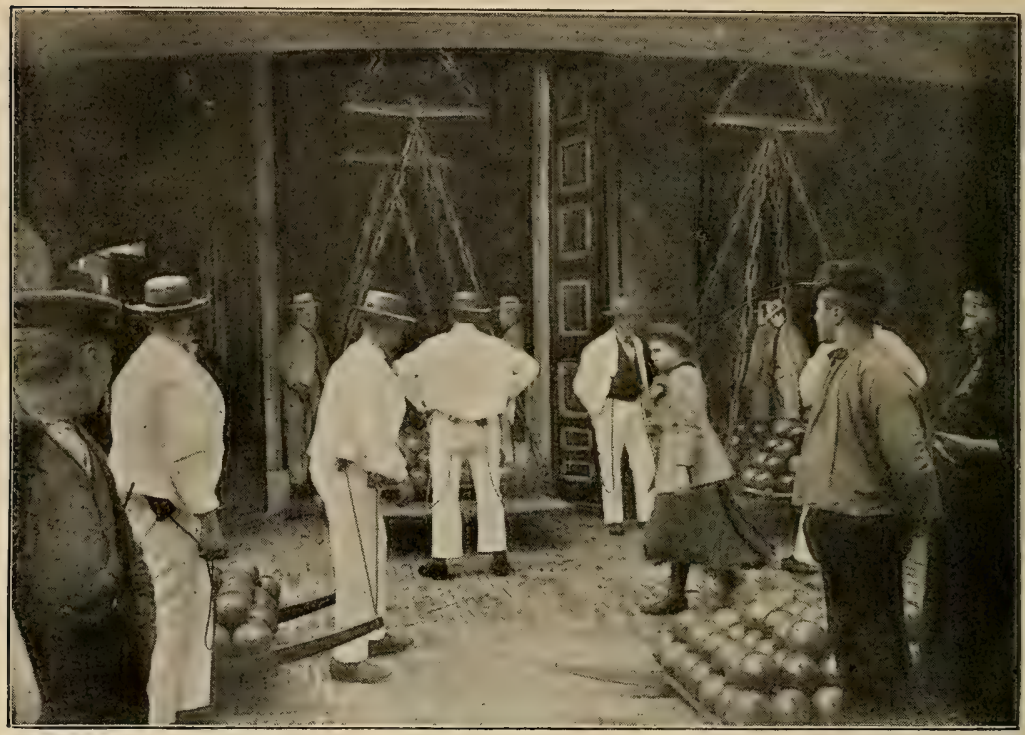

Fig. 91.-Weighing Edam cheese at the market at Hoorn.

at about $\$ 7.50$ per case. This is fifteen cents per pound, and ought to encourage the manufacture of this kind of cheese. Many wholesale houses are very anxious to buy it in large quantities.

\section{Method of Manufacture.}

The description already given will give a fair idea of Edam cheese as found in Holland. As the methods of manufacture used in Holland are crude, the method here given will be for practical and scientific conditions as found in America. 


\section{Quality of Milk Required.}

As has been explained, Edam is really a cheese in which the lactic fermentation is developed. The milk then must be such as is used for Cheddar, and the acidity should be determined by the rennet test in like manner; in fact, the milk should be colored and set, and the curd eut and firmed in the same manner as for Cheddar. When one-eighth of an inch of acid shows on the hot iron (corresponding to .2 per cent acid), the whey should be drawn and the eurd stirred free from whey.

\section{Handling the Curd for Edam.}

The curd is held for a time in the vat or curd sink in a granular ecndition, to air and develop acid, until it will string half an inch to an inch on the iron, and then it goes into the molds.

\section{Edam Molds.}

The molds for Edam cheese, as found in Holland, are mostly made of wood, - but manufacturers of dairy supplies in this country have found difficulty in making them of wood, so
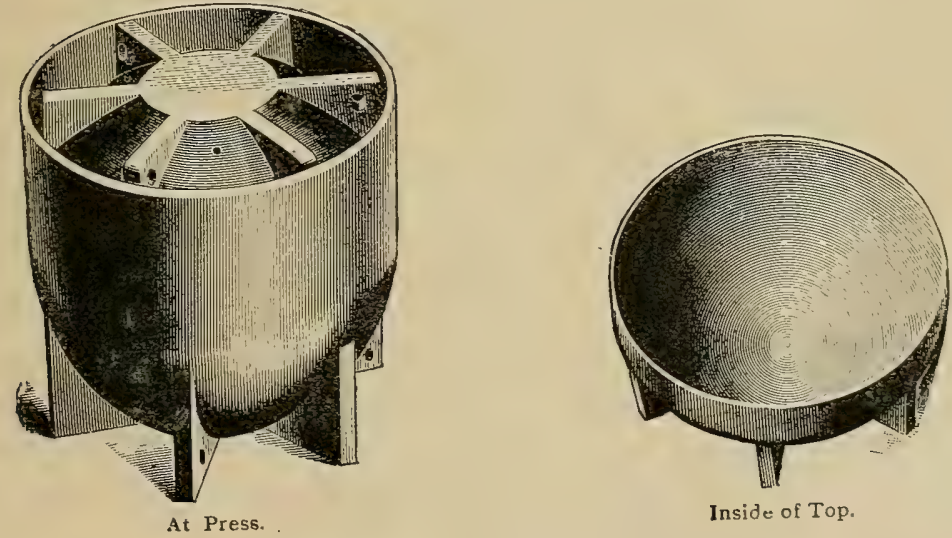

Fig. 92.-Edam Cheese Molds.

that they will hold their shape and not check. They are therefore making castiron molds which are turned down and galvanized. Each mold consists of two parts-a bottom part shaped like a bowl with hemispherical bottom; and a top, the interior of which is a true hemisphere that fits into the bottom 
part, and when pushed into it leaves an interior space perfectly spherical. The two halves have flanges on the ends which make them set squarely against other molds or the press heads. Holes drilled through these flanges enable the maker to insert an iron hook and pull the top and bottom apart. Several small holes through the ends of the halves allow the whey to escape from the imprisoned curd.

\section{Method of Pressing.}

In Holland two cheese go in a press together, one mold on top of the other with a wooden $4 \times 4$, 3 feet long, placed above them both for pressure. A Young-America gang press is better than this, as it saves both labor and space.

\section{I. Hooping the Curd.}

The curd is packed in the mold as tight as it can be crowded with the hands, and is rounded off on top. The cover is placed on top and the mold placed in the press. Pressure is applied gradually for a few minutes and full pressure put on in ten minutes. In half an hour the cheese is taken out and dressed.

\section{Dressing Edam Cheese.}

If just the right amount of eurd is placed in the mold, the cheese will be spherical and not much of a paring will have to be taken off where the edge of the two hemispheres meet. A bandage of cheese eloth is now wet with warm water and wrapped around the cheese, and a small cap laid on each end. This coming between the iron mold and curd makes the cheese close perfectly. Care should be taken to lap the cloth evenly so that when taken off from the cheese deep wrinkles will not be left. The cheese is pressed for the remainder of twenty hours. It is then taken out, and if desired, the bandage may be taken off immediately, or it may be left until later to prevent cracking. It ean, however, probably be taken off more easily when fresh from the mold.

\section{Salting Edam Cheese.}

The cheese is now rubbed with salt and placed in a salting cup. This is a cup slightly larger than the bottom part of the mold. It holds the cheese in shape and allows a thin layer $n f$ salt on the underside. It is salted daily, turning it each time, until it feels hard. It then goes to the curing shelves. 


\section{Curing Edam Cheese.}

The curing process is practically the same as for Cheddar, and the same conditions must be obtained; that is, a temperature of about sixty degrees and a relative humidity of about eighty.

\section{Shelves for New Cheese.}

The shelves for the new cheese have holes about two inches in diameter reamed out on the top side so that the cheese does not get out of shape, setting squarely on its end. After a month or six weeks it can be set on end without injury to the cheese. Of course, each cheese is turned and rubbed every day or two, and if any tendency to crack occurs (which is one of the serious difficulties that will be met) a very little salt scattered on the surface will check this tendency. When the cheese is a month old, a little cheese grease or oil rubbed on the surface will prevent a too rapid drying out.

\section{Length of Curing Period.}

This kind of cheese will not be a success unless it is cured at a temperature not to exceed sixty-five degrees for at least eight or ten months. A year of euring will be better. The fine flavor comes from the lactic-acid fermentation to start with, and then a slow curing in which the curd is changed to soluble peptones, such as give this cheese and Cheddar their particular flavors.

\section{Preparing the Cheese for Market.}

The cheese, when fully cured, should be washed and then scraped or turned down in a lathe. If the fancy requires it, the rind may be colored with an alcoholic solution of carmine, as previously indicated, and then wrapped in tinfoil to prevent further evaporation.

A box 18x24 inches, six inches deep will hold a dozen cheese. Paper should be put in the top and bottom of the box and thin pieces of board placed between them.

\section{QUESTIONS ON CHAPTER XIX.}

1. What are the characteristics of Edam cheese? 2. Where did Edam cheese originate? 3. What is peculiar about the farms in Holland? 4. What breed of cattle is kept in Holland? 
5. Do farm dairies or cheese factories predominate? 6. In what kind of a vessel is the cheese made and how is the temperature regulated? 7. Of what material are the houses in Holland built, and how does this affect the temperature of the curing rooms? 8. What are the elimatic conditions in Holland in regard to the conditions for curing cheese? 9. Is Edam a sweet-curd or an acid-curd cheese? 10. What kind of a starter is used in Holland? 11. What is the purpose of the whey starter as understood by the Dutchmen? 12. How is the cheese in Holland treated for marketing? 13. Where are the principal cheese markets in North Holland held? 14. What kind of Edams reach the consumer in the United States? 15. How are some of the cheese colored? 16. What conditions are necessary to obtain a fine Edam cheese? 17. What are the possibilities for the manufacture of Edam in America? 18. What kind of a market is there for Edam in this country? 19. What quality of milk is required for Edam cheese? 20. How is the milk treated until the whey is drawn? 21. How much acid should there be on the curd at the time of dipping? 22. How long and in what condition is the curd held until ready for the press? 23. Of what material are Edam molds in Holland made? 24. Of what material are they made in this country? 25. Describe an Edam mold. 26. What kind of press is required for pressing Edams? 27. How is the curd put into the mold? 28. How long is the cheese left in the press before dressing? 29. How is an Edam cheese dressed? 30. How long is an Edam cheese pressed? 31. What particular care should be taken in dressing the cheese? 32. Why is the bandage used on the cheese? 33. When is the bandage removed? 34. What is one of the most serious diffieulties to be met with in the manufacture of Edam? 35. How is Edam salted? 36. How long is Edam cheese salted? 37. How may cheese be prevented from cracking? 38. On what kind of shelves should the new cheese be placed and why? 39. How long should cheese be cured? 40. Upon what conditions does the flavor of Edam cheese depend? 41. How are Edams prepared for market? 
CHAPTER XX.

\section{COTTAGE, NEUFCHATEL AND SOFT CREAM CHEESE.}

\section{Utilization of Skim Milk.}

A great many eity dairies that turn a large part of their milk into cream have skim milk left on their hands, and to make the business pay as well as possible, they naturally look for a means of disposing of this skim milk. Usually there is quite a demand for the sour-milk eurd, known as Dutch cheese, cottage cheese, or Schmierkäse.

\section{Method of Manufacture.}

As this has been made probably for centuries, it would seem an easy task, and so it is, if conditions are just right, but as large dairies sometimes have difficulty in obtaining uniform results, a short chapter treating about the manufacture of this cheese from a scientific standpoint may be helpful.

\section{Curdling Power of Acid.}

As has been explained the easein of milk is precipitated by rennet and dilute acids. Sweet milk can be heated to the boiling point without curdling, but as acid develops, the milk wili first be coagulated at the higher temperatures, and then as the acidity increases, the temperature at which it will curdle is gradually lowered until skim milk containing .6 to .7 per cent of acid will curdle spontaneously. At about $70^{\circ} \mathrm{F}$. skim milk will not increase in acidity above nine-tenths of a per cent, as the growth of the lactic acid germ is checked. Van Slyke and Hart found approximately 5 per cent of sugar in milk used by them. When the milk contained .9 per cent acid (the maximum amount), 1.5 per cent milk sugar, or 28 per cent of that originally present, has disappeared; 62 per cent of the milk sugar that disappeared was left in the form of lactic acid. The re- 
mainder probably disappeared in the form of carbonic acid and other volatile substances.

\section{I. Effect of Fat on Per Cent of Acid in Milk.}

Fat in milk or cream takes the place of some of the milk serum. Cream containing 35 per cent fat will curdle with about five-tenths of a per cent of lactic acid, and milk containing 5 per cent fat will develop hardly more than seven-tenths per cent of acid. This is because the fat displaces a portion of the serum.

\section{Abnormal Fermentations.}

When other fermentations than pure lactic acid oceur, trouble may ensue, for gas may make the eurd froth so that it may be impossible to use it, or the curd may be slimy or the flavor may be impaired. The way out of such a difficulty is to use a lactic ferment starter in the milk (112).

\section{Measuring the Acidity.}

As acidity plays such an important part, it may be desirable to measure the acid. For this a Farrington alkaline tablet test outfit is to be recommended. In addition to the apparatus previously described for testing milk for an acidity of two-tenths per cent (106), a graduated glass cylinder of 100 c. c. capacity is required for measuring the water carefully. One tablet is used for each 19.5 c. c. of water, or five tablets for 97 c. c. of water. The titration is then made with 17.5 c. c. of milk measured into the teacup with a Babcock pipette. Each cubic centimeter of the alkali solution required is equal to one-hundredth of one per cent of lactic acid.

\section{Moisture, How Regulated.}

A very important factor in the manufacture of cottage cheese is the control of the moisture content. Seventy-five per cent of moisture makes a smooth cheese of good texture. More water makes it soft and sticky and less makes it harsh like sawdust. The time and temperature used in firming is the important thing here as in the manufacture of Cheddar cheese. The following rule will usually apply: Set the milk at $70^{\circ} \mathrm{F}$. until it coagulates. Cut it fine with a curd knife. Then heat to $90^{\circ}$ F. in thirty minutes. In ten or fifteen minutes draw the whey and dip as described in paragraph 365 . 
Van Slyke and Hart made careful investigations with regard to the influence of the temperature of souring and of subsequent heating upon the moisture content and the texture of the cheese, some results of which are given in the following table :*

INFLUENCE OF TEMPERATURE OF SOURING AND HEATING UPON MOISTURE IN CHEESE.

\begin{tabular}{|c|c|c|c|c|c|c|c|}
\hline 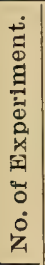 & 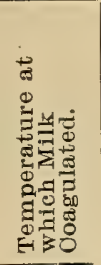 & 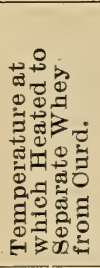 & 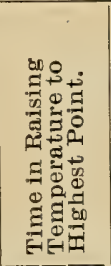 & 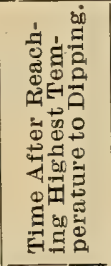 & 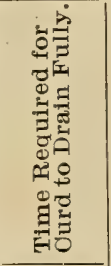 & $\begin{array}{c}\text { Water } \\
\text { in } \\
\text { Oheese. }\end{array}$ & $\begin{array}{l}\text { Texture of } \\
\text { Oheese. }\end{array}$ \\
\hline & Deg. F. & Deg. F. & Minutes & Minutes & Minutes & Per cent. & \\
\hline 1 & 60 & 80 & 60 & 15 & 135 & 77.6 & good \\
\hline 2 & 60 & 90 & 20 & 5 & 145 & 78.8 & soft \\
\hline 3 & 70 & 80 & 30 & 30 & 150 & 81.5 & mushy \\
\hline 4 & 70 & 90 & 40 & 15 & 10 & 73.5 & good \\
\hline 5 & 80 & 90 & 20 & 10 & 60 & 74.9 & good \\
\hline 6 & 80 & 100 & 35 & 5 & 50 & 71.8 & slightly dry \\
\hline 7 & 90 & 100 & 20 & 0 & 5 & 71.5 & slightly dry \\
\hline 8 & 90 & 110 & 30 & 0 & 5 & 68.1 & tough, hard \\
\hline
\end{tabular}

\section{Dipping the Cheese.}

As soon as the curd has settled so that it will not interfere with the whey strainer, the whey is drawn off and the curd is dipped with a curd pail into a cloth strainer. This strainer is made of linen strainer cloth, and is in the form of a tube so that it can be slipped over a wooden frame. The ends of the frame are supported by wooden horses, which are set over a drain to catch the whey. The curd is stirred in this strainer to free it from the excess of whey. Perhaps a little cream or butter may be added to the curd at this time to make it softer and more palatable. Cottage cheese, like other kinds, is more desirable if it contains a good quantity of butter fat. A little dry sage or caraway seed may also be worked into it to give it flavor. Salt to suit the taste, about two pounds to the thousand pounds of milk, is also worked in. 


\section{Hydrochloric Acid Cheese.}

Milk may be coagulated at once by the use of ten ounces of chemically pure hydrochloric acid, sp. gr. 1.20, diluted to ten times its volume, per 100 pounds of milk. The milk to be used should be at a temperature of $70^{\circ}$ to $80^{\circ} \mathrm{F}$. The acid is added slowly and stirred in earefully to evenly distribute it. Stir until the whey appears clear. The whey is then drawn off and the curd dipped and salted as described in paragraph 365. The yield of cheese by either method will depend upon the composition of the skim milk and the water retained, but it will be from sixteen to twenty pounds per 100 pounds of skim milk. The cost of acid is four or five cents per 100 pounds of milk, or onefourth cent per pound of cheese. The disadvantage of the hydrochlorie acid method is the lack of sour milk flavor to the cheese. This can be produced in a measure by adding some sour cream or sour milk to the curd.

\section{Marketing the Cheese.}

Local conditions may affect the form in which the cheese is put up for sale. It ean be put into balls or loaves, which are cut later, or in paper packages, such as are used for oysters and ice cream. It always pays to put up any article in as clean and attractive a form as possible.

\section{Neufchatel and Soft Cream Cheese.}

Imitation Neufchatel and soft cream cheese are similar to cottage cheese, but made in a slightly different manner. The Imitation Neufchatel is made from milk containing three or four per cent fat while the milk for the cream cheese should contain five to ten per cent fat, the higher per cents making the finer quality of cheese. The milk is first mixed with a good starter from two to five per cent of its bulk, and then set with rennet at $80^{\circ} \mathrm{F}$. When coagulated it is set into a refrigerator or cold water is run around it without breaking the coagulum. It is cooled to $60^{\circ} \mathrm{F}$. if possible and left for twenty-four hours. The acid will probably develop to .6 per cent, giving a rich ripened cream flavor. It is then earefully turned into a cheese cloth bag and hung up for twenty-four hours to drain. If too moist, a twisting of the neck of the bag will assist in the expulsion of moisture. After the twenty-four hours' draining in the bag it is 
salted. It can be worked into rolls by filling a tube and pushing it out with a plunger. The rolls are wrapped first in parchment paper and then in tinfoil.

The cream cheese can be printed with a butter printer.

This kind of cheese is perishable as it contains a great deal of moisture and must be consumed within a week. It should be kept in the refrigerator.

\section{QUESTIONS ON CHAPTER XX.}

1. Give two kinds of substances that eurdle the casein? 2. What per cent of lactic acid must be present in skim milk to curdle it? 3. What per cent of lactic acid will curdle cream containing 35 per cent fat? 4. Why does it take a higher per cent of lactic acid to curdle skim milk than eream? 5. What effect has temperature on the curdling power of lactic acid? 6 . What will be the effect of abnormal fermentations on the quality of cottage cheese? 7. How may the per cent of lactic acid in the milk be measured? 8 . What is the effect of too much acid on the curd? 9. At what temperature should the milk be set? 10. How high is it necessary to heat the curd to get it firm? 11. How is the curd separated from the whey? 12. Describe the strainer into which the curd is dipped. 13. What is the olject of adding cream or butter to the curd? 14. How much salt is required for cottage cheese? 15. What substances may be mixed with the cheese for flavor? 16. How should cottage cheese be marketed? 17. How is hydrochloric-acid cheese made? 18. What proportion and what kind of acid should be used? 19. What is the disadvantage of making hydrochloric acid cheese? 20. Describe the method of manufacture of Imitation Neufchatel and soft cream cheese. 


\section{CHAPTER XXI.}

\section{FOREIGN AND DOMESTIC CHEESE OF MINOR IMPORTANCE.}

In this chapter brief information will be given as to the manufacture of a number of foreign and domestic cheeses that are now made to a limited extent in this country. Investigations with regard to the possibility of manufacturing other kinds of foreign cheeses than those given below are being conducted at the present time, and it is likely that the manufacture of other styles than those here considered will soon be found practicakle and prove a commercial success under our American conditions, if rightly managed.

\section{Camembert Cheese.}

Camembert cheese is a soft French cheese which is manufactured on an extensive scale in Northwestern France, and imported to this country in large quantities every year. The subject of the manufacture of this cheese in the United States has been studied by Storrs (Conn.) Experiment Station, in cooperation with the U. S. Dept. of Agriculture, and very promising results have been obtained. The method of manufacture is described as follows by the Station mentioned:*

The fresh whole milk is warmed to $85^{\circ} \mathrm{F}$., and a starter, preferably a pure culture of lactic-acid kacteria, is added. A rather high degree of acidity ( 0.30 to 0.35 per cent) is allowed to develop, and suffieient rennet (about 8 to 10 ec. per 100 pounds of milk having an acidity of 0.3 per cent) is then added to the milk at the temperature mentioned to secure the desired texture of the curd in one and one-half to two hours. The curd is cut, stirred gently, and allowed to stand for about fifteen minutes, when the bulk of the whey is removed. After being

*Bull. 35, 46; Bur. An. Industry Bull. 71, 98; Farmers' Bull. 296. 
stirred thoroughly the curd is dipped into galvanized-iron forms or hoops, 4 inches in diameter and 5 inches in height and open at both ends. They rest upon a mat made of fine bamboo strips. The cheeses are allowed to drain naturally for four to five hours, when they are inoculated with cultures of camembert molds and turned. The next morning they are removed from the forms and salted by rubbing salt on the surface. When the curd is not cut, as is the custom in France, a higher acidity of the milk is necessary ( 0.40 to 0.45 per cent), and a longer period is allowed for draining. The next day after salting the cheeses are transferred to the first ripening room, which must be nearly saturated with moisture and kept at a temperature of 60 to $62^{\circ}$ F. When placed on boards the cheeses are turned daily. During the second week they are wrapped in tin foil or parchment paper and usually put into small round wooden boxes, after which they are transferred to the second euring room, which is kept at a temperature of 56 to $60^{\circ}$ and may have a lower percentage of moisture than the first room. Here the cheeses remain for one to two weeks longer when they are ready for the market.

Twelve to fifteen lbs. of Camembert cheese (or 20 to 30 cheeses) will be obtained from 100 lbs. of whole milk.*

\section{Canned Cheese.}

This cheese is sold under various names, Pot or Canned Cheese, Club House, Canadian Club, ete. It is easily prepared on a small seale from good well-cured Cheddar cheese. The rind is pared off, and the cheese cut into small pieces and run through a meat-grinding machine. One ounce of good melted butter per pound of cheese is then added and worked into the cheese till it is perfectly homogenous. It is filled into small jars or jelly glasses, the inside of which is coated with a layer of melted butter, filling the jars nearly level and covering the cheese with a thin layer of melted butter. The jars are covered with parchment paper or tin foil and are kept in a cool place until sold or wanted for use. Any housekeeper can easily put up cheese in this way, and small dairy farms ean supply the local market with such cheese to advantage. Cheese thus canned does

*Circ. 111, Ill. Experiment Station. 
not become dry before being used up; it is very palatable and in a convenient form to go directly on the table, and is soft enough to be spread on bread or crackers, if desired.*

\section{Farm Cheddar Cheese.}

For a farm dairy it will be much easier to make up sweetcurd cheese than sour-curd cheese, described in chapters VI to $X$. For this purpose it is necessary to have a curd-knife, a cheese-vat, and a cheese-press; the method of procedure is as follows :

The milk, which must be clean and sweet, is heatea to $90^{\circ}$ $\mathrm{F}$., and if any artificial color is required it is added at this time. Set the milk with enough rennet extract to coagulate in 20 to 30 minutes. About four ounces of Hansen's rennet extract per $1000 \mathrm{lbs}$. of milk will prove a sufficient amount.

As soon as the curd will break over the finger cut it fairly fine; then raise the temperature one degree in 3 minutes until $108^{\circ} \mathrm{F}$. is reached, at the same time stirring carefully to keep the curd particles apart. Hold at $108^{\circ} \mathrm{F}$. till the curd is firm, that is, till the pieces do not feel mushy. Then draw the whey and stir till the whey is well drained out. Salt at the rate of $2 \frac{1}{2} \mathrm{lbs}$. of salt to $100 \mathrm{lbs}$ of curd, and when the salt is well worked in, it may be put to press. It will, however, improve the quality if kept warm and allowed to stand a number of hours before salting and pressing. The cheese should te cured in a room (preferably a cellar) where the temperature can be kept at $60^{\circ} \mathrm{F}$. Higher temperatures may spoil it. The cheese should be cured for two or three months before it is sold. $\dagger$

\section{Gouda or Pantegras Cheese.}

Gouda or Pantegras cheese originated in South Holland, and takes its name from the eity of Gouda. It is made to some extent in America for shipment to the West Indies, where it is known as Pantegras cheese. It is larger than Edam, and pressed as flattened spheres. It is a sweet-curd cheese, which is salted in brine and eured in the same manner as Edam. It must be made from good milk, as gassy fermen-

* Modern Dairy Science and Practice, Van Slyke, p. 118; see also Utah Exp. Sta., bull. 96; Ore. Exp. Sta. bull. 78, and Farmers' Bull. 210.

†Woll, Handbook for Farmers and Dairymen, 5th ed., pp. 321-22, Monrad, ABC in Cheese Making, p. 18, Dean, Canadian Dairying, p. 97, and Farmers' Bull. 160. 
tations will spoil it. In the hot summer months its manufacture is dispensed with for this reason. It is packed four in a case, the case having little holes covered with wire screen for ventilation.*

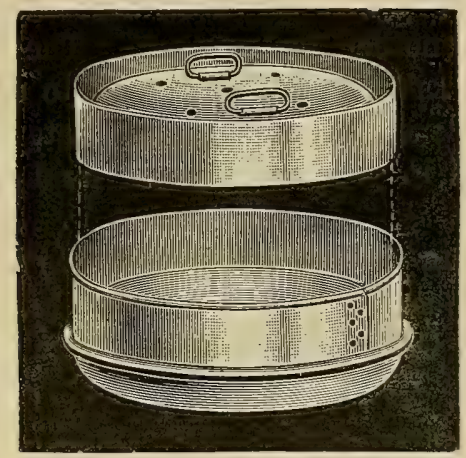

Fig: 93.-Form used for Gouda cheese.

\section{Italian Cheeses.}

Cococavallo, Scamorze or Buttiro. For this Italian cheese, the milk is skimmed and then coagulated with rennet, and the curd is firmed and allowed to settle to the bottom of the vat. The whey is then drawn off. The curd is cut into pieces and piled on a draining table. After a number of hours of draining, it is cut into small strips and thrown into a vat of hot water. The small strips of eurd melt together into a mass resembling taffy. The cheese-maker then draws it out in a string and molds it by hand. The usual shape is that of "Indian clubs," but it may be in the form of animals. Each form, as fast as made, is thrown into a vat of cold water, to set it in the shape into which it has been drawn. After a number of hours in this cold water, it goes into a brine bath for salting. After salting, it is hung up by a string to cure. It may be marketed green, or may be cured several months. A small cheese may weigh only a pound, a large one five or six pounds. A small ball of butter is sometimes worked into the curd, when it is termed Buttiro cheese. The cheese is shipped in barrels.

*The description of this and the Italian cheeses is taken from the author's article in Bailey, Cyclopedia of American Agriculture, Vol. III. See also Dean, Canadian Dairying, p. 182; Minn. Exp. Station, bull. 35, Geneva (N. Y.) Sta. Bull. 56, and Penna. Station Report 1896, p. 79. 
Ricotte. This is an albumen cheese made by heating the whey drawn from the former cheese, to about $200^{\circ} \mathrm{Fahr}$. The addition of sour whey helps to coagulate the albumen, which is skimmed out and put into perforated tin eylinders atout six inches in diameter. These tin molds are slightly tapering, and are set one into another for pressure. The albumen block is then rubbed with salt and set on a shelf to dry for weeks. A steam-heated kiln may be used to facilitate the drying. The cheese is wrapped in parchment paper, and packed in barrels for shipment.

Italians coming to America have brought with them their methods of cheese-making. In Sullivan and Orange counties, New York, and in Geuga county, Ohio, there are factories making such cheese.

\section{Danish Pasteurized Skim-Milk Cheese.}

The value of skim milk as a human food article is better appreciated in European countries than with us, where Boards of Health in some cities even prohibit its sale for this purpose, on account of the danger of its being sold fraudulently as whole milk. This applies also to food products made from skim milk, especially skim-milk cheese.

During late years an important industry has developed in Denmark in making cheese from pasteurized skim milk or from pasteurized skim milk to which 10,25 or 50 per cent of whole milk has been added. A very palatable and nutritious cheese is made by the method worked out by the Danes, and as the subject is of interest to our makers as a possible means of utilizing large quantities of skim milk for the manufacture of a valuable human food, the method of making Danish skim cheese or part skim cheese will be given here.

The best results have been obtained with 75 per cent centrifugal skim milk and 25 per cent whole milk (or a corresponding quantity of cream).* The skim milk is heated to $180^{\circ} \mathrm{F}$. in a continuous pasteurizer; 6 to 8 per cent of good butter milk is added as a starter, the amount used for pure skim milk being ten per cent. The mixture of milk and butter milk will contain about .21 per cent acid and is set without further ripening. The

*Private communication from Dr. Orla Jensen, Copenhagen, Denmark. 
usual amount of rennet extract is added to the milk, and this is set at a temperature of $95^{\circ} \mathrm{F}$. The milk is left for half an hour before the eurd is cut, and the temperature then raised with two or three intervals to $100^{\circ}$ to $102^{\circ} \mathrm{F}$. The chesse is made by the granular process, no curd mill being used. The eurd is salted at the rate of two or three pounds per 1000 pounds milk. A 30-pound round cheese and 16-pound square cheese are the common sizes made. The cheese is pressed in an upright press for 24 hours, and is then placed in the curing room. There are two different curing rooms, the first one is kept at a temperature of $54^{\circ}$, with a relative humidity of $90^{\circ}$. The temperature of the second curing room is kept at $59^{\circ}$, with a humidity of $92^{\circ}$. The cheese is kept in the first room for three weeks and is then transferred to the second curing room where it remains until sold, at two to five months old. When ripe the cheese is well broken down, and has a uniformly clean flavor and a good texture. It sells for about ten cents a pound wholesale (75 per cent skim) and five cents a pound for full-skim cheese.

\section{Sage Cheese.}

Sage cheese is a favorite cheese with some people and is manufactured to a limited extent in certain localities in this country. It is made in exactly the same way as common American Cheddar cheese, with the exception that a sage flavor is imparted to it, preferably by adding sage leaves to the curd, three ounces being sufficient for the curd from $1000 \mathrm{lbs}$. of milk. The sage should be weighed, all stems picked out, and the leaves finely powdered and added to the eurd just before salting.*

The Swiss "Schabziger," green, or "Kräuter" cheese resembles sage cheese in so far as powdered leaves of a plant are added in its manufacture. This cheese, which is found on our markets as small grayish green cones, is made from sour skim milk and butter milk, the dried and powdered leaves of rock clover (of the sweet-clover family) being thoroughly mixed with the ground curd.

*Michigan Spec. b. 21; Farmers' Bull. No. 202. 


\section{APPENDIX.}

Table I. Composition of Milk and Its Products.

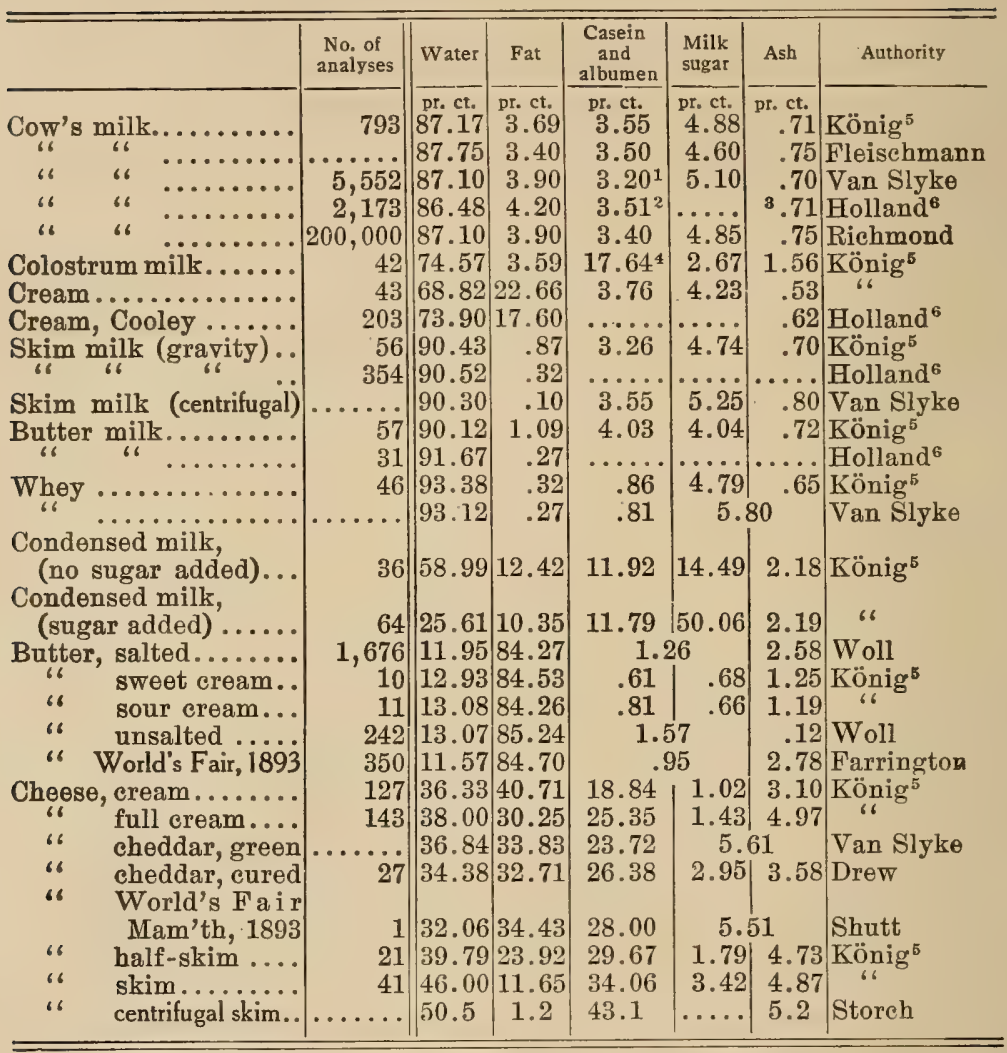

1.70 per cent. albumen. 2 Forty-two analyses.

8 Eight analyses.
413.60 per cent. albumen.

5 Mostly European samples.

6 Massachusetts' samples. 
Table II. Analyses of Different Kinds of Cheese, in Per Cent.

\begin{tabular}{|c|c|c|c|c|c|c|}
\hline & Water & Fat & Proteins & $\begin{array}{c}\text { Sugar or } \\
\text { Lactic } \\
\text { Ac1d, etc. }\end{array}$ & Ash & Authority \\
\hline $\begin{array}{l}\text { Camembert........... } \\
\text { Oream Oheese...... }\end{array}$ & $\begin{array}{l}45.2 \\
30.7\end{array}$ & $\begin{array}{l}30.3 \\
63.0\end{array}$ & $\begin{array}{r}19.8 \\
4.9\end{array}$ & $3^{2}$ & $\begin{array}{l}4.7 \\
1.2\end{array}$ & $\begin{array}{l}\text { Duclaux } \\
\text { Vieth }\end{array}$ \\
\hline $\begin{array}{l}\text { Oheddar, ripened... } \\
\text { Oheddar, Oanadian. } \\
\text { Danish, half skim... } \\
\text { Danish, full skim.... }\end{array}$ & $\begin{array}{l}31.7 \\
34.0 \\
46.7 \\
52.9\end{array}$ & $\begin{array}{r}36.8 \\
31.0 \\
15.0 \\
4.8\end{array}$ & $\begin{array}{l}25.5 \\
26.0 \\
33.2 \\
35.9\end{array}$ & \multicolumn{2}{|c|}{$\begin{array}{l}6.0 \\
9.0 \\
5.1 \\
6.4\end{array}$} & $\begin{array}{l}\text { Van S1yke } \\
\text { Dean } \\
\text { Storch } \\
\text { Storch }\end{array}$ \\
\hline 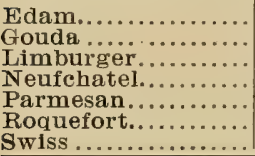 & $\begin{array}{l}36.6 \\
36.8 \\
35.7 \\
34.5 \\
31.8 \\
36.9 \\
36.1\end{array}$ & $\begin{array}{l}29.0 \\
26.5 \\
34.2 \\
41.9 \\
19.5 \\
30.6 \\
29.5\end{array}$ & $\begin{array}{l}25.7 \\
28.3 \\
21.2 \\
13.0 \\
41.2 \\
25.3 \\
28.0\end{array}$ & $\begin{array}{l}3.6 \\
3.2 \\
3.0 \\
7.0 \\
1.2 \\
1.8 \\
3.2\end{array}$ & $\begin{array}{l}5.1 \\
5.2 \\
2.9 \\
3.6 \\
6.3 \\
5.4 \\
3.1\end{array}$ & $\begin{array}{l}\text { König } \\
\text { König } \\
\text { Fleischmann } \\
\text { Fleischmann } \\
\text { König } \\
\text { König } \\
\text { Fleischmann }\end{array}$ \\
\hline
\end{tabular}

Table III. The Cheese Market of the United States. (Tном.)

\begin{tabular}{|c|c|c|c|c|c|c|}
\hline \multirow{2}{*}{$\begin{array}{l}\text { HARD OHEESES. } \\
\text { English cheddar }\end{array}$} & \multirow{2}{*}{ Milk. } & \multirow{2}{*}{$\mid \begin{array}{c}\text { Yield of } \\
\text { Oheese } \\
\text { per } 100 \\
\text { lbs. Milk } \\
\end{array}$} & \multirow{2}{*}{ Ripening. } & \multirow{2}{*}{$\begin{array}{l}\text { Marketable } \\
\text { Period. }\end{array}$} & \multicolumn{2}{|c|}{ Retail Price per Lb } \\
\hline & & & & & Europe. & U. s. \\
\hline $\begin{array}{l}\text { English cheddar } \\
\text { (best) .............. } \\
\text { dan. or Ämeri- }\end{array}$ & Whole milk & $9-11$ & 6-12 mo. & $6 \mathrm{mo}$. or more & $\$ 0.22-26$ & \\
\hline $\begin{array}{l}\text { can cheddar.... } \\
\text { Edam.............. } \\
\text { Swiss ............ } \\
\text { Parmesan...... }\end{array}$ & $\begin{array}{l}\text { Whole milk } \\
\text { Low fat } \\
\text { Low fat } \\
\text { Low fat }\end{array}$ & $\begin{array}{l}9-11 \\
8-11 \\
8-11 \\
8-11\end{array}$ & $\begin{array}{c}\text { 3̈-12 mo. } \\
\text { Long period } \\
\text { Long period } \\
2-3 \text { years }\end{array}$ & $\begin{array}{l}\text { Months } \\
\text { Very long } \\
\text { Very long } \\
\text { Very long }\end{array}$ & $\begin{array}{l}0.15^{*} \\
0.15-24 \\
0.24-28 \\
0.32\end{array}$ & $\begin{array}{l}0.14-18 \\
0.33 \\
0.26-35 \\
\cdots\end{array}$ \\
\hline $\begin{array}{l}\text { SOFT OR FANCT } \\
\text { OHEESES. }\end{array}$ & & . & & & & \\
\hline $\begin{array}{l}\text { Oamembert...... } \\
\text { Gorgonzola } \\
\text { Stilton (best)..... } \\
\text { Amer."Neuf- }\end{array}$ & $\begin{array}{l}3.5-4 \% \text { fat } \\
\text { Whole milk } \\
\text { Whole milk }\end{array}$ & $\begin{array}{r}12-15 \\
9-11 \\
8-10\end{array}$ & $\begin{array}{c}4 \text { weeks } \\
4 \text { months } \\
3-6 \text { months }\end{array}$ & $\begin{array}{l}10 \text { days } \\
1-2 \text { mo. } \\
2 \text { mo. (?) }\end{array}$ & $\begin{array}{l}0.26-36 \\
0.23-24 \\
0.25-35\end{array}$ & $\begin{array}{l}0.50-70 \\
0.45 \\
0.45-60\end{array}$ \\
\hline chatel" \& Oream & $\begin{array}{l}\text { Mostly poor } \\
\text { in fat. }\end{array}$ & $12-14(?)$ & Eaten fresh & Few days & & $0.20-60$ \\
\hline
\end{tabular}

* London, October, 1905. 
Table IV. Yield of Cheese from 100 lbs. of Milk.

\begin{tabular}{|c|c|c|c|c|c|c|c|c|c|c|c|c|}
\hline \multirow{2}{*}{ 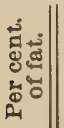 } & \multicolumn{11}{|c|}{ LACTOMETER DEGREES. } & \\
\hline & 26 & 27. & 28 & 29 & 30 & 31 & 32 & 33 & 34 & 35 & 36 & \\
\hline & 28 & 7.41 & 7.54 & 7.67 & 7.81 & 7.94 & 8.07 & 8.20 & 8.33 & 8.47 & 8.60 & \\
\hline & 7.44 & 7.57 & 7.70 & 7.83 & 7.96 & 8.09 & 8.22 & 8.35 & 8.49 & 8.62 & 8.76 & \\
\hline .7 & 7.59 & 7.72 & 7.85 & 7.99 & 8.12 & 8.25 & 8.38 & 8.51 & 8.64 & 8.77 & 8.91 & \\
\hline .8 & 7.74 & 7.87 & 8.00 & 8.14 & 8.27 & 8.40 & 8.53 & 8.67 & 8.80 & 8.94 & 9.07 & \\
\hline .9 & 7.90 & 8.03 & 8.16 & 8.30 & 8.44 & 8.56 & 8.69 & 8.82 & 8.95 & 9.09 & 9.22 & \\
\hline 0 & 8.05 & 8.18 & 8.31 & 8.45 & 8.58 & 8.71 & 8.84 & 8.97 & 9.11 & 9.24 & 9.37 & \\
\hline 3.1 & 8.21 & 8.34 & 8.47 & 8.60 & 8.74 & 8.87 & 9.00 & 9.13 & 9.26 & 9.39 & 9.53 & \\
\hline .2 & 8.36 & 8.4 .4 & 8.62 & 8.75 & 8.89 & 9.02 & 9.15 & 9.28 & 9.42 & 9.55 & 9.68 & \\
\hline 3.3 & 8.52 & 8.65 & 8.78 & 8.91 & 9.05 & 9.18 & 9.31 & 9.44 & 9.57 & 9.70 & 9.84 & \\
\hline .0. & 8.67 & 8.80 & 8.93 & 9.06 & 9.20 & 9.33 & 9.46 & 9.59 & 9.73 & 9.86 & $\mathbf{9 . 9 9}$ & \\
\hline 3. & 8.82 & 8.96 & 9.09 & 9.22 & 9.35 & 9.48 & 9.62 & 9.75 & 9.88 & 10.01 & 10.15 & \\
\hline 3. & 8.98 & 9.11 & 9.24 & 9.37 & 9.50 & 9.63 & 9.77 & 9.90 & 10.03 & 10.17 & 10.30 & \\
\hline 3. & 9.13 & 9.26 & 9.39 & 9.52 & 9.65 & 9.78 & 9.92 & 10.05 & 10.19 & 10.32 & 10.46 & \\
\hline 3. & 9.29 & 9.42 & 9.55 & 9.68 & 9.81 & 9.94 & 110.00 & 10.21 & 10.34 & 10.4 & 10 & \\
\hline 3. & 9.44 & 9.57 & 9.70 & 9.84 & 9.97 & 10.10 & 10.23 & 10.36 & 10.50 & 10.64 & 10.77 & \\
\hline 4. & 9.60 & 9.73 & 9.86 & $|10.00|$ & 10.13 & 10.26 & 10.39 & 10.53 & 10.66 & 10.79 & 10 & \\
\hline 3. & 9.75 & 9.88 & 10.02 & 10. & 10. & 10. & 10. & 10.68 & 10.81 & 10. & 11 & \\
\hline .2 & 9.90 & 10.03 & 10.17 & 10. & 10. & 10. & 10. & 10. & 10. & 11.10 & 11 & \\
\hline 4.8 & 10.06 & 10.19 & 10.32 & 10 & 10 . & 10 & 10 & 10 . & 11. & 11.25 & 11.39 & \\
\hline & & & & & & & & & & 11. & 11.55 & \\
\hline 4. & 10. & 10 & 10. & 10. & 10 . & 11. & 11. & 11. & 11.4 & 11. & 11.70 & \\
\hline & & & & & & & & & & & 11 & \\
\hline 4. & 10.67 & 10. & 10 & 11. & 11. & 11. & 1 & 11. & 11. & 11.8 & 12.01 & \\
\hline & & & & & & & & & & & & \\
\hline & & & & 11. & 11. & 11 & 1 & 11. & 12 & 12. & 12. & \\
\hline & & & & & & & & & & & & \\
\hline & 11. & & & & 11. & 11 & 12 & 12. & 12. & 12. & 12. & \\
\hline & & & & & & & & & & & & \\
\hline & 11. & & 11.86 & 11. & 12. & 12 & & 12. & 12. & 12. & 12.8 & \\
\hline & & & & & & & & & & & & \\
\hline & 11. & & & & & & 12 & & & 13 & 13 & \\
\hline & $12.07 \mid$ & 12. & & & & & & & & & & \\
\hline & & 12. & & & 12 & & & & & & 13.57 & \\
\hline & & & & & & & & & & & & \\
\hline b. & & 12. & 12. & & & & & & & 13. & 13.87 & \\
\hline & 12.69 & 12.82 & 12.95 & 13.09 & 13.22 & 13.35 & 13.49 & 13.62 & 13.75 & 13.89 & 14.02 & 6 \\
\hline
\end{tabular}

\section{GOVERNMENT STANDARDS OF PURITY FOR CHEESE.*}

1. Cheese is the sound, solid, and ripened product made from milk or cream by coagulating the casein thereof with rennet or lactic acid, with or without the addition of ripening ferments and seasoning, and contains, in the water-free substance,

*Circ. No. 19, Office of the Secretary, U. S. Dept. of Agxiculture. 
not less than fifty (50) per cent of milk fat. By act of Congress, approved June 6, 1896, cheese may also contain added coloring matter.

2. Skim-milk cheese is the sound, solid, and ripened product made from skim milk by coagulating the casein thereof with rennet or lactic acid, with or without the addition of ripening ferments and seasoning.

3. Goat's milk cheese, ewe's milk cheese, etc., are the sound, ripened products made from the milks of the animals specified by coagulating the casein thereof with rennet or lactic acid, with or without the addition of ripening ferments or seasoning.

\section{DEFINITION OF A GOOD AMERICAN CHEDDAR CHEESE:*}

Flavor. Should have a fine, nutty, pleasing acid flavor.

Texture. Smooth, silky and elose boring.

Color. Even and slightly translucent.

Finish. Should have a smooth rind covered with closefitting bandage and have a square edge.

\section{DEFECTS IN AMERICAN CHEDDAR CHEESE.*}

\section{Defects in Flavor.}

A. Acid Fuavors. Indicated by a sour smell and taste.

Cause. (1) Ripening the milk too much before setting.

(2) Use of too much starter.

(3) Use of sharp and over-ripe starter.

(4) Insufficient cook at the time of drawing the whey.

Remedy. (1) Ripen milk less before setting.

(2) Use less starter; from one-half to one per cent is usually sufficient.

(3) Never use a starter which is sharp in taste or in which whey appears.

(4) Get the curd heated to 98 or $100^{\circ} \mathrm{F}$. at least $1 \frac{1}{2}$ hour before drawing the whey and develop oneeighth of an inch string on the hot iron.

*By M. Michels, in charge of Butter and Cheese Scoring Exhibitions, Wisconsin Dairy School. See also Publow, Defects in American Cheddar Cheese, Bull. 257, Cornell Exp. Station. 
B. Lacking Flavor. Lacking in taste and smell.

Cause. (1) Setting the milk underripe.

(2) Cooking a slow-working curd up too rapidly.

(3) Too much washing of the curd when plaserd on the racks or after milling.

Remedy. (1) Set the milk at .18 to .19 per cent of acid.

(2) The curd should be firm and develop one-eighth inch string on the hot iron in about $11 / 2$ hour after heating to $100^{\circ}$ and the drawing of the whey.

(3) When necessary to ise water, do not wash, but simply rinse the curd.

C. Fermented Fruit Flanors. Indicated by a fermented whey or fermented fruit smell and somewhat sickening to the taste.

Cause. (1) Unclean cans in which milk is delivered.

(2) Unclean factory conditions.

(3) Added with the starter.

Remedy. (1) Cans in which whey is returned should be emptied in the forenoon and properly washed and cared for before the milk is put in.

(2) Keep everything atout the factory sweet and clean. Watch out for leaky vats and leaky dipper handles.

(3) This flavor usually gets into the starter can by leaving it uncovered in unclean surroundings. When troubled with flavors of this kind it is usually hard to develop sufficient acid on the eurd.

D. Bitter Flanors. Indicated by a bitter taste.

Cause. (1) Aged milk.

(2) May develop in the starter.

(3) By bacteria brushed from the cows udder while milking.

Remedy. (1) Milk should iot be more than two days old.

(2) Set the starter with a small amount of mother starter, at $70^{\circ}$, rather than use a large amount 
of mother starter and set at 55 or $60^{\circ}$ (one quart of mother starter to $100 \mathrm{lbs}$. of pasteurized skim milk is sufficient).

(3) Milk in clean stables with clean hands.

E. WeEdy or Food Fravors. Indicated by a weedy and food smell.

Cause. (1) Cows feeding on weeds.

(2) Feeding strong-scented feed just before or while milking.

(3) Exposing milk in an atmosphere laden with food flavors.

Remedy. (1) Give the cows plenty of good pasture so that they will not feed on weeds to the extent that this flavor will be noticed in the milk.

(2) Never feed silage, brewers' grains, or slightly decayed feed shortly before or during milking.

(3) Never keep the milk in a warm room with feed of any kind.

F. Strable Flavors. Bad taste and cow-stable smell.

Cause. (1) Uncleanliness in milking.

(2) Keeping the milk or cream in or near a dirty cowstable.

Remedy. (1) See that the stable and the cows are clean at milking, and always milk with clean, dry hands.

(2) All milk should be removed from the stable as soon as the milking is finished. Never keep the milk or cream near the stable or manure piles.

G. Unclean OR OFF Fladvors. Indicated by an unclean smell or taste.

Cause. (1) Often a combination of defects.

(2) Unclean cans and other utensils coming in contact with the milk.

(3) Unclean milking.

(4) Exposing the milk to impure air.

(5) Using impure water in setting the milk or in rinsing the curd. 
(6) Using a starter of unclean flavor.

(7) These terms are often used when the judges fail to find a suitable description.

\section{Defects in Texture.}

A. Dry Textures. Appear dry and hard and do not mold between the fingers.

Cause. (1) Lack of butter fat in milk.

(2) Heating the curd too high in the whey.

(3) Stirring too dry on the racks.

(4) Using too much salt.

(5). Insufficient curing before milling and salting.

Remedy. (1) No butter fat should ever be removed from the milk.

(2) Set at such ripeness that $100^{\circ}$ will give the curd a sufficient cook.

(3) Leave enough moisture so that curd will mat in about 15 minutes after stirring.

(4) Use $1 / 4 \mathrm{lb}$. of salt to every $10 \mathrm{lbs}$. of cheese made.

(5) Keep the curd warm so that the curing will not be checked.

B. Coriky Textures. Appear corky or rubber-like.

Cause. (1) Cutting the curd too fine.

(2) Too much cook.

(3) Handling curds roughly, thereby losing part of the fat.

Remedy. (1) Cut no finer than is necessary to insure a thorough cook.

(2) Study the firmness and cook no higher than necessary. $100^{\circ} \mathrm{F}$. is usually sufficient.

(3) Stir the curd constantly, but gently. The whey should never appear milky.

C. ACID Textures. Appear short and mealy. Look faded in color and sour to the taste.

Cause. (1) Ripening the milk too much before setting.

(2) The use of too much starter.

(3) The development of too much acid before the curd is properly firmed. 
(4) Developing too much acid in the whey.

(5) Insufficient stirring when out of the whey.

Remedy. (1) Study the ripeness of the milk daily and you will always know the proper point at which to set the milk.

(2) It is seldom necessary to use more than one per cent of starter.

(3) Allow an hour and a half between the time of heating to 98 or $100^{\circ}$ and the development of one-eighth inch string on the hot iron.

(4) Never develop more than one-eighth inch string in the whey unless the curd had an over-cook.

(5) Never allow pools of whey to collect on the curd after matting.

When necessary to make over-ripened milk into cheese-First, use an extra amount of rennet so as to coagulate the milk quickly. Second, cut the coagulated milk into finer pieces than ordinary. Third, heat the curd more rapidly and to a higher temperature.

D. Weak Textures. May be close boring, yet soggy. This fault usually appears with cold weather and with increased richness of milk.

Cause. (1) Insufficient cook.

(2) Heating eurd too rapidly.

(3) Insufficient drainage.

(4) Cutting the curd too coarse.

(5) Not using enough salt.

(6) Matting the curd down too thin before milling.

Remedy. (1) As the mill grows richer and the weather colder it takes a trifle more heat and time to properly firm the eurd.

(2) The lower the acidity of the milk when set, the slower should be the cooking process.

(3) The curd must be stirred sufficiently dry when out of the whey.

(4) Cut to about the size of corn kernels.

(5) As the yield increases use more salt, one-quarter of a pound to every 10 pounds of cheese made. 
(6) Do not pile the curd more than three or four layers deep and re-pile often.

E. Open Textures. Cheese very soft and full of holes.

Cause. (1) Insufficient development of acid.

(2) Insufficient pressure while in press.

(3) Too high a temperature of euring room.

Remedy. (1) The eurd should never show less than $11 / 2$ inch string on the hot iron when salted.

(2) Tighten the press often, or still better, have a continuous-pressure press.

(3) If possible keep the temperature of the curing room down to $65^{\circ}$.

F. Gassy Textures. Indicated by spongy texture and full of small openings throughout the cheese.

Cause. (1) Produced by bacteria brushed into the milk with dirt from eow's udder while milking.

(2) Use of unclean cans.

(3) Gassy starters.

Remedy. (1) Cows should not be allowed to wade in stagnant pools of water; and the udder should be brushed free of loose dirt before milking.

(2) Cans in which the milk is carried must be kept clean; also the whey tank at the factory.

(3) A gassy starter should never be used, but should be thrown away and a new one prepared. Heat the curd more slowly while cooking. A gassy curd is always slow in developing acid and for this reason a little more acid may be developed in the whey. Pile the curd quite deep before milling. After milling the curd should be well stirred and aired. Use a trifle more salt.

G. Greasy Textures. Indicated by free butter fat between particles of curd which are not cemented together.

Cause. (1) Very rich milk, two days old.

(2) Setting the milk at too high a temperature.

(3) Piling and maturing the eurd too much at high temperatures. 
Remedy. (1) When necessary to make up old milk handle very gently and carefully from start to finish.

(2) Do not set the milk at too high a temperature.

(3) Pile the curd less and mill earlier. Rinse with water at $90^{\circ} 15$ minutes before salting and use a trifle more salt.

\section{Defects in Color.}

A. DeAD OR FADED IN COLOR. The cause and remedy the same as in acid texture.

B. Mottled in Color. Uneven color in the cheese, most noticeable in the case of colored cheese.

Cause. (1) Mixing curds of different colors.

(2) Uneven development of acid on curd.

(3) Allowing the curd to mat into large lumps while heating.

(4) Adding a curdy starter without draining.

(5) Adding starter after the milk has been colored.

Remedy. (1) Curds from different vats or days should never be mixed.

(2) Do not allow portions of curd to remain in the whey until the rest has been stirred dry, and do not let the whey collect in pools on the curd while matting.

(3) Keep the particles of curd separate and stirred while heating.

(4) Strain all starters.

(5) Always add starter before you do the color.

\section{Defects in Finish.}

A. MAKE-UP or Finish. High edge.

Cause. (1) Improperly fitting followers.

(2) Applying pressure too quickly.

(3) Dressing cheese before sufficient pressure has been applied.

Remedy. (1) Fit followers closely by loosening fibre ring and tack further out; if then too short tack extra small piece between the two ends. 
(2) Apply pressure steadily but gently.

(3) Make certain the cheese has been pressed sufficiently so as to keep its shape when press is opened. Take all wrinkles out of the bandage by pulling up tight and lap over one inch; if too long same should be cut off.

(4) Apply pressure gradually after dressing.

B. CHECKed Rinds.

Cause. (1) Creamery curds.

(2) Pressing when too cold.

(3) The use of hard and impervious press cloths.

(4) Lack of pressure while in the press.

(5) Too rapid drying when first taken from the press.

Remedy. (1) Rinse curd before salting and if necessary wash with warm water when dressing, or the following morning.

(2) Keep hoops and press at ordinary room temperature.

(3) Keep press cloths soft by washing daily in water and washing powder, or in a pail of whey.

(4) The pressure must be kept up for several hours after dressing. The use of a continuous-pressure press is recommended.

(5) Do not place new cheese in a current of air or near an open window.

\section{STANDARDS FOR GRADING CANADIAN CHED. DAR CHEESE.*}

First Grade. Flavor: Clean, sound and pure.

Body and Texture: Close, firm and silky.

Color: Good and uniform.

Finish: Fairly even in size, smoothly finished, sound and clean surfaces, straight and square.

Boxes: Strong, clean, well made and nailed. Ends to be of seasoned timber. Close fitting. Weights stenciled or marked with rubber stamp.

Second Grade. Flavor: "Fruity," not clean, "turnipy," or other objectionable flavor. 
Body and Texture: Weak, open, loose, "acidy," too soft, too dry.

Color: Uneven, mottled, or objectionable shade.

Finish: Very uneven in size, showing rough corners, black mold, dirty or cracked surfaces, soft rinds.

Boxes: Too large in diameter; top edge of box more than one-half inch below the top of the cheese. Made of light material. Ends made of improperly seasoned material.

Third Grade. Flavor: Rancid, badly "off," anything inferior to second grade.

Body and Texture: Very weak, very open, showing pinholes or porous, very "acidy," very soft or very dry.

Color: Badly mottled, or very objectionable shade.

Finish: Anything worse than second grade.

Boxes: No question of boxes sufficient to make third grade if other qualities are good.

The following scale of points indicates the relative value of the different divisions of quality: Flavor, 40 ; body and texture, 30 ; color, 15 ; finish and boxing, 15 . For further explanations of qualities and defects, reference is made to the original publication cited. 


\section{INDEX}

Acid test, Manns', 64; Marschall, 65. Acidimeter, use in cheese making, 64 Acidity test, Farrington, 50.

Aeration of milk, 18.

Aerators, different kinds, 18.

Albumen, 2.

Albuminoids, 1.

Alkaline tablet test, 50 .

American Cheddar cheese, definition of a good, 199.

American dairy salt, composition, 79.

Analyses of different kinds of cheese, 197; of milk and other dairy products, 196.

Annatto color, 53.

Ash, 2.

Babcock test, 24; apparaturs used, 25 ; reading, $26,29$.

Bacteria in milk, varieties, 15.

Bacterial infection, bad flavor from, 14.

Bad flavors in milk, causes, 14.

Bath room in cheese factory, 127.

Block Swiss cheese, 138, 154; boxing, 159; handling in cellar, 159; pressing, 154.

Brick cheese, 162; characteristics, 162; curing process, 166; dipping curd, 163; draining koards, 164; draining table, 164; milk for, 162; molds, 164; Munster, 168; pressing, 165; salting, 165; shipping, 168.

Buyer's stencil, 108.

Buttiro cheese, 192.

By-laws for cheese-factory associations, 131.

Camembert cheese, 189.

Canadian Cheddar cheese, score, 111, 207; standards for, 206.

Canadian Club Cheese, 190.

Canned cheese, 190.

Casein, 1; test for, 33.
Cheddar cheese, Canadian, standards for, 206; defects in, 199; defects in flavor, 199; in texture, 202; in color, 205; in finish, 205; factories; in New York, 48; in Ohio, 49; in Wisconsin, 49; farm, 191; history, 48 ; processes of manufacture, 49. Cheddar system of cheese making, 49. Cheddars, weight and diameter, 83.

Cheese, anal'rsesi, 8, 195; bandages, 84; boxing, 106; cold-curing, 104; color, 113; constituents recovered in making, 10; corky, 113; cracked, 114; cracks in, 89; crumbly, 114; curing, 94; effect of too much salt, 80; flavor, 111; greasing, 88; green, composition, 8; gross appearance, 113; hard, 114; judging, 110; marking, 108; mealy, 114; packages, common, 82; paraffining, 105; poison, 115; pressing, 82 ; print, 90 ; pasty, 114; rates for making, 133; rusty spots, 114; salt, 113; selling, 108; shrinkage in curing, 102; standards for purity, 198; testing, 29; texture, 112; weak-bodied, 114; weighing, 106; yield from milk of different quality, 6, 135, 198.

Cleanliness in cheese factories, 19.

Cloth circles, 89.

Club House cheese, 190.

Cheese color, 53 ; requirements of different markets, 54, 113.

Cheese cloth circles, 89.

Cheese factory associations, organization, 131; by-laws, 131.

Cheese factories, construction, 117; cost, 130; equipment, 128, 129; operation, 117.

Cheese in cold storage, 39.

Cheese making, first steps' 50.

Cheese market of the United States, 197.

Cheese, moldy, cleaning of, 89. 
Cheese presses, 83; Helmer, 84; Moore's, 83; Sprague, 83.

Cheese press cloths, 89.

Cheese score, American, 110; Canadian, 111, 207; English, 111.

Cheese trier, 111.

Cococavallo cheese, 192.

Cold-curing of Cheddar cheese, 104.

Cold-storage cheese, 89.

Colostrum milk, 8.

Composite milk samples, 32.

Cottage cheese, 184; dipping, 186; hyärochloric-acid cheese, 187; marketing, 187; method of manufacture, 184 ; regulation of moisture, 185.

Cream cheese, 187.

Curd, composition, 8; cutting, 57; heating, 59. milking, 71; overripe, cooking, 60 ; salting, 78 .

Curd knives, 57.

Curd mills, 72; Barnard, 74; B. \& W., 73; Elgin, 72; Fuller, 74; Gosselin, 74; Harris, 74; Kasper, 74; McPherson, 73; PohI, 72; Roe. 72; Whitlow, 73.

Curd rack, 66.

Curd rakes, 60 .

Curd sink, 69 .

Curd stirrer, 61.

Curd test, the Wisconsin, 15.

Curds. from milk of different quality, 17; pin-holey, 68; steaming, 77; washed, 68 .

Curing cheese, 94; at different temperatures, 94; changes in, 94; shrinkage in, 102.

Curing room, 117; floor, 118; air, condition of, 101; supplying moisture, 101; moisture in, 95.

Curing rooms, central, 103.

Curing shelves, 94 .

Dairy salt, American, composition of, 79 .

Daisies, 83.

Danish pasteurized skim milk cheese, 193.

Dean's method of payment for milk at factories, 135 .

Dividends, figuring, 133.

Drum Swiss cheese, 138, 153; boxing, 159; pressing, 153.

Edam cheese, 174; characteristics, 174; curing, 182; dressing, 181; market, description of, 177; method of manufacture, 179; or- igin, 174; molds, 180; possibilities of manufacture, in America, 181; preparing for market, 182; salting, 181.

English cheese score, 111.

Enzymes, 34.

Export cheese, Danish, 193.

Factory cleanliness, 19; statement, 135; surroundings, 22.

Fancy cheeses, 189.

Farm Cheddar cheese, 191.

Farrington alkaline tablet test, 50, 64.

Fat, 3; effect on quality of cheese, 5; effect on quantity of cheese, 6, $135 ;$ loss in whey, 9.

Fat globules, 3 .

Feed, bad flavors in milk from, 14.

Ferments, organized, 34; unorganized, 34.

Figuring dividends, 133; ty Dean's method, 135; by fat test, 134; by pooling system, 134.

Flats, 83.

Foreign cheeses, 189.

Fraser gang hoops, 86 .

Galactase, 35.

Glaesler cheese, 141, 144.

Gouda cheese, 191.

Government standards for purity of cheese, 198.

"Green cheese," 194.

Haris curd mill, 74 ; rennet test, 37.

Hart's casein test, 33 .

Helmer cheese press, 84.

Herrick, curd knife, 67.

Holland, farming in, 174.

Hoops, Fraser gang, 83, 84, 86; Wilson, 86 .

Hot-iron test, 63.

Humidity, relative, table showing, 98 .

Hygrometer, 96.

Hygroscope, 96.

Ideal Cheddar cheese, 110.

Imitation Neufchatel cheese, 187.

Infection of milk, 15.

Italian cheese, 192.

Judging cheese, 110.

Kasper curd mill, 74.

Knife mills, 72 .

Kraeuter cheese, 194. 
Lactometer, Board of Health, 31; Quevenne, 30.

Limburger cheese, 169; cellar, 172; characteristics, 169; cooking curd, 170; curing, 172; dipping curd, 170; milk for, 169; origin, 169; pressing table, 171; salting, 171; shipping, 172; utensils, 169.

Manns' acid test, 64 .

Making cheese, rates for, 133.

Marschall acid test, 64; rennet test, 40 ; errors to be avoided with, 41 .

McPherson curd rake, 61.

Milk, aeration, 18; care, 18; composite samples, 32 ; composition, 1 , 4, 196; contamilation, 12; cooling, 19; factory, variations, 4; over-ripe, tests for, 50; products, composition, 196; samples, preserving, 32 ; secretion, 12; sugar, 2 ; testing, 24; thief, 32 ; time of secretion, 13; uses, 1; utensils, care of, 19; watered, detection of, 31 .

Molds, how to kill, 22.

Moldy cheese, cleaning, 89.

Monrad rennet test, 39 .

Muenster cheese, 168.

Neufchatel cheese, 187.

Niszler cheese, 141.

Pantegras cheese, 191.

Paracasein, 94.

Paraffining cheese, 105; tank for, 106. Pasteurized skim milk cheese, 193.

Peg mills, 72.

Pepsin, scale, compared with rennet, 46; use in cheese making, 55.

Poison cheese, 115.

Pooling system, method of payment by, 134.

Potted cheese, 190.

Press cloths, 89.

Print cheese, 90.

Proteins', 1.

Psychrometer, 96.

Quevenne lactometer, 30 .

Records, keeping daily, 91.

Relative humidity, tables, 98.

Rennet, action of, 43 ; thermal destruction point, 45.
Rennet, effect of acid, 37, 43; alkali, 43 ; anesthetics, 44 ; heat, 36 ; milk preservatives, 46 ; salt, 44 ; soluble calcium salts, 46; temperature, 44 ; water in milk, 44.

Rennet extract, 35; effect of strength, 45; manufacture, 35 .

Rennet test, 37; in Swiss-cheese making, 144; Marschall, 40.

Rennets, commercial, 35.

Ricotte cheese, 193.

Rusty spots in cheese, 114.

Sage cheese, 195.

Salt and its impurities. 78.

Salt, effect of too much, on cheese, 80.

Salting cheese, temperature, 81.

Sampling tube, Scovell, 32.

Scale boards, 107.

Scamorze cheese, 192.

Schabziger cheese, 194.

Scoring cheese, scale for, 110.

Scovell sampling tube, 32.

Septic tank, 125, 126.

Skim milk cheese, 193.

Soaked curd cheese, 69.

Soft cream cheese, 187.

Standards for purity of cheese, government, 198.

Startaline, 53.

Starter, lactic ferment, 52; use in cheese making, 52.

Stencil, buyer's, 108.

Suk-earth ducts, 120.

Swiss cheese, 137; block, 138; cause of glaesler, 144; cellars, 158; characteristics, 137; color, 140; description, 137; determining quality, 138; dipping curd, 152; drum, 138; flavor, 139; grades, 140; glaesler, 141; how tried, 141; marking, 155; method of manufacture, 147; milk for, 144; niszler, 141; prices of different grades, 142; requirements, 141 ; salting, 156; texture, 139; where made, 137; whey from, 9; work in curing room, 158.

Swiss curd, cutting, 149.

Swiss harp, 149.

Swiss kettles, 146.

Test committee, 132.

Udder, structure, 12. 
Washing curds, 68.

Watered milk, detection, 31.

Whey, composition, 9; drawing, 63; from Swiss cheese, 9 ; losses of fat, 9 .

Whey tank, how built, 126.

Wilson cheese hoops, 86 .
Wire stirrer, 149.

Wisconsin curd test, 15.

Yield of cheese from 100 lbs. of milk, 198; from milk of different composition, 6, 135.

Young Americas, 82.

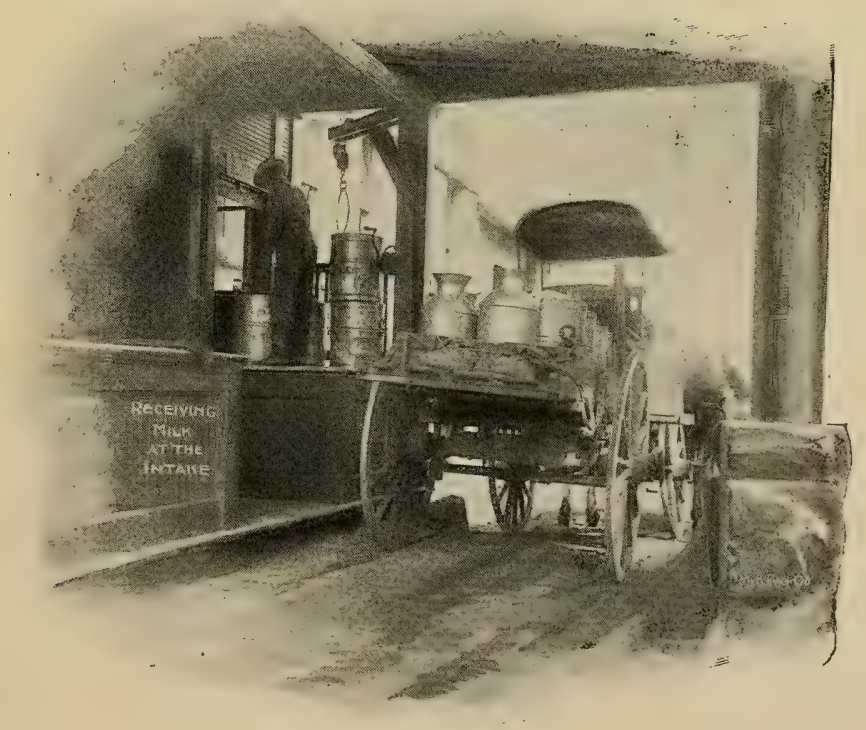




\section{THE MARSCHALL RENNET TEST}

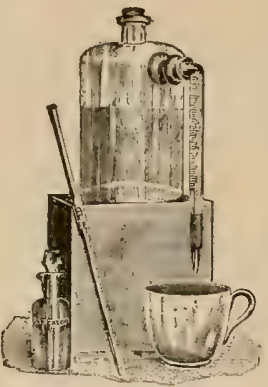

Is known by Cheesemakers all over the world and

\section{THE MARSCHALL ACID TEST}

on account of its simplicity is rapidly replacing all breakable and complicated apparatus for the accurate determination of the acidity of milk and cream. See page 64 of this book.

\section{OVER 50 MILLION LBS, OF CHEESE}

was made in Wisconsin with

Price, Complete, $\$ 4.00$

The Marschall Rennet Extract

during 1908, and nearly all the best prizes and the highest scores of the year went to our customers. Shipped direct to you from our Laboratory at Madison, Wisconsin. Also

Cheese Color, Rennet Powder, Rennet Tablets, Dry Neu!ralizers, Etc.

The Marschall Dairy Laboratory, Madison, Wisconsin

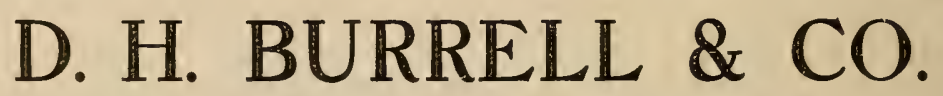

\section{LITTLE FALLS, . . NEW YORK}

Branches: Rome, New York and Brockville, Ontario

Manufacturers of and dealers in apparatus and supplies for the manufacture of cheese and butter, and also for the handling of milk in any quantity.

SOME OF OUR SPECIALTIES ARE

Sanitary Milk and Cream Vats

Sprague Automatic Adjustable Presses

"Simplex" Cream Pasteurizers

"Simplex". Tubular Coolers

"Facile" Babcock Testers, etc.

Write for:Our Catalog and Price List

Mention DECKER, CHEESE MAKING, when writing 10 advertisers 


\section{Chr. Hansen's Dairy Preparations ARE WORLD'S STANDARDS}

Leaders in every country where butter and cheese are made -. Europe, America, Australia

Chr. Hansen's Danish Rennet Extract, Danish Cheese Color, Danish Butter Color, Lactic Ferment Culture Rennet Tablets and Cheese Color Tablets for Cheese Making on the Farm. : : : : : CHR. HANSEN'S LABORATOKY BOX 1000 LITTLE FALLS, NEW YORK

\section{BOOKS by PROF. F. W. WOLL}

A HANDBOOK FOR FARMERS AND DAIRYMEN, Fifth Edition,

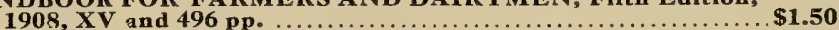
GROTENFELT'S MODERN DAIRY PRACTICE, Third American Edition, 1905, 286 p p.....................................

A BOOK ON SILAGE, Second Edition, 1900, 234 pp., ........... 1.00 TESTING MILK AND ITS PRODUCTS, 18th Edition, 1908, 292 pp, (Jointly with Prof. E. H. Farringiton)............................ Sent prepaid on receipt of the price given

MENDOTA BOOK CO., Madison, Wis.

\section{The Creamery Package Mfg. Co.}

Manufacturers and Dealers in Supplies and Apparatus for Cheese Factories, Creameries I) and Dairies. i:

\section{Catalog Free---Correspondence Solicited}

\section{Main House CHICAGO, ILLINOIS}

Branches:

Kansas City, Mo. Minneapolis, Minn. Waterloo, la. Omaha, Nebraska Rutland, Vermont

Mention DECKER, CHEESE MAKING when writing to Advertisers 


\section{The Cheese Maker's Library}

DECKER_CHEESE MAKING; Domestic and Foreign, 1909. New revised edition by F. W. Woll . . \$ \$1.75

FARRINGTON-WOLL_TESTING MILK AND

ITS PRODUCTS, eighteenth edition, 1908 . . . . . 1.00

Wing-Milk and its Products, sixth edition, 1903 ... 1.50

Dean-Canadian Dairying, 1903 ............ 1.00

Grotenfelt_-Modern Dairy Practice, 1905 . .... . . 2.00

Russell_Dairy Bacteriology, fifth edition, 1903 . . . . 1.00

Monrad-A B C in Cheese Making, fourth edition, $1902 \quad .50$

Monrad_Cheese Making in Switzerland ......... $\quad .50$

Woll-Handbook for Farmers and Dairymen, 1908... 1.50

Fleischmann —Book of the Dairy, $1896 \ldots \ldots$. . . . 3.00

Kirchner-Handbuch der Milchwirtschaft, fifth edition,

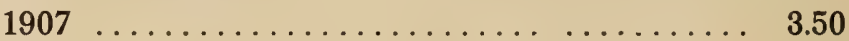

V. Klenze-Handbuch der Käserei-Technik, 1884 ... . 4.25

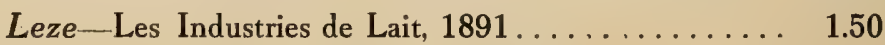

The preceding books will be sent prepaid on receipt of draft or money order for $\$ 20.00$. Separate books will be sent prepaid on receipt of the price given.

\section{Mendota Book Co., Madison, Wis.}







SAN 259909 

LIBRARY OF CONGRESS

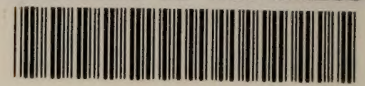

000089122415 